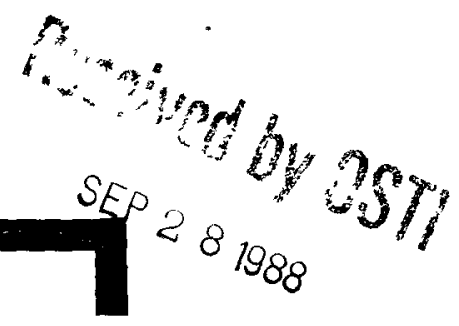

\title{
Waste Package/Repository
}

\author{
Impact Study
}

$\mathrm{BMI} / \mathrm{ONWI} / \mathrm{C}--3 / 2$

TI89 000050

\section{Final Report}

\author{
SEPTEMBER 1985 \\ PREPARED AS PART OF THE \\ CONCEPTUAL DESIGN OF A HIGH-LEVEL \\ NUCLEAR WASTE REPOSITORY IN SALT \\ UNITED STATES DEPAATMENT OF ENERGY \\ CONTRACT DE-AC02-83WM46656
}

This document is

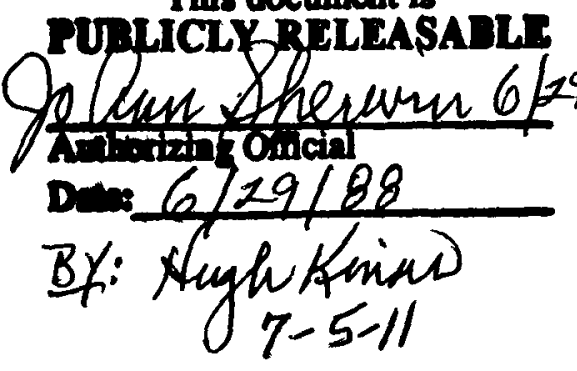

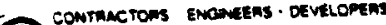

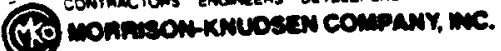

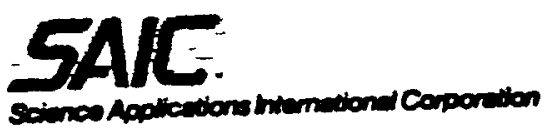

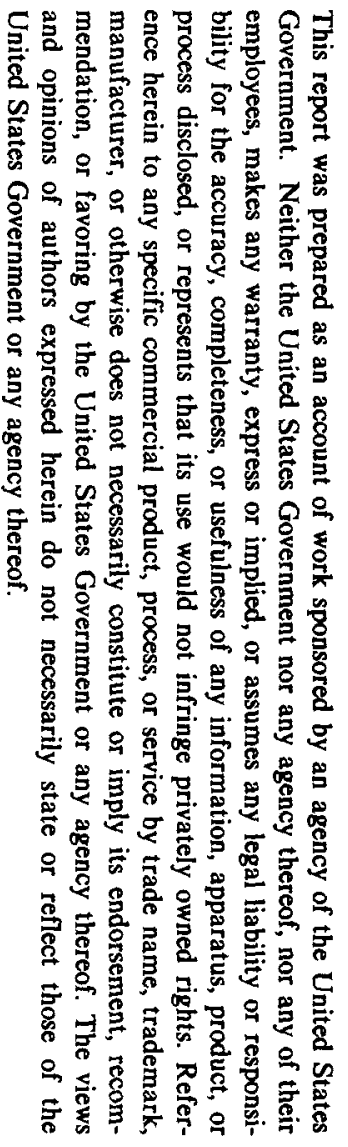

$\frac{8}{2}$

IN ASSOCIATION WITH 


\section{DISCLAIMER}

This report was prepared as an account of work sponsored by an agency of the United States Government. Neither the United States Government nor any agency Thereof, nor any of their employees, makes any warranty, express or implied, or assumes any legal liability or responsibility for the accuracy, completeness, or usefulness of any information, apparatus, product, or process disclosed, or represents that its use would not infringe privately owned rights. Reference herein to any specific commercial product, process, or service by trade name, trademark, manufacturer, or otherwise does not necessarily constitute or imply its endorsement, recommendation, or favoring by the United States Government or any agency thereof. The views and opinions of authors expressed herein do not necessarily state or reflect those of the United States Government or any agency thereof. 


\section{DISCLAIMER}

Portions of this document may be illegible in electronic image products. Images are produced from the best available original document. 
ENGINEERING STUDY REPORT APPROVAL SHEET

HIGH LEVEL NUCLEAR WASTE REPOSITORY IN SALT

WASTE PACKAGE/REPOSITORY IMPACT STUDY

FINAL REPORT

This Engineering Study Report Approval Sheet indicates that the signees have approved the subject report and have found it to meet all requirements as specified by Fluor's Statement of Work for Conceptual Design of a High Level Nuclear Waste Repository in Salt and/or the Department of Energy. This Approval Sheet should be removed from the report prior to final publication by DOE.

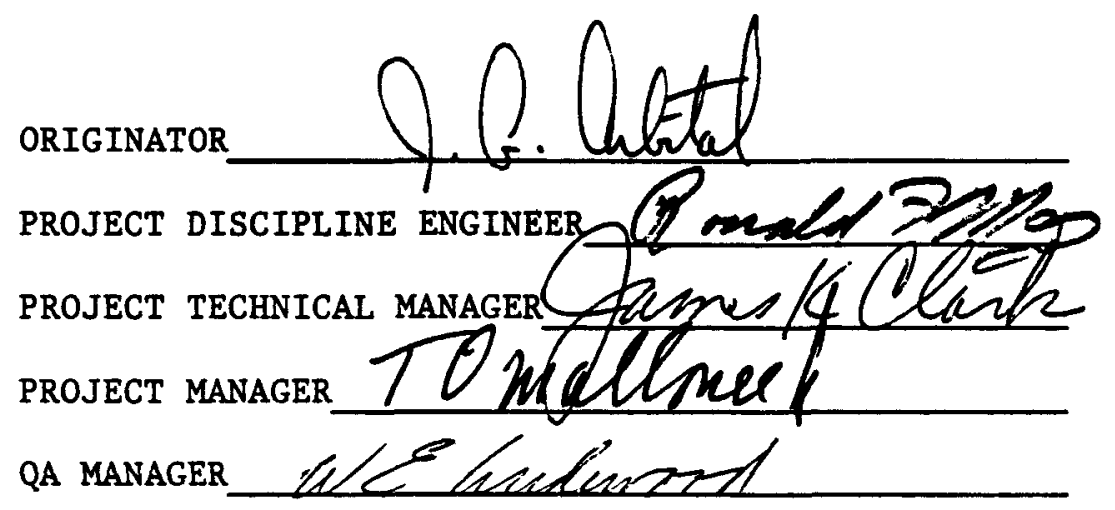

Date $\frac{9-20-85}{9-23 n 85}$
Date $\frac{9-20-85}{9-20-85}$
Date $\frac{9-20-85}{9-20-85}$




\section{DISCLAIMER}

This report was prepared as an account of work sponsored by an agency of the United States Government. Neither the United States Government nor any agency thereof, makes any warranty, expressed or implied, or assumes any legal liability or responsibility for the accuracy, completeness, or usefulness of any information, apparatus, product, or process disclosed, or represents that its use would not infringe privately owned rights. Reference herein to any specific commercial product, process, or service by trade name, trade mark, manufacturer, or otherwise, does not necessarily constitute or imply its endorsement, recommendation, or favoring by the United States Government or any agency thereof. The views and opinions of authors expressed herein do not necessarily state or reflect those of the United States Government or any agency thereof.

\section{TECHMICAL STATUS}

This technical report is being archived in advance of DOE technical review because of Congressional shutdown of the Salt Repository Project. Because of project termination, DOE has expedited the report clearance process to ensure availability of project data. A sumary of the review status of this report is attached. 


\section{ACKNOWLEDGEMENTS}

This study has been performed by Sclence Applications International Corporation (SAIC). SAIC is a subcontractor to Fluor Technology Inc., which Is the prime contractor to DOE for the Conceptual Design of a High-Level Nuclear Waste Repository in Salt. Technical support was provided to SAIC by ESD Corporation, Morrison-Knudsen Company and Fluor Technology, Inc. Special thanks are extended to the Salt Project Report Coordinator for compilation, review and production of the report. 
The Waste Package/Repository Impact Study was conducted to evaluate the feasibility of using the current reference salt waste package in the salt repository conceptual design. All elements of the repository that may impact waste package parameters, i.e., (size, weight, heat load) were evaluated. The repository elements considered included waste hoist feasibility, transporter and emplacement machine feastbility, subsurface entry dimensions, feasibility of emplacement configuration, and temperature limits. The evaluations are discussed in detall with supplemental technical data included in Appendices to this report, as approprlate. Results and conclusions of the evaluations are discussed in light of the acceptability of the current reference waste package as the basis for salt conceptual design. Finally, recommendations are made relative to the salt profect position on the application of the reference waste package as a basis for future design activities. 
FOREWORD

The National Waste Terminal Storage (NWTS) program was established in 1976 by the U.S. Department of Energy's (DOE) predecessor, the Energy Research and Development Administration. In September 1983, this program became the Civilian Radioactive Waste Management (CRWM) Program. Its purpose is to develop technology and provide facilities for safe, environmentally acceptable, permanent disposal of high-level waste (HLW). HLW includes wastes from both commerclal and defense sources, such as spent (used) fuel from nuclear power reactors, accumulations of wastes from production of nuclear weapons, and solidified wastes from fuel reprocessing.

The information in this report pertains to integration of the waste package used to contain the spent fuel into the overall repository conceptual design. To date, waste package and repository design efforts have proceeded in parallel, under separate contractors, but with limited attention to common design areas. This report was prepared to identify impacts on the current waste package and repository design concepts resulting from joint consideration of respective design requirements.

Fluor Technology, Inc., is the prime contractor to DOE for conceptual design of a high-level nuclear waste repository in salt. This engineering study report was prepared as part of that conceptual design effort. 


\section{SUMMARY}

\section{S. I BACKGROUND}

This report documents the Waste Package/Repository Impact Study. Fluor's Statement of Work (SOW) (DOE 1983) does not specify the requirement for this study; however, during the performance of SOW paragraph 4.10.1, Waste Package Conceptual Design, the need for this study became apparent. The original intent of SOW paragraph 4.10.1 was to integrate the current reference waste package into repository conceptual design activities. Later, it was recognized that lack of consideration of repository needs in the reference waste package design could lead to incompatibility of the package and repository. Therefore, this study was performed to assess the sultablitity of the reference waste package for the salt repository conceptual design in order to establish a waste package basis for conceptual design. The intent of this study was to evaluate waste package design parameters with respect to repository needs and then recommend the package parameters which best satisfy repository needs. The reference waste package basis for this study was the Alternate II borehole package as described in ONWI-517 (ONWI, 1985); this package contains twelve pressurized water reactor (PWR) assemblies.

\section{S.2 APPROACH}

An integrated approach to waste package evaluations was developed for this study. It relied on ongoing sow work elements for supporting data or to perform specific analyses upon request. The study was structured and arranged to initially evaluate the reference waste design parameters against known repository constraints (e.g., waste hoist weight limits). Later, the focus of the study was to indicate potentially modified waste package parameters which best comply with the repository constraints.

The following is a brief description of the nine study tasks:

Task 1, Study Basis - Establish data base for use throughout the study. 
Task 2, Heat Load - Determine maximum allowable package heat load before temperature limits of the salt and waste form are exceeded.

Task 3, Weight - Identify a range of package envelopes and weights which included the reference package and alternatives to the reference waste package. Also determine envelopes and weights for associated shielded transfer casks.

Task 4, Emplacement Mode - Determine suitable emplacement mode for current reference package and assess its feasibility from repository design standpoint.

Task 5, Transporter - Evaluate concepts for subsurface transporters and assess feasibility of transporting reference waste package.

Task 6, Hoist - Review holst state-of-the-art and determine capability for hoisting alternative waste packages.

Task 7, Subsurface Layout - Determine impact of subsurface layout requirements on waste package design.

Task 8, Length - Assess benefits to repository design of a shorter waste package.

Task 9, Integration - Compile results and prepare report.

\section{S.3 CONCLUSIONS}

After evaluation of the reference and alternative waste packages to identify Impacts resulting from salt repository design considerations, the overall conclusion reached is that the reference waste package, with a design capacity of 12 PWR assemblies is acceptable for use in conceptual design of the repository. All repository design elements, can incorporate the reference waste package while remaining within currently available technology. While the 12 PWR assembly package was found to be acceptable, this conclusion had one potential exception. Conservative thermal analyses conducted during this 
study indicate that the reference package thermal loading $(6.6 \mathrm{~kW})$ may be excessive, because the cladding temperature limits may be exceeded. (Maximum allowable cladding temperature is assumed to occur at center-most fuel pin in the package.) However, this finding did not alter the conclusions of the study (see Section S.3.2).

The conclusions of this study are summarized in the following paragraphs.

\section{S.3.1 Weight}

From the standpoint of package weight, a maximum of $42 \mathrm{MT}$ package was assumed in the evaluations. This package "unit" consisted of a 12 PWR assembly waste package within an attendant transfer cask. The operations considered that are impacted by package weight include:

1. Handling a shielded package in the surface facilities.

2. Transfer of the shielded waste package down the waste shaft.

3. Subsurface transport of the shielded waste package.

4. Package handling during emplacement and during retrieval.

Conclusions from these evaluations indicated that a shielded waste package of this weight is acceptable for incorporation into repository design using currently available technology.

\section{S.3.2 Thermal Analysis}

Analyses of waste package thermal loading were conducted to establish the maximum quantity of spent fuel that could be contained in each package. In performing these analyses the following two criteria were utilized:

1. Maximum fuel cladding temperature of $375^{\circ} \mathrm{C}$.

2. Maximum salt temperature of $250^{\circ} \mathrm{C}$.

Evaluations were conducted to estimate internal package thermal gradients as well as expected salt temperature profiles for various package heat loadings using a range of areal thermal loadings. 
In all cases the internal cladding temperature limit of $375^{\circ} \mathrm{C}$ proved to be the restraining criteria. Calculations conducted by Westinghouse for the reference waste package (ONWI, 1985) indicated a temperature differential between the package centerline and surface of $200^{\circ} \mathrm{C}$. Imposing this additional constraint 1 imited salt temperatures to $175^{\circ} \mathrm{C}$ (1.e., $375^{\circ} \mathrm{C}$ centerline $-200^{\circ} \mathrm{C}$ differential). The Westinghouse calculations therefore concluded that a 12 PWR assembly package was acceptable as long as salt temperatures are limited to about $175^{\circ} \mathrm{C}$. Similar thermal calculations performed by Fluor during this study indicate that only about 6 to 9 PWR assemblies where allowable from the standpoint of the $375^{\circ} \mathrm{C}$ cladding temperature limit. However, the Fluor calculations did not consider heat conducting fins within the package as did the Westinghouse calculations. The use of fins could conceivably reduce the centerline temperature of the 12 assembly package to within the limits.

At the present time, however, it was concluded that the repository could be designed to accept waste package designs holding 12 PWR assemblies (33,000MWD/MTU burn-up, 10-year aged fuel). Resulting thermal loadings and package spacings to limit salt temperature to $175^{\circ} \mathrm{C}$ are well within the criteria limits for conventional subsurface designs. Table S-1 summarized waste package and repository design parameters from evaluations for the reference waste package.

Although repository design can accommodate the maximum package heat loading, there is some question on the ability of the waste package to handle this much heat. Preliminary results indicate that fuel cladding temperature limits $\left(375^{\circ} \mathrm{C}\right)$ could be exceeded for any one of the following reasons. These factors are dictated by waste package design, not reposttory design.

1. Assumptions made in calculations for reference waste package internal heat transfer should be verified. Fluor's independent calculations resulted in higher predicted cladding temperature for a $175^{\circ} \mathrm{C}$ package surface temperature $\left(450^{\circ} \mathrm{C}\right.$ versus $350^{\circ} \mathrm{C}$ ). A cladding temperature of $450^{\circ} \mathrm{C}$ would exceed the criterion of $375^{\circ} \mathrm{C}$. 
Table S-1. Reference Thermal Design Parameters for Waste Package and Repository

Waste Package

Parameter

No. Assemblies/Package

12 PWR

Heat Load

$6.6 \mathrm{~kW}(\mathrm{a})$

cladding Temperature

$350^{\circ} \mathrm{C}(\mathrm{b})$

Surface Temperature

$175^{\circ} \mathrm{C}(\mathrm{b})$

Temperature Limits - Cladding

$375^{\circ} \mathrm{C}$

- Salt (Package Surface)

$250^{\circ} \mathrm{C}$

Repository

Parameter

Local Areal Loading

$24 \mathrm{~W} / \mathrm{m}^{2}(\mathrm{c})$

Package Spacing (pitch)

$7.5 \mathrm{~m}(\mathrm{~d})$

Max Salt Temperature Center of

backfilled drift (@ 50 yrs)

$125^{\circ} \mathrm{C}$

for $24 \mathrm{~W} / \mathrm{M}^{2}$

(a) 33,000 MWD/MTU burn up; 10 year aging.

(b) Calculated values specified in ONWI-517 (ONWI, 1985).

(c) Maximum value before waste package temperature 1 lmits would be exceeded.

(d) Based on 30 CFR 57.2100 subsurface layout and preferred emplacement mode of horizontal borehole in-pillar emplacement. 
2. Recelpt of higher burn-up (1.e., 45,000MWD/MTU) fuel and younger spent fuel (five years old), resulting in packages with a greater heat load than $6.6 \mathrm{~kW}$, as in the reference package.

3. Emplacement operations requiring crushed salt backfill in excess of about two inches could lead to excess package centerline temperature unless areal loading is drastically reduced. Crushed salt acts as a thermal insulator. The insulation quality of a thick salt layer could cause the centerline cladding temperature limit to be exceeded.

\section{S.3.3 Stress Analysis}

Evaluation of external stresses on the package indicates a significant dependency on emplacement mode. All emplacement modes were considered in the stress analysis. For the preferred mode of emplacement, horizontal in-pillar, the reference waste package designs are adequate to withstand the resulting stresses.

\section{S.3.4 Emplacement Mode}

Various emplacement modes were considered to determine the preferred mode for the salt repository. Horizontal borehole in-pillar was selected as the preferred mode; however, until it is baselined, the vertical in-floor emplacement mode is the reference. The preferred mode was evaluated for feasibility of using the reference waste package. Assessment of this feasibility was based on temperature criteria, stress limits, and equipment availability for emplacement and retrieval.

The evaluations indicated that on these bases the reference waste package was acceptable for emplacement in the preferred mode. Feasibility of vertical emplacement of the reference waste package has been established through past design efforts (ONWI, 1981). 


\section{S.3.5 Subsurface Transporter}

The selected waste package must be transportable in a shielded condition from the waste shaft to the emplacement area. Using a worst case shielded waste package weighing $42 \mathrm{MT}$ and measuring 16 feet long by 48 inches in diameter, results indicate no significant concerns for subsurface transportation using currently available technology.

Assuming the preferred transportation vehicle, crawler with skid steering, entry clearance widths of 18 feet (20-foot wide rooms with frregular wall surface) and $18 \times 18$ foot intersection clearances present no problem with maneuverability.

\section{S.3.6 Waste Holst}

One of the primary concerns involving integration of the waste package with the repository design involves the ability of the waste hoist to lower and raise the required load. The Fluor team conducted separated evaluations of the desired transfer mode. These studies indicated a preference (based on safety concerns) for transfer of the waste package in a shielded condition. This applied to all operations involving the waste hoist.

Evaluations of existing holst technology Indicate that a payload of 52 MT is the maximum which can be handled using current technology. As the maximum weight for the worst case shielded waste package is $42 \mathrm{MT}$, it is concluded that the current reference waste package can be accommodated using currently available hoist technology. Physical dimensions for the worst case shielded waste package are also acceptable for holst on-loading and off-loading operations.

\section{S.3.7 Subsurface Layout}

The primary factors in assessing the impact of waste package on subsurface layout include package length, weight, and heat content. From the subsurface layout standpoint, limitations on drift dimensions, salt temperature limits, areal loading requirements, and feasibility of emplacement/retrieval operations could impact the waste package decision. 
Typical panel layouts indicate there are no incompatibilities between repository deslgn and any of the alternative package designs considered. Overall areal heat loading will be parameter that determines the area required for waste emplacement. For any specified areal loading, package spactng can be adjusted as necessary depending on the heat content of each package. The lower the package thermal loading the more packages required, and the closer they can be spaced. Specifications of all waste package alternatives are therefore consistent with requirements for subsurface design and within acceptable limits for the development of subsurface drifts, emplacement entries, and intersections.

\section{S.3.8 Waste Package Length}

Qualitative evaluations of the reduction of waste package length indicate that the advantages realized do not out-welgh the potentlal disadvantages. These disadvantages are associated with the breaching of cladding that would be required to reduce fuel rod length to accommodate shorter waste packages. The waste package feasibility evaluations have shown no element of repository design that cannot accommodate the reference waste package length.

\section{S.4 RECOMMENDATIONS}

As a result of the study evaluations, the following recommendations have been made:

1. The reference waste package should be adopted, at the present time, as the basis for conceptual design of the salt repository.

2. The reference waste package should be used in design activities assoclated with preparation of the Site Characterization Plan (SCP) and SCP Conceptual Design Report. 


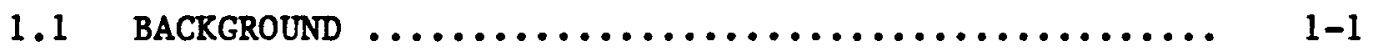

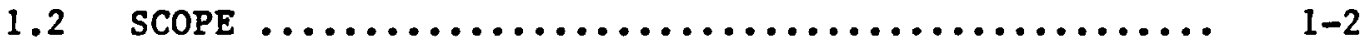

1.3 TECHNICAL APPROACH $\ldots \ldots \ldots \ldots \ldots \ldots \ldots \ldots \ldots \ldots \ldots \ldots . \ldots \ldots$

1.4 CONTENTS OF THIS REPORT $\ldots \ldots \ldots \ldots \ldots \ldots \ldots \ldots \ldots \ldots \ldots$ 1-4

3.1 WASTE PACKAGE DIMENSIONS/WEIGHT ENVELOPE ........ 3-2

3.2 WASTE PACKAGE THERMAL ANALYSIS $\ldots \ldots \ldots \ldots \ldots \ldots \ldots . . . \ldots$ 3-8

3.2.1 Internal Package Temperature Analysis ..... 3-8

3.2.2 Analysis of Maximum Salt Temperature ....... 3-13

3.2.3 Thermal Response in the Room and P11lar

Region ......................... 3-19

3.3 WASTE PACKAGE STRESS FIELD EVALUATION ........... 3-19

3.4 EMPLACEMENT MODE EVALUATIONS $\ldots \ldots \ldots \ldots \ldots \ldots \ldots \ldots \ldots . . \ldots \ldots$

3.4.1 Temperature Evaluation ............... 3-22

3.4.2 Stress Evaluation .................. 3-23

3.4.3 Emplacement Equipment Feasibility ........ 3-23

3.4.4 Retrieval Equipment Feastbility ......... 3-27

3.5 TRANSPORTER FEASIBILITY $\ldots \ldots \ldots \ldots \ldots \ldots \ldots \ldots \ldots \ldots \ldots . . \ldots \ldots$

3.6 HOIST FEASIBILITY ........................ 3-29 
TABLE OF CONTENTS

(Continued)

Page

3.6.1 Study Approach $\ldots \ldots \ldots \ldots \ldots \ldots \ldots \ldots \ldots \ldots . . . \ldots$ 3-33

3.6.2 Hoist System Constraints .............. 3-34

3.6.3 Holst Payload Calculation .............. 3-34

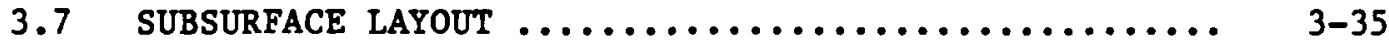

3.8 LENGTH ASSESSMENT $\ldots \ldots \ldots \ldots \ldots \ldots \ldots \ldots \ldots \ldots \ldots \ldots . \ldots \ldots$ 3-37

3.8.1 Package Consideration ................. 3-38

3.8.2 Case 1 - Constant Number of Packages ...... 3-39

3.8.2.1 Surface Systems $\ldots \ldots \ldots \ldots \ldots \ldots \ldots$ 3-39

3.8.2.2 Transfer Cask .............. 3-41

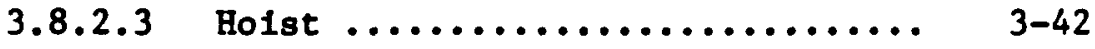

3.8.2.4 Subsurface Layout/Emplacement

Mode .................... 3-42

3.8.2.5 Transporter $\ldots \ldots \ldots \ldots \ldots \ldots \ldots \ldots .3-42$

3.8.3 Case 2 - Increased Number of Packages ...... 3-43

3.8.3.1 Surface System ............. 3-43

3.8.3.2 Transfer Cask ............... 3-43

3.8.3.3 Hoist $\ldots \ldots \ldots \ldots \ldots \ldots \ldots \ldots \ldots \ldots$ 3-43

3.8.3.4 Subsurface Layout/Emplacement Mode 3-44

3.8.3.5 Transporter ................ 3-44

3.8.4 Preliminary Conclusions Regarding Shorter

Packages ........................ 3-44

4 RESULTS AND CONCLUSIONS $\ldots \ldots \ldots \ldots \ldots \ldots \ldots \ldots \ldots \ldots \ldots \ldots$ 4-1 
TABLE OF CONTENTS

(Continued)

Page

4.1 WASTE PACRAGE WEIGHTS AND DIMENSIONS .......... 4-1

4.2 REPOSITORY THERMAL ANALYSIS $\ldots \ldots \ldots \ldots \ldots \ldots \ldots \ldots . \ldots . \ldots . \ldots$

4.3 WASTE PACKAGE STRESS CONDITIONS $\ldots \ldots \ldots \ldots \ldots \ldots \ldots . . \ldots 4-4$

4.4 EMPLACEMENT MODE ....................... 4-6

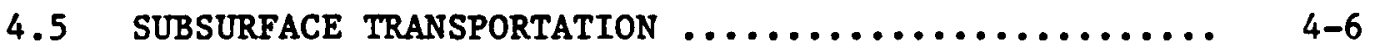

4.6 WASTE HOIST TECENOLOGY $\ldots \ldots \ldots \ldots \ldots \ldots \ldots \ldots \ldots \ldots . \ldots . \ldots 4$

4.7 SUBSURFACE LAYOUT $\ldots \ldots \ldots \ldots \ldots \ldots \ldots \ldots \ldots \ldots \ldots \ldots . \ldots . \ldots . \ldots . \ldots$

4.8 WASTE PACRAGE LENGTH $\ldots \ldots \ldots \ldots \ldots \ldots \ldots \ldots \ldots \ldots \ldots . \ldots . . \ldots$

5 RECOMMENDATIONS/OBSERVATIONS $\ldots \ldots \ldots \ldots \ldots \ldots \ldots \ldots \ldots \ldots \ldots \ldots$

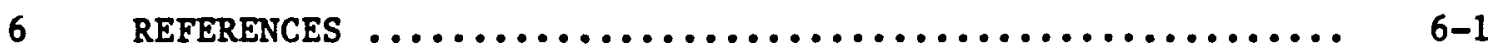

APPENDIX A. CALCULATIONAL METHODS $\ldots \ldots \ldots \ldots \ldots \ldots \ldots \ldots \ldots \ldots$ A-1

APPENDIX B. THERMAL ANALYSIS DATA $\ldots \ldots \ldots \ldots \ldots \ldots \ldots \ldots \ldots \ldots \ldots$ B-1

APPENDIX C. WASTE PACRAGES STRESS FIELD ANALYSIS $\ldots \ldots \ldots \ldots \ldots \ldots$ C-1

APPENDIX D. EMPLACEMENT MODE SELECTION $\ldots \ldots \ldots \ldots \ldots \ldots \ldots \ldots \ldots$ D-

APPENDIX E. SUBSURFACE TRANSPORTER MODE SELECTION $\ldots \ldots \ldots \ldots \ldots$ E-1

APPENDIX F. HOIST SYSTEM DECISIONS AND CALCULATIONS $\ldots \ldots \ldots \ldots$ F-1

APPENDIX G. WASTE PACKAGE/REPOSITORY IMPACT STUDY - DETAILED

STUDY OUTLINE ....................... G-1

AAPENDIX H. KEPNER-TREGOE (K-T) METHODOLOGY ........... H-1

$044 / 4032.14 \quad x 1 v$ 
TABLE OF CONTENTS

(Continued)

GLOSSARY

LIST OF ACRONYMS 
2-1 Waste Package/Repository Impact Study Data Base ....... 2-2

2-2 Reference Waste Package Design for Consolidated Spent

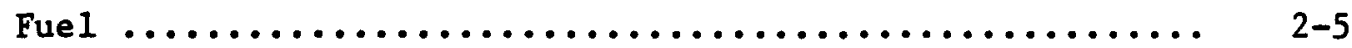

3-1 Waste Package Alternatives .................... 3-3

3-2 Transfer Cask Data ........................ 3-5

3-3 Transfer Cask Data - Alternate Fuel ............... 3-7

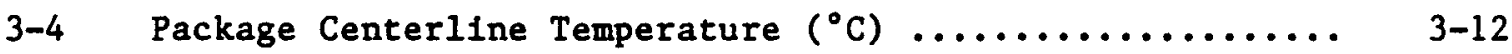

3-5 Alternate Emplacement Modes .................... 3-14

3-6 Effects of Package Shortening on the Package .......... 3-40

3-7 Effects of Package Length Decrease on Surface and Subsurface Systems .......................... 3-46

4-1 Worst Case Weight and Dimensions for a Waste Package within a Transfer Cask ......................... 4-2

4-2 Reference Thermal Design Parameters for Waste Package and Repository ............................. 4-5 
2-1 Reference Subsurface Layout ................... 2-6

3-1 Package Internal Thermal Gradients ................ 3-11

3-2 Areal Loading Data ........................ 3-17

3-3 Maximum Salt Temperature Versus Annulus Thickness and

Areal Loading ................................ 3-18

3-4 Emplacement Machine Elevation .................. 3-24

3-5 Emplacement Machine Plan View .................. 3-25

3-6 Intersection of $18 \mathrm{ft}$ Entries ................... 3-28

3-7 Forty Eight Inch Diameter Cask Shown ............... 3-30

3-8 Sixteen Foot Long Cask Shown on Cat 235-D-7 Crawlers .... 3-31

3-9 Crawler Vehicle at Intersection .................. 3-32

3-10 Emplacement Panel Configuration, In-Pillar Emplacement .. 3-36 


\section{INTRODUCTION}

This report documents the technical effort and results of the Waste Package/Repository Impact study. This work has been conducted in direct support of Statement of Work (SOW) (DOE 1983), Paragraph 4.10, Waste Package.

\subsection{BACKGROUND}

The overall waste package Work Breakdown Structure (WBS) element (WBS 1.3.4.1.5) has as its end product the design and development of waste packages for use in the repository. Although Fluor is the salt repository conceptual design contractor, the design of the waste package in not included in Fluor's scope of work. The waste package will be designed by another entity under the direction of Salt Repository Project Office (SRPO) and the Office of Nuclear Waste Isolation (ONWI). Within the waste package WBS, Fluor was given the sow responsibility to:

1. Integrate waste package designs into the repository.

2. Interface with the activities, and incorporate results from other waste package WBS tasks.

3. Support the waste package data base being maintained by others.

Consequently, it can be assumed that as far as the repository design process is concerned, the waste package should be treated as a fixed component or a "given" to be incorporated into the repository design. There is some flexibility in that the sow allows the repository design contractor to review the existing waste package with respect to the site-specific geology and evolving repository design concepts. If necessary, the contractor may identify the need for modifications. 
It is therefore recommended that repository-specific requirements are directly incorporated into waste package design activities. To provide a repository Input to waste package design, the Waste Package/Repository Impact Study was developed and conducted in the first half of the repository conceptual design effort. This study was developed to evaluate waste package design parameters with respect to repository design and then recommend the parameters which best satisfy repository needs. These recommendations would then be direct input to the waste package design contractor.

\subsection{STUDY SCOPE}

The objective of this study was to assess the impacts of the repository design on waste package design and to recommend values of design parameters for the waste package. As a package basis for conceptual design, the recommendation was to be based on analyses and evaluation of repository design elements to determine the waste package design that is most compatible with repository design. A reference waste package was identified that was similar to the Alternate II borehole package for consolidated spent fuel in ONWI-517 (ONWI, 1985). Potential impacts on the repository by the reference waste package concept were to be analyzed, and modifications to package design parameters to reduce these impacts, if any, were to be recommended.

The repository design elements evaluated during this study included the general areas of thermal loading and temperature limits, emplacement mode, subsurface transporter, waste holst, and subsurface layout. Technical tasks assoclated with each of these repository elements were developed and then integrated into a logic network. This is described in detail in Section 1.3 , Technical Approach.

The technical tasks rely on input from work efforts in other sow activitles. For example, Fluor's evaluation of the impact of waste package weight on holst design uses data generated by Fluor's holst technology task (sOW 4.4.2.8, Waste Hoist Technology). Conducting this study leads to data for those activities that have a waste package interface so that repository 
design can proceed. The Identification of current values for design parameters was achieved by focusing other SOW activities on the waste package interface and, in essence, establishing a position for repository design. In some cases, design decisions were made using the Repner-Tregoe (KT) decision analysis technique as a tool (Kepner and Tregoe, 1981).

\subsection{TECHNICAL APPROACH}

An integrated approach to waste package impact evaluations was developed for this study. This approach relles on ongoing sow work elements to either supply data to this study or perform specific support analyses upon request. The support from other sow elements is within the current scope of those elements. Identification of the supporting SOW elements is provided in Appendix $G$. In addition, participation in this task will benefit the supporting sow elements by providing a mechanism to resolve design issues caused by the current reference waste package design.

This study has been organized by nine separate tasks, the final task being integration and preparation of the report. The tasks are structured and arranged to Initially allow the reference waste package design parameters to be evaluated against repository constraints (e.g., waste holst weight limits). The analysis will then indicate waste package design parameters which best comply with the repository constraint. The following discussion briefly describes the technical tasks, however, a more detalled description of the tasks is presented in Appendix G. The logic network for the nine tasks is shown in Appendix G. The nine tasks are as follows:

Task 1, Study Basis - Establish data base for use throughout the study.

Task 2, Heat Load - Determine maximum allowable package heat load before temperature limits are exceeded.

Task 3, Weight - Identify range of package envelopes and determine package weight. Also determine weight of shielded transfer casks. 
Task 4, Emplacement Mode - Determine suitable emplacement mode for current reference package and assess its feasibility from repository design standpoint.

Task 5, Transporter - Evaluate concepts for subsurface transporters and assess the feasibility of transporting reference waste package.

Task 6, Hoist - Review hoist technology state-of-the-art and determine capability for holsting alternative waste package.

Task 7, Subsurface Layout - Determine impact of subsurface layout requirements on waste package design.

Task 8, Length - Assess benefits to repository design of a shorter waste package.

Task 9, Integration - Compile results and prepare report.

\subsection{CONTENTS OF THIS REPORT}

Section 2 presents the data base used for all technical tasks in this study. Section 3 describes the technical evaluations for each study task. Section 4 presents the results and provides conclusions. It is followed by recommendations in Section 5. References are given in Section 6 . There are seven appendices attached (Appendix A through Appendix G). The first six provide technical backup data and the seventh (Appendix G) presents the detailed outline which was used to scope the entire study. 


\section{STUDY BASIS}

Prior to inftiating technical evaluations, a study data base was established. This provided a common data set for all study analyses. The data and data sources are presented in Table 2-1.

The data base has undergone an extensive project-wide review and a review by DOE/ONWI. The data are used in other activities on the Salt Repository Conceptual Design Project and by other Salt Repository Project Office (SRPO) technical activities.

For all data base entries on Table 2-1 a source is 11sted. In some cases, actual data values are not listed because the detail is too voluminous to fit on the table. In these cases, a description of the data is given so that the reader can locate it in the sources 11 isted.

Table 2-2 includes the reference waste package design for consolidated spent fuel (PWR12). Figure 2-1 provides a schematic of the repository subsurface layout used for technical evaluations during this study. 
Table 2-1. Waste Package/Repository Impect Study - Date Base

\begin{tabular}{|c|c|c|c|c|}
\hline & Date Base Pereneter & Affected Taoke & Dete Sources & Dete. \\
\hline DB2: & $\begin{array}{l}\text { Specification of S1te for } \\
\text { Evoluntion } \\
\text { Site Properties }\end{array}$ & $\begin{array}{l}\text { General } \\
2 \text { - Beat Loed } \\
\text { 4- Enplocenent Hode } \\
\text { 7 - Layout }\end{array}$ & slte EA' (DOE, 1984a) & $\begin{array}{l}\text { The Deaf Sulth site will be uned for stie-apecific } \\
\text { dato. }\end{array}$ \\
\hline DB3: & $\begin{array}{l}\text { Weste Porme ond } \\
\text { Charecteristica }\end{array}$ & $\begin{array}{l}\text { 2 - Heet Loed } \\
\text { 3 - Wetght } \\
\text { 5 - Irensporter } \\
\text { - Lensth Aoceesment }\end{array}$ & 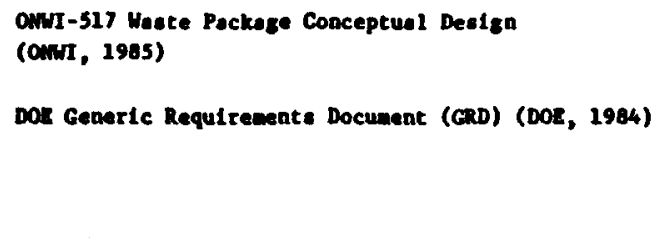 & 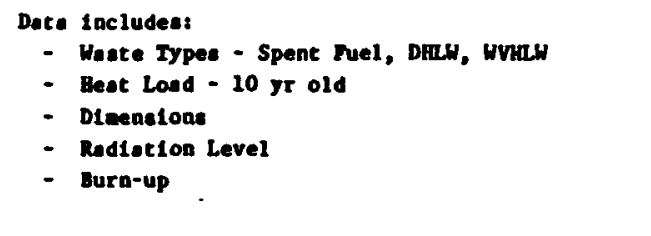 \\
\hline DS4: & $\begin{array}{l}\text { Baneline Peckage } \\
\text { Speciflcatione }\end{array}$ & 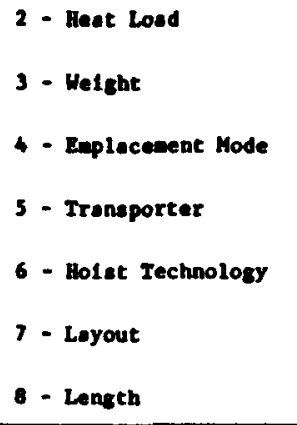 & OMnI-51) (ONWI, 1985) & $\begin{array}{l}\text { The Alternate II borahole packuge for spent fuel } \\
\text { frou own-517 la the current onn reference. } \\
\text { Toble } 2-2 \text { gives opecifications for reference } \\
\text { vaste package. }\end{array}$ \\
\hline DBS: & Waste Recelpt Rates & $\begin{array}{l}\text { 6 - Hol at Technoloey } \\
7 \text { - Loyout }\end{array}$ & $\begin{array}{l}\text { DOE GRD (DOE, 1984) } \\
\text { DOE MIEst on Plen (DOE, 1985) }\end{array}$ & 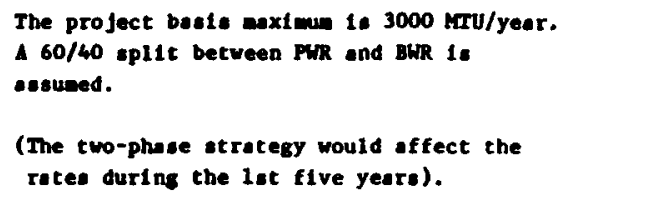 \\
\hline DB6: & Enplocenent Hode - Position & $\begin{array}{l}\text { 4 - Enplacenent Mode } \\
\text { 5 - Trensporter } \\
7 \text { - Layout }\end{array}$ & OANII-517 (ONUI, 1985) & $\begin{array}{l}\text { Inttial bosts for this atudy should be vertical in } \\
\text { the floor (borehole). } \\
\text { This has been the accepted basis for previous } \\
\text { studies in the progran, and no modifications have } \\
\text { yet been formilzed. }\end{array}$ \\
\hline
\end{tabular}

*Date 1dentification nuaber, 1.e. DBI - Date Base $\| 1$. 
Table 2-1, (Sheet 2 of 3)

\begin{tabular}{|c|c|c|c|c|}
\hline & Dote Dose Paraneter & Affected Taeke & Dete Sources & Date. \\
\hline DB7: & $\begin{array}{l}\text { Applicable Gasay Mina Regu- } \\
\text { lations - Position }\end{array}$ & 1 - Loyout & $\begin{array}{l}30 \mathrm{CR} 37 \text { - MInI ne Reguletions } \\
\text { (MSH, 1985) }\end{array}$ & $\begin{array}{l}\text { Requil resents in } 30 \mathrm{CrR} 57.21000 \text { are the basle for } \\
\text { thls position. }\end{array}$ \\
\hline Dse: & $\begin{array}{l}\text { Eaploylare Diessendy/Con- } \\
\text { solidation - Position }\end{array}$ & $\begin{array}{l}\text { 2 - Heat Load } \\
3 \text { - WeIght } \\
7 \text { - Loyout } \\
\text { - Length Asacuswent }\end{array}$ & $D O E$ GRD (DOE, 1984) & 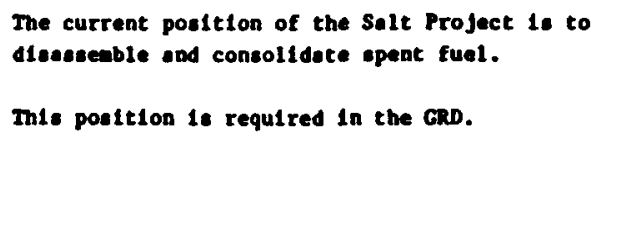 \\
\hline DB9: & $\begin{array}{l}\text { Teaperature Lintta - } \\
\text { Position }\end{array}$ & $\begin{array}{l}\text { 2 - Beat Loed } \\
\text { 3- Heteht } \\
\text { - Elplacement Mode } \\
\text { 7 - Leyout }\end{array}$ & OMNI-517 (OWNI, 1985) & $\begin{array}{l}\text { Teaperature Linite } \\
\text { Meximun Cledding }-375^{\circ} \mathrm{C} \\
\text { Moxinum Selt }-250^{\circ} \mathrm{C}\end{array}$ \\
\hline DE10: & Retrievability - Ponition & 4 - Replacemene Mode & DOE Mlosion Plon (DOE, 1985) & $\begin{array}{l}\text { Retrlevability for } 50 \text { yeare efter enplacement } \\
\text { begine is assumed by the Salt Project and this } \\
\text { etudy. }\end{array}$ \\
\hline DB11: & $\begin{array}{l}\text { Pocksege Performonce } \\
\text { Requil rewent: }\end{array}$ & $\begin{array}{l}\text { 2 - Heot Loed } \\
3 \text { - Helght } \\
\text { 4 - Eaplecement Mode }\end{array}$ & $\begin{array}{l}10 \text { CFR 60.111 - Repository Performance } \\
\text { (ARC, 1984) } \\
\text { OAWI-463 - Package Perfornonce } \\
\text { Specifications (ONMI, 1983.) }\end{array}$ & Package contoinment $11 \mathrm{fe}$ of $300-1000$ yeors. \\
\hline DB12: & Peckege Desi ign Requi rement: & $\begin{array}{l}\text { 2 - Heat Load } \\
\text { 3. Welght }\end{array}$ & $\begin{array}{l}\text { OMWI-463 - Package Perforanace } \\
\text { Spec1f1cations (OWWI, 1983a) } \\
\text { OMNII-423-Waste Package Deaign Speca } \\
\text { (OWWI, 1983b) }\end{array}$ & $\begin{array}{l}\text { General application as needed. } \\
\text { Requi rements will be opplied as apecified. }\end{array}$ \\
\hline D813: & $\begin{array}{l}\text { Packege Corrosion Allowancel } \\
\text { Structural Strength }\end{array}$ & 3 - Weight & 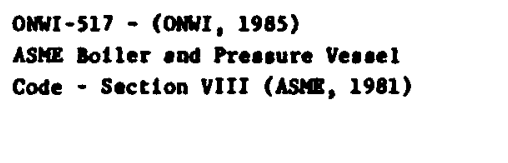 & $\begin{array}{l}\text { Wall thicknesses as epecified in OWWI-517 will be } \\
\text { used al Initiol basie. } \\
\text { Modified thickness for atructural atrength would } \\
\text { be in accordance with ASHE code. }\end{array}$ \\
\hline
\end{tabular}


Toble 2-1. (Sheet 3 of 3)

\begin{tabular}{|c|c|c|c|}
\hline Data Bose Paraseter & Affected Task: & Date Sources & Data \\
\hline DB14: NRC Desten Criterle & General & 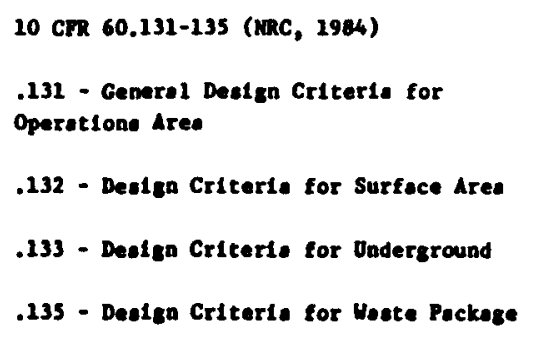 & $\begin{array}{l}\text { General application as needed. } \\
\text { Requl rements will be opplied es opectfied in } \\
\text { the reguletiona. }\end{array}$ \\
\hline Da15: Packese Shape Aesunaption & $\begin{array}{l}\text { 2 - Heat Loed } \\
\text { 4 - Eeplecement Mode } \\
\text { 3 - Trensporter } \\
7 \text { - Layout }\end{array}$ & ONWI-S1) (OWNI, 2985) & $\begin{array}{l}\text { A cylindricel ohape for the packege has been } \\
\text { ancused as the basis for thls atudy. }\end{array}$ \\
\hline DB16: Amblent Temperetures & 2 - Heat Losd & Site ed (DOR, 19840) & $\begin{array}{l}\text { Amblent rock at repository depth in Denf Salth - } \\
30^{\circ} \mathrm{C} \text {. } \\
\text { Hot cell ir tempersture and aubeurfece oir } \\
\text { temperature will be deterwined. Typlcel ronge of } \\
\text { tempereturee for hot cells - } 85-95^{\circ} \mathrm{F} \text {. }\end{array}$ \\
\hline DB17: Baseline Subsurface Loyout & $\begin{array}{l}\text { 5 - Traneporter } \\
\text { J - Loyout }\end{array}$ & Site id (DOR, 1984a) & $\begin{array}{l}\text { Loyout in EA used as besle and modified to reflect } \\
\text { current Snlt Project conceptusl dealgn ponition } \\
\text { (P1gure 2-1). }\end{array}$ \\
\hline DE18: Shlelding Requl resents. & 3 - Weight & $49 \mathrm{CrR} 173$ (DOT, 1984) & $\begin{array}{l}200 \text { mrea/hx for Internittent exposure such } \\
\text { os at surface of ohipping casks. }\end{array}$ \\
\hline $\begin{array}{l}\text { DA19: Solt Propertles } \\
\text { for Thermol Analyal. }\end{array}$ & 2 - Heat Loed & $\begin{array}{l}\text { RSI-0204-Thermomechent cel Anolyete } \\
\text { (RR/SPEC, 1984) }\end{array}$ & $\begin{array}{l}\text { Properties Include: } \\
\text { - Denalty of Solt } \\
\text { - Specific Heat } \\
=\text { Theranl Conductivity } \\
\text { (teap. dependent) }\end{array}$ \\
\hline DE20: Source Ierm & 3 - Weight & ORIGEM-2 Conputer Code (ORM, 1980) & Neutron/Goma dose as a function of waste age. \\
\hline
\end{tabular}


Table 2-2. Reference Waste Package Design for Consolidated Spent Fuel(a)

\begin{tabular}{|c|c|c|}
\hline & PWR & BWR \\
\hline $\begin{array}{l}\text { Canister } \\
\text { O.D., cm } \\
\text { Length, cm } \\
\text { Wall ThIckness, cm (b) } \\
\text { Gross Weight, MT } \\
\text { Heat Load, kW } \\
\text { Number of Assemblies }\end{array}$ & $\begin{array}{l}62 \\
400 \\
0.2 \\
8.4 \\
6.6 \\
12\end{array}$ & $\begin{array}{r}62 \\
435 \\
0.2 \\
8.8 \\
5.7 \\
30\end{array}$ \\
\hline $\begin{array}{l}\text { Overpack } \\
\text { O.D., cm } \\
\text { Length, cm } \\
\text { Thickness, cm } \\
\text { Cylinder } \\
\text { Heads } \\
\text { Gross Weight (ful1), MT } \\
\text { Material }\end{array}$ & $\begin{array}{c}84.5 \\
446 \\
10 \\
18.3 \\
17.7 \\
\text { Carbon Steel(c) }\end{array}$ & $\begin{array}{c}84.5 \\
482 \\
10 \\
18.3 \\
18.7 \\
\text { Carbon Steel(c) }\end{array}$ \\
\hline $\begin{array}{c}\text { Borehole (vertical) } \\
\text { Diameter, cm } \\
\text { Depth, cm } \\
\text { Total } \\
\text { Package Cover }\end{array}$ & $\begin{array}{r}90 \\
587 \\
140\end{array}$ & $\begin{array}{r}90 \\
622 \\
140\end{array}$ \\
\hline Backfil1 & Crushed Salt & Crushed Salt \\
\hline
\end{tabular}

(a) Based on the Alternate II borehole package in ONWI-517 (ONWI, 1985).

(b) Sheet metal - 14 gauge

(c) ASTM A216 Grade WCA 


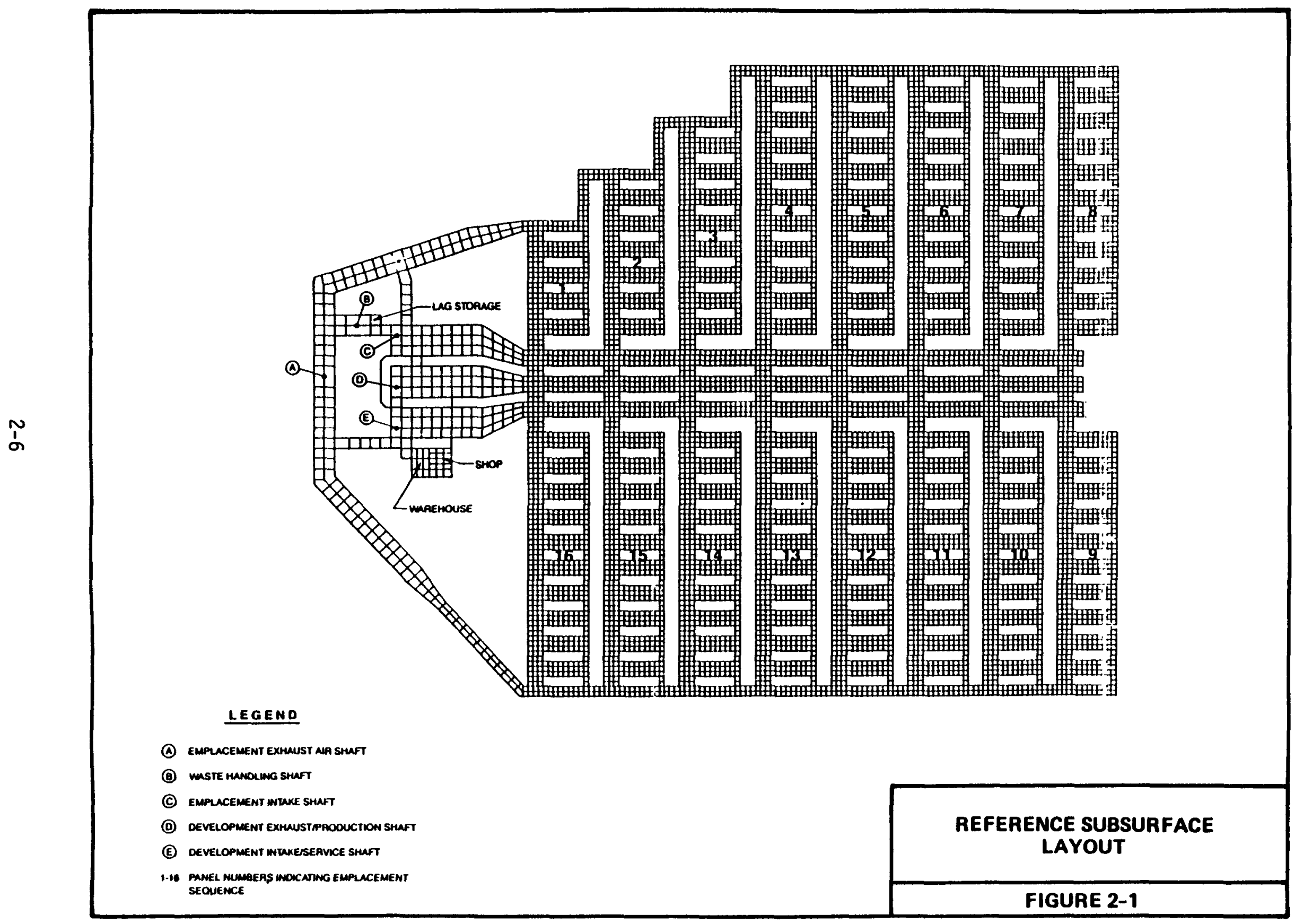




\section{TECHNICAL EVALUATIONS}

This study has been structured into nine tasks as described in Section 1.3. The first eight tasks involved either the generation of data for use throughout the study or the evaluation of the 1mpacts of repository considerations on waste package design. Task 1, Study Basis, is a data generation task and is discussed in detail in Section 2. Task 3, Weight, is also a data generation task and is discussed below in Section 3.1. Task 8, Length, is a purely qualitative assessment of the potential benefits of reducing package length. This assessment is presented below in Section 3.8. The remainder of the study tasks involved quantitative technical evaluations.

The evaluation tasks are discussed below in the following subsections:

Task 2, Heat Load - Section 3.2; Stress Analysis - Section 3.3

Task 4, Emplacement Mode - Section 3.4

Task 5, Transporter - Section 3.5

Task 6, Hoist - Section 3.6

Task 7, Subsurface Layout - Section 3.7 .

The evaluations examined the feasibility of using the reference waste package in the repository. The reference waste package used for this study is essentially the ONWI-438 (ONWI, 1983) Alternate II spent fuel package for borehole emplacement with the capacity increased from 10 PWR fuel assemblies to 12 (Table 2-1). For purposes of this study, the reference package was referred to as the PWR12 package. The dlameter was increased slightly to accomodate the two additional PWR fuel assemblies. The 12-assembly package is consistent with current concepts being considered by ONWI. This is discussed further in Section 3.1.

It was an objective of this study that analyses indicate whether the systems at the repository could reasonably accommodate the reference package. Furthermore, if the repository systems could not accommodate the reference package, it was intended that there would be a recommendation for modification of that waste package. Other package sizes were developed as example cases of modified packages to be used as alternatives in technical evaluations (Section 3.1). 
Supporting documentation for these evaluations, as appropriate, are provided in appendices to this report.

\subsection{WASTE PACKAGE DIMENSIONS/WEIGHT ENVELOPE}

This was a data generation task. Preceding all technical evaluations for this study, a range of package sizes was developed to provide physical data for the required evaluation analyses. The range includes, as end points, a relatively small waste package ( 3 PWR spent fuel assembly capacity) and a large package similar to that currently being considered by ONWI (12 PWR spent fuel assembly capacity). The range consists of four waste package alternatives, each containing the consolidated fuel rods from a different number of PWR assemblies (spectifically 3,6, 9, and 12). For each package, the number of fuel rods was based on a Babcock and Wilcox $15 \times 15$ PWR fuel assembly. This fuel assembly contains 208 active fuel rods. It was selected as a reference for this analysis because it's specifications are representative of over 80 percent of the PWR fuel used at the current time. The packages themselves were modeled after the cylindrical packages described in ONWI-517 (ONWI, 1985). The ONWI-517 package consists of a thin-walled steel canister containing consolidated fuel rods surrounded by a thick walled carbon steel overpack with thick heads at both ends. The waste package alternatives developed here are similar to these in most respects. An exception is the elimination of internal structures, such as radial heat conduction fins. It should be noted that from a repository design standpoint, only package heat load, external dimensions and gross weight are important.

The four package alternatives developed for these evaluations are referred to as PWR3, PWR6, PWR9, PWR12 (the notation reflects the number of fuel assemblies contained in the package). This notation will appear throughout the text. The diameters of these packages were determined by the mathematical modeling of close-packed pin bundles with the aid of a computer program developed for this purpose. The canister diameters for the PWR 3 through PWR12 were direct output from the program. Appendix A describes in detail the computer program and the application of it to determine the canister diameters for the four package alternatives. Table 3-1 summarizes the canister (waste 
Table 3-1. Waste Package Alternatives ${ }^{(a)}$

\begin{tabular}{|c|c|c|c|c|}
\hline Design Feature & PWR3 & PWR6 & PWR9 & PWR1 2 \\
\hline \multicolumn{5}{|l|}{ Waste Form } \\
\hline $\begin{array}{l}\text { \# PWR Assy(b) } \\
\text { \# Fuel Pins } \\
\text { Canister ID, cm(c) } \\
\text { Canister OD, cm } \\
\text { Canister Length, cm } \\
\text { Weight, net, MT } \\
\text { Weight, net, MTU } \\
\text { Weight, gross, MT(d) } \\
\text { Initial Power, kW(e) }\end{array}$ & $\begin{array}{r}3 \\
624 \\
31.1 \\
33.1 \\
400 \\
1.97 \\
1.41 \\
2.32 \\
1.65\end{array}$ & $\begin{array}{r}6 \\
1248 \\
43.4 \\
45.4 \\
400 \\
3.95 \\
2.82 \\
4.45 \\
3.3\end{array}$ & $\begin{array}{r}9 \\
1872 \\
52.3 \\
54.3 \\
400 \\
5.92 \\
4.23 \\
6.53 \\
4.95\end{array}$ & $\begin{array}{r}12 \\
2496 \\
60.0 \\
62.0 \\
400 \\
7.90 \\
5.64 \\
8.62 \\
6.6\end{array}$ \\
\hline \multicolumn{5}{|l|}{ Overpack } \\
\hline $\begin{array}{l}\text { Inner Dlameter, cm } \\
\text { Outer Diameter, cm(f) } \\
\text { Overall Length, cm(g) } \\
\text { Head Thickness, cm(f) } \\
\text { Weight, gross, MT }\end{array}$ & $\begin{array}{r}35.6 \\
55.6 \\
446 \\
18.3 \\
7.63\end{array}$ & $\begin{array}{r}47.9 \\
67.9 \\
446 \\
18.3 \\
11.35\end{array}$ & $\begin{array}{r}56.8 \\
76.8 \\
446 \\
18.3 \\
1.4 .62\end{array}$ & $\begin{array}{r}64.5 \\
84.5 \\
446 \\
18.3 \\
17.77\end{array}$ \\
\hline
\end{tabular}

(a) For reference consolidated PWR spent fuel.

(b) BW $15 \times 15$ assy is reference

$$
\begin{array}{ll}
\text { Specs - } & 208 \mathrm{p} i n s / a s s y \\
& 1.09 \mathrm{~cm} \text { pin OD } \\
& 389 \mathrm{~cm} \mathrm{pin} \mathrm{length} \\
& 550 \mathrm{~W} / \mathrm{assy} \\
& .47 \mathrm{MTU} / \text { assy }
\end{array}
$$

(c) Thin-walled carbon steel canister.

(d) Material $1 \mathrm{~s}$ carbon steel - density $=7.86 \mathrm{~g} / \mathrm{cm}^{3}$.

(e) $33000 \mathrm{MWD} / \mathrm{MTU}$ burn-up; 10-year decay.

(f) Based on current ONWI concept (Westinghouse, 1984).

(g) Excluding pintle. 
form) dimensions for the four alternatives. Canister wall thickness was assumed and length reflected full length fuel rods. This study assumed no intentlonal cladding breach, so package lengths reflect only full length rods (1.e., no fuel rod chopping, shearing, etc., for purposes of reducing waste package length).

The alternative waste packages also include a thick-walled carbon steel overpack. Thickness of both the walls and heads of the overpacks assumed here reflect current concepts being considered by ONWI.

Table 3-1 summarizes the overpack specifications for the four alternatives. The PWR12 waste package is simflar in dimension and capacity to that currently being considered by ONWI as a potential candidate for conceptual design (described in Westinghouse, 1984). The three other waste packages offer alternatives with less total handing weight and reduced thermal power for analysis and comparison of the impacts on repository design.

For each package alternative, a shielded transfer cask was conceived. This type of cask would function as an individual package shield during transfer within the repository, allowing operators entry to handing areas as required. They were considered in this study since total waste package handling weight and external dimensions may include a transfer cask. Transfer casks are not over-the-road shipping casks and do not have the same integrity. Shielding calculations were performed to determine transfer cask thickness. Carbon steel casks were assumed. Thicknesses of casks were determined for surface dose rates of 50,100 , and $200 \mathrm{mrem} / \mathrm{hr}$. The latter value is based on that allowed by Department of Transportation regulations for nuclear shipping casks (DOT, 1984). The other values offer more conservative options. Appendix A describes the shielding calculations performed for this study. Transfer cask specifications for the 4 package alternatives are given in Table 3-2. Each of the 3 dose rates are shown. For purposes of evaluating feasibility of repository equipment to handle the waste package weight, the $50 \mathrm{mrem} / \mathrm{hr}$ transfer cask was applied (as a worst case) with a maximum gross welght for analysis of $42 \mathrm{MT}$. It should be noted that actual transfer casks would include peripheral structures and systems (i.e., internal hoist mechanism) which could increase the weight slightly. 
Table 3-2. Transfer Cask Data

\begin{tabular}{|c|c|c|c|c|c|}
\hline Dose & Design Feature & PWR3 & PWR6 & PWR9 & PWR12 \\
\hline $\begin{array}{l}50 \text { mrem/hr }(e) \\
\text { @ surface }\end{array}$ & $\begin{array}{l}\text { Overpack OD, cm } \\
\text { Shield OD, cm(a) } \\
\text { Shield Thickness, cm } \\
\text { Overall Length, cm(b) } \\
\text { Shield Weight, MT(c) } \\
\text { Gross Weight, MT(d) }\end{array}$ & $\begin{array}{r}55.6 \\
90.36 \\
16.11 \\
490 \\
15.15 \\
22.78\end{array}$ & $\begin{array}{r}67.9 \\
104.20 \\
16.88 \\
490 \\
18.87 \\
30.22\end{array}$ & $\begin{array}{r}76.8 \\
114.02 \\
17.34 \\
490 \\
21.63 \\
36.25\end{array}$ & $\begin{array}{r}84.5 \\
122.34 \\
17.64 \\
490 \\
24.00 \\
41.78\end{array}$ \\
\hline $\begin{array}{l}100 \text { mrem } / \mathrm{hr}(e) \\
\text { C surface }\end{array}$ & $\begin{array}{l}\text { Overpack OD, cm } \\
\text { Shield OD, cm(a) } \\
\text { Shield Thickness, cm } \\
\text { Overall Length, cm(b) } \\
\text { Shield Weight, MT(c) } \\
\text { Gross Weight, MT(d) }\end{array}$ & $\begin{array}{r}55.6 \\
87.38 \\
14.62 \\
490 \\
13.48 \\
21.11\end{array}$ & $\begin{array}{r}67.9 \\
101.20 \\
15.38 \\
490 \\
16.91 \\
28.26\end{array}$ & $\begin{array}{r}76.8 \\
111.02 \\
15.84 \\
490 \\
19.47 \\
34.09\end{array}$ & $\begin{array}{r}84.5 \\
119.30 \\
16.13 \\
490 \\
21.64 \\
39.41\end{array}$ \\
\hline $\begin{array}{l}200 \text { mrem/hr(e) } \\
\text { @ surface }\end{array}$ & $\begin{array}{l}\text { Overpack OD, cm } \\
\text { Shleld OD, cm(a) } \\
\text { Shleld Thickness, cm } \\
\text { Overall Length, cm(b) } \\
\text { Shield Weight MT(c) } \\
\text { Gross Weight, MT(d) }\end{array}$ & $\begin{array}{r}55.6 \\
84.48 \\
13.17 \\
490 \\
11.91 \\
19.54\end{array}$ & $\begin{array}{r}67.9 \\
98.26 \\
13.91 \\
490 \\
15.05 \\
26.40\end{array}$ & $\begin{array}{r}76.8 \\
108.06 \\
14.36 \\
490 \\
17.40 \\
32.02\end{array}$ & $\begin{array}{r}84.5 \\
116.32 \\
14.64 \\
490 \\
19.38 \\
37.15\end{array}$ \\
\hline
\end{tabular}

(a) Air gap between shield and overpack $-1.27 \mathrm{~cm}$ total.

(b) Shield top and bottom head thickness are assumed to be equal to wall thickness for this analysis. It is recognized that this is a conservative assumption, however it offers some flexibllity in the future to reduce transfer cask length and weight if necessary. A $10 \mathrm{~cm}$ long void added to length.

(c) Carbon steel shield, density $=7.86 \times 10^{-6} \mathrm{MT} / \mathrm{cm}^{3}$.

(d) Complete loaded transfer cask

(e) Based on 10-year old PWR fuel, 33000 MWD/MTU burn-up. 
The waste thermal power given in Table 3-1 and the shield thicknesses in Table 3-2 reflect nominal spent fuel burn-up (33000 MWD/MTU) and a 10-year decay period prior to disposal. It is conceivable however, that spent fuel with higher burn-ups and shorter decay periods (e.g. $45000 \mathrm{MWD} / \mathrm{MTU}$ and 5-years decay) will be received at the repository. On this basis, the impacts to the waste package (and transfer cask) envelope due to modified fuel characteristics were assessed and then evaluations of the feasibility of handling this waste were conducted. Modifications of burn-up and age have no affect on waste package size. Thermal power however, is effected. Shielding requirements will vary and therefore transfer cask thickness is also effected. Greater burn-up's tends to increase thermal power and shield thickness. Shorter decay periods have the same net effect. Table 3-3 summarizes the higher package heat loads and greater shield (transfer cask) thickness for cases of 45000 MWD/MTU burn-up and 5-year decay periods. The weight of the package and transfer cask for the PWR12 package (Case III) on Table 3-3 is $42 \mathrm{MT}$. The $42 \mathrm{MT}$ weight reflects $200 \mathrm{mrem} / \mathrm{hr}$ cask surface dose rate (shielding requirements for $50 \mathrm{mrem}$ was not analyzed for the higher burnup case). The reference PWR12 package (w1th nominal burn-up) and cask with a $50 \mathrm{mrem} / \mathrm{hr}$ dose rate also weighs $42 \mathrm{MT}$. Therefore, $42 \mathrm{MT}$ was considered the worst case weight in this study. If it is found that 42 MT is very close to a repository weight limitation then a closer look at the higher burnup waste may be necessary. Especially, if shielding to $50 \mathrm{mrem} / \mathrm{hr}$ is desired, since it could bring the weight of the reference package and transfer cask to $47 \mathrm{MT}$. 
Table 3-3. Transfer Cask Data - Alternate Fuel

Case I. $\quad 33000 \mathrm{MWD} / \mathrm{MTU}$ - 5 year age at emplacement

\begin{tabular}{lrrrrr} 
Design Feature & PWR3 & & PWR6 & PWR9 & PWR12 \\
\hline Overpack OD, cm & 55.6 & 67.9 & 76.8 & 84.5 \\
Overpack Weight, MT & 7.63 & 11.35 & 14.62 & 17.77 \\
Shield Thickness, cm(a) & 14.36 & 15.16 & 15.65 & 15.96 \\
Overal1 Length, cm(b) & 490 & 490 & 490 & 490 \\
Shield OD, cm(c) & 86.86 & 100.76 & 110.64 & 118.96 \\
Shield Weight, MT(d) & 13.20 & 16.63 & 19.20 & 21.38 \\
Gross Weight, MT(e) & 20.83 & 27.98 & 33.82 & 39.15
\end{tabular}

Case II. $45000 \mathrm{MWD} / \mathrm{MTU}$ - 10 year age at emplacement

$\begin{array}{lrrrr}\text { Design Feature } & \text { PWR3 } & \text { PWR6 } & \text { PWR9 } & \text { PWR12 } \\ \text { Overpack OD, cm } & 55.6 & 67.9 & 76.8 & 84.5 \\ \text { Overpack Weight, MT } & 7.63 & 11.35 & 14.62 & 17.77 \\ \text { Shield Thickness, cm(a) } & 14.88 & 15.72 & 16.23 & 16.54 \\ \text { Overal1 Length, cm(b) } & 490 & 490 & 490 & 490 \\ \text { Shield OD, cm(c) } & 87.90 & 101.88 & 111.80 & 120.12 \\ \text { Shield Weight, MT(d) } & 13.77 & 17.35 & 20.03 & 22.28 \\ \text { Gross Weight, MT(e) } & 21.40 & 28.70 & 34.65 & 40.05\end{array}$

Case III. $45000 \mathrm{MWD} / \mathrm{MTU}$ - 5 year age at emplacement

\begin{tabular}{lrrrr} 
Design Feature & PWR3 & PWR6 & PWR9 & PWR12 \\
\hline Overpack OD, cm & 55.6 & 67.9 & 76.8 & 84.5 \\
Overpack Weight, MT & 7.63 & 11.35 & 14.62 & 17.77 \\
Shield Thickness, cm(a) & 16.22 & 17.13 & 17.69 & 18.03 \\
Overall Length, cm(b) & 490 & 490 & 490 & 490 \\
Shield OD, Cm(c) & 90.58 & 104.70 & 114.72 & 123.10 \\
Shield Weight, MT(d) & 15.27 & 19.20 & 22.14 & 24.61 \\
Gross Weight, MT(e) & 22.90 & 30.55 & 36.76 & 42.38
\end{tabular}

(a) Surface dose - $200 \mathrm{mrem} / \mathrm{hr}$ (50 mrem/hr shielding was not determined).

(b) Thickness of top and bottom transfer cask head equal to wall thickness.

(c) Air gap - $1.27 \mathrm{~cm}$ total.

(d) Carbon steel $-7.86 \times 10^{-6} \mathrm{MT} / \mathrm{cm}^{3}$.

(e) Loaded transfer cask. 


\subsection{WASTE PACKAGE THERMAL ANALYSIS}

Thermal calculations were performed to determine if the reference waste package heat loading resulted in temperature limits being exceeded. Temperature limits are given in Table 2-1, Study Data Base, (Item \#9) and are:

1. Maximum cladding temperature $375^{\circ} \mathrm{C}$

2. Maximum salt temperature $250^{\circ} \mathrm{C}$

The analyses were approached in two parts:

1. Evaluation of internal package heat transfer to determine if the $375^{\circ} \mathrm{C}$ cladding temperature would be exceeded by the reference package thermal loading of $6.6 \mathrm{~kW}$ (PWR12).

2. Performance of salt temperature calculations to determine if the salt/package interface would exceed $250^{\circ} \mathrm{C}$ for the $6.6 \mathrm{~kW}$ package (PWR12).

The internal heat transfer analyses was conducted for information and did not have a bearing on the recommendation of package modifications. The reason being, that package internal design (which affects internal temperature) is not the responsibility of the salt repository conceptual design contractor. On the other hand, the salt temperature calculations and results are important to repository design and if the salt limits were exceeded by the reference package, definite modifications would be recommended.

\subsubsection{Internal Package Temperature Analysis}

Preliminary thermal analyses of spent fuel rod bundles were conducted to determine maximum cladding (package centerline) temperature. A simplified model was developed to determine the temperature gradient between package surface and the centerline using radiative heat transfer only. The following assumptions were used: 
1. Large axial length-to-radius ratio cylindrical canister is assumed, such that the end effects can be neglected. The heat generation per linear unit of package is assumed to be uniform. With these assumptions, the problem is reduced to a two-dimensional $(r-\theta)$ problem.

2. The cantster is made of a high thermal conductivity material, such that a uniform temperature can be assumed for the canister wall.

3. All spent fuel rods are cylindrical in shape with the same diameter.

4. Fuel rods are not perfectly straight, therefore, when they are closepacked only a few "points" on each rod are in contact with other rods. Assume all contact surfaces at the contact "points" are small so that heat conduction through the contact "points" is negligible, therefore, only radiation heat transfer is assumed.

5. The canister is filled with air (or any low conductivity gas). The thermal conduction through air can be neglected.

6. Natural convection within the canister is neglected.

7. Since the fuel rod cladding is a high thermal conductivity material, uniform surface temperature can be defined for each rod.

8. Spent rods have the same heat generation rate.

9. Since the spent rods are packed in a cylinder (assumption \#1), the rod w11l be packed in a symmetrical pattern. It was further assumed that the distribution of the heat flux within the canister is also symmetrical. Therefore, the problem can be reduced to a onedimensional problem as a function of radial distance from the canister centerline. This is a conservative assumption because of the lack of lab or industry data on rod bundle heat transfer. 
10. Assume that all surfaces of the rods are gray (independent of frequency) surfaces with an emissivity of $(\varepsilon) 0.2$. This is a conservative assumption based on unoxidized cast iron.

11. The energy emitted by any rod surface is diffusively distributed.

12. No radial conducting fins within the package, or any other means of removing heat from the centerline, were assumed. This would cause the temperature results to be conservatively high.

With all of the above assumptions, the complicated problem of thermal energy distribution within a bundle of close-packed spent fuel rods reduces to a spent fuel rod packing problem and a radiative heat transfer calculation.

A problem similar to this was studied by Cox (1977). The basic difference between this cantster problem and the Cox study lies in the differences in the packing pattern. In Cox's work, the spent fuel rods are packed in either a hexagonal array or a square array, whereas in this conceptual design work, the rods are packed in a cylindrical array.

The radiative transfer calculation proposed by Cox applies exactly to this case. Therefore, all of those results are applicable to this study, and the equations used here related to the radiative transfer calculation will be extracted from Cox's original report without deviation.

Application of radiation heat transfer to the four alternative spent fuel waste packages (Table 3-1) resulted in temperature gradients between package surface and centerline shown on Figure 3-1. Package centerline temperature is plotted against package surface temperature for the four different package thermal loadings. Actual centerline temperatures have also been shown (Table 3-4). From the data it can be concluded that according to the analysis conducted during this study, approximately six PWR spent fuel assemblies may be maximum package capacity allowed without, exceeding the $375^{\circ} \mathrm{C}$ cladding temperature limits. 


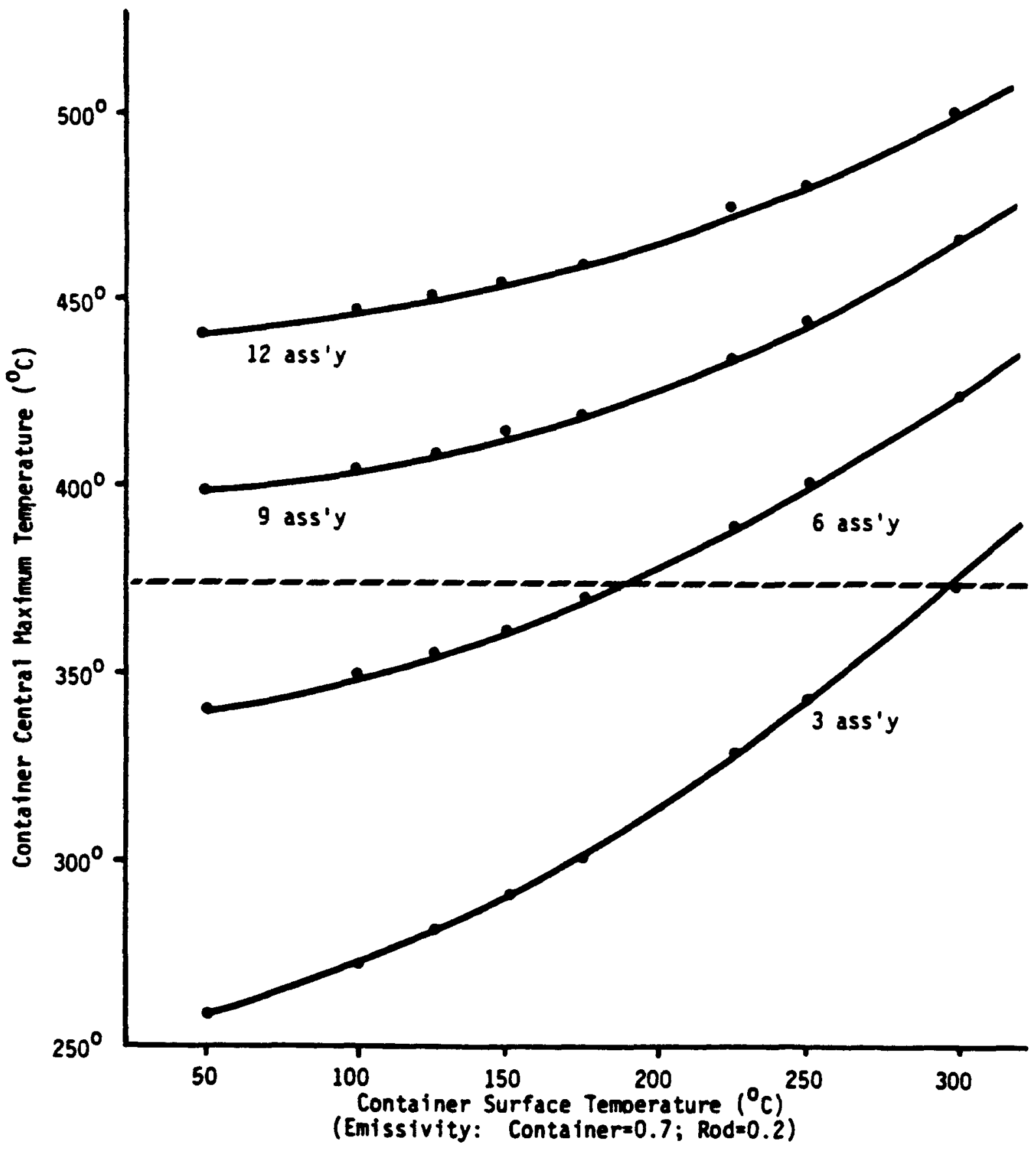

PACKAGE INTERNAL THERMAL GRADIENTS 
Table 3-4. Package Centerline Temperature $\left({ }^{\circ} \mathrm{C}\right)$

(Emissivity: Container $=0.7 ; \operatorname{Rod}=0.2$ )

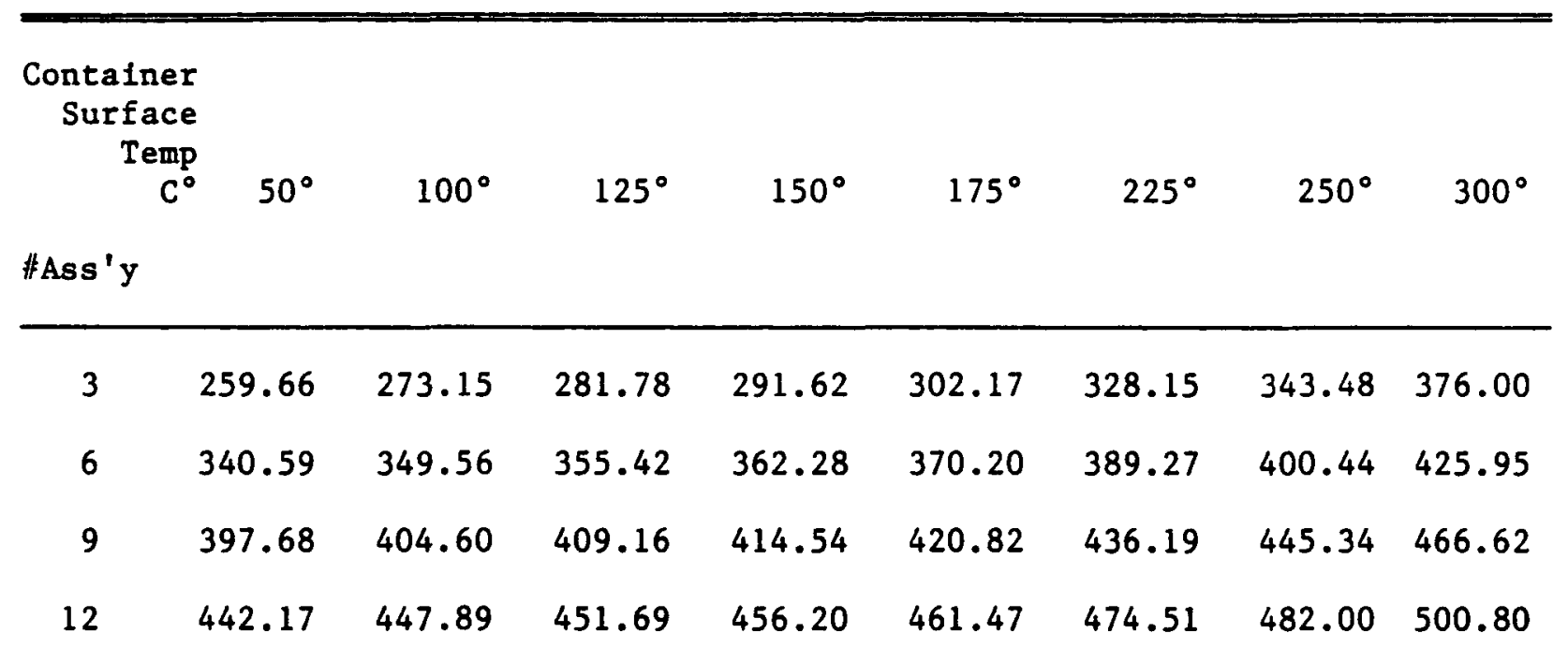

These analyses are contrasted by calculations performed by Westinghouse (ONWI, 1985), which showed that for the case of twelve consolidated PWR spent fuel assemblies in a package centerline temperatures would remain below the $375^{\circ} \mathrm{C}$ cladding limft. One difference in the two calculations and possibly a contributor to the contrast was that Westinghouse included radial conducting fins within the package and Fluor did not. It is possible to effect the centerline temperature by using appropriately sized conducting fins, to the point that the $375^{\circ} \mathrm{C}$ centerline limit is not exceeded with the 12 assembly package.

Another important observation was made during this investigation. Both these study calculations and the Westinghouse calculations showed a thermal gradient between the package surface and the centerline of about $200^{\circ} \mathrm{C}$. The Westinghouse calculations showed this gradient (actually closer to $175^{\circ} \mathrm{C}$ than $200^{\circ} \mathrm{C}$ ) for the 12 assembly package, whereas these study calculations showed this gradient for the 6 assembly package. For the 12 assembly package, this 
study (Figure 3-1) shows a gradient of $275^{\circ} \mathrm{C}$. Using the $200^{\circ} \mathrm{C}$ gradient, and assuming the package centerline is at the limit of $375^{\circ} \mathrm{C}$, the maximum package surface temperature may be on the order of $175^{\circ} \mathrm{C}$. This translates to a maximum allowable salt temperature of $175^{\circ} \mathrm{C}$. As a design parameter, this value is necessary in determining areal thermal loading and package spacing. Its application is discussed in Section 3.2.2.

\subsubsection{Analysis of Maximum Salt Temperature}

A series of thermal response calculations were performed to predict the maximum salt temperature near an emplaced waste package. The maximum salt temperature is a key variable because design criterion limits the maximum salt temperature to $250^{\circ} \mathrm{C}$ (Table 2-1). The specific objective of these calculations is to evaluate the feastbility of the reference waste package with respect to meeting the maximum salt temperature. An additional objective of these calculations was to support the emplacement mode selection by assessing the effect of various emplacement modes on maximum salt temperature.

The maximum salt temperature is a function of emplacement mode, thermal areal loading, waste package power level, and the thermal conductivity of salt. Variations of thermal areal loading and package power level are relatively straightforward. Variations of emplacement mode are less straightforward because of the number of emplacement modes (17) Investigated (see Appendix D) and because of the geometric complexity of certain modes. The 17 alternative emplacement modes are listed in Table 3-5. Rather than attempt to calculate the salt temperatures for all 17 modes, a few representative modes have been selected for analysis and the results of these analyses are extended/extrapolated to the other emplacement modes that were investigated. The validity of this approach is based on selecting representative modes that bound the expected thermal response and on the observed insensitivity of maximum salt temperature to minor geometric variations in emplacement mode. 
Table 3-5. Alternative Emplacement Modes (a)

\begin{tabular}{|c|c|c|c|c|c|c|}
\hline No. & VERT/HORIZ & OPENING & LOCATION & SLEEVED & SINGLE & COMMENTS \\
\hline 1 & Vertical & Hole & Room Floor & No & Yes & Shielded \\
\hline $1 \mathrm{~A}$ & Vertical & Hole & Room Floor & Yes & Yes & Shielded \\
\hline 2 & Vertical & Slot & Room Pillar & No & Yes & Shielded \\
\hline 3 & Horizontal & S1ot & Room Plllar & No & Yes & Shielded \\
\hline $3 \mathbf{A}$ & Horlzontal & slot & Rm Mid-pillar & No & Yes & Unshielded \\
\hline 3B & Horizontal & Slot & Rm Mid-pillar & No & Yes & Shtelded \\
\hline $3 c$ & Horizontal & Drift & $\begin{array}{l}\text { Pillar Side- } \\
\text { drift }\end{array}$ & No & Yes & Shielded \\
\hline 4 & Horizontal & Open & $\begin{array}{l}\text { Room Floor } \\
\text { (corner) }\end{array}$ & No & Yes & Unsheilded \\
\hline 5 & Horfzontal & Open & $\begin{array}{l}\text { Room Floor } \\
\text { (nonparallel) }\end{array}$ & No & Yes & Unshielded \\
\hline 6 & Horizontal & $\begin{array}{l}\text { Trench } \\
\text { (center) }\end{array}$ & $\begin{array}{l}\text { Room Floor } \\
\text { (parallel) }\end{array}$ & No & Yes & Shielded \\
\hline $6 \mathrm{~A}$ & Horizontal & $\begin{array}{l}\text { Trench } \\
\text { (center) }\end{array}$ & $\begin{array}{l}\text { Room Floor } \\
\text { (parallel) }\end{array}$ & No & Yes & Unshtelded \\
\hline 6B & Horfzontal & Trench & $\begin{array}{l}\text { Room Floor } \\
\text { (nonparallel) }\end{array}$ & No & Yes & Unshlelded \\
\hline $6 \mathrm{C}$ & Horizontal & $\begin{array}{l}\text { Trench } \\
\text { (corner) }\end{array}$ & $\begin{array}{l}\text { Room Floor } \\
\text { (parallel) }\end{array}$ & No & Yes & Unshielded \\
\hline 7 & Horizontal & Hole & Room Pillar & Yes & Yes & - \\
\hline $7 \mathrm{~A}$ & Horfzontal & Hole & Room Plllar & No & Yes & - \\
\hline 8 & Horlzontal & Hole & Room Pillar & Yes & Mu1t1 & $600 \mathrm{ft}$ \\
\hline 8A & Horizontal & Hole & Room Pillar & No & Mult1 & $300 \mathrm{ft}$ \\
\hline
\end{tabular}

(a) See Figure D-1 for a graphical presentation of these emplacement modes. 
From the 17 alternative emplacement modes, five representative modes were selected for thermal analysis, and are as follows:

1. Mode 1: Vertical borehole in room floor, unsleeved;

2. Mode 3B: Horizontal slot at mid-height of the room pillar, parallel to entry centerline;

3. Mode 8A: Long horizontal borehole in room pillar, unsleeved;

4. Mode 4: Horizontal on room floor, surrounded by crushed salt and parallel to entry centerline and in corner of room; and

5. Mode 1': Variation on Mode 1. Same as Mode 1 with crushed salt backfill in the annular space between package and borehole.

Detailed thermal calculations of these five modes are shown in Appendix $B$. The calculations are arranged as follows:

6. Section B.1 - Vertical Borehole Analysis (Mode 1) - No crushed salt backf1ll was assumed. From the thermal standpoint, this mode is very representative of the horizontal borehole emplacement in the pillar.

7. Section B.2 - Horizontal Slot Analysis (Mode 3B).

8. Section B.3 - Long Horizontal Borehole Analysis (Mode 8A).

9. Section B.4 - Analysis of Waste Package Emplacement on the floor of the entry, covered by crushed salt (Mode 4 ).

10. Section B.5 - Vertical Borehole Analysis with varying thickness of a crushed salt annulus (Mode $1^{\prime}$ ). Would also apply to the horizontal borehole emplacement mode. 
For extrapolation of the results from the five representative modes to the other modes, Appendix B, Section B.6 was included. This ensured proper consideration of all emplacement mode alternatives.

The results of these analyses indicate that, with an appropriate choice of areal thermal loading, the reference waste package can satisfy the salt temperature 1 imit of $250^{\circ} \mathrm{C}$. In addition, the calculated salt limit of $175^{\circ} \mathrm{C}$ (from Section 3.2.1) can also be satisfied. In either case, a proper balance must be achieved between package thermal loading, areal thermal loading and thickness of crushed salt surrounding the package. As recommended in Section 3.2.1, the maximum allowable salt temperature for a PWR12 package may be on the order of $175^{\circ} \mathrm{C}$. From the data in Figure 3-2, a salt tempearture of $175^{\circ} \mathrm{C}$ is achleved, for the reference PWR12 package, at an areal thermal loading of about $24 \mathrm{~W} / \mathrm{m}^{2}$. (A crushed salt annulus 1 inch thick was assumed in Figure 3-2). This value for areal loading therefore represents the maximum allowable before very near-field temperature limits (cladding and salt) are exceeded. It is considered, by this study, as an upper bound areal loading for the reference waste package. Other repository design factors, such as rock thermal expansion and creep rate, may be more constraining and tend to drive the areal loading down. That would be perfectly acceptable and is highly probable. The loading however, should not be above the $24 \mathrm{~W} / \mathrm{m}^{2} 1$ imit.

As a sample of the data concering crushed salt thickness variations, the situation for the vertical borehole emplacement mode with varying thicknesses of the crushed salt annulus is shown on Figure 3-3 (Mode 1). The reference package exceeds the $250^{\circ} \mathrm{C}$ limit with about three inches of crushed salt at 30 $\mathrm{W} / \mathrm{m}^{2}$. At $20 \mathrm{~W} / \mathrm{m}^{2}$ with the $250^{\circ} \mathrm{C} 1 \mathrm{imit}$, five inches of crushed salt could be tolerated. The lower package loadings give greater flexibility for annulus thickness. If, on the other hand, the calculated salt limit of $175^{\circ} \mathrm{C}$ was applied, Figure 3-3 indicates that for the reference package at $20 \mathrm{~W} / \mathrm{m}^{2}$, about only two inches of crushed salt could be tolerated. For an areal loading of $24 \mathrm{~W} / \mathrm{m}^{2}$, the upper limtt, Figure 3-3 indicates that only about one inch of crushed salt can be tolerated. Emplacement with less than a one inch gap, would not be practical from a tolerance standpoint. 


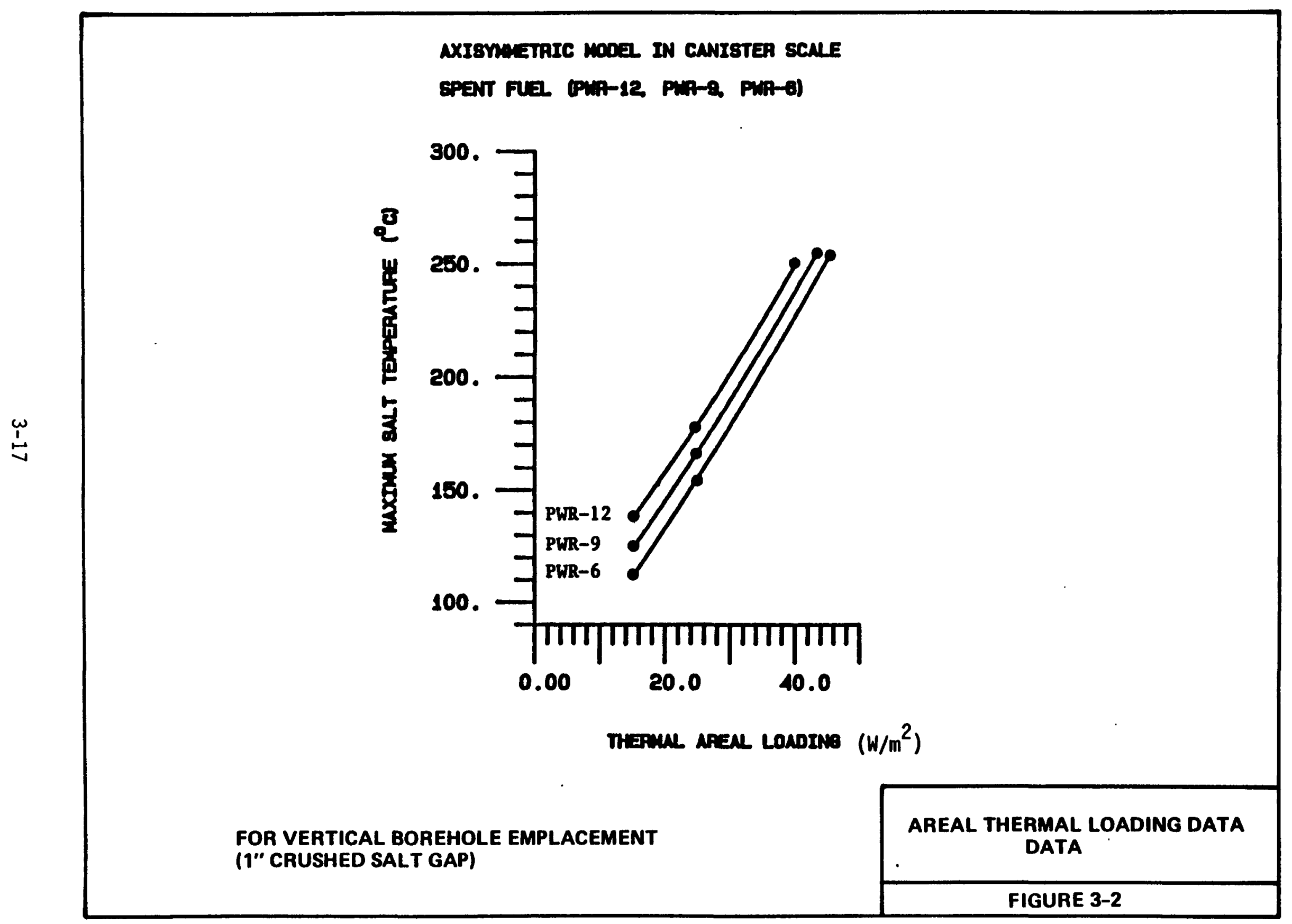




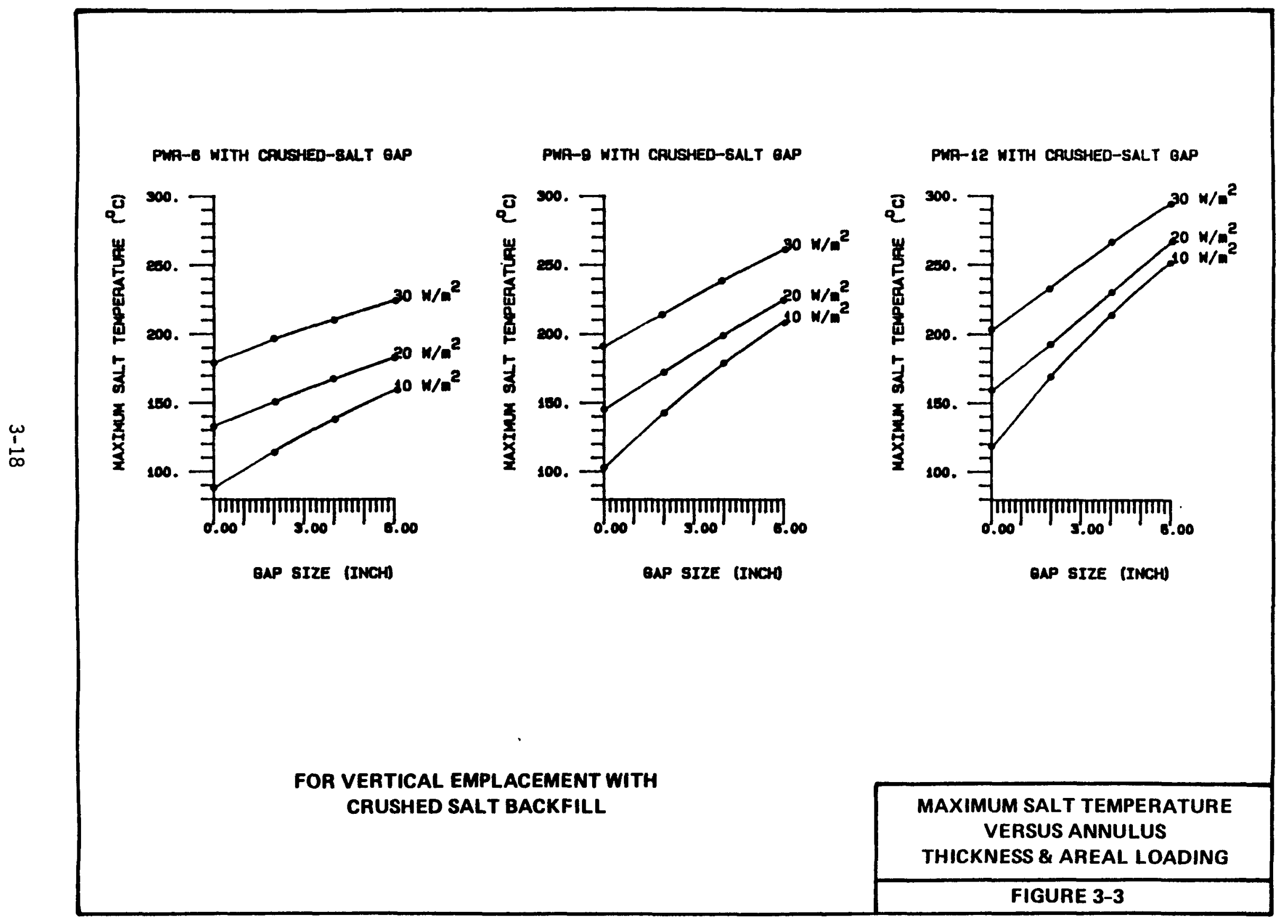




\subsubsection{Thermal Response in the Room and Pillar Region}

A series of calculations were performed to predict the thermal response in the room and pillar region at 50 to 70 years after emplacement. While these calculations did not have a direct bearing on the feasibility of the reference waste package, they were important in evaluating emplacement modes and areal thermal loading from the standpoint of potential rock temperatures to be handled during remining and retrieval. The salt temperatures encountered during retrieval (retrieval can begin up to 50 years after emplacement) will have a major impact on retrleval operations. The salt creep rate is highly dependent on salt temperature. The creep rate will have a bearing on the parameter of the remaining operation (e.g., entry size, entry location, ventilation requirement, excavation rate and maintenance required to keep entries). It is therefore necessary to determine a maximum creep rate that can be tolerated during retrieval. Once this value is established, repository designs can be conducted to limft salt temperature to a level that would give acceptable creep rates. Retrieval equipment will also be affected by temperatures in the rock (i.e., availability, complexity). The design of this equipment must be considered when determining the salt temperature limitations during retrleval. Detailed analyses of these responses have been included in Appendix B, Section B.8. It has been shown that rock temperatures in the 50 year time frame are driven primarily by emplacement mode and areal thermal loading, and individual package loading is an insignificant contributor. Therefore, from the standpoint of room and pillar temperatures, the reference package with a $6.6 \mathrm{~kW}$ thermal loading is acceptable.

\subsection{WASTE PACRAGE STRESS FIELD EVALUATION}

An evaluation was conducted to verify if the stresses resulting on the waste package after emplacement exceeded the design stress limit of the reference waste packages described in Table 2-1. The reference vertical borehole emplacement mode as well as the preferred horizontal borehole emplacement mode (Section 3.4) were considered. In addition, the 15 other emplacement mode alternatives (see Appendix D) were investigated. 
A series of calculations and analyses were performed to determine the mechanical response to an emplaced waste package. The specific objective of these studies was to determine the peak radial stress for the 17 candidate emplacement modes and to identify those emplacement modes that might cause a waste package to fail. The technical approach to this study was to (1) perform numerical analyses of two representative modes, and (2) to extend these results to other emplacement modes by evaluating the potential failure mechanisms for a waste package.

Detailed calculations and data pertaining to the waste package stress analysis are presented in Appendix C. It has been shown that for the vertical borehole emplacement mode, with a $2.54 \mathrm{~cm}$ (1 inch) annular air gap between package and borehole, the peak radial stress is below the $21.4 \mathrm{MPa}$ design limit for the reference package in the hoop mode (ONWI, 1985). This general result should be applicable to emplacement in any borehole, including horizontal. The results for the horizontal slot emplacement mode show a similar behavior: a $2.54 \mathrm{~cm}$ air gap will provide sufficient stress relief to keep the peak radial stress below $21.4 \mathrm{MPa}$.

There has been sufficient data generated from these analyses to verify that the reference waste package can withstand rock stresses in the reference vertical emplacement mode and the preferred horizontal borehole emplacement mode.

The review of potential fallure mechanisms considered a unfform radial loading (the hoop mode), a concentrated load on one side of a canister, and a bending load normal to the package centerline. The response to these loads indicates that bending modes or stress concentrations from local geologic failures posed the greatest threat to a waste package, and that an air gap will eliminate the threat from a concentrated load on one side of a package.

As a result of the analyses presented in Appendix C, general guidelines pertaining to the mechanical response of the waste package are as follows:

1. An Initial radial air gap of one inch or more should be present for all emplacements. Ignoring thermal considerations, the air gap can 
be replaced by a thicker gap filled with crushed salt to provide an equivalent delay of the stress buildup on the canister.

2. A vertical borehole at the room center and a horizontal borehole at the wall mid-height have the lowest stress levels (Modes 1, 1A, 7, $7 \mathrm{~A}, 8,8 \mathrm{~A})$.

3. In-floor trench emplacements are satisfactory if the burlal depths are not shallow (Mode 6). However, a safe minimum depth has not been established. The same is true for in-pillar slots of sufficient depth (Modes 3, 3B, 3C).

4. In-floor trench emplacements should be backfilled with solid salt blocks with a fit-up clearance that is smaller than an air gap around the canister so that the blocks will accommodate the 1ithostatic pressures.

5. Shallow in-floor trenches (Modes 6A, 6B, 6C) will be in areas of greater salt creep and thus potentlally greater stresses on the emplaced package. Shallow plllar slot emplacements are undesirable because of the possibility of salt faflure on the lower edge of the slot (Mode 3A).

6. On-floor emplacement (Modes 4,5) concepts locate the waste packages in areas of greater salt creep and thus greater stresses on the package.

7. Vertical in-pillar emplacement (Mode 2) has the potential to result in package failures in the longitudinal bending mode.

\subsection{EMPLACEMENT MODE EVALUATIONS}

The feasibility of using the reference waste package with the salt project preferred emplacement mode was evaluated. The evaluation involved determining waste package/emplacement mode feasibility from the following standpoints: 
1. Will the reference package in the preferred emplacement mode create a situation where salt temperature limits are exceeded?

2. Will stress levels on the waste package after emplacement exceed the design limits on the reference waste package?

3. Is equipment technology available to perform the emplacement?

If any of these evaluations showed incompatibility, then modifications to the waste package (i.e., in weight, heat load, etc.) would be recommended.

At the time of this study, the salt respository conceptual design program had not yet selected a preferred emplacement mode. Since a mode is required as a basis for these evaluations, the ongoing emplacement mode design study (SOW 4.1.6.2 "Waste Process and Mine Emplacement Study") was brought to a tentative conclusion concurrently with the waste package evaluation. A detailed decision analysis was conducted to select a preferred emplacement mode from the repository standpoint. This analysis is documented in Appendix D. The decision analysis assumed a reference point of vertical emplacement in the floor of disposal rooms. As the analysis was conducted, the data Indicated that horizontal borehole emplacement in the pillar had some definite advantages over the reference vertical case and the other alternatives considered. Therefore, a tentative decision was reached to proceed further in this study with the horizontal borehole emplacement mode. The boreholes would be in the pillar and have the capacity for a single package. The evaluation of waste package feasibility was then conducted on the basis of this emplacement mode.

\subsubsection{Temperature Evaluation}

An in-depth assessment of salt temperatures for the preferred emplacement mode and the reference waste package was conducted. This analysis is described in detafl in Section 3.2.2 with back-up data in Appendix $B$. The evaluations have shown that a $6.6 \mathrm{~kW}$ waste package (reference package) can be emplaced horizontally in the pillar without exceeding salt temperature limits. 


\subsubsection{Stress Evaluation}

The stress levels on the waste package after emplacement have been calculated. A summary of these calculations is provided in Section 3.3 with back-up data in Appendix C. Results indicate that the reference package design can withstand the maximum stresses applied in the horizontal emplacement configuration.

\subsubsection{Emplacement Equipment Feasibility}

An evaluation of equipment technology was conducted to determine the feasibility of emplacing the reference waste package (approximately 18 MT) in a horizontal borehole. For this evaluation, the following assumptions were made:

1. The horizontal hole in the pillar will be at an elevation approxImately midway between floor and roof and controlled to a predetermined height within \pm 6 inches.

2. The hole in the pillar will be horizontal (parallel to the floor). It is assumed that the borehole will be within $\pm 3^{\circ}$ of horizontal.

3. The hole depth measured from the wall to the extreme depth will be 21 feet.

4. Room operating envelopes dimensions will be: (see Section 3.7)
a. Height 13.5 feet
b. Width 18 feet

On the basis of these assumptions and considering the reference package weight combined with the weight of the associated transfer cask (42 MT total), an emplacement machine was devised as shown in Figures 3-4 and 3-5. This vehicle, as shown, is similar in many respects to the transport vehicle discussed in Section 3.5. The gross weight of the machine will be similar (200,000 pounds) as will the ground pressure (20-30 psi). 


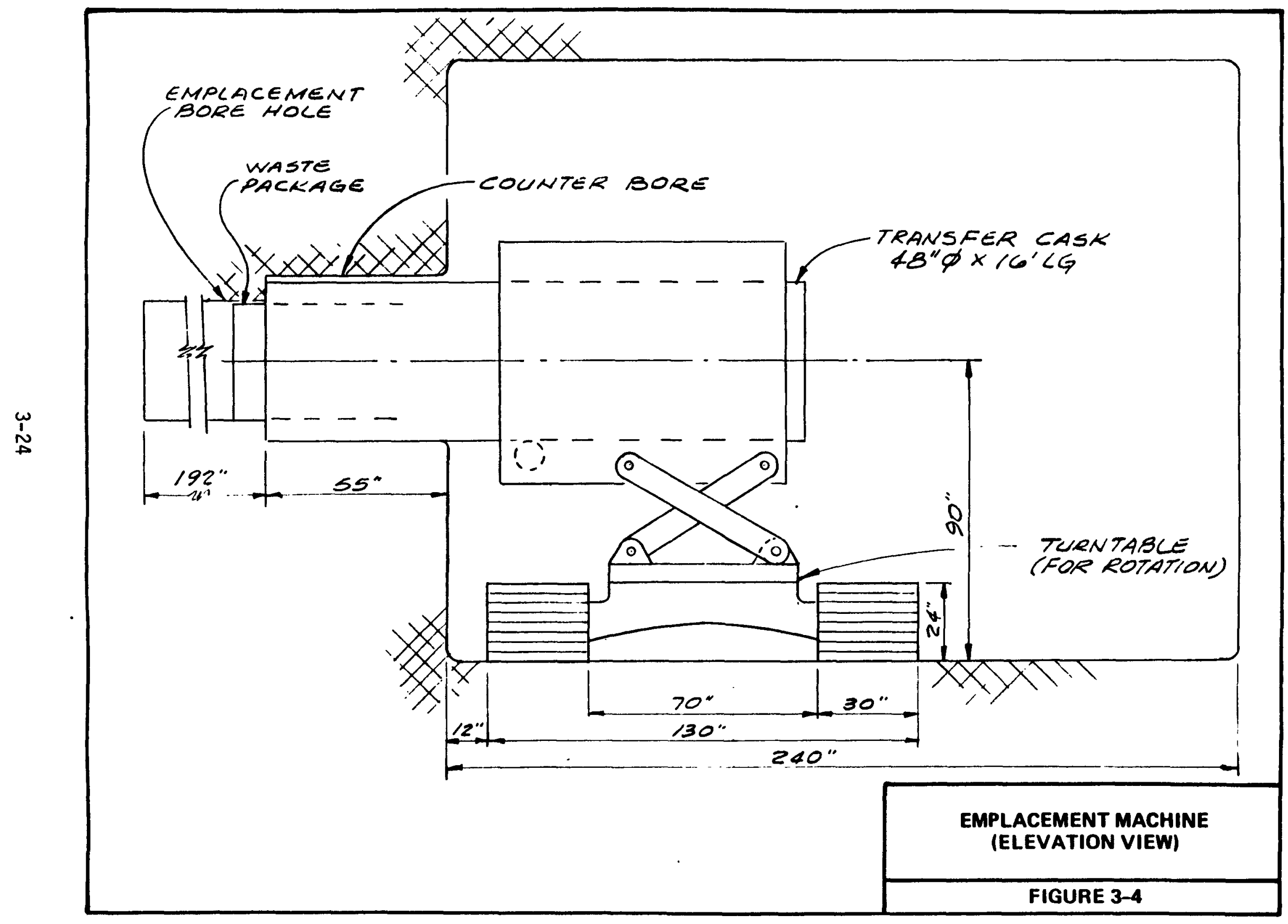




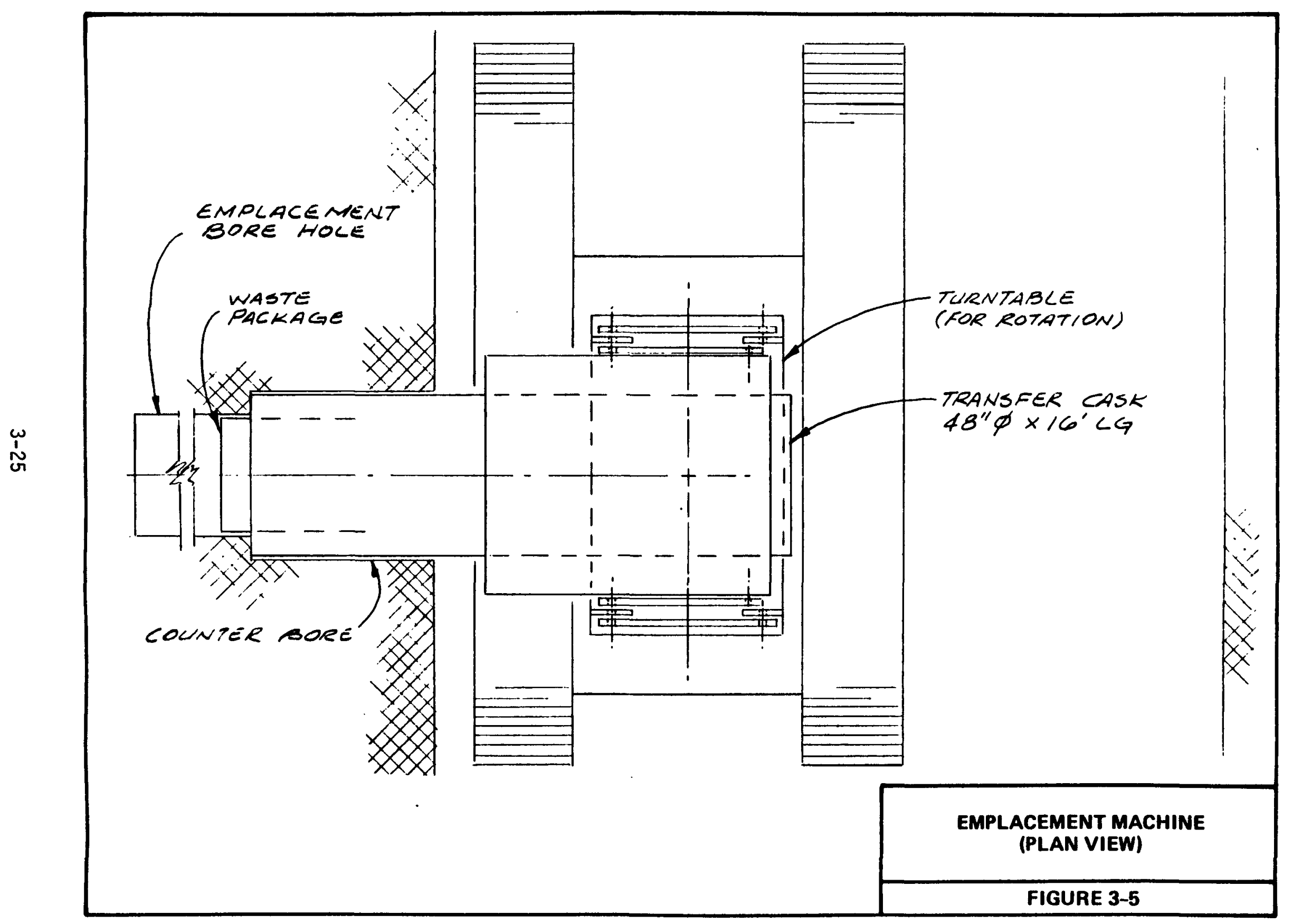


The crawler frame proposed for the emplacement machine is of the type used for underground continuous mining machines as compared to the excavator frame proposed for the transporter. The miner type crawler frame is lower in overall height. This lower height is necessary to provide space for the mechanism to level and align the transfer cask with the horizontal borehole.

In the assumptions, tolerances for the location and angular alignment of emplacement boreholes were defined. These were needed in order to evaluate equipment feasibility. If these assumed tolerances cannot be practically maintained on the basis of mining technology, the machine described here could be outfitted with the necessary alignment features. The crawler frames proposed in this concept are of the kind used by such manufacturers as Joy, Jeffrey, Ingersol Rand, and National Mine Service. For example, an applicable crawler frame which is currently available is the Joy Model No. $12 \mathrm{HM} 10$ (Joy, 1985).

The advantage of these crawler frames is their lower overall weight and extremely high load capacity. They are not well suited, however, to use at high speed, or for long distances. This combination of characteristics fits the needs of the emplacement machine which does not need to travel long distances as does the transporter. It does however need to support a large cantllevered load (as the transfer cask is shifted over toward the pillar) which it will be capable of.

On the basis of the evaluation discussed here, an emplacement machine can be envisioned for this application, using existing technology, and is therefore feasible. No modifications to the reference waste package are required for compatibility with the preferred emplacement mode either from the thermal, stress or equipment standpoint.

The above data on equipment design was developed to assess waste package feasibility only. It does not reflect equipment concept selection for the salt repository conceptual design. 


\subsubsection{Retrieval Equipment Feasibility}

During the operational life of the repository, occasional retrieval of waste packages for performance assessment purposes will be required. In addition, retrieval of all emplaced waste, for safety considerations, may become necessary. The retrievability of waste packages is therefore a necessary part of design. As an objective of this study, it must be determined if the reference waste package can be retrieved and if that retrieval is technically feasible.

Retrieval concerns primarily impact mine design and areal loading, and therefore the ability to re-open the mine and retrleve the waste. The waste package dimensions and weights have little bearing on these parameters. The waste package would impact the design of the machine to physically extract the package from its emplacement position. Since equipment for emplacement is feasible (Section 3.4.3), simflar equipment for retrieval is assumed to be appropriate and therefore feasible.

\subsection{TRANSPORTER FEASIBILITY}

The feasibility of transporting the reference waste package (PWR12) in the underground facility was investigated. Initially, a mode of transport was selected that was considered most appropriate for this application. The subsurface dimensions were based on the reference layout (Section 2.0). Appendix $E$ describes the selection of the transport mode (e.g. wheels, tracks, crawlers). Once the mode was selected, analogous type of equipment was reviewed to determine if suitable equipment was avallable or within state-ofthe-art. A critical area in the waste transport is in negotiating intersections of entries. Figure 3-6 1llustrates this intersection. This Appendix E evaluation was based on the following package and underground entry assumptions:

1. Transporter payload is a loaded transfer cask:

$$
\text { a. Length - } 16 \text { feet }(490 \mathrm{~cm})
$$




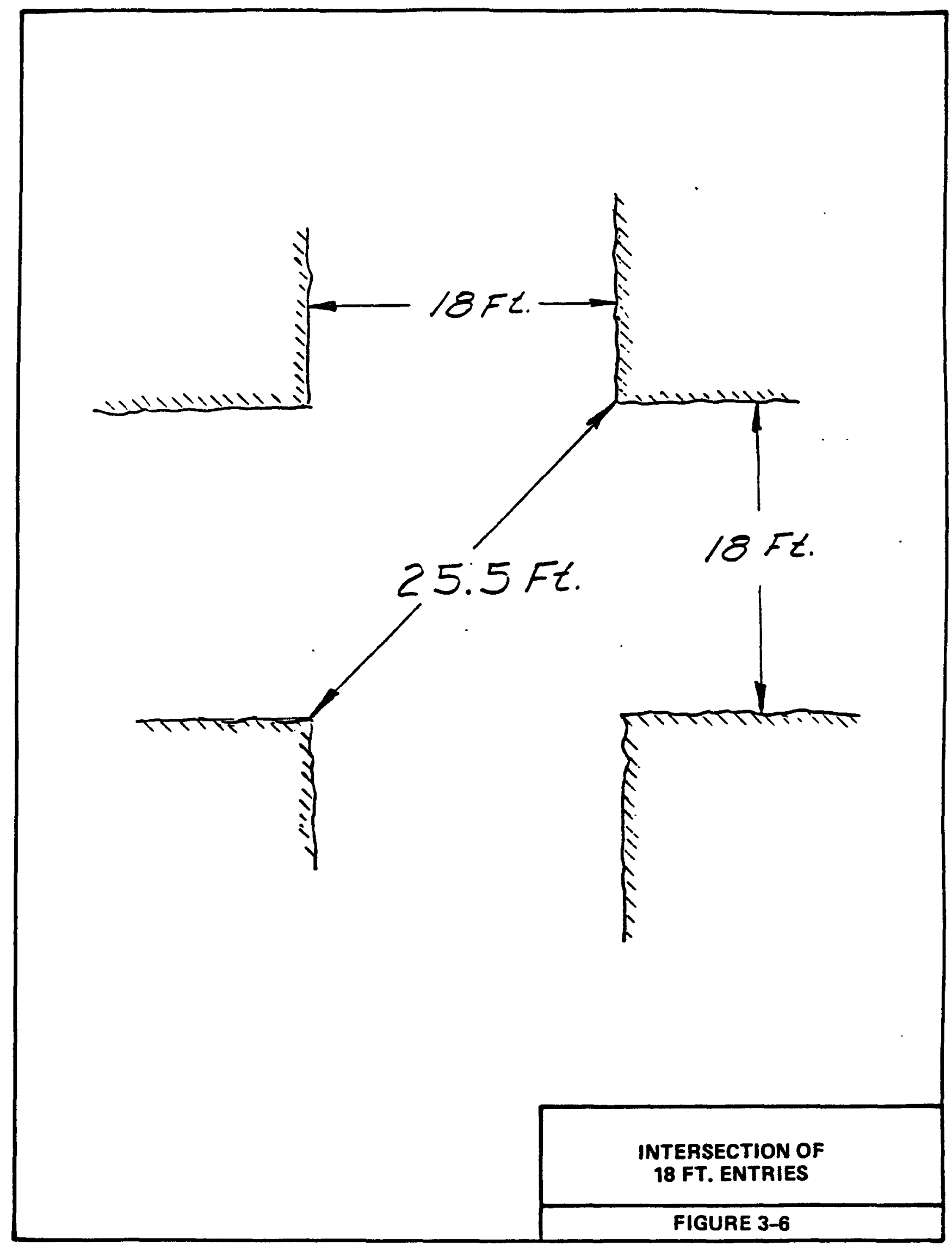

3-28 


$$
\begin{aligned}
& \text { b. Diameter - } 48 \text { inches }(122 \mathrm{~cm}) \\
& \text { c. Weight - } 46 \text { tons }(42 \mathrm{MT})
\end{aligned}
$$

2. Underground operating envelope dimensions would be slightly less than the $20 \times 15$ foot design dimensions because of rough wall surfaces and salt creep. These dimenions would be:

$$
\begin{aligned}
& \text { a. Width }-18 \text { feet }(5.5 \mathrm{~m}) \\
& \text { b. Height }-13.5 \text { feet }(4.1 \mathrm{~m})
\end{aligned}
$$

The method selected by the Fluor project team for underground transfer (selection process is discussed in Appendix E) was a crawler-type vehicle with skid steering. A crawler-type transporter capable of handling loaded transfer casks welghing $42 \mathrm{MT}$, and measuring 16 feet long by 48 inches in diameter designed to operate in underground workings with places 18 feet wide by 13.5 feet high is practical. Figures $3-7$ and $3-8$, respectively, show an end view and a side elevation of a transfer cask of these dimensions on a crawler frame utilizing components produced by Caterpillar Tractor. These figures are based on using a "Cat" Model 235-D7 excavator crawler frame (Catepillar, 1984). The feasibility of this type of vehicle negotiating an intersection is illustrated on Figure 3-9.

A vehicle like the one shown in Figure 3-9, will have a gross weight (loaded) of approximately 200,000 pounds. Based on the standard 235-D7 crawler with 30-inch track plates, the ground pressure will be approximately 20 pounds per square inch. This is well within acceptable limits for salt floor bearing pressure (DOE, 1984a). A specification sheet for this equipment and layout drawings are given in Appendix E, Figures E-1 and E-2, respectively.

\subsection{HOIST FEASIBILITY}

The feasibility of hoisting the reference waste package with currently avallable holsting technology was evaluated. This was accomplished by identifying maximum payloads that can be transferred using current technology and then comparing these to the payload weight of the reference waste package. 


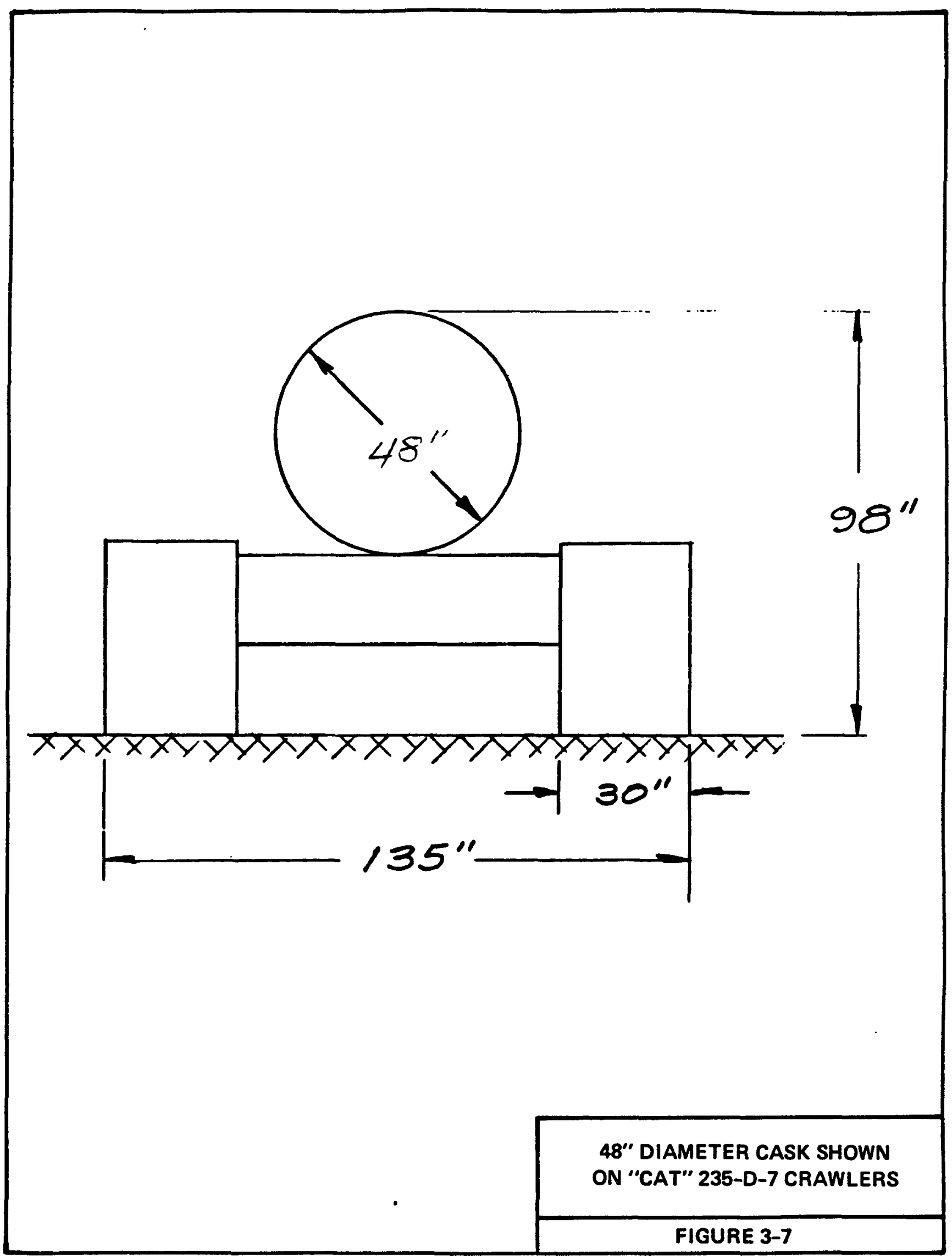




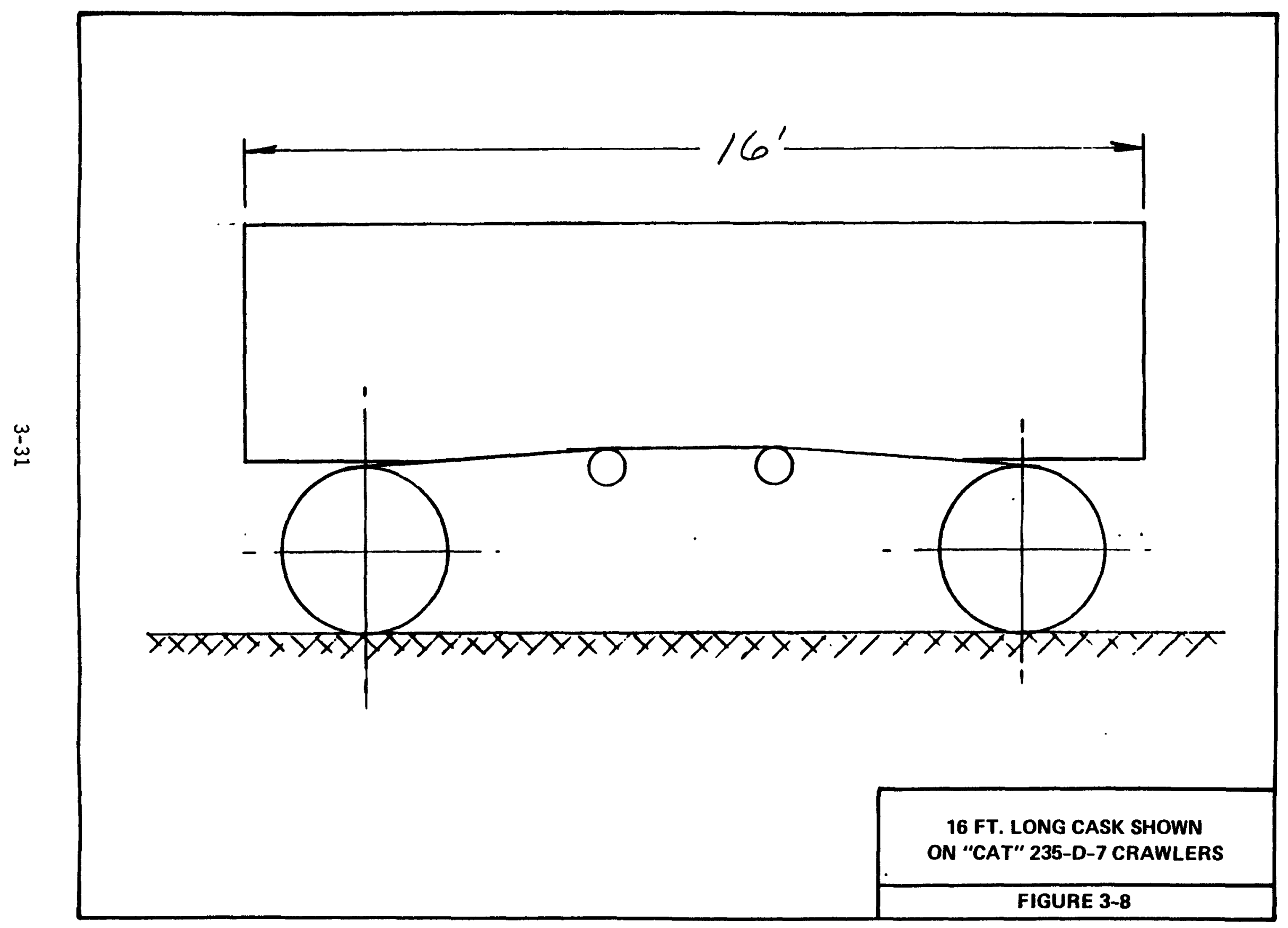




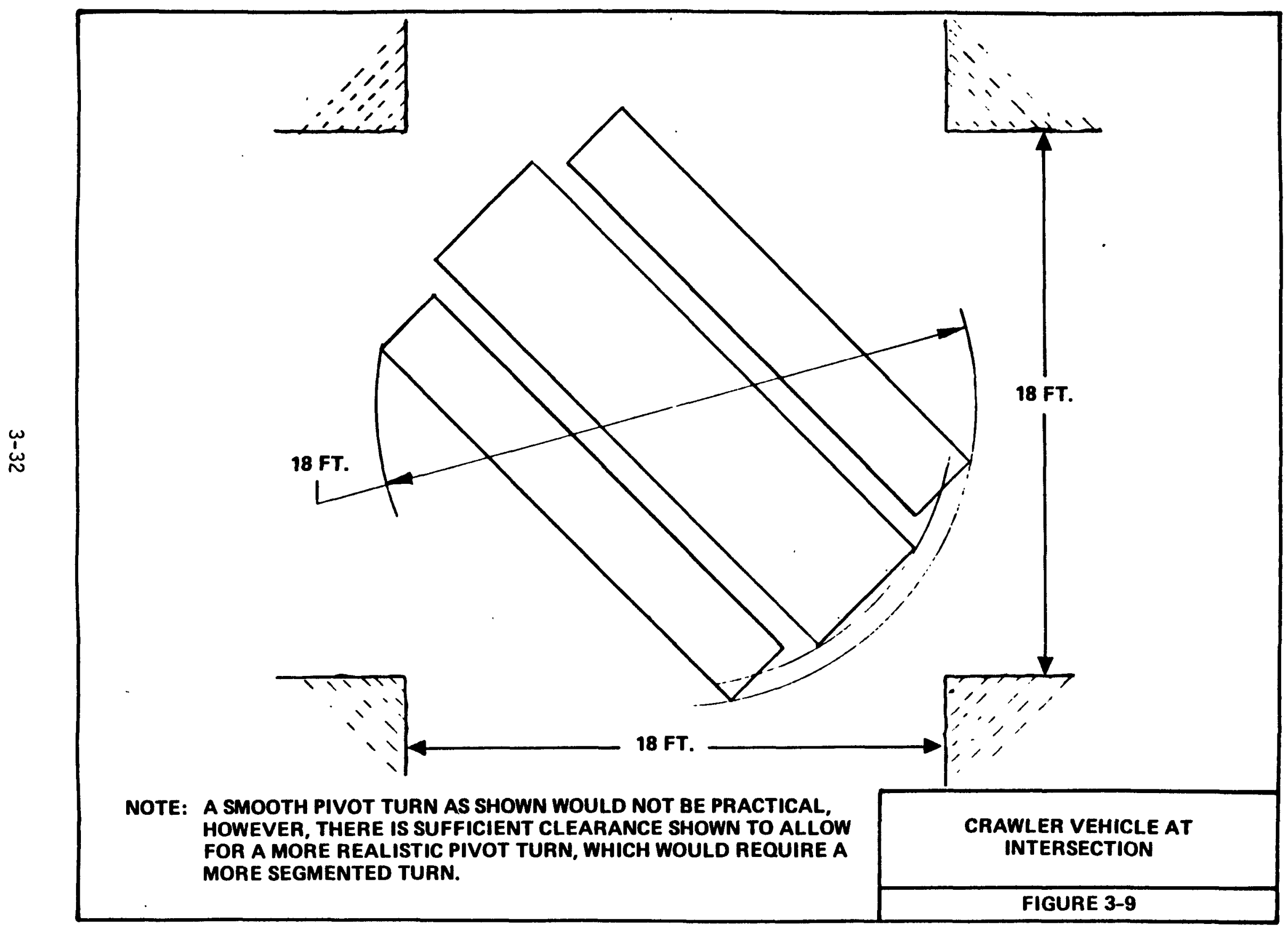


Initially, the reference payload weight was determined. The PWR12 package weighs about $18 \mathrm{MT}$ (from Table 3-1). It was decided that the payload will include a shield (transfer cask) as discussed in Appendix F. The transfer cask for a $50 \mathrm{mrem} / \mathrm{hr}$ dose weighs about $24 \mathrm{MT}$ (from Table 3-2). The payload welght of concern for hoisting was then $42 \mathrm{MT}$. The determination of technical feasibility of hoisting this payload was then approached.

\subsubsection{Study Approach}

A literature search of installed holst specifications was conducted to examine the current state of technology and identify existing high capacity holst system parameters, which Include: total suspended load, shaft depth, number of ropes, and friction wheel diameter.

This avallable technology information defined criteria for hoist system constraints and payload calculations. The resulting criteria was used with an assumed hoisting distance of $3,000 \mathrm{ft}$ and conservative safety factors to calculate maximum payload capabilities.

An examination of installed holst system specifications helped define the criteria used to perform this study. The following criteria were obtained by examining installed hoist system specifications of various manufacturers including Rexnord Inc. ${ }^{(*)}$, American M.A.N. Corporation ${ }^{(* *)}$, and ASEA ${ }^{(* * *)}$. Although there are other hoist manufacturers, these three were chosen as being representative of manufacturers of large hoist systems with offices and installation experience in the United States.

\footnotetext{
* Rexnord, Inc., P.0. Box 383, M1lwaukee, WI 53201

** American M.A.N. Corporation, 50 Broadway, New York, NY 10004

*** ASEA Industrial Systems, Inc., 66 Bobet Rd., San Mateo, CA 94402
} 


\subsubsection{Hoist System Constraints}

Consideration of hoisting weights and shaft depth indicates use of a friction-type holst. This was determined in the study associated with project SOW paragraph 4.4.2.8, "Waste Hoist Technology." This is reported in deliverable number 4.4-12 (Fluor, 1985). For these systems, standard technology values were identified by determining hoist system constraints. These values, derived by examining system specifications of existing hoist installations, were used to quantify the study criteria for constraints and payload calculations.

1. Maximum total suspended load $=252$ tons (ASEA, 1983)

2. Wheel diameter of holst system with above load $=197$ in. (ASEA, 1983)

3. Maximum number of ropes $=8$, for systems examined (ASEA, 1983)

These criteria values are not absolute maximums to be applied to waste hoist technology, but rather maximums existing under "standard technology" definitions. Further design effort could provide fustification for exceeding these maximum values, if required.

\subsubsection{Hoist Payload Calculation}

On the basis of system requirements and technology constraints, maximum allowable holst payloads were calculated.

The detailed calculations are provided in Appendix F, Section F.2. The calculations indicate a maximum payload capacity of 52.4 MT (57.8 tons). Therefore, using maximum parameters of presently installed friction hoists, and under the assumption of avallable technology, the maximum waste hoist payload is $52.4 \mathrm{MT}$. This value is safely above the weight of the PWR 12 package and transfer cask for $50 \mathrm{mrem} / \mathrm{hr}$ dose (42 MT). 


\subsection{SUBSURFACE LAYOUT}

The evaluation of the subsurface layout considered the reference waste package and the horizontal emplacement mode. This evaluation also determined the feasibility of a suitable subsurface layout. Package dimensions, while important to entry size, did not constitute a major concern here since layouts for the reference package have been shown to be possible in the past (ONWI, 1981). The concerns in this evaluation were as follows:

1. Can a subsurface layout be designed to accommodate horizontal emplacement in the pillar using the current gassy mine regulations in MSHA (1985)?

2. Can the areal thermal loading be achieved with an acceptable package spacing?

Analysis of subsurface layouts has lead to a feasible approach for emplacing the reference package in a horizontal borehole in the pillar. The in-pillar configuration, as shown in Figure 3-10, utilizes the concept of emplacing waste in abutment pillars. Abutment pillars, between sets of emplacement entries, are sited to provide $80 \mathrm{ft}$ of undisturbed plllar between the waste packages. The resulting overall pillar width is 122 feet (Figure 3-10).

Barrier pillar widths were not defined for this emplacement panel configuration. All entries are $20 \mathrm{ft}$ wide by $15 \mathrm{ft}$ high to accomodate the horizontal in-pillar emplacement mode. Working envelopes in all entries are $18 \mathrm{ft}$ wide by $13.5 \mathrm{ft}$ high. The overall dimenstons of the waste emplacement panel to accommodate this emplacement mode $1 \mathrm{~s} \sim 5,000 \mathrm{ft}$ by $1,200 \mathrm{ft}$ with an overall extraction ratio of about 26 percent.

Areal thermal loading for this layout and the reference $6.6 \mathrm{~kW}$ waste package has been investigated. Package spacing requirements and salt temperature limitations were involved in the analysis (Figure 3-2). The details of this were presented in Appendix B. It was determined that this layout imposes no restrictions on achieving the areal thermal loading with horizontal borehole emplacement of the reference waste package. 


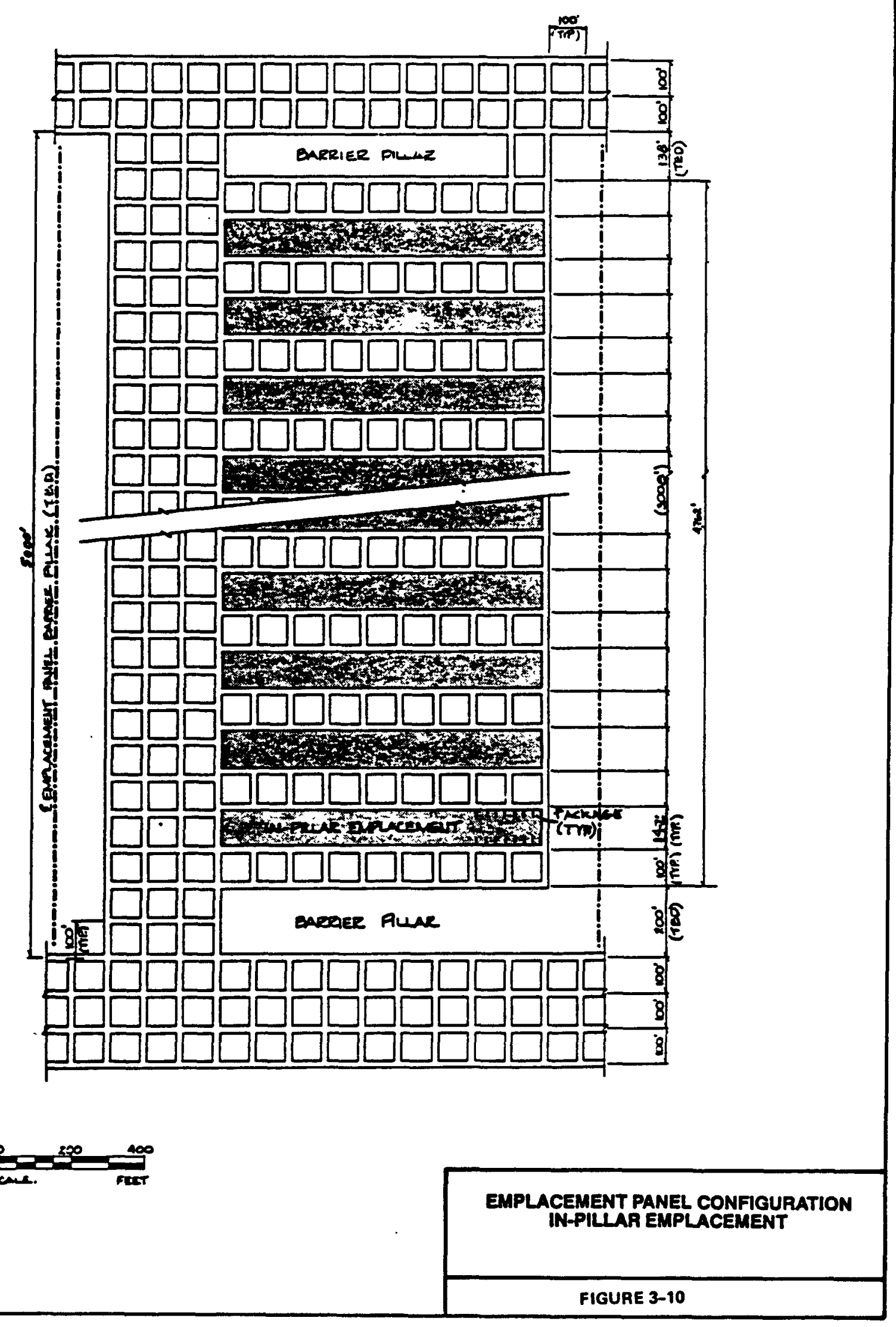




\subsection{LENGTH ASSESSMENT}

The objective of this part of the Waste Package/Repository Impact Study was to examine and reduction of the waste package length and determine the Impact of this change on surface and subsurface design features. Several shorter package lengths were considered to identify resulting impacts on repository equipment, facilities, and layouts.

A qualitative investigation was carried out to assess the effects of package shortening. Since there has been no definitive design of surface facilities the results are necessarily very general in nature. Definite design decisions have been made regarding the hoist and subsurface facilities, therefore it was possible to be more spectific in identifying the effects of packae shortening.

The approach to this assessment was to begin with the reference package description and whatever reference design decisions were currently avallable. Many of these design decisions were developed during the other tasks in this study. Two possible cases of departure from the baseline case were then considered, including:

Case 1: Use shorter waste packages, but maintain the same number of packages per metric tonne of spent fuel. This constant package volume approach would include a package which is shorter than the reference package, but with a greater diameter.

Case 2: Use shorter waste packages but allow an increase in the number of packages per metric tonne of spent fuel. This would involve a package which is shorter than the reference waste package, but with a similar diameter.

For the purpose of this analysis and to show clear results, the assessment was carried out with a package length reduction factor of 2 . Shortening by a lesser amount may not show enough benefits to be useful in decision making. Given a factor of 2 in waste package shortening, the shorter 
waste packages would have the following configuration when compared to the reference package.

Case 1: Package lenth equal to $1 / 2$ reference length; package diameter equal to the reference diameter $\mathrm{X} \sqrt{2}$; number of packages is constant.

Case 2: Package length equal to $1 / 2$ reference length; package diameter equal to reference diameter; number of packages doubled.

This section has four subsections. Subsection 3.8 .1 briefly describes the Impact of package shortening on the package Itself and on package design constraints. Subsection 3.8 .2 is a discussion of the impacts on the repository of the first package shortening case: a shorter package with the same volume as the reference package. Subsection 3.8.3 discusses the repository impacts of the the second case: a shorter package, with the same diameter as the reference package. Subsection 3.8.4 presents some preliminary conclusions based on the qualitative assessments described in 3.8 .2 and 3.8.3.

\subsubsection{Package Consideration}

This section discusses the implication to the package if the length were to be reduced. The reference consolidated fuel package is designed on the basis of the assumption that fuel assemblies will be disassembled and the rods bound tightly together. It is assumed that the cladding is not breached during consolidation and the rods are at their orfginal length.

In order to make the waste package shorter than the reference package, the rods must be either bent or cut shorter. The cladding in spent fuel is brittle, so it 18 generally assumed that bending rods in half would result in breakage and breach of cladding. All other shortening methods, such as cutting would also result in breach of cladding. This is considered to be an undesirable results, because one of the barriers that contains fission products would be destroyed. In designing the repository and waste package, the cladding would not be available as an engineered barrier. This would be a significant drawback of any strategy to decrease waste package length. 
Section 3.2 describes temperatures associated with the reference package concept. Case 1 for shorter packages would involve an increase in diameter. The increase in diameter reduces the surface area to volume ratio by a factor of about $\sqrt{2}$, thus it involves a significantly different geometry. Temperatures are likely to increase at the package centerline. More detailed analysis are required to determine the extent of increase. Case 2 would involve a small increase in surface area to volume ratio. Case 2 is likely to decrease centerline temperatures because of less total thermal power per package. The resulting decrease in temperature would be relatively small.

Criticality concerns within the package itself would be reduced for the Case 2 consideration and possibly increased for Case 1 . Should it be determined that short packages are worthy of further consideration, then criticality analyses should be conducted in more detall. The impacts on the package are summarized in Table 3-6.

\subsubsection{Case 1 - Constant Number of Packages}

This case involves the decrease in package length and corresponding increase in package diameter to maintain constant volume capacity per package. The package diameter would Increase as the square root of the proportionate length decrease. If the length is $1 / 2$ of the reference package, then the diameter would increase by $\sqrt{2}$. The same weight of spent fuel (MTU) would be contained in each of these short packages as in the reference package.

\subsubsection{Surface Systems}

Weight loadings and the type of package handling equipment would remain unchanged for the Case 1 short package. Since the total number of packages would not change, it follows that the total capacity of the handing systems would be unchanged. Only slight configuration changes would be needed for lifting and conveying the shorter, larger diameter packages. 
Table 3-6. Effects of Package Shortening on the Package

\begin{tabular}{lcc}
\hline & Case 1 & Case 2 \\
\hline $\begin{array}{l}\text { Potential for Assumption of Cladding } \\
\text { as an Engineered }\end{array}$ & Eliminated & Eliminated \\
Centerline Cladding Temperature & & Increase \\
Criticality & Possible & Decrease \\
& Secrease in & Probable \\
& Safety & Safety \\
\hline
\end{tabular}


Where shielded handling is required, loads may decrease somewhat since there will probably be some small decrease in shielding weight. Note that shielding weight is not cut in half since the diameter of shielding is increased by about 40 percent. See further discussion in Section 3.8.2.2.

Larger diameter afr locks and transfer parts would be required and transporter carrier sizes might have to be increased. However, some advantages may be realized in reduced hot cell height and other facility changes due to shorter packages. A more detailed assessment could be done later when more design information on the surface facilities is available.

Some safety advantages may be realized. Since shorter, larger diameter packages will be less prone to tip over, they may require fewer restraints and other safety devices.

The overall effect of the Case 1 package on the surface facilities would probably be a moderate advantage. More detafled assessment of this could be done after a more definitive design on the surface factlities is available.

\subsubsection{Transfer Cask}

The transfer cask would decrease in length in proportion to package length decrease. However, for Case 1 there would be an accompanying increase in the diameter of the cask. Assuming that the shielding thickness remains the same, the OD would increase in proportion to the square root of proportionate length decrease. However, if we consider the self shielding that would be provided by the larger dlameter waste package, the thickness of shielding required in the transfer cask would probably decrease. Consequently, the volume of shielding (and therefore, weight) would probably decrease. The decrease in shielding length and thickness would be more significant than diameter increase. The overall effect on the transfer cask of Case 1 is therefore 11kely to be:

1. An increase in outside diameter of less than the square root of proportionate length decrease

2. An overall reduction of weight of the transfer cask 
The overall weight of the package plus cask would probably be somewhat reduced for Case 1. The weight of the package would be about the same as, or less than, the reference package. A similar trend would occur with the transfer cask as discussed in section 3.8.2.2. The number of packages to be handled will be the same as for the reference package. The overall effect would be a slight reduction in holst weight loading, with no important changes in hoist design.

\subsubsection{Subsurface Layout/Emplacement Mode}

The repository subsurface layout and emplacement mode are very sensitive to package geometry. Package length is particularly important, once minimum requirements due to other factors (mine safety, equipment clearances, general design practice) are satisfied. Entry size may be directly affected by choice of package length. Subsurface design is less sensitive to changes in package diameter. Also, package diameter does not have to increase a great deal for associated length decreases in the Case 1 scenario. The 15 foot entry height required for the reference package could $11 k e l y$ be reduced some as package length decreases. Also, if horizontal emplacement is used, the drift width could be decreased from 20 feet. Smaller drifts would have some significant impact on mining cost and mine design, since lower extraction ratios would be possible. Note that room size or pillar size decreases will not be in proportion to package length decreases, since there will be fixed minimums to meet other requirements. Overall, some significant advantages in mine design could be realized for the Case 1 package.

\subsubsection{Transporter}

The effects of the Case 1 length change on the transporter would depend on whether a choice was made to take advantage of mine layout and room size changes that could be made. If the layout is changed, then the transporter design requirements would reduce proportionate to package length. A transporter with less length could be used, but at the same time the drift size would decrease. Except for possible overall reduction of length the transport 
design (crawler) would likely not change substantially, since the weight loading would be essentially unaffected. The larger diameter of the package (and transport cask) might in fact be unfavorable to transporter design. The overall impact of Case 1 on the transporter design would likely be slightly negative.

\subsubsection{Case 2 - Increased Number of Packages}

In this case the length of the packages would be decreased, while the number of packages would be increased. The diameter of the packages would be the same as the reference package. In some respects, this is a more significant departure from the reference package than Case 1, because it results in changes in package length, package capacity, and number of packages.

\subsubsection{Surface System}

The increased number of packages to be handled for Case 2 is the key factor for the surface facilities. The packages would be lighter but there would be more to handle. Weight loadings on cranes and transporters could be proportionately reduced on a per package basis. In some cases, the number of equipment items might be increased. In the case of other equipment, welght loads might be kept the same, with provision for multiple package handling. If used, multiple package handling will likely impose further burdens on safety design. Such things as airlocks and transport gallerles would be essentially unaffected. The overall impact of Case 2 on the baseline systems is likely to be very slightly negative.

\subsubsection{Transfer Cask}

In Case 2 the transfer cask volume would be reduced in proportion to length, but more packages would be handled. The overall effect is likely to be negligible.

\subsubsection{Hoist}

Weight requirements for the holst would be reduced if smaller packages were handled. There would be no change in hoist technology used. In fact, 
the higher throughput might necessitate multiple package handing; the result of multiple package hoisting might be no change to hoist capacity requirements. Handling of multiple packages could complicate hoist safety. There is essentially no favorable or unfavorable effect on the holst.

\subsubsection{Subsurface Layout/Emplacement Mode}

The advantages discussed under Case 1 will exist for Case 2. These advantages include smaller drifts, possibly smaller pillars, and a smaller subsurface area. Some unfavorable effect on layout will result from the larger number of packages. The need to provide more emplacement sites will mean that some of the reduction in mined volume that was realized for Case 1 cannot be realized for Case 2 .

\subsubsection{Transporter}

The favorable effects on the transporter design discussed under Case 1 are diminished by the need to design for handling a larger number of packages. For the layout required for the reference package case (see Section 3.8.2.5), no real advantage or disadvantage of Case 2 are indicated. The transporter for Case 2 would be lighter and smaller than the transporter for the reference package. It could be lighter than the Case 2 transporter, but the geometry would be similar. The ease in maneuvering a smaller, lighter transporter would be outweighed by the need to transport twice as many packages. The overall impact of Case 2 is likely to be negative.

\subsubsection{Preliminary Conclusions Regarding Shorter Package}

If 1 t were permissible to breach fuel cladding, there may be some small advantages in using shorter packages. Qualitative effects of a package length reduction on surface and subsurface have been discussed in Section 3.8. These effects have been summarized in Table 3-7 using a relative rating scale. The relative ratings are used only to facilitate presenting a concise picture of the effects discussed. No other significance should be attached to the values. As can be seen in the summary table, Case 1 offers a fair degree of potential 
overall advantages while Case 2 offers relatively little advantage. All advantages must be welghed against the impacts on package considerations as discussed In Section 3.8.1. Overall, it would appear qualitatively that there would be little advantage realized by decreasing the length of the waste package. 
Table 3-7. Effects of Package Length Decrease on Surface and Subsurface Systems (a)

\begin{tabular}{lccc}
\hline & $\begin{array}{c}\text { Case 1 } \\
\text { Constant No. } \\
\text { of Packages }\end{array}$ & $\begin{array}{c}\text { Case 2 } \\
\text { Increased No. } \\
\text { of Packages }\end{array}$ & $\begin{array}{c}\text { Reference } \\
\text { Package } \\
\text { PWR12 }\end{array}$ \\
\hline Surface Fac1lities & +1 & -1 & 0 \\
Transfer Cask & +1 & 0 & 0 \\
Holst & 0 & 0 & 0 \\
Repository Layout/Emplacement Mode & +3 & +2 & 0 \\
Transporter - Layout Changed & -1 & -1 & 0 \\
Transporter - Layout Unchanged & +1 & 0 & 0 \\
\hline
\end{tabular}

(a) Rated on scale of 0 to 3 relative to other effects in the table.

Symbols:

+ means favorable

0 means essentially no effect

- means unfavorable 


\section{RESULTS AND CONCLUSIONS}

After evaluation of the alternative waste packages to identify impacts resulting from salt repository design considerations, the overall conclusion reached is that waste packages with the reference design capacity of twelve (12) PWR assemblies is acceptable for use in repository conceptual design. While the 12 PWR assembly package was found to be acceptable, this conclusion had one potential exception. Thermal analyses conducted during this study Indicate that the reference package thermal loading ( $6.6 \mathrm{~kW})$ may be excessive because the cladding temperature limits may be exceeded. On this basis, a smaller and cooler waste package in the range of 6 to 9 PWR assemblies may be appropriate. Although, it should be noted that the thermal analyses conducted for this study differed from other analyses that found 12 assemblies to be acceptable.

The following sections present results and conclusions from the specific waste package evaluations conducted as part of this study.

\subsection{WASTE PACRAGE WEIGHTS AND DIMENSIONS}

The weights and dimensions of the reference waste package are summarized on Table 4-1. Waste package alternatives (including the reference case) along with transfer casks have been summarized in Section 3.1, Tables 3-1 thru 3-3. As indicated, the maximum size package/transfer cask combination results from a PWR12 with a transfer cask sized for a surface dose rate of $50 \mathrm{mrem} / \mathrm{hr}$. This cask was considered the worst case (from weight standpoint) and was used throughout the evaluations requiring weight. The weight of the waste package may impact the following operations:

1. Handling a shielded package in the surface facilities.

2. Transfer of the shielded package in the waste shaft.

3. Subsurface transport of the shielded package.

4. Package handling during emplacement and during retrieval. 
Table 4-1. Worst Case Weight and Dimensions for a Waste Package within a Transfer Cask

\begin{tabular}{lc}
\hline \multicolumn{1}{c}{ Design Feature } & Value \\
\hline & 12 \\
No. of PWR Assemblies & $33,000 \mathrm{MWD} / \mathrm{MTU}$ \\
Average Burn Up & 10 years \\
Average Age & Carbon Steel \\
Material & $490 \mathrm{~cm}$ \\
Overall Length & $122.3 \mathrm{~cm}$ \\
Overall Diameter & $42 \mathrm{MT}$ \\
Gross Weight & $6.6 \mathrm{~kW}$ \\
Thermal Power & $50 \mathrm{mrem} / \mathrm{hr}$ \\
Surface Dose (Surface of Cask) & \\
& \\
\hline
\end{tabular}


Conclusions from these evaluations indicated that a shielded waste package of these dimensions and weight is acceptable for incorporation into repository design using currently available technology.

\subsection{REPOSITORY THERMAL ANALYSIS}

Analysis of waste package thermal loading was conducted to establish the maximum quantity of spent fuel that could be contained in each package (Section 3.2). In performing these analysis the following two criteria were utilized:

1. Maximum fuel cladding temperature $375^{\circ} \mathrm{C}$.

2. Maximum salt temperature $250^{\circ} \mathrm{C}$.

Evaluations were conducted to estimate internal package thermal gradients as well as expected salt temperature profiles for various package heat loadings. In all cases the fuel cladding temperature 1 imit of $375^{\circ} \mathrm{C}$ proved to be the restraining criteria.

The calculations conducted for this study indicated cladding temperature could be as great as the $450^{\circ} \mathrm{C}$ range for the PWR 12 packages. In order to avoid exceeding the $375^{\circ} \mathrm{C}$ cladding limit, these calculations determined that packages in the range of PWR6 to PWR9 produced the highest acceptable heat load. It should be noted that calculations by others (ONWI, 1985) indicated that the cladding temperature of the PWR12 would not exceed the $375^{\circ} \mathrm{C}$ cladding temperature limit. That result differs with the results of this study because of the use of radial conducting fins to remove heat from the center of the package and thus lower the centerline temperature.

On the basis of the calculations performed by Westinghouse (ONWI, 1985), a temperature difference between the package centerline (cladding) and surface of about $200^{\circ} \mathrm{C}$ was indicated for the reference package. Utilizing this calculated value for a package with a cladding temperature of $375^{\circ} \mathrm{C}$ yields a salt temperature of $175^{\circ} \mathrm{C}$ (1.e., $375^{\circ} \mathrm{C}$ centerline $-200^{\circ} \mathrm{C}$ differential). This is well below the maximum allowable salt temperature of $250^{\circ} \mathrm{C}$; therefore, salt temperature did not become a limiting factor. 
At the present time however, it was concluded that the waste package designs holding 12 PWR assemblies (33,000MWD/MTU burn up, 10 year aged fuel) are acceptable for repository design. Thermal loadings and package spacings resulting from the largest package are well within the criteria limits for subsurface designs considered to date. Table 4-2 summarizes waste package and repository thermal design parameters resulting from evaluations for the reference waste package.

Although repository design can accommodate the maximum package heat loading, there is some question on the ability of the waste package to handle this much heat. Preliminary results indicate that cladding temperature 1 imits $\left(375^{\circ} \mathrm{C}\right)$ could be exceeded for any one of the following reasons. These reasons are dictated by waste package design, not repository design:

1. Assumption made in calculations for reference waste package internal heat transfer need to be verified. Fluor's calculations on the PWR12 (without internal fins) resulted in higher predicted cladding temperature for a $175^{\circ} \mathrm{C}$ package surface temperature $\left(450^{\circ} \mathrm{C}\right.$ vs. $350^{\circ} \mathrm{C}$ ) as indicated on Figure 3-1. A cladding temperature of $450^{\circ} \mathrm{C}$ would exceed the criterion of $375^{\circ} \mathrm{C}$.

2. Receipt of higher burn-up (1.e., 45,000MWD/MTU) and younger spent fuel ( 5 years old), resulting in packages with a greater heat load than $6.6 \mathrm{~kW}$, as in the reference package.

3. Emplacement operations requiring crushed salt backfill in excess of about two inches could lead to excess package centerline temperatures unless areal loading is drastically reduced. Crushed salt acts as a thermal insulator. The insulating quality of a thick crushed salt layer could cause the cladding temperature limit to be exceeded.

\subsection{WASTE PACKAGE STRESS CONDITIONS}

Evaluation of stresses imposed on emplaced waste packages (Section 3.3), indicate the external stresses on the package will vary with the emplacement 
Table 4-2. Reference Thermal Design Parameters for Waste Package and Repository

Waste Package

No. Assemblies/Package

Heat Load

Cladding Temperature

Surface Temperature

Temperature Limits - Cladding

Salt (Package Surface)
Parameter

12 PWR

$6.6 \mathrm{~kW}(\mathrm{a})$

$350^{\circ} \mathrm{C}$ (b)

$175^{\circ} \mathrm{C} \mathrm{(b)}$

$375^{\circ} \mathrm{C}$

$250^{\circ} \mathrm{C}$

Repository

Parameter

Local Areal Loading

Package Spacing (pitch)

Max Salt Temperature Center of

backfilled drift (@ 50 yrs)

for $24 \mathrm{~W} / \mathrm{m}^{2}$
$24 \mathrm{w} / \mathrm{m}^{2}(\mathrm{c})$

$7.5 \mathrm{~m}$ (d)

$125^{\circ} \mathrm{C}$

(a) 33,000MW/MTU burn up; 10 year aging.

(b) Calculated valves specified in ONWI-517 (ONWI, 1985)

(c) Maximum value before waste package temperature limits would be exceeded

(d) Based on subsurface layout in Figure 3-10 and preferred emplacement mode of horizontal borehole in-pillar emplacement. 
mode selected. For the preferred mode of emplacement (Section 3.4), horizontal borehole in-pillar, reference package designs are adequate to withstand the resulting stresses.

\subsection{EMPLACEMENT MODE}

As discussed in Section 3.4, various emplacement modes were considered to determine the preferred mode for the salt reposttory (Appendix D). Horizontal borehole in-pillar was selected as the preferred mode; however, until it is baselined the vertical in-floor emplacement mode is the reference. The preferred mode was then evaluated for feasibility of using the reference waste package. The determination of feasibility was based on temperature criteria, stress limfts, and equipment availability for emplacement and retrieval.

The evaluations indicated that on these bases the reference waste package was acceptable for emplacement in the preferred horizontal mode. Feasibility of vertical emplacement of the reference waste package has been established through past design efforts (ONWI, 1981).

\subsection{SUBSURFACE TRANSPORTATION}

The selected waste package must be transportable in a shielded condition from the waste shaft to the emplacement area. Using a shielded waste package with worst case weight and geometry (42MT and measuring $490 \mathrm{~cm}$ long by $122 \mathrm{~cm}$ in diameter), results indicate no significant concerns for subsurface transportation using currently avallable technology (Section 3.5). Since the transport mechanism is technically feasibly, operational concerns can be handled.

Assuming the preferred transportation vehicle, crawler with skid steering, (see Section 3.5) entry clearance widths of 18 feet (20 Foot wide rooms with irregular wall surface) and $18 \times 18$ foot intersection clearances present no problem with maneuverability. 
One of the primary concerns involving integration of the waste package with the repository design involves the ability of the waste hoist to lower and raise the required load. The Fluor team conducted separate evaluations which have indicated a design requirement for transfer of the waste package in a shielded condition (see Appendix F).

Evaluations of existing hoist technology indicate that a payload of 52.4 MT is the maximum which can be handled using current technology (see Section 3.6). As the maximum welght for the worst case shielded waste package is $42 \mathrm{MT}$, it is concluded that the current reference waste package can be accommodated using currently available hoist technology. Physical dimensions for the worst case shielded waste package present no problems for hoist on-loading and off-loading operations.

\subsection{SUBSURFACE LAYOUT}

The primary factors in assessing the impact of waste package on subsurface layout include package length, weight, and heat content. From the subsurface layout standpoint, limitations on drift dimensions, salt temperature limits, areal loading requirement, and feasibility of emplacement/retrieval operations could Impact the waste package decision.

Typical panel layouts presented in Section 3.7 indicate there are no incompatibilities between repository design and any of the alternative package designs considered. Overall areal heat loading will determine the area required for waste emplacement. For any specifled areal loading, package spacing can be adjusted as necessary depending on the heat content of each package. The lower the package thermal loading, the more packages required, and the closer they can be spaced. Therefore, speciflcations of all waste package alternatives (Table 3-1) are consistent with requirements for subsurface design and within acceptable limits for the development of subsurface drifts, emplacement entrles, and intersections. 


\subsection{WASTE PACKAGE LENGTH}

Reduction of package length will require cutting or folding of fuel rods. It is assumed that this w11l breach cladding. This is considered to be an undesirable action, because it would amount to a breach of an engineered barrier.

Putting aside the question of whether a breach of cladding is acceptable, analysis was conducted regarding the impact of using shorter waste packages. This was a qualitative analysis. It concluded that using a shorter waste package was either equivalent to, or only slightly more advantageous, than using the reference package.

Throughout the study, the waste package feasibility evaluations have not encountered any element of repository design that cannot accommodate the reference waste package length. On this basis and on the above conclusion, the reference waste package is preferable to a shorter package and should be used in the conceptual design. 


\section{RECOMMENDATIONS/OBSERVATIONS}

As a result of the evaluations conducted during this study, two recommendations are made. In addition, several observations are provided for use during future waste package and reposttory design activities.

Recommendation 1

The reference waste package design as described in Table 2-2 was found to be acceptable from a repository design standpoint. It should be adopted as the basis for conceptual design of the salt repository. It should also be used as the waste package baseline for work related to the Site Characterization Plan (SCP) and SCP-Conceptual Design Report.

Observation 1

There may be some benefits derived from reducing the heat load of the waste package from the 12 PWR assembly case $(6.6 \mathrm{~kW})$. Results from thermal evaluations conducted for this study indicate that reduced heat loads in the range of 6 PWR assemblies per package $(3.3 \mathrm{~kW})$ are consistent with the claddIng limit of $375^{\circ} \mathrm{C}$. Reduced package thermal loadings would also offer an advantage in providing a degree of conservatism in the waste package design. Such conservatism can be viewed as an insurance policy against unforeseen design developments. In contrast to this, however, results from other analyses by Westinghouse (ONWI, 1985) have shown that 12 PWR assemblies per package is acceptable for the $375^{\circ} \mathrm{C}$ cladding temperature limit.

\section{Observation 2}

Changes in the waste package reference design resulting from evaluations suggested in Recommendation 2 and Observation 1 above, should be incorporated into the repository design process as soon as practical. Due to current program schedules, the impact of such changes during repository conceptual design are not likely to be significant. Waste package conceptual design should be 
well established, however, before the start of License Application design. If the design changes take place during License Application Design, the impacts could be more significant and could effect the License application date.

\section{Observation 3}

Standardization of waste package diameter for (PWR and BWR) spent fuel, DHLW and WVHLW could have positive benefits in terms of waste package fabrication and handling. This would only require slight diametrical modifications to the reference packages and should be considered during package advanced conceptual design. 


\section{REFERENCES}

ASEA, 1983. ASEA Pamphlet CR07-3001E 1983-05, Mine Hoists Reference List. ASME, See American Society of Mechanical Engineers.

American Soclety of Mechantcal Engineers, 1981; ASME Boiler and Pressure Vessel Code, Section VIII, Division 1, An American National Standard.

Caterpillar, 1984. Caterpillar Equipment Catalog, Caterpillar Industrial Products, Inc., Peorta, I11., 61629

Cox, 1977. Radioactive Heat Transfer in Arrays of Parallel Cylinders, ORNL-5239, Oak Ridge National Laboratory, Oak Ridge, TN, June.

DOE, See U.S. Department of Energy.

DOT, See U.S. Department of Transportation.

Fluor, 1985. Waste Holst Technology Report, for U.S. Department of Energy, Columbus Operations, Project Deliverable No. 4.4-12.

Harmon, James H., 1973. "Holst and Hoisting System," SME Mining Engineering Handbook, Volume 1 and 2, Soclety of Mining Engineers of the American Institute of Mining, Metallurgical, and Petroleum Engineers, Inc., New York, New York.

Joy, 1985. Joy Equipment Catalog, Joy Manufacturing Corporation, Franklyn, PA 16323.

Kepner and Tregoe, 1981. The New Rational Manager, Princeton Research Press, Princeton, N.J.

Mine Safety and Health Administration, 1985. "Safety and Health Standards Metal and Nonmetal Underground Mines," 30CFR57.21000, Washington, D.C., April. 
MSHA, See Mine Safety and Health Administration.

NRC, See U.S. Nuclear Regulatory Commission.

Oak Ridge National Laboratory, 1980. Isotope Generation and Depletion Code, ORIGEN-2, RSIC-CCC-371, Oak Ridge, TN.

Office of Nuclear Waste Isolation, 1981. NWTS Conceptual Reference Repository Description (CRRD), ONWI-258, Volume II, "Facility and System Description," Office of Nuclear Waste Isolation, Columbus, Ohio, May.

Office of Nuclear Waste Isolation, 1983a. Interim Performance Specifications for Conceptual Waste Package Designs for Geologic Isolation in Salt

Repositories, ONWI-463, Office of Nuclear Waste Isolation, Columbus, Ohio, June.

Office of Nuclear Waste Isolation, 1983b. Engineered Waste Package System Design Specifications, ONWI-423, Office of Nuclear Waste Isolation, Columbus, Ohio, May.

Office of Nuclear Waste Isolation, 1985. Waste Package Reference Conceptual Designs for a Repository in Salt, ONWI-517, Battelle Memorial Laboratory, Columbus, Ohio.

ONWI, See Office of Nuclear Waste Isolation.

ORNL, See Oak R1dge National Laboratory.

$\mathrm{RE} / \mathrm{SPEC}$, See RE/SPEC, Inc.

RE/SPEC, Inc. 1984. Thermomechanical Analyses of Conceptual Repository Designs for the Paradox and Permian Basins, RSI-0204, draft report for Office of Nuclear Waste Isolation, Columbus, Ohio.

Tiley, G.L., 1957. "Friction Hoist Design Considerations," Annual Meeting, The Mining Society of Nova Scotia, Transactions, Volume LX, Nova Scotia, Canada. 
U.S. Department of Energy, 1983. Statement of Work for Architect/Engineer Services: Conceptual Design of a High Level Nuclear Waste Repository in Salt, U.S. Department of Energy, Washington D.C., September.

U.S. Department of Energy, 1984. Generic Requirements for Mined Geologic Disposal System, Volume I, Office of Civilian Radioactive Waste Management, Germantown, MD, July.

U.S. Department of Energy, 1984a. Draft Environmental Assessment, Deaf Smith County Site, Texas, DOE/RW-0014, Washington, D.C., December.

U.S. Department of Energy, 1985. Mission Plan for the Civilian Radioactive Waste Management Program, DOE/RW-0005, Washington, D.C., June.

U.S. Department of Transportation, 1984. "Shippers - General Requirements for Shipments and Packaging," 49CFR173, Washington, D.C.

U.S. Nuclear Regulatory Commission, 1984. "Disposal of High-Level Radioactive Waste in Geologic Repositories: Technical Criteria," 10CFR60, Washington, D.C., January.

Westinghouse, 1984. Waste Package Reference Conceptual Designs for a Repository in Salt, WTSD-TME-001 Rev. A, Westinghouse Electric Corporation, Madison, PA, November. 


\section{APPENDICES}

Appendices A through $H$ Are included here. These represent technical support and back-up data for the evaluations conducted during this study. In the appendices, tables are included in the text and figures directly follow the text. 
APPENDIX A

\section{CALCULATIONAL METHODS}


APPENDIX A

TABLE OF CONTENTS

$\underline{\text { Page }}$

A. 1 ROD BUNDLE DIAMETER CALCULATIONS $\ldots \ldots \ldots \ldots \ldots \ldots \ldots \ldots$ A-5

A.1.1 Objectives ....................... A-5

A.1.2 Cylindrical Close-Packing of Spent Fuel Rods ... A-5

A.2 SHIELDING CALCULATIONS $\ldots \ldots \ldots \ldots \ldots \ldots \ldots \ldots \ldots \ldots \ldots$ A-12

A.2.1 Objective $\ldots \ldots \ldots \ldots \ldots \ldots \ldots \ldots \ldots \ldots \ldots \ldots \ldots \ldots$ A-12

A.2.2 Source Description .................. A-12

A.2.3 Geometry ....................... A-14

A.2.4 Results .............................. A-15

A.2.5 Shielding for Modified Fuel .............. A-15

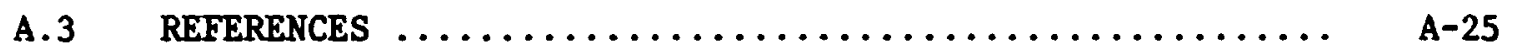


APPENDIX A

\section{LIST OF TABLES}

\section{$\underline{\text { Page }}$}

A-1 Rod Bundle Packing Factors $\ldots \ldots \ldots \ldots \ldots \ldots \ldots \ldots \ldots \ldots \ldots \ldots \ldots$

A-2 Summary of Salt Source Terms for B\&W Fuel Assembly 10 years

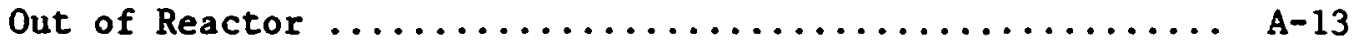

A-3 Transfer Cask Thickness $\ldots \ldots \ldots \ldots \ldots \ldots \ldots \ldots \ldots \ldots \ldots \ldots$ A-16

A-4 Neutron Dose Rate $\ldots \ldots \ldots \ldots \ldots \ldots \ldots \ldots \ldots \ldots \ldots \ldots \ldots \ldots \ldots \ldots$ 
APPENDIX A

LIST OF FIGURES

Page

A-1 Schematic Diagram of a Cylindrical Packing ........... A-18

A-2 Schematic Diagram of the Basic Cylindrical Packing Pattern A-19

A-3 Schematic Diagram of Rods in the Extra Rows in a Cylindrical Packing ......................... A-20

A-4 Closest Packing of Rods in a Cylinder $\ldots \ldots \ldots \ldots \ldots \ldots \ldots A-21$

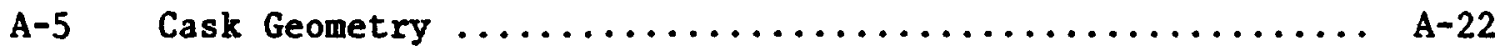

A-6 Cask Thickness $\ldots \ldots \ldots \ldots \ldots \ldots \ldots \ldots \ldots \ldots \ldots \ldots \ldots \ldots \ldots$ A-23

A-7 Cask Thickness B\&W Fuel $\ldots \ldots \ldots \ldots \ldots \ldots \ldots \ldots \ldots \ldots \ldots \ldots \ldots \ldots$ 


\section{APPENDIX A}

\section{CALCULATION METHODS}

\section{A. 1 ROD BUNDLE DIAMETER CALCULATIONS}

\section{A.1.1 Objective}

In order to determine the diameters of the waste package alternatives listed in Table 3-1 a method to determine the diameter of a fuel rod bundle was needed. To accomplish this, the following calculations were performed.

\section{A.1.2 Cylindrical Close-Packing of Spent Fuel Rods}

The following section describes an analytical method devised to determine the diameter of a cylindrical canister for a close-packed fuel rod bundle. This analytical solution has been coded into a computer subroutine. Computer graphics have been used to illustrate the fuel rod bundles in a canister. No internal structures, such as compartments or radial heat conduction fins were included.

The inside diameter of the cylindrical canister is defined as $D_{c}$. The diameter of the rod is $d_{r}$. Assuming a uniform pitch to diameter ratio, $p$, the pitch diameter is

$$
d_{p}=p d_{r} . \quad d_{p} \text { is a variable, } P \text { is also PDR }
$$

The dimensionless diameter of the cylinder can be defined as

$$
D=D_{c} / d_{p} \quad \text { or } \quad D=D_{c} / d_{r} * P D R
$$

and the dimensionless pitch diameter of the rod is unity, $d=d_{r} / d_{p}=1$.

The closest packing of identical rods in a cylinder has a basic hexagonal packing pattern with extra rows of rods packed between the bow-shaped area segment left between the last (outermost) row of the hexagonal packing and the 
cylindrical boundary of the canister. Figure A-1 shows a typical cylindrical packing pattern. The dotted line delineates the basic hexagonal packing pattern within the cylinder. Besides the center rod (shaded in black), the hexagonal pattern can be separated into six identical equilateral triangular regions (separated by the dashed lines). Outside this basic equilateral triangular pattern (dot-shaded region), several extra rows of rods can be packed in the bow-shaped segment (rods with the slash shades). Therefore, the basic pattern of cylindrical packing consists of all the shaded rods in Figure A-1. In order to have the closest packing, the rod on the $k^{\text {th }}$ row has to sit in between two rods in the adjacent row. Since the cylindrical packing is a symmetrical pattern, the packing of rods in the extra rows (in the slash shaded area) follows the odd-even rule, i.e., in packing rods beyond the basic equilateral triangular pattern, the number of rods in a row has to alternate between even and odd numbers as each extra row is packed.

The maximum number of rods on the side of the basic equilateral triangle within the dot-shaded areas can be packed in a cylinder of diameter $D$ with rod (or pitch) diameter $d$ is

$$
\mathrm{n}_{\mathrm{d}}=\text { Integer } \frac{\mathrm{D}-\mathrm{d}}{2 \mathrm{~d}}
$$

where integer is defined as the integer part of the real number in the bracket (in the sense of FORTRAN intrinsic library routine IFIX). The total number of rods in this basic triangle is:

$$
n_{t r}=n_{i=1}^{n_{d}} i=n_{d}\left(n_{d}+1\right) / 2
$$

Now let us consider the equilateral triangle with $\left(n_{d}+1\right)$ rods on each side (Figure A-2). The segment area of interest is bounded by line $\mathrm{HA}, \mathrm{AE}, \mathrm{EF}$, and FGH. The maximum height of the segment is the distance between point $B$ and $G$.

$$
B G=O G-O B=\frac{D}{2}-h \text {. }
$$




$$
=\frac{D}{2}-n_{d} d \sin 60^{\circ}
$$

The center distance between two rows of rods $\ell$ is

$$
\ell=\mathrm{d} \sin 60^{\circ} .
$$

The maximum extra rows that can be packed in the segment can be determined as

$$
\mathrm{n}_{\text {row }}=\text { Integer } \frac{\mathrm{BG}-\mathrm{d} / 2}{\ell}
$$

The number of rods in each of these extra rows can be determined in the following order. For the $\mathrm{k}^{\text {th }}$ extra row, the distance OP (Figure A-3) is

$$
\mathrm{OP}=\mathrm{h}+\mathrm{k \ell}+\frac{\mathrm{d}}{2}
$$

Since $O Q$ is the radius of the cylinder, the distance $Q P$ can be determined as

$$
Q P=\left(\frac{D}{2}\right)-O P^{2}
$$

For the first estimate, the number of rods in the $k^{\text {th }}$ extra row is

$$
\mathrm{n}_{\mathrm{k}, 1}=\operatorname{Integer}\left(\frac{2 Q P}{\mathrm{~d}}\right)
$$

As stated previously, the number of rods in the extra rows has to follow the odd-even rule. The second estimate of the number of the rod in the $k^{\text {th }}$ extra row can be determined as

$$
\begin{gathered}
n_{k, 2}=n_{k-1}-1-2 * \text { Integer } \frac{n_{k-1}-n_{k, 1}}{2} \\
\text { for } k=1, \ldots n_{\text {row }}
\end{gathered}
$$

Notice that $n_{0}$ is the number of rods in the side of equilateral triangle $O A E$ (Figure $A-2$ ) and is equal to $n_{d}+1$. In general, the number of $n_{k}, 2$ often underestimates the total number of rods that can be closely packed in the $k^{\text {th }}$ extra row due to the conservative estimation method described above. In order to check whether or not another rod can be packed at the end of each extra row, the following procedure is used. Let us assume that another rod can be packed 
at both ends of the $k^{\text {th }}$ row with the estimated number of rods $n_{k, 2}$. From the geometry (Figure A-3) the distance from the added rod center $V$ to the middle point of the $k^{\text {th }}$ row, $T$, is

$$
\mathrm{VT}=\frac{1}{2} \mathrm{n}_{\mathrm{k}, 2} \mathrm{~d}+\frac{\mathrm{d}}{2}
$$

The distance between the center of the cylinder 0 to the point $T$ is

$$
\text { OT }=h+k \ell \text {. }
$$

then the distance between the center of the cylinder to the center of the added rod ov can be calculated as

$$
O V=V T^{2}+O T^{2}
$$

Extend line oV for a distance of $1 / 2 \mathrm{~d}$ to $\mathrm{OU}, \mathrm{i} . \mathrm{e}$.

$$
\mathrm{OU}=\mathrm{OV}+\frac{\mathrm{d}}{2}
$$

It is obvious that if the distance $O U$ is less than the radius of the cylinder, an extra rod can be packed in each of the $k^{\text {th }}$ row.

$$
\begin{aligned}
& n_{k}=n_{k, 2} \quad \text { if } \text { OU }>\frac{D}{2} . \\
& n_{k}=n_{k, 2}+2 \text { if } \text { OU } \leq \frac{D}{2} .
\end{aligned}
$$

The total number of rods in the segment $n_{\text {seg }}$ is

$$
n_{\text {seg }}={ }_{k=1}^{n_{\text {row }}} n_{k} .
$$

The total number of rods that can be packed in a cylinder is

$$
\mathrm{n}=6\left(\mathrm{n}_{\operatorname{seg}_{\mathrm{tr}}}\right)+1
$$

A subroutine CYLPAK was coded according to above procedure to calculate the total number of rods packed in a cylinder ( $n$; NTOTAL), number of extra 
rows ( $n_{\text {row }}$; NOROW) and the number of rods in each of the extra rows ( $n_{k}$; NKROW), for a given dimensionless cylinder diameter ( $D ; D C Y L)$ and dimensionless pitch diameter of the rod ( $d$; DROD).

To apply this method, first, $D$, is calculated

$$
D=\frac{D_{c}}{d_{r}^{\frac{1}{t}} \text { PDR }}
$$

Table A-1 gives the total number of rods corresponding to the value of $D$. Table A-1 column 1 gives values for D. For example, the capacity for a $41 \mathrm{~cm}$ ID canister for $1.1 \mathrm{~cm}$ OD close-packed rods will be determined.

$$
\begin{aligned}
D_{c} & =41 \mathrm{~cm} \\
{ }_{d_{r}} & =1.1 \mathrm{~cm} \\
P^{\prime} & =1 \text { (assumes perfect rod-to-rod contact) } \\
D & =41 / 1.1 * 1 \\
& =37.27
\end{aligned}
$$

This must be rounded to the next lower integer, so $D$ is 37 . From Table A-1, column 3, the maximum number of rods for a $D$ of 37 is 1165 , and the most efficient packing of the rods for this case is as illustrated in Figure A-4.

This method was applied to the canister alternatives in this study. PDR was more conservatively set at 1.02. Pins from a BW $15 \times 15$ have an ID of $1.09 \mathrm{~cm}$. A PDR of 1.02 relates to a gap between pins in the array of $0.22 \mathrm{~mm}$. Westinghouse (ONWI, 1985) assumed a gap of $0.08 \mathrm{~mm}$, so that the assumption here is about 3 times that assumed in ONWI (1985). The $0.08 \mathrm{~mm}$ gap assumed by Westinghouse was applied to account for rod growth during burn-up. From the standpoint of loading canisters, this growth amount appears as a gap between rods of original diameter. This study assumed a larger gap to account for more rod growth and other potential rod irregularities.

For the cases assumed in this study, the following canister IDs were calculated:

$$
\begin{aligned}
& \mathrm{d}_{r}=1.09 \mathrm{~cm} \\
& P D R=1.02
\end{aligned}
$$


Table A-1. Rod Bundle Packing Factors

crejmoen $)$ (moo)

TOTAL No. Of TOTAL no. Of noos

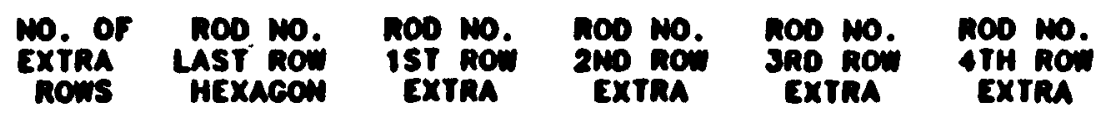

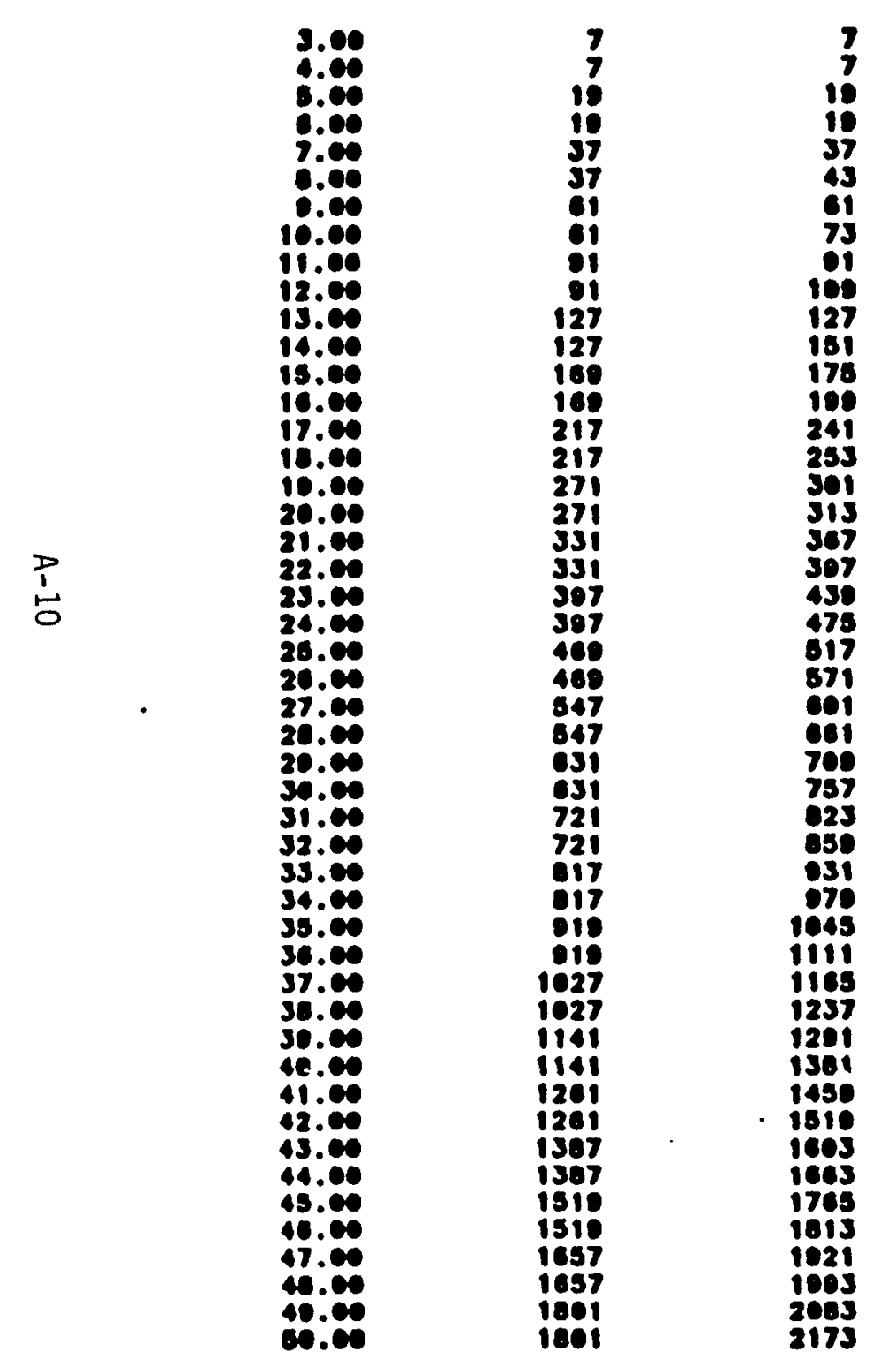


Table A-1. Rod Bundle Packing Factors (cont.)

\begin{tabular}{|c|c|c|c|c|c|c|c|}
\hline 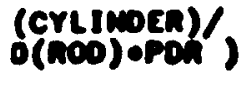 & $\begin{array}{l}\text { Toral Mo. of } \\
\text { Hoos. } \\
\text { MEX. PACK. }\end{array}$ & $\begin{array}{l}\text { Total Mo. or } \\
\text { moOS } \\
\text { crLO. PACK. }\end{array}$ & $\begin{array}{l}\text { Mo. of } \\
\text { Exina } \\
\text { Rows }\end{array}$ & $\begin{array}{l}\text { Roo Mo. } \\
\text { LAst now } \\
\text { MEXAGON }\end{array}$ & $\begin{array}{l}\text { nod no. } \\
\text { ist now } \\
\text { ExtaA }\end{array}$ & $\begin{array}{l}\text { Rod No. } \\
\text { 2NO Row } \\
\text { EXTRA }\end{array}$ & $\begin{array}{l}\text { ROD No. } \\
\text { 3RO ROW } \\
\text { EXTRA }\end{array}$ \\
\hline
\end{tabular}

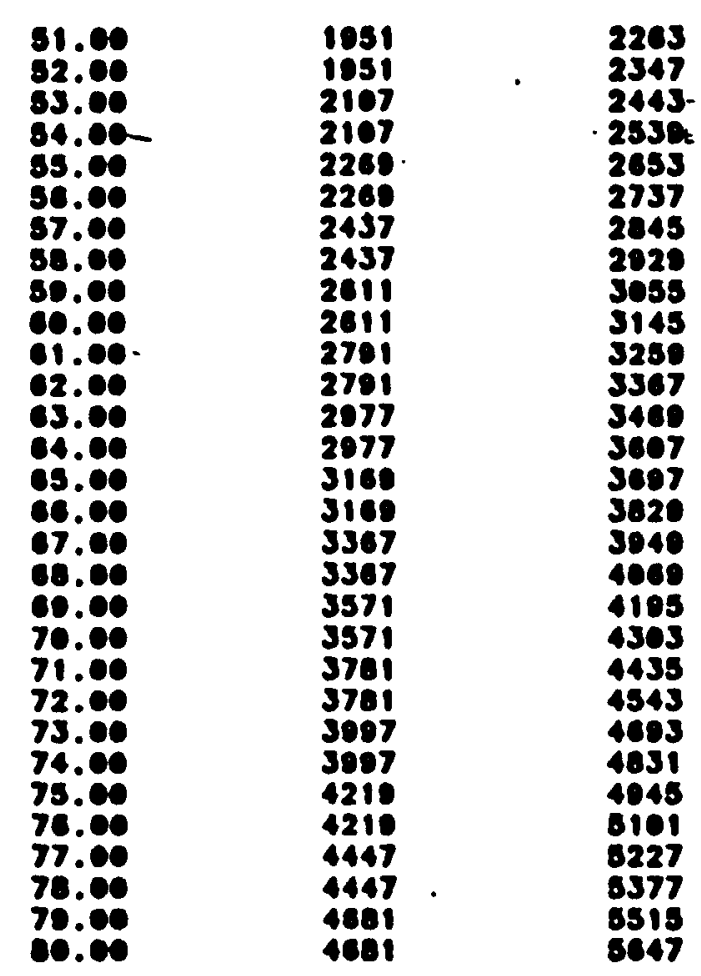

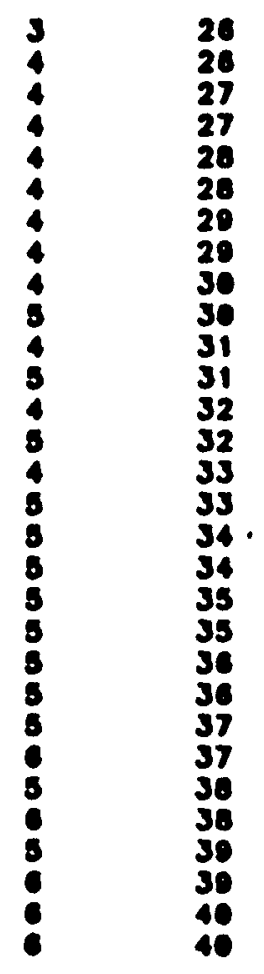

21
23
22
24
23
25
24
28
25
27
26
26
27
20
28
30
20
31
30
32
31
33
32
34
33
35
34
36
35
37

10
20
10
21
20
22
21
23
22
24
23
25
24
20
25
27
26
20
27
20
28
30
20
31
30
32
31
33
32
34

13
15
14
16
15
10
16
20
17
21
18
22
10
23
20
24
21
25
22
26
23
27
24
28
25
20
20
30
20
31

0
1
11
12
12
73
10
14
11
15
12
18
15
10
10
20
17
21
10
22
10
23
20
24
21
25
24
20 


\begin{tabular}{|c|c|c|c|c|}
\hline Alternative & 輩 ${ }^{(a)}$ & Max 非 Rods ${ }^{(b)}$ & $\mathrm{D}^{(\mathrm{b})}$ & $\underline{\text { Canister ID }}^{(\mathrm{C})}$ \\
\hline PWR3 & 624 & 661 & 28 & $31.1 \mathrm{~cm}$ \\
\hline PWR6 & 1248 & 1291 & 39 & $43.4 \mathrm{~cm}$ \\
\hline PWR9 & 1872 & 1921 & 47 & $52.3 \mathrm{~cm}$ \\
\hline PWR12 & 2496 & 2539 & 54 & $60.0 \mathrm{~cm}$ \\
\hline
\end{tabular}

\footnotetext{
(a) BW $15 \times 15-208$ rods/assy

(b) From Table A-1, nearest value of $\mathrm{D}$ that would include required 非 rods.

(c) Calculated: canister ID $=0 * \frac{\mathrm{rod}}{\operatorname{roDR}}$.
}

Since the $D$ value for each case corresponded to more rods than are actually loaded into these canisters, the canister IDs contain some extra space.

\section{A.2 SHIELDING CALCULATIONS}

\section{A.2.1 Objective}

Determine the thickness of a carbon steel transfer cask required to reduce the dose rate on the surface, from various quantities of $B \& W$ PWR fuel assemblies, to surface dose rates of 50, 100 and $200 \mathrm{mrem} / \mathrm{hr}$.

\section{A.2.2 Source Description}

The source terms were obtained from application of the ORIGEN-2 computer code (ORNL, 1980) to PWR fuel. The results were transformed into the equivalent photons/sec. in a 12 energy group spectrum to be used in the Fluor Shielding Design Code (SDC) (ORNL, 1975). The results of these calculations are shown in Table A-2.

\footnotetext{
:Babcock and Wilcox PWR fuel assembly. This fuel assembly was used as a reference because its specifications are representative of over $80 \%$ of the PWR fuel used in current generation reactors.
} 
Table A-2. Summary of Salt Source Terms for B\&W Fuel Assembly 10 Years Out of Reactor

\begin{tabular}{rcccccc}
\hline \hline & Mean & & PH/Sec & PH/Sec & PH/Sec & PH/Sec \\
Group & Energy & PH/Sec & PWR3 & PWR6 & PWR9 & PWR12 \\
Number & 33,000 & 33,000 & 33,000 & 33,000 & 33,000 & 33,000 \\
\hline & & & & & & \\
1 & $1.035 \mathrm{E}-01$ & $1.938 \mathrm{E}+14$ & $2.733 \mathrm{E}+14$ & $5.465 \mathrm{E}+14$ & $8.198 \mathrm{E}+14$ & $1.093 \mathrm{E}+15$ \\
2 & $2.450 \mathrm{E}-01$ & $1.343 \mathrm{E}+13$ & $1.894 \mathrm{E}+13$ & $3.788 \mathrm{E}+13$ & $5.681 \mathrm{E}+13$ & $7.575 \mathrm{E}+13$ \\
3 & $4.559 \mathrm{E}-01$ & $1.320 \mathrm{E}+14$ & $1.862 \mathrm{E}+14$ & $3.723 \mathrm{E}+14$ & $5.585 \mathrm{E}+14$ & $7.446 \mathrm{E}+14$ \\
4 & $6.576 \mathrm{E}-01$ & $5.714 \mathrm{E}+15$ & $8.056 \mathrm{E}+15$ & $1.611 \mathrm{E}+16$ & $2.417 \mathrm{E}+16$ & $3.223 \mathrm{E}+16$ \\
5 & $7.831 \mathrm{E}-01$ & $2.375 \mathrm{E}+14$ & $3.348 \mathrm{E}+14$ & $6.696 \mathrm{E}+14$ & $1.004 \mathrm{E}+15$ & $1.339 \mathrm{E}+15$ \\
6 & $8.892 \mathrm{E}-01$ & $6.558 \mathrm{E}+13$ & $9.247 \mathrm{E}+13$ & $1.849 \mathrm{E}+14$ & $2.774 \mathrm{E}+14$ & $3.699 \mathrm{E}+14$ \\
7 & $1.011 \mathrm{E}+00$ & $4.005 \mathrm{E}+13$ & $5.646 \mathrm{E}+13$ & $1.129 \mathrm{E}+13$ & $1.694 \mathrm{E}+14$ & $2.259 \mathrm{E}+14$ \\
8 & $1.282 \mathrm{E}+00$ & $8.273 \mathrm{E}+13$ & $1.167 \mathrm{E}+14$ & $2.333 \mathrm{E}+14$ & $3.500 \mathrm{E}+14$ & $4.666 \mathrm{E}+14$ \\
9 & $1.469 \mathrm{E}+00$ & $3.435 \mathrm{E}+13$ & $4.844 \mathrm{E}+12$ & $9.687 \mathrm{E}+12$ & $1.453 \mathrm{E}+13$ & $1.937 \mathrm{E}+13$ \\
10 & $1.595 \mathrm{E}+00$ & $4.595 \mathrm{E}+12$ & $6.479 \mathrm{E}+12$ & $1.296 \mathrm{E}+14$ & $1.944 \mathrm{E}+13$ & $2.592 \mathrm{E}+13$ \\
11 & $1.735 \mathrm{E}+00$ & $8.821 \mathrm{E}+12$ & $1.244 \mathrm{E}+13$ & $2.488 \mathrm{E}+13$ & $3.731 \mathrm{E}+13$ & $4.975 \mathrm{E}+13$ \\
12 & $2.238 \mathrm{E}+00$ & $1.338 \mathrm{E}+11$ & $1.886 \mathrm{E}+11$ & $3.772 \mathrm{E}+11$ & $5.658 \mathrm{E}+11$ & $7.544 \mathrm{E}+11$
\end{tabular}

*Photons/second 
The PWR fuel parameters of the four waste packages follows:

\begin{tabular}{|c|c|c|c|c|c|}
\hline \multirow[t]{2}{*}{$\begin{array}{l}\text { Babcock and Wilcox } \\
\text { (B\&W) PWR Fuel - }\end{array}$} & \multirow[t]{2}{*}{$15 \times 15$} & \multicolumn{4}{|c|}{ - 208 Rods/Assembly } \\
\hline & & PWR3 & PWR6 & PWR9 & PWR12 \\
\hline \# Assemblies & & 3 & 6 & 9 & 12 \\
\hline \# Fuel Rods & & 624 & 1248 & 1872 & 2496 \\
\hline Total MTU & & 1.41 & 2.82 & 4.23 & 5.64 \\
\hline Power, watts & & 1650 & 3300 & 4950 & 6600 \\
\hline Burn up & & & A11 & 33,000 & $\mathrm{MWD} / \mathrm{MTU}$ \\
\hline Spent Fuel Age & & & A11 & 10 yea & \\
\hline
\end{tabular}

The total neutron production from the ORIGEN-2 run was $1.927 E 8 \mathrm{n} / \mathrm{sec} / \mathrm{MTHM}$. It was assumed that all the neutrons generated escaped from the canister, without any self-absorption, and were evenly distributed over the canister surface.

\section{A.2.3 Geometry}

The geometry used for the SDC run is shown in Figure A-5. The following dimensions were used (from Table 3-1):

PWR3 PWR6 PWR9 PWR12

\begin{tabular}{|c|c|c|c|c|}
\hline \multicolumn{5}{|l|}{ Canister } \\
\hline $\mathrm{OD}, \mathrm{cm}$ & 33.1 & 45.4 & 54.3 & 62.0 \\
\hline Length, $\mathrm{cm}$ & \multicolumn{3}{|c|}{ Al1 400} & \\
\hline Thickness, $\mathrm{cm}$ & \multicolumn{3}{|c|}{ A11 1} & \\
\hline \multicolumn{5}{|l|}{ Overpack } \\
\hline $\mathrm{OD}, \mathrm{cm}$ & 55.6 & 67.9 & 76.8 & 84.5 \\
\hline Thickness, cm & \multicolumn{3}{|c|}{ A11 10} & \\
\hline \multicolumn{5}{|l|}{ Fuel } \\
\hline Rod Length, cm & \multicolumn{3}{|c|}{ A11 389} & \\
\hline Fueled Length, cm & \multicolumn{3}{|c|}{ A11 366} & \\
\hline
\end{tabular}




\section{A.2.4 Results}

The shielding calculations were performed using SDC with the dose point on the cask surface at the center of the fueled region. The dose vs thickness results calculated are shown in Table A-3 and graphically in Figure A-6. Figure A-7 plots the carbon steel vs dose rate for each package size.

The neutron dose rates for each package are shown in Table A-4. The dose rate equivalence were obtained from NBS (1983) and the worst case assumed, i.e., neutron energy $>10 \mathrm{Mev}$. It can be seen that the neutron contributions will be negligible to the final dose rate.

\section{A.2.5 Shielding for Modified Fuel}

Shielding requirements for higher burn up and shorter decayed fuel have been determined. This was accomplished by comparing ORIGEN-2 calculations for the modified fuel to the base case which was nominal burn up $(33,000 \mathrm{MWD} / \mathrm{MTU})$ and 10-year decay, and then ratioing the shield thickness accordingly. The resulting shield thickness ratios are as follows:

$$
\begin{aligned}
& \text { Case I: } \quad \frac{\text { Modified }}{\text { Base }}=\frac{33,000 \mathrm{MWD}-5 \mathrm{yr}}{33,000 \mathrm{MWD}-10 \mathrm{yr}}=1.09 \\
& \text { Case II: } \quad \frac{\text { Modified }}{\text { Base }}=\frac{45,000 \mathrm{MWD}-10 \mathrm{yr}}{33,000 \mathrm{MWD}-10 \mathrm{yr}}=1.13 \\
& \text { Case III: } \frac{\text { Modified }}{\text { Base }}=\frac{45,000 \mathrm{MWD}-5 \mathrm{yr}}{33,000 \mathrm{MWD}-10 \mathrm{yr}}=1.23
\end{aligned}
$$

Table 3-3 reflects transfer casks with shielding thickness determined by these ratios. 
Table A-3. Transfer Cask Thickness*

\begin{tabular}{|c|c|c|c|c|c|c|}
\hline \multirow{2}{*}{$\begin{array}{r}\text { mrem/hr } \\
\text { PWR Number }\end{array}$} & \multicolumn{2}{|c|}{50} & \multicolumn{2}{|c|}{100} & \multicolumn{2}{|c|}{200} \\
\hline & $\mathrm{cm}$ & in & $\mathrm{cm}$ & in & $\mathrm{cm}$ & in \\
\hline 3 & 16.11 & 6.343 & 14.62 & 5.76 & 13.17 & 5.18 \\
\hline 6 & 16.88 & 6.647 & 15.38 & 6.06 & 13.91 & 5.48 \\
\hline 9 & 17.34 & 6.828 & 15.84 & 6.24 & 14.36 & 5.65 \\
\hline 12 & 17.64 & 6.944 & 16.13 & 6.35 & 14.64 & 5.76 \\
\hline
\end{tabular}

$(\stackrel{*}{*})$ Thickness of carbon steel 
Table A-4. Neutron Dose Rate

\begin{tabular}{ccc}
\hline PWR Number & $* \mathrm{n} / \mathrm{CM}^{2}$ & MREM $/ \mathrm{Hr}$ \\
\hline 3 & $6.9 \mathrm{E} 3$ & 0.5 \\
6 & $9.9 \mathrm{E} 3$ & 0.7 \\
9 & $12.3 \mathrm{E} 3$ & 0.9 \\
12 & $14.3 \mathrm{E} 3$ & 1.0 \\
\hline
\end{tabular}

$\star_{n}$ - Nuetrons 


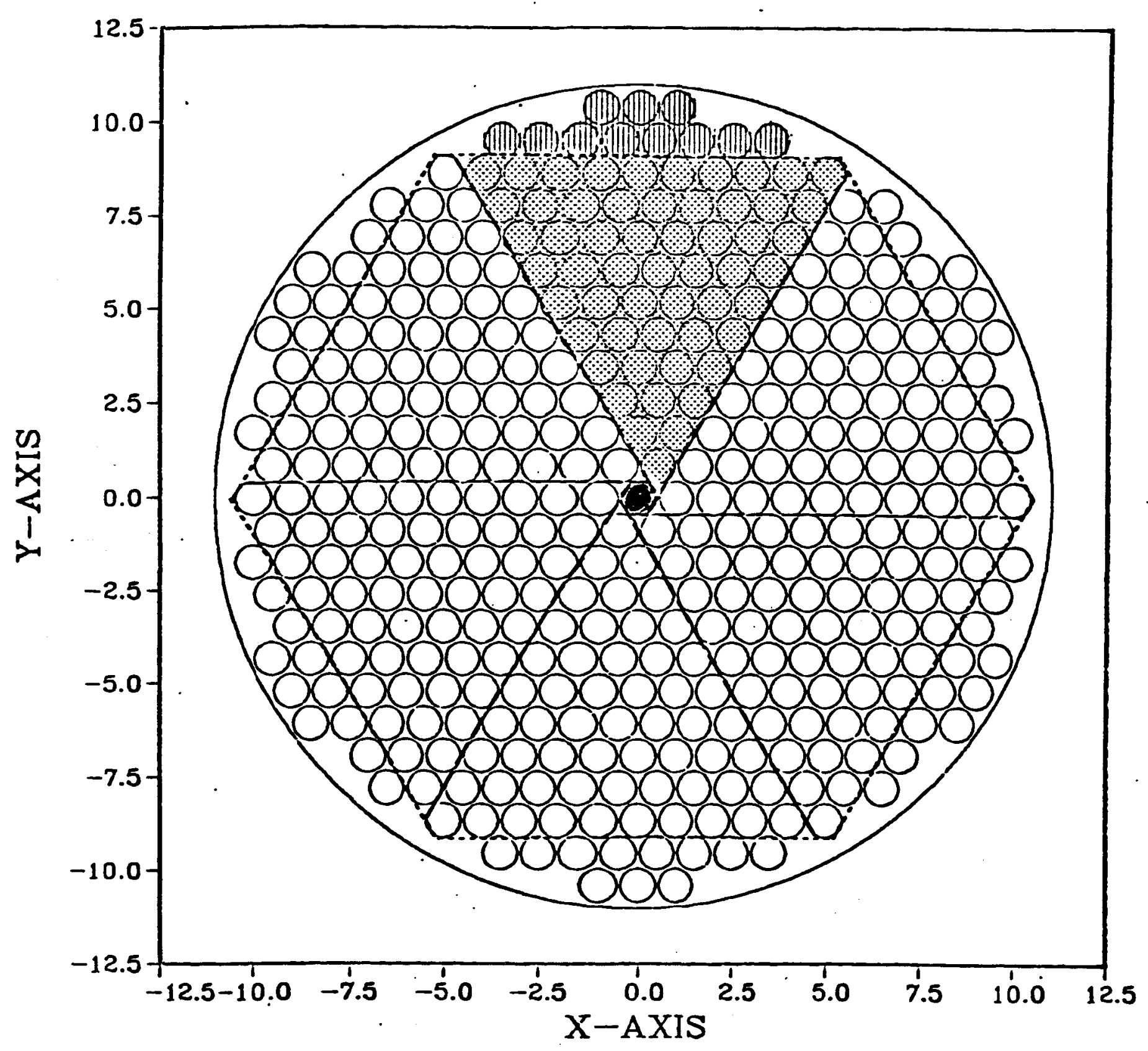

Figure $A-1$

SCHEMATIC DIAGRAM OF A CYLINDRICAL PACKING 

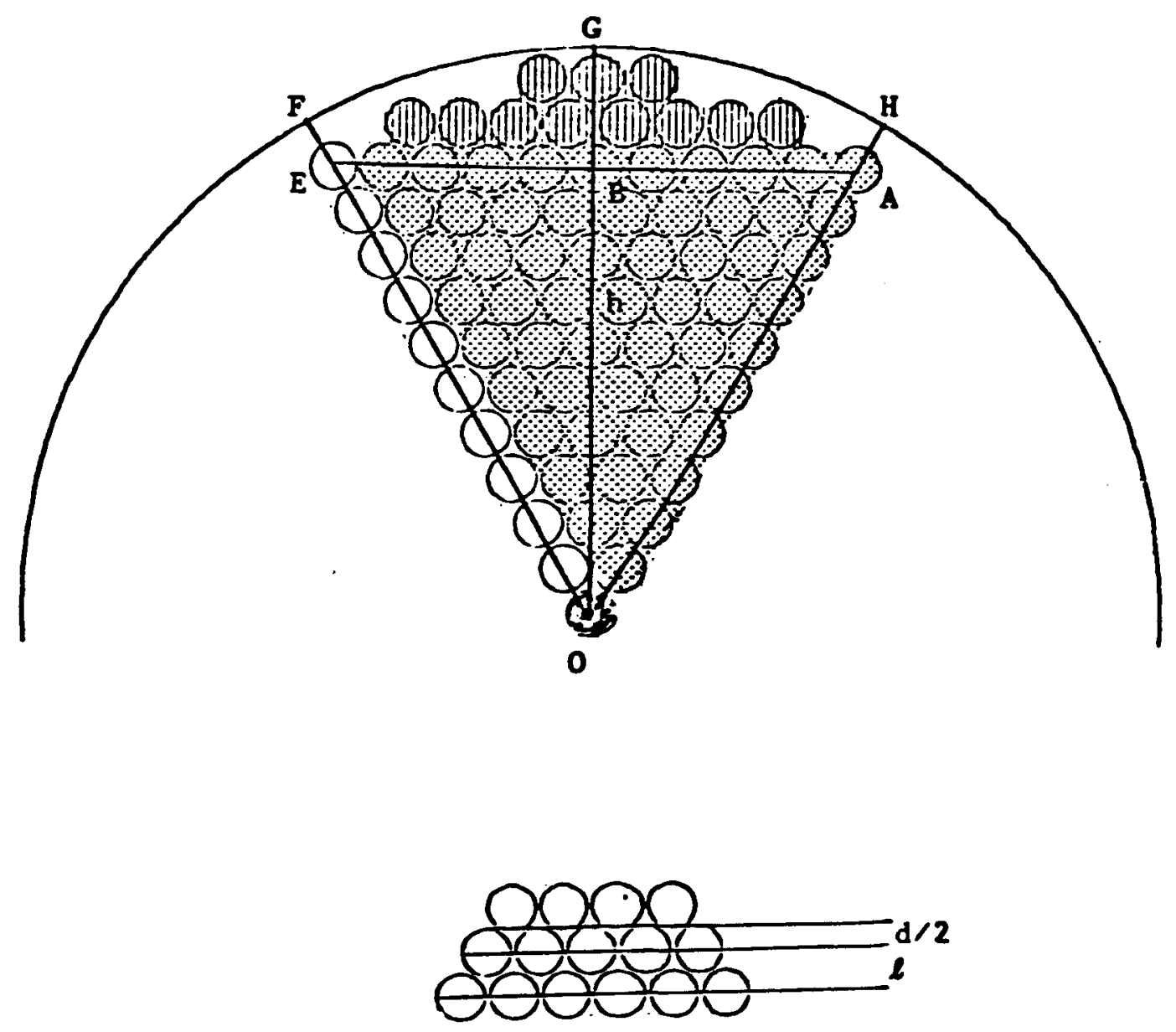

Figure $A-2$

SCHEMATIC DIAGRAM OF THE BASIC CYLINDRICAL PACKING PATTERN (ALL SHADED RODS) 


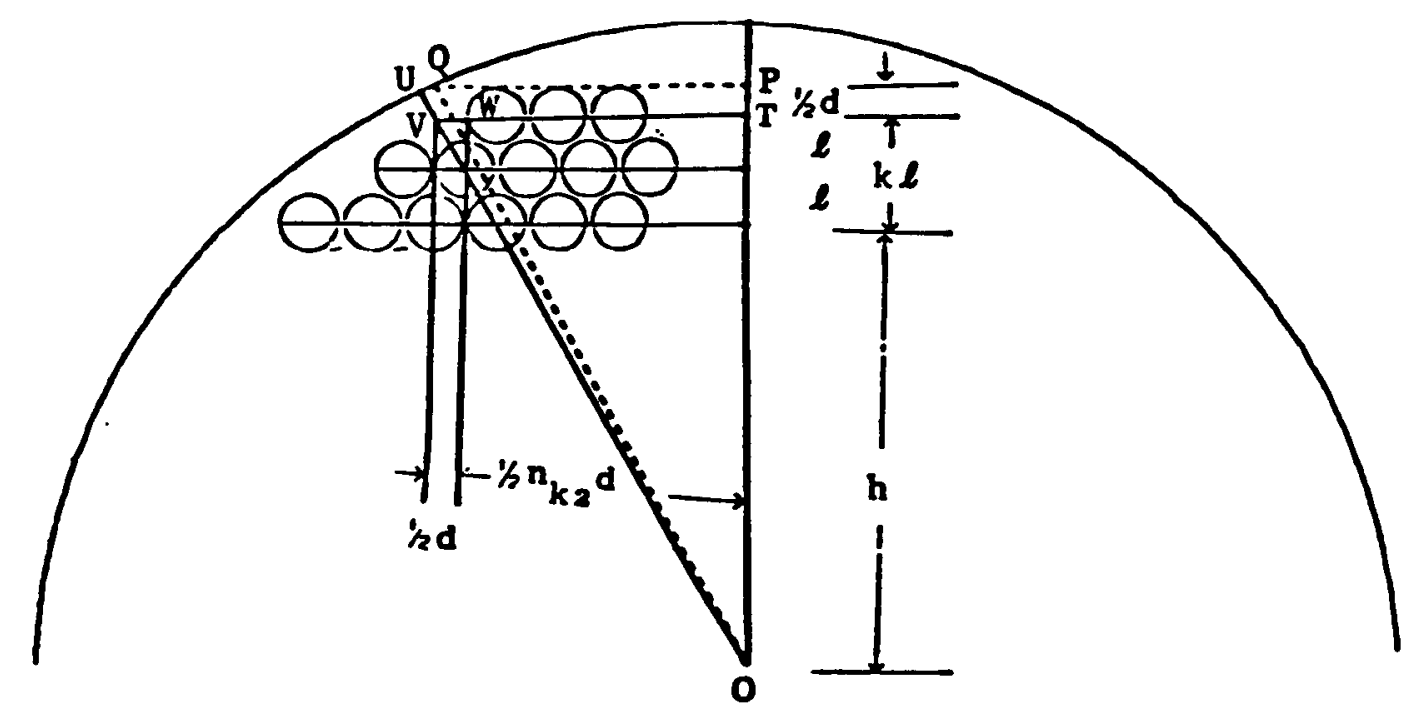

Figure $A-3$

SCHEMATIC DIAGRAM OF RODS IN THE EXTRA ROWS IN A CYLINDRICAL PACKING 


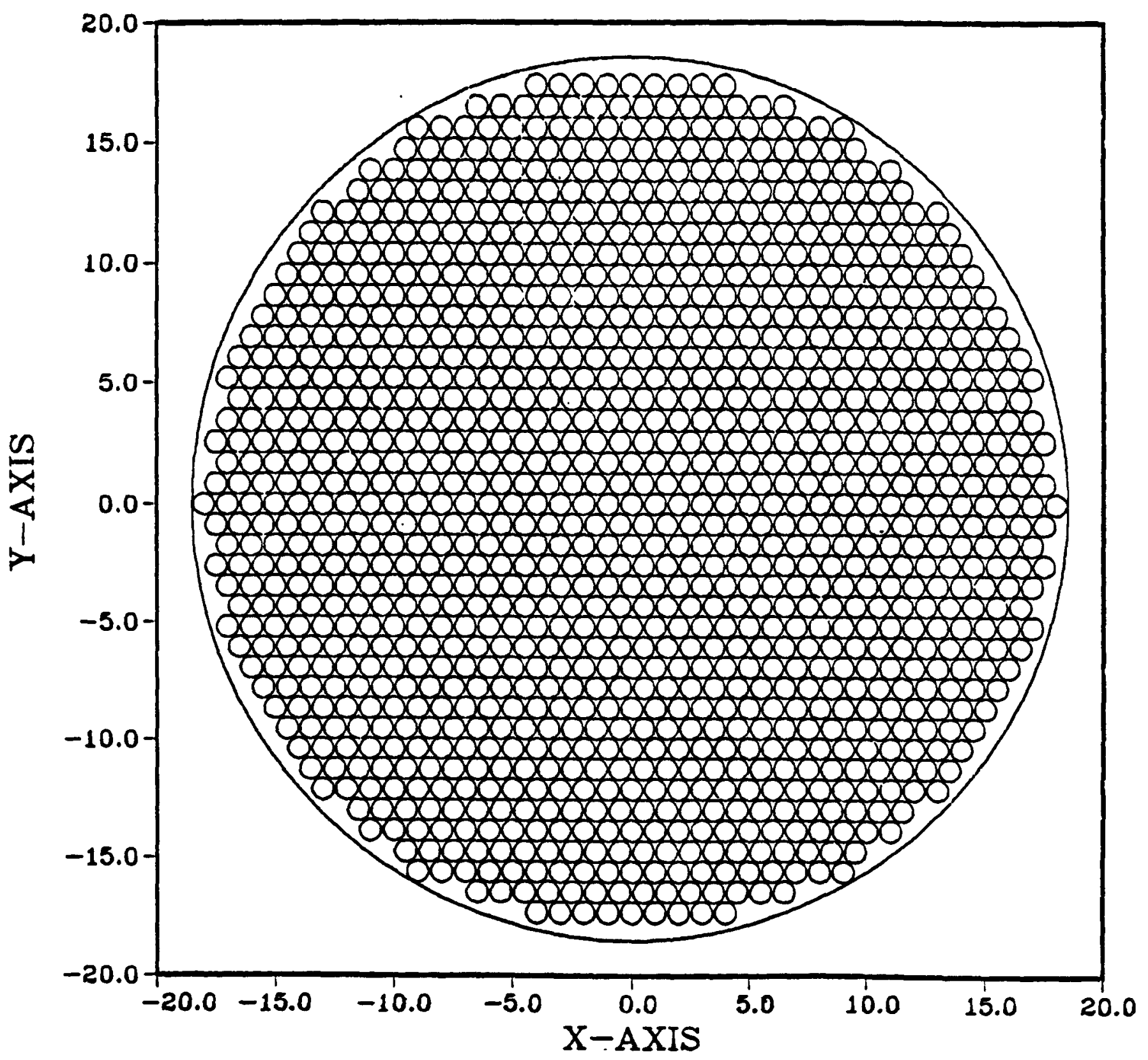

Figure A-4.

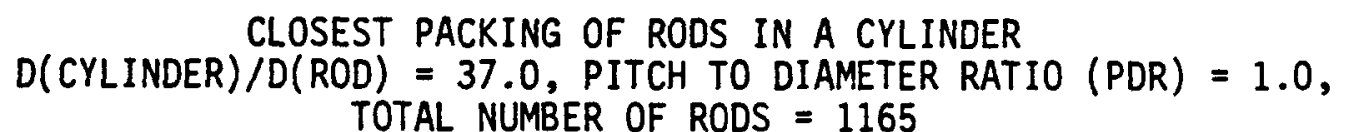




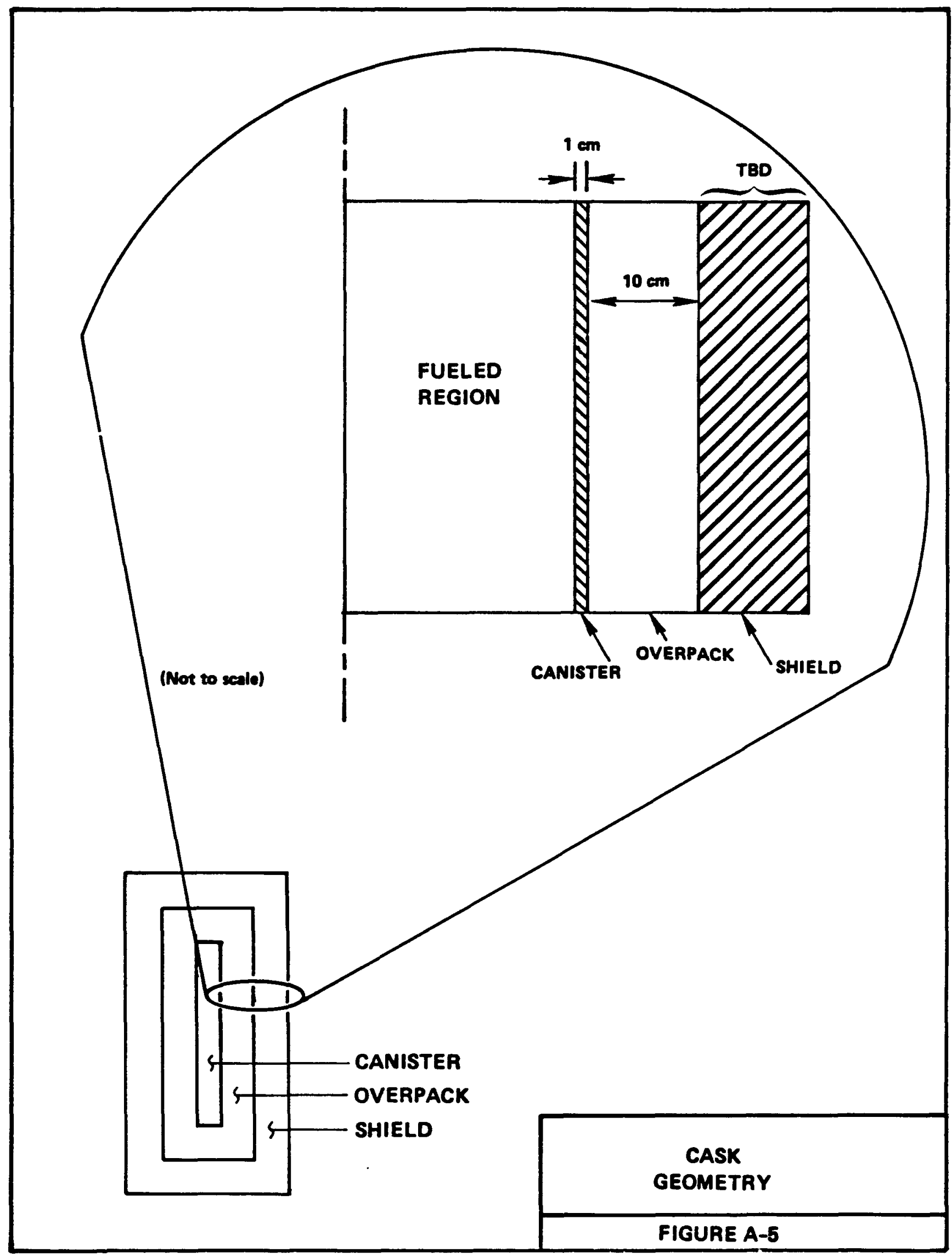


FIGURE A-6

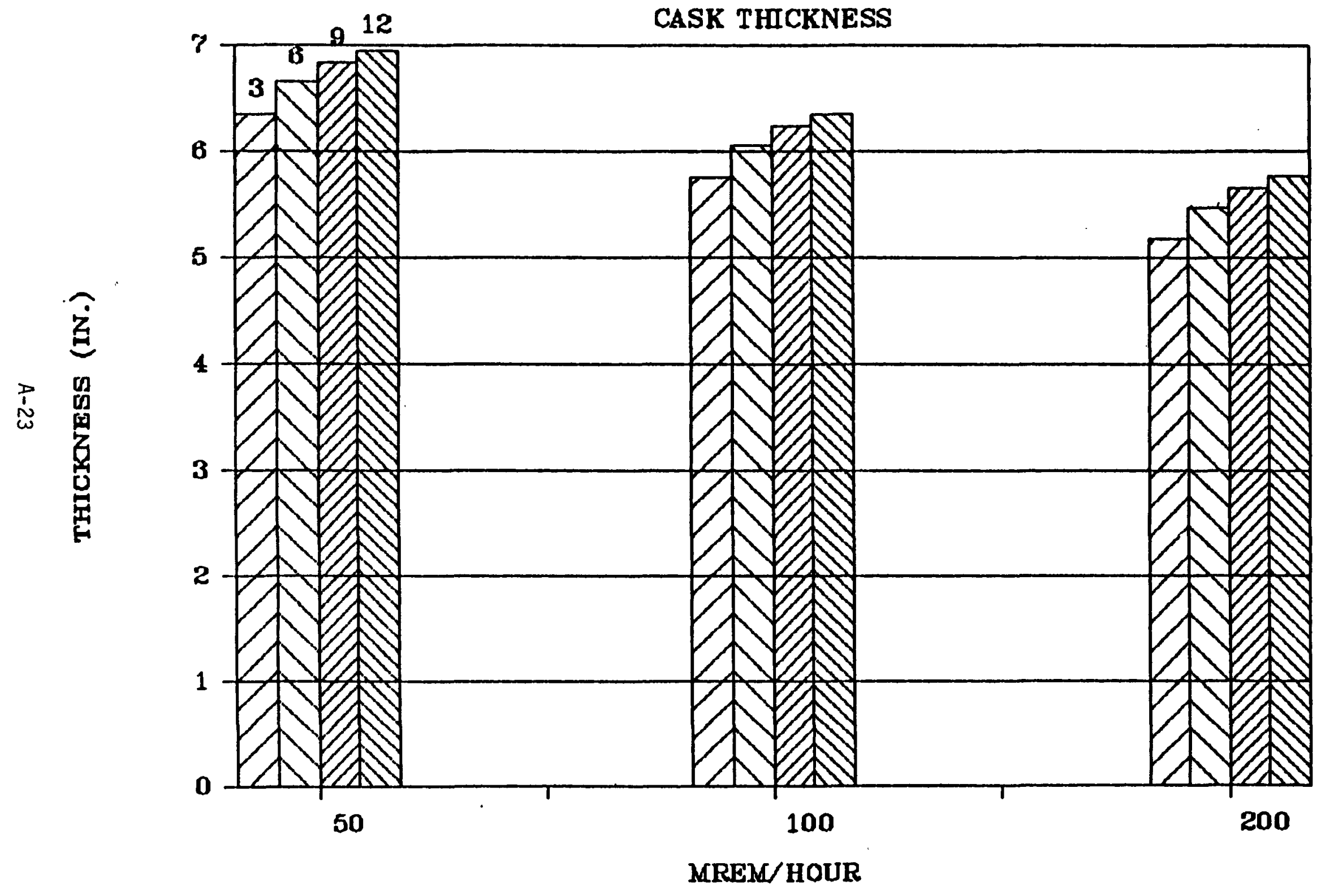




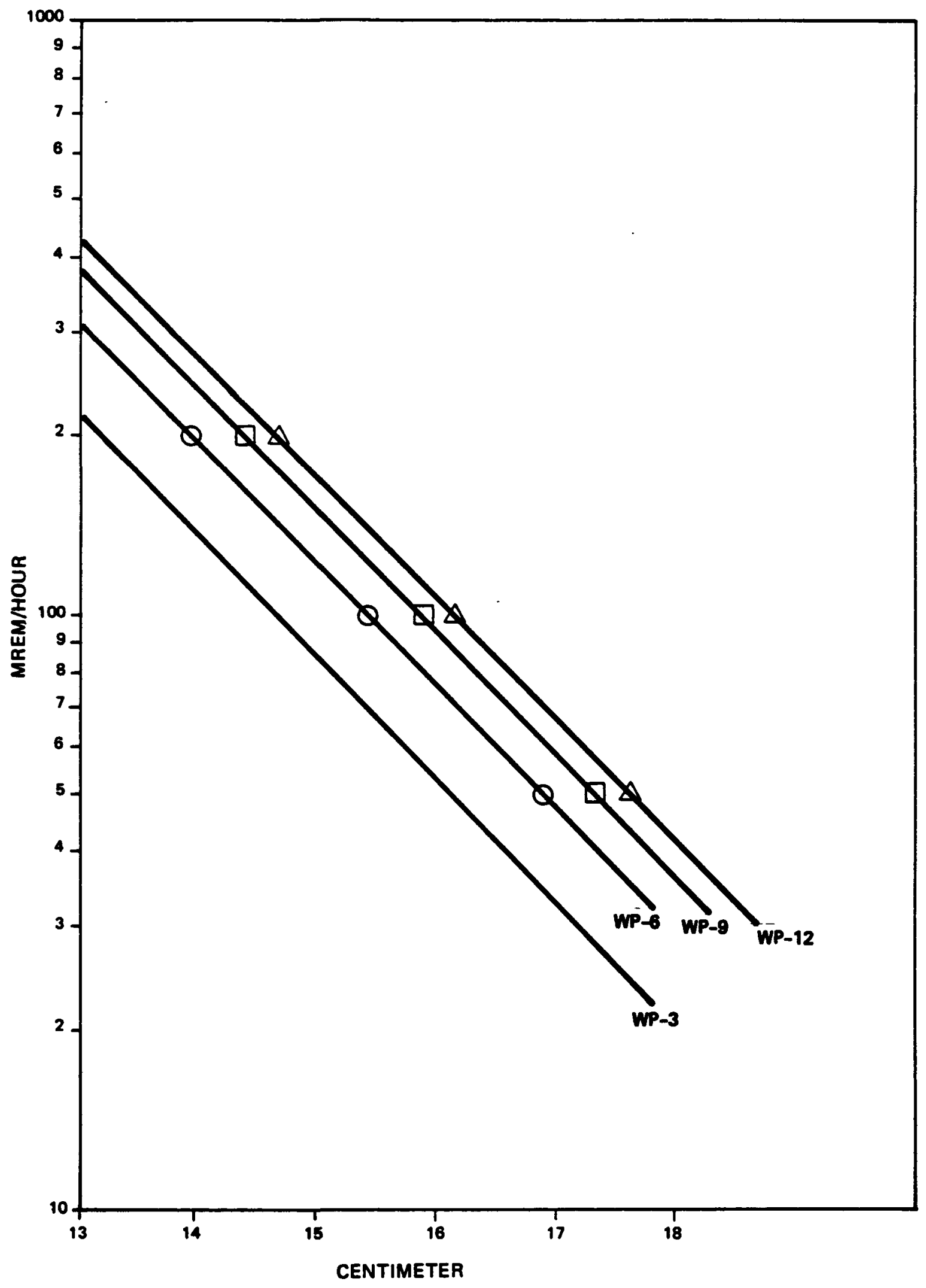

FIGURE A-7

CASK THICKNESS

B\&W FUEL 


\section{A.3 REFERENCES}

NBS, 1983. EPA/NIH (Environmental Protection Agency/National Institute of Health) Mass Spectra Data Base, Supplement 2, NSRDS-NBS-63-SUPPL-2, prepared for the Environmental Protection Agency, Washington, D.C., National Cancer Institute, Bethesda, MD.

ONWI, 1983. Engineered Waste Package Conceptual Design, Technical Report, ONWI-438, by Westinghouse Electric Corporation, April.

ORNL, 1975. Kernel Integration Shield Design Code for Radioactive Fuel Handling Facilities, SDC, Oak Ridge National Laboratory, Oak Ridge, TN, RSIC-CCC- 060 .

ORNL, 1980. Isotope Generation and Depletion Code, ORIGEN-2, Oak Ridge National Laboratory, Oak Ridge, TN, RSIC-CCC-371. 
APPENDIX B

THERMAL ANALYSES 
APPENDIX B

TABLE OF CONTENTS

$\underline{\text { Page }}$

B.1 THERMAL ANALYSES OF EMPLACEMENT IN A VERTICAL BOREHOLE - B-11

B.2 THERMAL ANALYSIS OF EMPLACEMENT IN A HORIZONTAL SLOT ... B-15

B.3 THERMAL ANALYSIS OF EMPLACEMENT IN A LONG HORIZONTAL BOREHOLE ............................ B-18

B.4 THERMAL ANALYSIS OF EMPLACEMENT IN CRUSHED SALT ...... B-19

B.5 THERMAL ANALYSIS OF EMPLACEMENT IN A VERTICAL BOREHOLE WITH CRUSHED SALT BACKFILL ................... B-21

B.6 EXTRAPOLATION OF RESULTS TO OTHER EMPLACEMENT MODES ... B-23

B.7 SUMMARY OF THE IMPACT OF MAXIMUM SALT TEMPERATURE ON

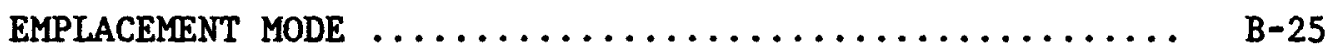

B. 8 THERMAL RESPONSE IN THE ROOM AND PILLAR REGION $\ldots \ldots \ldots \ldots$ B-25

B.8.1 Vertical Emplacement in the Room Floor and Horizontal Emplacement in the Room Pillar slot .............................. B-26

B.8.2 Temperature-Time Histories for Emplacement in a Long Horizontal Borehole in the Room Pillar .... B-28

B.8.3 Temperature Countours for Emplacement in a long Horizontal Borehole in the Room Pillar ....... B-33 
APPENDIX B

TABLE OF CONTENTS

(Continued)

Page

B.8.4 Effect of an Alternate Stratigraphy on Thermal Response ........................ B-34

B.9 STATIGRAPHY, MATERIAL PROPERTIES, AND MINE LAYOUT ..... B-35

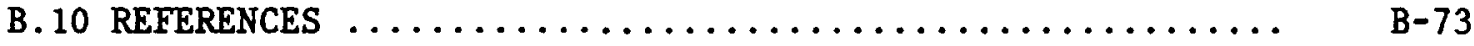


APPENDIX B

LIST OF TABLES

$\underline{\text { Page }}$

B-1 Thermal Properties $\ldots \ldots \ldots \ldots \ldots \ldots \ldots \ldots \ldots \ldots \ldots \ldots$ B-13

B-2 Normalized Power Decay Characteristics for Spent Fuel . B-14

B-3 Maximum Thermal Areal Loading and Minimum Package (or Borehole) Spacing .................... B-16

B-4 Temperature at 50 Years for Vertical Emplacement in a Borehole in Room Floor ..................... B-29

B-5 Temperature at 50 Years for Horizontal Emplacement in a Borehole in Room Floor .................... B-30

B-6 Room and Pillar Temperature at 50 Years After

Emplacement for the Long Horizontal Borehole ........ B-32

$044 / 00226 \quad B-4$ 
APPENDIX B

LIST OF FIGURES

$\underline{\text { Page }}$

B-1 Two Dimensional Axisymmetric Model for Calculating

Peak Salt Temperature for Emplacement in a Vertical

Borehole ............................ B-37

B-2 Peak Salt Temperature for Emplacement in a Vertical

Borehole $\ldots \ldots \ldots \ldots \ldots \ldots \ldots \ldots \ldots \ldots \ldots \ldots \ldots \ldots$ B -38

B-3 Maximum Salt Temperature as a Function of a Canister Spacing and Thermal Areal Loading for Emplacement in a Vertical Borehole ........................ B-39

B-4 Peak Salt Temperature for Emplacement in a Horizontal

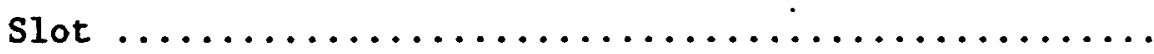

B-5 Maximum Salt Temperature as a Function of Canister Spacing and Thermal Areal Loading for Emplacement in a Horizontal slot ......................... B-41

B-6 Peak Salt Temperature for Emplacement in a Long Horizontal Borehole ..................... B-42

B-7 Maximum Salt Temperature as a Function of Borehole Spacing and Thermal Areal Loading for Emplacement in a Long Horizontal Borehole $\ldots \ldots \ldots \ldots \ldots \ldots \ldots \ldots \ldots \ldots$ B-43

B-8 Two-Dimensional Axisymmetric Model for Calculating Peak Salt Temperature with the Waste Package Surrounded by Crushed Salt ......................... B-44

B-9 Peak Salt Temperature for a Waste Package Surrounded by Crushed Salt ...................... B-45 
APPENDIX B

LIST OF FIGURES

(Continued)

$\underline{\text { Page }}$

B-10 Two-Dimensional Planar with the Waste Package Horizontally Emplaced at the Corner of a Room ....... B-46

B-11 Peak Salt Temperature with the Waste Package Horizontally Emplaced at the Corner of a Room; the Thermal Areal Loading is $25 \mathrm{~W} / \mathrm{m}^{2} \ldots \ldots \ldots \ldots \ldots \ldots \ldots \ldots \ldots \ldots \ldots$ B-47

B-12 Two-Dimensional Planar Model with the Waste Package Horizontally Emplaced in a Trench at the Corner of

B-48

B-13 Peak Salt Temperature with the Waste Package Horizontally Emplaced in a Trench at the Corner of a Room; the Thermal Areal Loading is $30 \mathrm{w} / \mathrm{m}^{2} \ldots \ldots \ldots \ldots \ldots$ B- 49

B-14 Two-Dimensional Axisymmetric Model for Calculating Peak Salt Temperature for Emplacement in a Vertical Borehole Backfilled with Crushed Salt ............ B-50

B-15 Maximum Salt Temperature Versus Gap Size for Emplacement in a Vertical Borehole Backfilled with Crushed

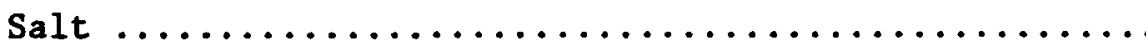

B-16 Two-Dimensional Planar Model for the Vertical and the

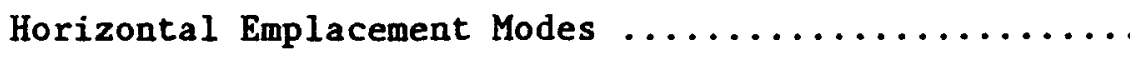

B-17 Temperature Contours for Vertical Emplacement in the Room Floor with a Thermal Area Loading of $20 \mathrm{~W} / \mathrm{m}^{2} \ldots$. B-53 
APPENDIX B

LIST OF FIGURES

(Continued)

$\underline{\text { Page }}$

B-18 Temperature Contours for Horizontal Emplacement in the Pillar Slot with a Thermal Areal Loading of $20 \mathrm{~W} / \mathrm{m}^{2}$

B-19 Room and Pillar Temperatures for Emplacement in a Vertical Borehole .......................... B-55

B-20 Temperature Contours for Emplacement in a Vertical

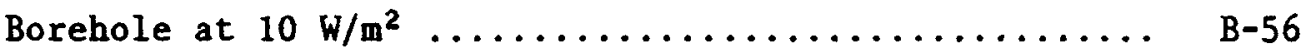

B-21 Temperature Contours for Emplacement in a Vertical

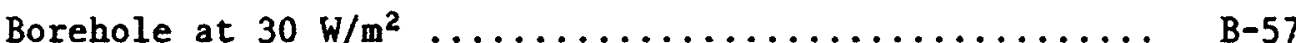

B-22 Room and Pillar Temperatures for Emplacement in a Horizontal Pillar Slot ..................... B-58

B-23 Temperature Contours for Emplacement in a Horizontal Pillar slot at $10 \mathrm{~W} / \mathrm{m}^{2} \ldots \ldots \ldots \ldots \ldots \ldots \ldots \ldots . \ldots . \ldots . \ldots . \ldots$

B-24 Temperature Contours for Emplacement in a Horizontal Pillar slot at $30 \mathrm{w} / \mathrm{m}^{2} \ldots \ldots \ldots \ldots \ldots \ldots \ldots \ldots \ldots \ldots \ldots$ B $60 \ldots \ldots$

B-25 Schematic Diagram of Eight Locations for TemperatureTime Histories for Horizontal Emplacement in a Long Borehole ........................... B-61

B-26 Temperature Time Histories at Locations $P, Q, R$, and $S$ for Horizontal Emplacement in a Long Borehole. See Legend for Explanation of Locations ............ B-62 
APPENDIX B

LIST OF FIGURES

(Continued)

$\underline{\text { Page }}$

B-27 Temperature Time Histories at Locations A, B, C, D, and E for PWR-6 Waste Packages Horizontally Emplaced in a Long Borehole. See Legend for Explanation of

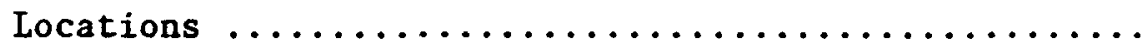

B-63

B-28 Temperature Time Histories at Locations A, B, C, D, and $E$ for PWR-9 Waste Packages Horizontally Emplaced in a Long Borehole. See Legend for Explanation of

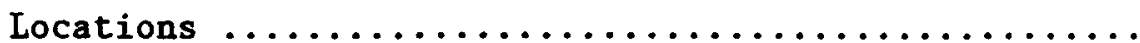

B-64

B-29 Temperature Time Histories at Locations A, B, C, D, and $\mathrm{E}$ for PWR-12 Waste Packages Horizontally Emplaced in a Long Borehole. See Legend for Explanation of

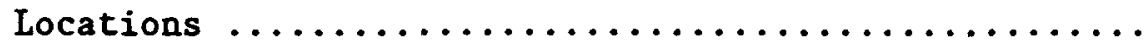

B-30 Two-Dimensional Planar Model for Horizontal Emplacement in a Long Borehole in the Pillar ............. B-66

B-31 Room and Pillar Temperatures for Emplacement in a Long Horizontal Borehole .................. B-67

B-32 Temperature Contours for Emplacement in a Long Horizontal Borehole at $10 \mathrm{~W} / \mathrm{m}^{2} \ldots \ldots \ldots \ldots \ldots \ldots \ldots$ B-68

B-33 Temperature Contours for Emplacement in a Long Horizontal Borehole at $20 \mathrm{w} / \mathrm{m}^{2} \ldots \ldots \ldots \ldots \ldots \ldots \ldots$ B-69

B-34 Temperature Contours for Emplacement in a Long Horizontal Borehole at $30 \mathrm{w} / \mathrm{m}^{2} \ldots \ldots \ldots \ldots \ldots \ldots$ B-70 


\section{APPENDIX B \\ LIST OF FIGURES \\ (Continued)}

Page

B-35 Two-Dimensional Planar Model for the Thermal Calculation with an Alternate Stratigraphy (J. Friemel

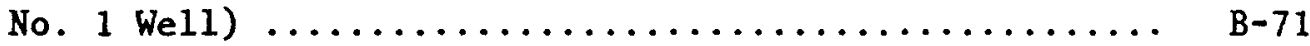

B-36 Comparison of Temperature Contours at 50 Years After Emplacement for Calculations with the Detten and J. Friemel Stratigraphies .................. B-72 
APPENDIX B

THERMAL ANALYSES

A series of thermal response calculations has been performed to predict the maximum salt temperature near an emplaced waste package and the salt temperatures in the 50 to 70 year timeframe. The maximum salt temperature is a key variable because a functional design criterion limits the maximum salt temperature to $250^{\circ} \mathrm{C}$ for the conceptual design of a waste repository in salt (Table 2-1). There are indications, however, that $175^{\circ} \mathrm{C}$ maximum salt temperature may be a more appropriate value (Section 3.2.1).

The maximum salt temperature (which occurs directly adjacent to the emplaced package) is a function of emplacement mode, thermal areal loading, waste package power level, and the thermal conductivity of salt. Variations of thermal areal loading, package power level, and thermal conductivity are relatively straightforward. Variations of emplacement mode are less straightforward because of the number of emplacement modes (17) and because of the geometric complexity of certain modes with respect to thermal modeling. Rather than attempt to calculate all 17 modes, a few representative modes have been selected for analysis, and the results of these analyses are extended/extrapolated to the other emplacement modes. The validity of this approach is based on selecting representative modes that bound the expected thermal response and on the observed insensitivity of maximum salt temperature to minor geometric variations in emplacement mode.

The representative modes for thermal analysis are as follows:

1. Mode 1: vertical borehole in room floor, unsleeved

2. Mode 3B: horizontal slot at mid-height of the room pillar, parallel to drift

3. Mode 8A: long horizontal borehole in room pillar, unsleeved 
4. Mode 4: horizontal on room floor, surrounded by crushed salt and parallel to entry centerline and in corner of room.

5. Mode 1': Mode 1 modified to include crushed salt backfill in the annular space between package and borehole.

(Mode Notation, e.g., 3B, is described in Appendix D.)

The thermal analyses for each of the representative emplacement modes are described in the next subsections, followed by a detailed discussion of the applicability of these results to the 17 emplacement modes. The results of these calculations show that all emplacement modes can be designed to limit the maximum salt temperature to $250^{\circ} \mathrm{C}$ (and also $175^{\circ} \mathrm{C}$ ), although the package power level and the thermal areal loading may have to be drastically reduced for a package surrounded by crushed salt.

\section{B.1 THERMAL ANALYSIS OF EMPLACEMENT IN A VERTICAL BOREHOLE (MODE 1)}

A series of calculations has been performed to predict the maximum salt temperature for a waste package that is emplaced in a vertical borehole beneath the room floor. These calculations were performed for three package power levels and for three values of thermal areal loading.

The calculations were performed with PWR12, PWR9, and PWR6 spent fuel packages. The spent fuel is assumed to be 10 years out of the reactor, and the package power levels are $6.6 \mathrm{~kW}, 4.95 \mathrm{~kW}$, and $3.3 \mathrm{~kW}$, respectively.

For each type of package, the maximum salt temperature is evaluated for a low, a medium, and a high value of the thermal areal loading. Typical values are 15,25 , and $40 \mathrm{~W} / \mathrm{m}^{2}$.

For each type of package and each value of the areal loading, calculations were performed with an average value for the thermal conductivity for salt. The thermal conductivity of salt is temperature-dependent, so the average value is defined by the quadratic function of temperature in RSI-0204 (RE/SPEC, 1984). 
The thermal analyses were performed with the computer program, DOT (INTERA, 1983). Figure $B-1$ is a schematic diagram of the two-dimensional, axisymmetric model for the calculations. The computational model does not incorporate the detailed geometry of the waste package; instead, the waste package is represented by a uniform material with the thermal properties of spent fuel. Preliminary calculations (not reported here) demonstrated that the maximum salt temperature is not significantly affected by this approximation. The stratigraphy used for the calculations was for the Deaf Smith site, (DOE, 1984). The material properties and the power decay characteristic for the calculations are presented in Tables $\mathrm{B}-1$ and $\mathrm{B}-2$, respectively. The mine layout is discussed in Section B.9. The ambient salt temperature at the repository horizon was used as the initial temperature for the calculations. This value is $30^{\circ} \mathrm{C}$ and is used for all calculations presented in the Appendix.

The disposal room is assumed to be immediately backfilled with crushed salt at the time of emplacement. The assumption of immediate backfilling is conservative for two reasons. First, the thermal conductivity of crushed salt is much lower than intact salt, and a material with lower conductivity will tend to increase the maximum salt temperature. Second, there is no ventilation to cool the room walls.

The upper and lower boundaries of the computational model are adiabatic and are located $260 \mathrm{~m}$ from the room floor. The location of these boundaries is far enough from the waste package to simulate an infinite medium in the vertical direction (the typical temperature rise at these locations is less than $0.02^{\circ} \mathrm{C}$ ).

On Figure B-1, the radius of the outer boundary, $R_{m}$, is determined such that the cross-sectional area of the axisymmetric model equals a rectangular area associated with one package in the repository layout. This rectangular area is defined by the pillar spacing and the package pitch. Similarly, the radius of the room, $R_{r}$, is determined such that the (circular) cross-sectional area of the room equals the (rectangular) room area per package in the repository layout. This rectangular room area is one room width by one package pitch (spacing). 
Table B-1

Thermal Properties

\begin{tabular}{|c|c|c|c|c|c|}
\hline \multirow[b]{2}{*}{ Material Properties } & \multicolumn{5}{|c|}{ Materials } \\
\hline & $\begin{array}{r}\text { Spent } \\
\text { Fuel } \\
\end{array}$ & $\begin{array}{r}\text { Carbon } \\
\text { Steel } \\
\end{array}$ & Salt & Crushed Salt & Nonsalt \\
\hline Density $\quad\left(\mathrm{kg} / \mathrm{m}^{3}\right)$ & 8790 & 7833 & 2190 & 1533 & 2525 \\
\hline Specific Heat $\quad(\mathrm{J} / \mathrm{kg}-\mathrm{K})$ & 465 & 465 & 931 & 931 & 954 \\
\hline Thermal conductivity $(W / m-K)$ & * & 45 & $\star \star$ & $\star \star \star$ & $\star \star \star \star$ \\
\hline
\end{tabular}

* Thermal conductivity was assumed to be anisotropic $K_{\text {axial }}=5.5 ; \quad K(T)_{\text {radial }}=0.865+4.02 \times 10^{-5} T+3.17 \times 10^{-6} T^{2} \quad\left(T\right.$ in $\left.{ }^{\circ} \mathrm{C}\right)$

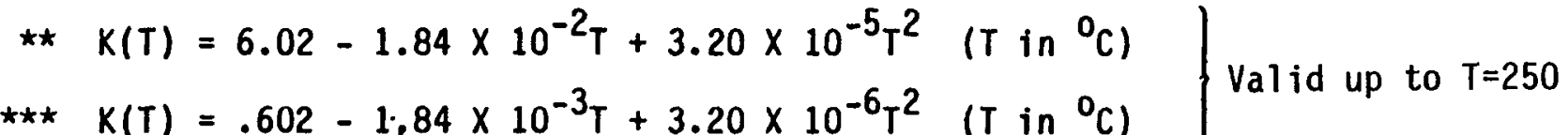

$\star \star \star \star \quad K(T)=3.22-9.33 \times 10^{-3} T+1.16 \times 10^{-5} T^{2}$ (T in $\left.{ }^{\circ} \mathrm{C}\right)$ 


\section{Table B-2}

Normalized Power Decay Characteristics for Spent Fuel (Ten Years Out-of-Reactor at the Time of Emplacement)

\begin{tabular}{|c|c|}
\hline $\begin{array}{c}\text { Time } \\
\text { (years) }\end{array}$ & Normalized Power \\
\hline 0.0 & 1.0000 \\
0.5 & 0.9828 \\
1.0 & 0.9660 \\
1.5 & 0.9494 \\
2.0 & 0.9331 \\
2.5 & 0.9171 \\
3.0 & 0.9013 \\
3.5 & 0.8858 \\
4.0 & 0.8706 \\
4.5 & 0.8557 \\
5.0 & 0.8410 \\
6.0 & 0.8220 \\
7.0 & 0.8033 \\
8.0 & 0.7852 \\
9.0 & 0.7674 \\
10.0 & 0.7500 \\
12.5 & 0.7166 \\
15.0 & 0.6847 \\
20.0 & 0.6250 \\
30.0 & 0.5240 \\
50.0 & 0.3890 \\
70.0 & 0.303 \\
& \\
\hline
\end{tabular}


The output from the DOT calculations includes temperature-time histories throughout the rock mass. In particular, the peak salt temperature is that temperature directly adjacent to the waste package at its mid height. The peak salt temperature varies with time, and it reaches a maximum value at some time after emplacement. This maximum value is the temperature that is limited by the design criterion of $250^{\circ} \mathrm{C}$ (see Table 2-1).

Figure B-2 presents time histories of peak salt temperatures, calculated with the average thermal conductivity of salt. The maximum salt temperature is derived from these time histories and is summarized in Figure B-3, which presents the maximum salt temperature versus package spacing and the maximum salt temperature versus thermal areal loading for calculations with the average thermal conductivity.

Figure B-3 presents the maximum temperature data in a format that is convenient for design purposes. For example, analyses by Westinghouse (ONWI, 1985) predict a $200^{\circ} \mathrm{C}$ temperature difference between the centerline and the surface of a PWR12 waste package. A functional design criterion limits the centerline temperature to $375^{\circ} \mathrm{C}$. The maximum salt temperature must then be reduced to $175^{\circ} \mathrm{C}$ to avoid exceeding the limit on the centerline temperature. In this case, Figure B-3 shows that the thermal areal loading must be less than 24, 26, and $29 \mathrm{~W} / \mathrm{m}^{2}$ for the PWR12, PWR9, and PWR6 packages, respectively. These results are summarized in Table $B-3(A)$.

\section{B.2 THERMAL ANALYSIS OF EMPLACEMENT IN A HORIZONTAL SLOT (MODE 3B)}

A series of calculations has been performed to predict the maximum salt temperature for a waste package that is emplaced in a horizontal slot at the midheight of the pillar. As with the previous thermal analyses, the calculations were performed for three package power levels and three values of the thermal areal loading.

The peak salt temperatures are determined with a three-dimensional analytic model because the temperature field for this emplacement mode cannot be accurately determined by a two-dimensional model. This analytic model represents the waste packages as point or line sources in a uniform rock mass 
Table B-3. Maximum Thermal Areal Loading and Minimum Package (or Borehole) Spacing (Assuming the Maximum Salt Temperature is Limited to $175^{\circ} \mathrm{C}$ )

(A) Emplacement in a Vertical Borehole in the Room Floor

\begin{tabular}{lllll}
\hline & PWR12 & PWR9 & PWR6 \\
\hline Maximum thermal areal loading $\left(\mathrm{W} . \mathrm{m}^{2}\right)$ & 24 & 26 & 29 \\
Minimum package spacing $(\mathrm{ft})$ & 30 & 21 & 13 \\
\hline
\end{tabular}

(B) Emplacement in a Horizontal Slot in the Room Pillar

\begin{tabular}{lllll}
\hline & PWR12 & PWR9 & PWR6 \\
\hline Maximum thermal areal loading $\left(\mathrm{W} / \mathrm{m}^{2}\right)$ & 24 & 26 & $24(\mathrm{a})$ \\
Minimum package spacing $(\mathrm{ft})$ & 30 & 21 & 15 \\
\hline
\end{tabular}

(C) Emplacement in a Long Horizontal Borehole in the Pillar

\begin{tabular}{lllll}
\hline & PWR12 & PWR9 & PWR6 \\
\hline Maximum thermal areal loading $\left(\mathrm{W} / \mathrm{m}^{2}\right)$ & 24 & 25 & 28 \\
Minimum borehole spacing $(\mathrm{ft})$ & 87 & 89 & 69 \\
& & & \\
\hline
\end{tabular}

(a) The packages are packed end-to-end. 
with constant thermal conductivity. The stratigraphy and the detailed geometry of the rooms are not modeled. The constant thermal conductivity of the rock mass is the average thermal conductivity of salt at $110^{\circ} \mathrm{C}$; this value is 4.7 $W / \mathbf{m}-\mathbf{K}$.

Individual waste packages are represented as point or line sources, depending on the canister's spatial relationship with a central "test" package. A waste package near the test package is modeled by 10 point sources, each of which generates one tenth of the power of the whole package. A package farther away from the test package is modeled by a single point source which generates the full power of the package. A package that is still farther away is modeled as part of a line source. This approach leads to an efficient computational procedure that preserves the spatial resolution of the model in the very near field, where it is needed for predicting peak temperature near the test package.

The decay characteristics of spent fuel are modeled by superposition of heat sinks. A heat sink is added to each heat source every year after emplacement, and the strength of the heat sink is the power decay of the heat source during that year. The normalized decay characteristic of spent fuel, which is assumed to be ten years out-of-reactor, is used (Table B-2).

Figure B-4 presents time history plots of peak salt temperature. Figure B-5 presents the maximum salt temperature versus package spacing and the maximum salt temperature versus thermal areal loading. These results show that the maximum salt temperatures are about $11^{\circ} \mathrm{C}$ higher at $15 \mathrm{~W} / \mathrm{m}^{2}$ for horizontal slot emplacement than for vertical emplacement. The maximum salt temperatures are $1-5^{\circ} \mathrm{C}$ higher at $25 \mathrm{~W} / \mathrm{m}^{2}$ for horizontal slot emplacement than for vertical emplacement. These differences are caused by three factors: the thermal conductivities of the analytic model and the DOT calculations are different, the stratigraphy for the analytic model and the DOT model are different, and the effective separation between packages is slightly less in the horizontal mode. Considering the differences in the computational methods, the results for maximum salt temperature are quite close. 
The results for the maximum thermal areal loading and the minimum package spacing are summarized in Table $\mathrm{B}-3(\mathrm{~B})$, assuming that the maximum salt temperature is limited to $175^{\circ} \mathrm{C}$ to meet the $375^{\circ} \mathrm{C}$ temperature limit at the package centerline: Note that the maximum thermal areal loading for the PWR6 waste package is not restricted by maximum salt temperature, but by the geometric restraint from packing the packages end to end.

\section{B.3 THERMAI ANALYSIS OF EMPLACEMENT IN A LONG HORIZONTAL BOREHOLE (MODE 8A)}

A series of calculations has been performed to predict the maximum salt temperature for waste packages that are emplaced horizontally in a 220-foot long borehole in the pillar. These calculations were performed for three package power levels, three values of the thermal areal loading, and with two expressions for the thermal conductivity of salt.

The emplacement mode investigated here assumes that the waste packages are emplaced in a 220-foot long horizontal borehole in the pillar. The room width and the room spacing are assumed to be 20 and $240 \mathrm{ft}$, respectively. Either 13 PWR6 packages, 10 PWR9 packages, or 7 PWR12 packages are emplaced in a borehole. The PWR6 packages are packed end to end, with a standoff distance of one package length from each access drift. The PWR9 and PWR12 packages are uniformly spaced within each borehole, except for the standoff distance of one package length. The "density" of the PWR9 and PWR12 packages was reduced because preliminary calculations (not reported here) showed that packing PWR9 or PWR12 packages end to end exceeded the maximum allowable salt temperature of $250^{\circ} \mathrm{C}$.

A three-dimensional analytic model is used to determine the peak salt temperature for this emplacement mode because these temperatures can not be accurately determined by a two-dimensional model. This analytic model represents the waste packages as point or line sources in a uniform material with constant thermal conductivity. The stratigraphy and the presence of the drifts cannot be incorporated into the analytic model. The constant thermal conductivity of the rock mass is the conductivity of salt at $110^{\circ} \mathrm{C}$. This value is $4.7 \mathrm{~W} / \mathrm{m}-\mathrm{K}$ for the average thermal conductivity. 
Individual waste packages are represented as point or line sources, depending on the canister's spatial relation with a central "test" package. A waste package near the test package is modeled by 10 point sources, each of which generates one tenth of the power of the whole package. A package farther away from the test package is modeled by a single point source which generates the full power of the package. A package that is still farther away is modeled as part of a line source. This approach leads to an efficient computational procedure that preserves the spatial resolution of the model in the near field, where it is needed for predicting peak temperature near the test package.

The decay characteristics of spent fuel are modeled by superposition of heat sinks. A heat sink is added to each heat source every year after emplacement, and the strength of the heat sink is the power decay of the heat source during that year. The normalized decay characteristic for spent fuel, which is assumed to be ten years out-of-reactor, is used (Table B-2).

Figure B-6 presents time history plots of peak salt temperature calculated with the average thermal conductivity. Figure B-7 presents the maximum salt temperature as a function of borehole spacing and thermal areal loading for these calculations. These results show that the maximum salt temperatures are $11-32^{\circ} \mathrm{C}$ higher at $15 \mathrm{~W} / \mathrm{m}^{2}$ and $1-9^{\circ} \mathrm{C}$ higher at $25 \mathrm{~W} / \mathrm{m}^{2}$ for the horizontal borehole than for the vertical or horizontal slot emplacement modes previously described. The results for the maximum thermal areal loading and the minimum package spacing are summarized in Table $B-3(C)$, assuming that the maximum salt temperature is limited to $175^{\circ} \mathrm{C}$ to meet the $375^{\circ} \mathrm{C}$ temperature limit at the package centerline.

\section{B.4 THERMAL ANALYSTS OF EMPLACEMENT IN CRUSHED SALT (MODE 4)}

A series of calculations has been performed to predict the maximum salt temperature for a waste package that is surrounded on several sides by crushed salt. The presence of crushed salt is expected to have a major impact on maximum salt temperature because the thermal conductivity of crushed salt is estimated to be one tenth that of intact salt, and the presence of a low conductivity material adjacent to the package will increase the local temperature field substantially. 
Emplacement Mode 4 involved a package surrounded by crushed salt on two sides. To analyze this case and generate data for other case, these calculations were performed for a package surrounded by crushed salt on four sides, on two sides, and on one side. The package surrounded by crushed salt on four sides is standing vertically, in the center of a drift. The package surrounded by crushed salt on two sides is lying horizontally in the corner of a drift. The package surrounded by crushed salt on one side is lying horizontally in a shallow trench in the floor of a drift. The other variables for the calculations were the thermal areal loading and the package power level. All the thermal analyses were performed with the DOT computer program (INTERA, 1983). Figure B-8 is a schematic diagram of the two-dimensional, axisymmetric model for a package surrounded by crushed salt on four sides. This computational model is similar to the model for vertical emplacement, except that the package is standing in the drift, surrounded by crushed salt at the time of emplacement.

Figure B-9 presents time-histories of peak salt temperature for a waste package surrounded by crushed salt on four sides. These results show that only the calculation with a $2.8 \mathrm{~kW}$ package at $6.4 \mathrm{~W} / \mathrm{m}^{2}$ has a maximum salt temperature below $250^{\circ} \mathrm{C}$. This package power level and thermal areal loading represent a significant restriction to repository design.

Figure B-10 is a schematic diagram of the two-dimensional, planar model for a package lying in the corner of a drift and surrounded by crushed salt on two sides. The two-dimensional planar model for this calculation is an approximation because a three-dimensional model is required for accurate analysis of maximum salt temperature. However, three-dimensional analyses were beyond the scope of this series of calculations, and the two-dimensional results are adequate for initial selection of emplacement mode.

The left and right boundaries of this model are axes of symmetry, located at the centerlines of two adjacent pillars. All boundaries of the model are adiabatic, and the upper and lower boundaries are located far enough from the waste package to simulate an infinite medium in the vertical direction. 
The waste package is represented by a square salt zone at the lower right corner of the room. The area of this zone is equal to the cross-sectional area of the waste package, and the equivalent power generation of the waste packages, viewed as a line source, is added to the salt zone.

The drift is assumed to be backfilled immediately after the waste is emplaced. The stratigraphy, material properties, and mine layout for this calculation are presented in Section B.9.

Figure B-11 presents a time history of peak salt temperature for a thermal areal loading of $25 \mathrm{~W} / \mathrm{m}^{2}$ for a waste package surrounded by crushed salt on two sides. The maximum salt temperature of $234^{\circ} \mathrm{C}$ occurs at 15 years after emplacement. Thermal areal loadings of 30 and $40 \mathrm{~W} / \mathrm{m}^{2}$ had peak salt temperatures of $255^{\circ} \mathrm{C}$ and $310^{\circ} \mathrm{C}$ at 1 year and 0.5 years after emplacement, respectively. (The maximum salt temperature would be somewhat greater for these cases.) Limiting the thermal areal loading to $25 \mathrm{~W} / \mathrm{m}^{2}$ is not a severe restriction on repository design; however, this two-dimensional analysis is not conservative and a threedimensional analysis should be performed if emplacement mode 4 is selected for conceptual design.

Figure B-12 is a schematic diagram of the two-dimensional, planar model for a package lying in a trench, surrounded by crushed salt on one side. This model is identical to Figure B-14, except that the source zone for the waste package is located below the room floor.

Figure B-13 presents a time history of peak salt temperature for a thermal areal loading of $30 \mathrm{~W} / \mathrm{m}^{2}$ for a waste package surrounded by crushed salt on one side. The maximum salt temperature of $220^{\circ} \mathrm{C}$ occurs at 25 years after emplacement. A thermal loading of $30 \mathrm{~W} / \mathrm{m}^{2}$ is not a restriction on conceptual design, but, as before, the two-dimensional approach is not conservative.

\section{B.5 THERMAL ANALYSIS OF EMPLACEMENT IN A VERTICAL BOREHOLE WITH CRUSHED} SALT BACKFILL (MODE 1')

A series of calculations have been performed to predict the maximum salt temperature for a waste package that is emplaced in a vertical borehole with an 
annulus of crushed salt surrounding the package. These calculations were performed for PWR12, PWR9, and PWR6 spent fuel packages, with thermal areal loadings of 10,20 , and $30 \mathrm{~W} / \mathrm{m}^{2}$, and with annulus (gap) widths of 2,4 , and 6 inches.

The thermal analyses were performed with the computer program, DOT (INTERA, 1983). In general, these analyses are identical to the thermal analyses for emplacement in a vertical borehole, as reported in Subsection B. 1 . Figure B-14 is a schematic diagram of the two-dimensional, axisymmetric model for the calculations. The computational model represents the waste package as a homogenized region of spent fuel, surrounded by a carbon steel overpack. The stratigraphy for the Deaf Smith site is used. The material properties, and the mine layout for the calculations are presented in Section B.9.

The disposal room is assumed to be immediately backfilled with crushed salt at the time of emplacement. The location of the upper and lower boundaries of the computational model is far enough from the waste package to simulate an infinite medium in the vertical direction.

The maximum salt temperature is derived from these time-histories and is summarized in Figure B-15. Figure B-15 presents the maximum salt temperature as a function of gap size, package power level, and thermal areal loading. The results for no gap, based on the calculations in Subsection B. 1 are also included in Figure B-15.

The results in Figure B-15 show that the maximum salt temperature for a 6-inch annulus (gap) of crushed salt increases by $46^{\circ} \mathrm{C}$ to $135^{\circ} \mathrm{C}$ in comparison to the maximum salt temperature with no gap (depending on package heat load and areal heat loading). Similarly, the maximum salt temperature with a 2-inch annulus of crushed salt increases by $18^{\circ} \mathrm{C}$ to $52^{\circ} \mathrm{C}$ in comparison to the maximum salt temperature with no gap (depending on package heat load and areal heat loading). The thickness of the annulus of crushed salt surrounding the package has a major impact on maximum salt temperature, and may require a lower package power level or lower thermal areal loading to meet the thermal design criteria. 


\section{B.6 EXTRAPOLATION OF RESULTS TO OTHER EMPLACEMENT MODES}

The computational results of Subsections B.1 through B.5 form a basis for estimating the thermal response of the 17 emplacement modes that are considered in this study. The 17 alternate emplacement modes are identified in Table 3-5. A specific discussion for each of the emplacement modes follows.

The thermal response of Mode 1, vertical emplacement in a borehole in the room floor, is analyzed in Subsection B.1. There is one potential variation on this basic mode: the use of a sleeved borehole (Mode 1A). A sleeved borehole should have lower values of maximum salt temperature than an unsleeved borehole because the additional metal will assist in conducting the heat away from the hottest location, the mid-height of the package. The calculations for an unlined borehole are therefore conservative for Mode $1 \mathrm{~A}$.

The thermal response of Mode 2, vertical emplacement in a slot in the room pillar, will be quite similar to the thermal response of Mode 3B. If the presence of drifts and stratigraphy is ignored, the maximum salt temperatures for Modes $3 \mathrm{~B}$ and 2 are almost identical because the package layouts will be almost identical for the same areal loading and package power level. Since the waste package is almost surrounded by intact salt and since the stratigraphy has little influence on thermal response (see Subsection B.4) the maximum salt temperatures for Modes 1 and 2 will be approximately the same.

The thermal response of Mode 3B, horizontal emplacement in a slot at pillar mid-height, is analyzed in Subsection B.2. The thermal response of Mode 3 , a horizontal slot at the base of the pillar, should be almost identical to the response of Mode 3B. The thermal response of Mode $3 C$, a cantilevered stub drift off the main drift, will be similar to Mode 3B; if the stub is filled with crushed salt after emplacement, the peak salt temperature will be increased, although this is probably not a major effect. The thermal response of Mode $3 \mathrm{~A}$, a shallow slot at pillar mid-height, will be similar to the calculation in Subsection B.4 for a package in a shallow trench. 
The thermal response of Mode 4, horizontal emplacement at the corner of the drift floor, is analyzed in Subsection B.4 The thermal response of Mode 5 , horizontal emplacement cross-wise on the drift floor, will be similar to Mode 4; however, this mode has the package surrounded by crushed salt on 3 sides, rather than on 2 sides. The maximum salt temperature will therefore be greater for Mode 5 than Mode 4, all other factors being equal. This difference may be substantial.

The thermal response of Mode 6, horizontal emplacement in a deep trench in the floor, should be similar to Mode 3B, horizontal emplacement in the pillar, because the analytic solution ignores the presence of the rooms and because the layout of packages will be similar for Modes 6 and 3B. The thermal response of Modes $6 \mathrm{~A}, 6 \mathrm{~B}$, and $6 \mathrm{C}$, horizontal emplacement in shallow trenches, will be similar to the trench calculation in Subsection B.4.

The thermal response of Mode 7A, horizontal emplacement in an unsleeved borehole in the pillar, will be almost identical to Mode 1, vertical emplacement in the floor. The thermal response of Mode 7 , the sleeved horizontal borehole, should have lower values of the maximum salt temperature than an unsleeved borehole because the additional metal will assist in conducting the heat away from the hottest location, the mid-height of the package. The calculations for the unlined borehole, Mode 1, are therefore conservative compared with Mode $1 \mathrm{~A}$, vertical borehole with sleeve.

The thermal response of Mode $8 \mathrm{~A}$, emplacement in long, unlined horizontal boreholes, is evaluated in Subsection B.3. These calculations are conservative for the lined borehole, Mode 8 , as discussed above for the comparison of Mode 7 to 7A.

Finally, most emplacement modes can incorporate a layer of crushed salt backfill around the waste package as necessary for design purposes. The thermal response with an annulus of crushed salt is analyzed in Subsection B.5 for emplacement in a vertical borehole. A reasonable approach for extrapolating the results for vertical emplacement to the other emplacement modes is to assume that the observed temperature increase from the layer of crushed salt will be valid for all emplacement modes. 
B.7 SUMMARY OF THE IMPACT OF MAXIMUM SALT TEMPERATURE ON EMPLACEMENT MODE

These computational results show that, with an appropriate choice of thermal areal loading and package power level, any of the 17 emplacement modes can satisfy the functional design criterion which limits the salt temperature to $250^{\circ} \mathrm{C}$. The modes which emplace a waste package in intact salt present little restriction on thermal areal loading or package power level. The modes which surround a waste package with crushed salt backfill may have a severe restriction on maximum areal loading or the package power level.

\section{B.8 THERMAL RESPONSE IN THE ROOM AND PILLAR REGION}

A series of calculations has been performed to predict the thermal response in the room and pillar region at 50 to 70 years after emplacement of nuclear waste. The thermal response in the room and pillar region is particularly important during remining and retrieval operations because the near field temperatures impact room closure rates, roof support needs, and mine ventilation requirements.

The temperature field in the room and pillar region is a function of thermal areal loading, emplacement mode, thermal conductivity of salt, and local stratigraphy. Based on previous experience with thermal analyses, the temperature field at late times is expected to be a strong function of the thermal areal loading but only a weak function of the other factors. Nonetheless, calculations have been performed with three values of thermal areal loading and with one alternate stratigraphy.

Calculations have also been performed with three representative emplacement modes. These modes are: emplacement in a vertical borehole in the room floor, emplacement in a horizontal slot in the room pillar, and emplacement of a group of packages in a long horizontal borehole in the room pillar. These emplacement modes are representative of the geometric configurations for the 17 emplacement modes and hence should bound the effect of emplacement mode on late time thermal response. In fact, the computational results show that the temperature fields at 50 to 70 years from these three emplacement modes are quite similar. 
The specific series of calculations that has been performed to predict the temperature field in the room and pillar region are as follows:

1. Two-dimensional thermal analyses of vertical emplacement in the room floor with the DOT program;

2. Two-dimensional thermal analyses of horizontal emplacement in a slot in the room pillar with the DOT program. These analyses included a calculation with an alternate stratigraphy.

3. Three-dimensional thermal analyses of horizontal emplacement in a long borehole in the room pillar with an analytic model;

4. Two-dimensional thermal analyses of horizontal emplacement in a long borehole in the room pillar with the DOT program;

The analyses of the long horizontal borehole were performed with a threedimensional analytic model to predict accurate temperature-time histories and again with a two-dimensional computer program to generate temperature contours in the near field of the emplaced waste package.

\section{B.8.1 Vertical Emplacement in the Room Floor and Horizontal Emplacement in the Room Pillar Slot}

The objective of these calculations is to predict the temperature field in the room and pillar region from a waste package emplaced in a vertical borehole in room floor or in a horizontal slot in the room pillar. These calculations were performed for three values of the thermal areal loading and with two expressions for the thermal conductivity of salt.

For each emplacement mode, the thermal response is evaluated for thermal areal loadings of 10,20 , and $30 \mathrm{~W} / \mathrm{m}^{2}$. The value of $30 \mathrm{~W} / \mathrm{m}^{2}$ is a high value that is based on the areal loading of commercial high-level waste in the Stearns-Roger design (Stearns-Roger, 1983). The value of $20 \mathrm{~W} / \mathrm{m}^{2}$ is an average design value. 
Calculations have been performed with an average value for the thermal conductivity of salt. The thermal conductivity of salt is temperature dependent, so the average value is defined by the quadratic function of temperature in RSI-0204 (RE/SPEC, 1984).

The thermal analyses are performed with the DOT computer program (INTERA, 1983). Figure B-16 is a schematic diagram of the two-dimensional, planar, room scale models for the vertical and the horizontal emplacement modes. These computational models do not simulate the detailed geometry of an individual waste package; rather, the waste packages in a room are averaged into a rectangular, two-dimensional thermal source whose power output is equivalent to one package per package pitch. The temperatures in the room and pillar region, except at locations near the waste packages, should not be significantly affected by this two-dimensional representation of the waste packages.

The stratigraphy for the Deaf Smith site, the material properties, the mine layout, and the power decay characteristic for spent fuel are presented in Section B.9. The initial ambient temperature of the rock mass is assumed to be $30^{\circ} \mathrm{C}$.

The disposal room is assumed to be backfilled with crushed salt at the time of emplacement. This assumption is conservative for two reasons. First, the thermal conductivity of crushed salt is much lower than intact salt, and backfilling with a low conductivity material will tend to increase the salt temperature in the pillar region. Second, there is no ventilation to cool the room walls.

The upper and lower boundaries of both models are adiabatic and are located at $260 \mathrm{~m}$ from the disposal room floor. These boundaries are far enough from the waste package to simulate an infinite medium in the vertical direction.

The right and left boundaries of the vertical emplacement model are the centerlines of the pillar and of the room, respectively. These boundaries are adiabatic because they are planes of symmetry. The right and left boundaries of the horizontal emplacement model are the centerlines of two adjacent 
pillars. These boundaries are assumed to be adiabatic. This assumption is valid if the centerlines of the pillars are planes of symmetry, which is true only if the waste packages are emplaced on alternate (right-hand and left-hand) sides of adjacent drifts. Emplacement on alternate sides of adjacent drifts will generate higher temperatures in the emplacement pillar than will emplacement always on the right side or always on the left side of the drifts. Therefore, the assumption of adiabatic boundaries at the centerlines of two adjacent pillars is conservative for pillar temperature.

The temperature contours for the vertical and the horizontal emplacement modes are presented in Figures $B-17$ and $B-18$, respectively. These calculations assume a thermal areal loading of $20 \mathrm{~W} / \mathrm{m}^{2}$ and the average conductivity for salt. Figures B-19 through B-24 contain a complete set of temperature time-histories and temperature contours from this series of calculations.

Tables B-4 and B-5 summarize the room and pillar temperatures at 50 years after emplacement for the vertical and the horizontal emplacement modes, respectively. For the horizontal emplacement mode, the average room temperature is 68,109 , and $153^{\circ} \mathrm{C}$ at 10,20 , and $30 \mathrm{~W} / \mathrm{m}^{2}$, respectively, assuming the average value for thermal conductivity. These average room temperatures are $1-3^{\circ} \mathrm{C}$ higher than those for the vertical emplacement mode. This minor difference is not considered significant. As an alternate comparison, the pillar centerline temperatures at the midheight of a room are 5 to $20^{\circ} \mathrm{C}$ higher for the horizontal emplacement mode than for the vertical emplacement mode. Finally, the room and pillar temperatures are $2-4^{\circ} \mathrm{C}, 4-8^{\circ} \mathrm{C}$, and $8-13^{\circ} \mathrm{C}$ higher at 10,20 , and $30 \mathrm{~W} / \mathrm{m}^{2}$, respectively, for the lower bound thermal conductivity than for the average thermal conductivity of salt. These results show that the average temperatures at 50 years are insensitive to vertical or horizontal emplacement or to the thermal conductivity of salt since these differences are within the accuracy band of the model used for the calculations.

\section{B.8.2 Temperature-Time Histories for Emplacement in a Long Horizontal Borehole in the Room Pillar}

A series of calculations has been performed to predict temperature-time histories in the room and pillar region for waste packages that are emplaced in 
Table B-4. Temperatures at 50 Years for Vertical Emplacement in a Borehole in Room Floor

\begin{tabular}{lcccc}
\hline $\begin{array}{l}\text { Thermal } \\
\text { Loading } \\
\left(\mathrm{W} / \mathrm{m}^{2}\right)\end{array}$ & $\begin{array}{c}\text { Room } \\
\text { Ceiling } \\
\left({ }^{\circ} \mathrm{C}\right)\end{array}$ & $\begin{array}{c}\text { Room } \\
\text { Center } \\
\left({ }^{\circ} \mathrm{C}\right)\end{array}$ & $\begin{array}{l}\text { Room } \\
\text { Floor } \\
\left({ }^{\circ} \mathrm{C}\right)\end{array}$ & $\begin{array}{c}\text { Pillar } \\
\text { Centerline } \\
\left({ }^{\circ} \mathrm{C}\right)\end{array}$ \\
\hline 10 & 64 & 68 & 73 & 66 \\
20 & 99 & 107 & 119 & 104 \\
30 & 136 & 149 & 169 & 143 \\
\hline
\end{tabular}


Table B-5. Temperatures at 50 Years for Horizontal Emplacement in a Pillar Slot

\begin{tabular}{lcccc}
\hline $\begin{array}{l}\text { Thermal } \\
\text { Loading } \\
\left(\mathrm{W} / \mathrm{m}^{2}\right)\end{array}$ & $\begin{array}{c}\text { Room } \\
\text { Ceiling } \\
\left({ }^{\circ} \mathrm{C}\right)\end{array}$ & $\begin{array}{c}\text { Room } \\
\text { Center } \\
\left({ }^{\circ} \mathrm{C}\right)\end{array}$ & $\begin{array}{l}\text { Room } \\
\text { Floor } \\
\left({ }^{\circ} \mathrm{C}\right)\end{array}$ & $\begin{array}{c}\text { Pillar } \\
\text { Centerline } \\
\left({ }^{\circ} \mathrm{C}\right)\end{array}$ \\
\hline 10 & 67 & 69 & 69 & 70 \\
20 & 107 & 110 & 111 & 114 \\
30 & 149 & 154 & 156 & 160 \\
\hline
\end{tabular}


a 220-ft long borehole. These calculations were performed for three package power levels, three values of the thermal areal loading, and with the average value and lower bound for thermal conductivity.

The emplacement mode investigated here assumes that the waste packages are emplaced in a 220-foot horizontal borehole in the pillar. The room width and the room spacing are assumed to be 20 and $240 \mathrm{ft}$, respectively. Either 13 PWR6 packages, 10 PWR9 packages, or 7 PWR12 packages are emplaced in a borehole. The PWR6 packages are packed end-to-end, with a standoff distance of one package length from each drift. The PWR9 and PWR12 packages are uniformly spaced within each borehole, except for the standoff distance of one package length. The "density" of the PWR9 and PWR12 packages was reduced because preliminary calculations (not reported here) showed that packing PWR9 or PWR12 packages end to end exceeded the maximum allowable salt temperature of $250^{\circ} \mathrm{C}$.

A three-dimensional analytic model is used to determine the temperaturetime histories at eight locations in the room and pillar region. The analytic model is identical to the model in Section B-3 for determining the maximum salt temperature for this emplacement mode. These eight locations are points $A, B$, $C, D, P, Q, R$, and $S$ in Figure $B-25$.

The temperature-time histories at the 8 locations are presented in Figures B-26 through B-29. Table B-6 summarizes the room and pillar temperatures at 50 years after emplacement. These results show that the room and pillar temperatures are directly affected by the areal thermal loading and are slightly affected by the package power level. The temperature variations between package loading at specific areal thermal loadings are less than $8^{\circ} \mathrm{C}$ at the drift floor and less than $14^{\circ} \mathrm{C}$ at the pillar centerline. Comparing the average room-floor temperatures and the average pillar-centerline temperatures to those calculated by the two-dimensional DOT mode, the differences are less than $8^{\circ} \mathrm{C}$. Considering the differences of the two models, these temperature differences are negligible. 
Table B-6. Room and Pillar Temperatures at 50 Years After Emplacement for the Long Horizontal Borehole

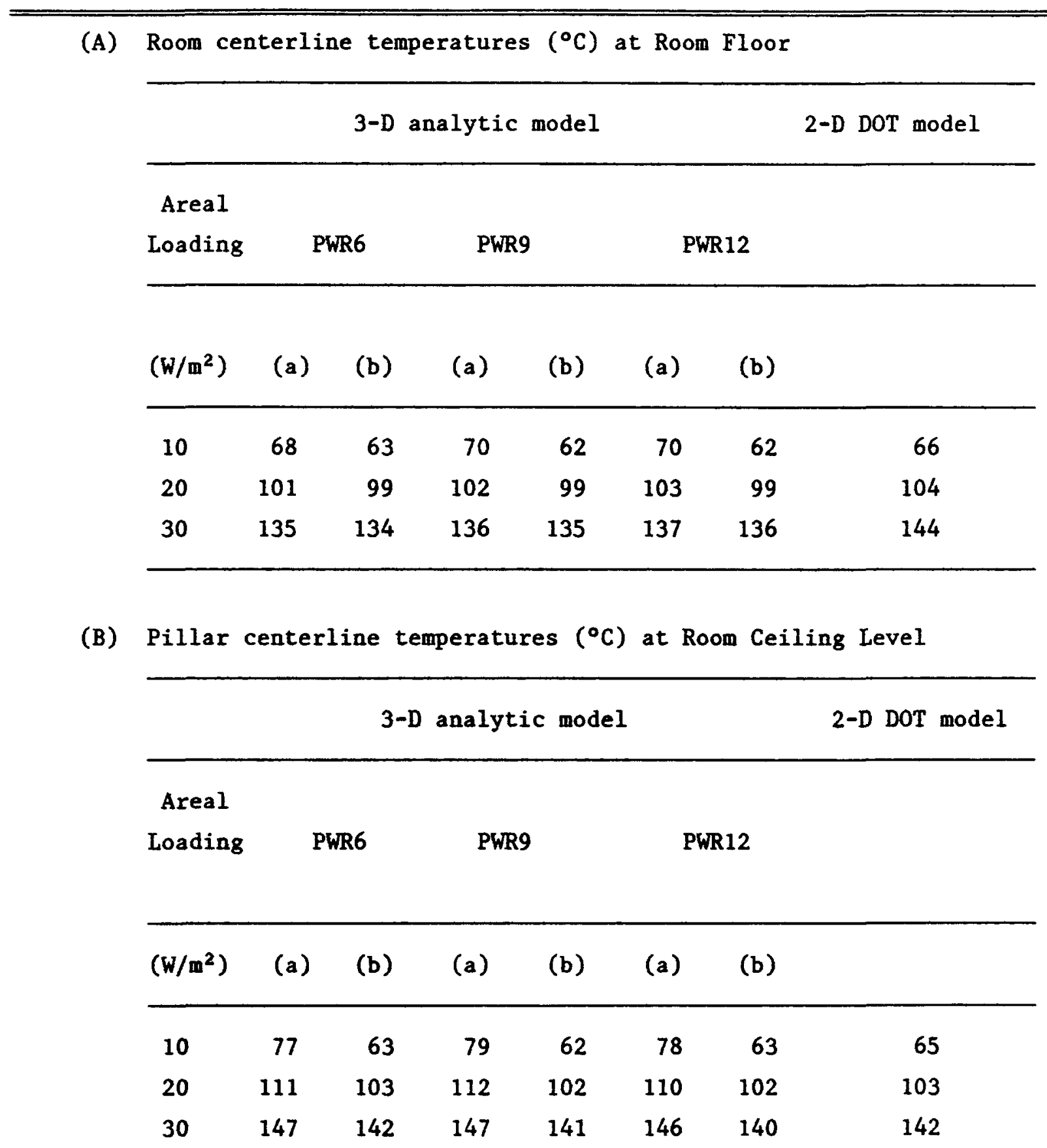

(a) at the vertical plane through the borehole

(b) at the vertical plane midway between two adjacent boreholes 


\section{B.8.3 Temperature Contours for Emplacement in a Long Horizontal Borehole in the Room Pillar}

The objective of these calculations is to obtain temperature contours in the room and pillar region for waste packages that are horizontally emplaced in a 220-foot long borehole in room pillar. The temperature field in the room and pillar region is calculated for thermal areal loadings of 10,20 , and $30 \mathrm{~W} / \mathrm{m}^{2}$ with the average in-situ thermal conductivity of salt. The output from each calculation is presented as temperature contours in the room and pillar region at $10,30,50$, and 70 years after emplacement.

A two-dimensional planar model is used to determine the temperatures in the room and pillar region. The temperature calculations are performed with the DOT computer program (INTERA, 1983). Figure B-30 presents a schematic diagram of the model. The stratigraphy, material properties, and mine layout are presented in Section B.9. The initial temperature is $30^{\circ} \mathrm{C}$.

The individual packages in a borehole are averaged into a rectangular, two-dimensional heat-source with a heat generation equivalent to the package power per borehole pitch. This two-dimensional approximation is a reasonable one because the time-histories in Subsection B.8.2 show that the temperature variation along the drift is minor. This model is then expected to be accurate, except for temperatures very close to the borehole.

The disposal room is assumed to be backfilled with crushed salt at the time of emplacement. This assumption is conservative because the thermal conductivity of crushed salt is much lower than intact salt, so the backfilling assumption will increase the salt temperature near each package.

The upper and lower boundaries of the model are adiabatic and are located at $260 \mathrm{~m}$ from the disposal room floor. These boundaries are far enough from the waste package to simulate an infinite medium in the vertical direction. The right boundary of the model is the centerline of the pillar, and the left boundary of the model is the centerline of the room. These boundaries are adiabatic because they are planes of symmetry. 
The temperature contours in the room and pillar region are presented in Figures B-31 through B-34. These results show that the average room temperatures at 50 years after emplacement are 66,104 , and $143^{\circ} \mathrm{C}$ for thermal areal loadings of 10,20 , and $30 \mathrm{~W} / \mathrm{m}^{2}$, respectively. These results can be compared to the average room temperatures for horizontal emplacement in a room slot: 68,109 , and $153^{\circ} \mathrm{C}$ for areal loadings of 10,20 , and $30 \mathrm{~W} / \mathrm{m}^{2}$. Again, emplacement mode has only a minor influence on late time temperatures.

Finally, the temperature differences between the two-dimensional model and the three-dimensional model are less than $8^{\circ} \mathrm{C}$ for the average room-floor temperatures and the average pillar-centerline temperatures. This temperature difference is very minor, considering the differences between these models. This result again indicates the insensitivity of the late time temperature response.

\section{B.8.4 Effect of an Alternate Stratigraphy on Thermal Response}

The computational models for the DOT analyses are based on a stratigraphy that is derived from the Detten No. 1 Well (Stone and Webster, 1984) at the Deaf Smith site. This stratigraphy is consistent with the computational models for previous thermal studies (RE/SPEC, 1984). However, since the performance of these studies, the J. Friemel No. 1 Well was drilled considerably closer to the proposed site, and it is therefore appropriate to consider the impact of the alternate stratigraphy on the thermal response.

The impact of the alternate stratigraphy has been evaluated by recomputing the thermal response for horizontal emplacement at $20 \mathrm{~W} / \mathrm{m}^{2}$ with the stratigraphy from the J. Friemel No. 1 Well (Stone and Webster, 1984) and with the floor of the repository $40 \mathrm{ft}$ below the top of the Lower San Andres Unit 4. This location corresponds to a repository depth of $2550 \mathrm{ft}$. This alternate stratigraphy is described in Section B.9.

As in Subsection B.8.1, the temperatures in the room and pillar region are evaluated with the DOT computer program using a two-dimensional, planar model. 
Figure B-35 is a schematic diagram of the model and alternate stratigraphy. The initial and boundary conditions for the model are identical to those in Subsection B.8.1.

Figure B-36 compares the temperature contours at 50 years from the corresponding calculations with the Detten and Friemel stratigraphies. The results show that the temperature differences are less than $2^{\circ} \mathrm{C}$ at 50 years. As expected, temperatures at the time they peak in the near-field (room and pillar region), are insensitive to minor changes in the stratigraphy.

\section{B.9 STRATIGRAPHY, MATERIAL PROPERTIES, AND MINE LAYOUT}

This subsection describes the stratigraphy, the material properties, and the mine layout that are the basis for the computational models in this Appendix.

The reference stratigraphy is based on the stratigraphic data from the Detten No. 1 Well. The raw stratigraphic data is not used in the computational models because modeling all the minor beds in a stratigraphy is unnecessary and uneconomical. Instead, the minor beds are lumped into major formations for computational simplicity. In the case of the Detten data, (RE/SPEC, 1984) had already created a lumped model for thermal analyses, and this model was adopted for this study. This model assumes that the material above the top of Lower San Andres 5 or below the top of Lower San Andres 3 is non-salt. This assumption is conservative (produces higher temperature) because the thermal conductivity of the non-salt material is lower than that of salt.

The alternate stratigraphy is based on the stratigraphic data from the J. Friemel No. 1 Well (Stone and Webster, 1984). The material above the top of the Upper San Andres or below the top of the Upper Clear Fork formation is again assumed to be non-salt. As before, this assumption is conservative. 
The depth of the repository for the Detten stratigraphy is $2575 \mathrm{ft}$ $(784.8 \mathrm{~m}$ ) (DOE, 1984). The floor of the repository for the J. Friemel stratigraphy is assumed to be $40 \mathrm{ft}$ below the top of lower San Andres Unit 4. The depth to the top of Unit 4 at the center of the proposed site is estimated to be $2510 \mathrm{ft}$ (see Figure 3-2a of BMI/ONWI-531, Vol. 1, ONWI, 1984). The depth to the floor of the repository is therefore $2550 \mathrm{ft}$ for the $J$. Friemel stratigraphy.

Five types of materials are considered in this investigation: salt, crushed salt, non-salt, carbon steel, and spent fuel. Non-salt layers are composed mainly of anhydrite and shale. The thermal properties of these materials, including the lower bound thermal conductivity of salt, are defined in Table B-1. The data in this table are based on the properties for the previous thermal studies (RE/SPEC, 1984), except that the lower bound thermal conductivity of salt is based on laboratory measurements reported in the Deaf Smith EA (DOE, 1984).

All waste packages are assumed to contain spent fuel that is ten years out of reactor at the time of emplacement. The normalized power decay characteristic for this fuel is defined in Table B-2. The data in this table are taken from the previous thermal studies.

For purposes of the thermal calculations, the repository layout is based on a preliminary design (see Figure 2-1) that is consistent with the gassy mine regulations ( $30 \mathrm{CFR} 57.21000$ ). This repository layout has a room width of 20 ft $(6.1 \mathrm{~m})$, an extraction ratio of 36 percent, and a crosscut spacing of $100 \mathrm{ft}$ $(30.48 \mathrm{~m})$. The repository layout for long horizontal borehole emplacement would be different. The room heights for vertical and horizontal emplacement are assumed to be $24 \mathrm{ft}$ and $15 \mathrm{ft}$ respectively. 
Figure B-1. Two-Dimensional Axisymmetric Model for Calculating Peak Salt Temperature for Emplacement in a Vertical Borehole.

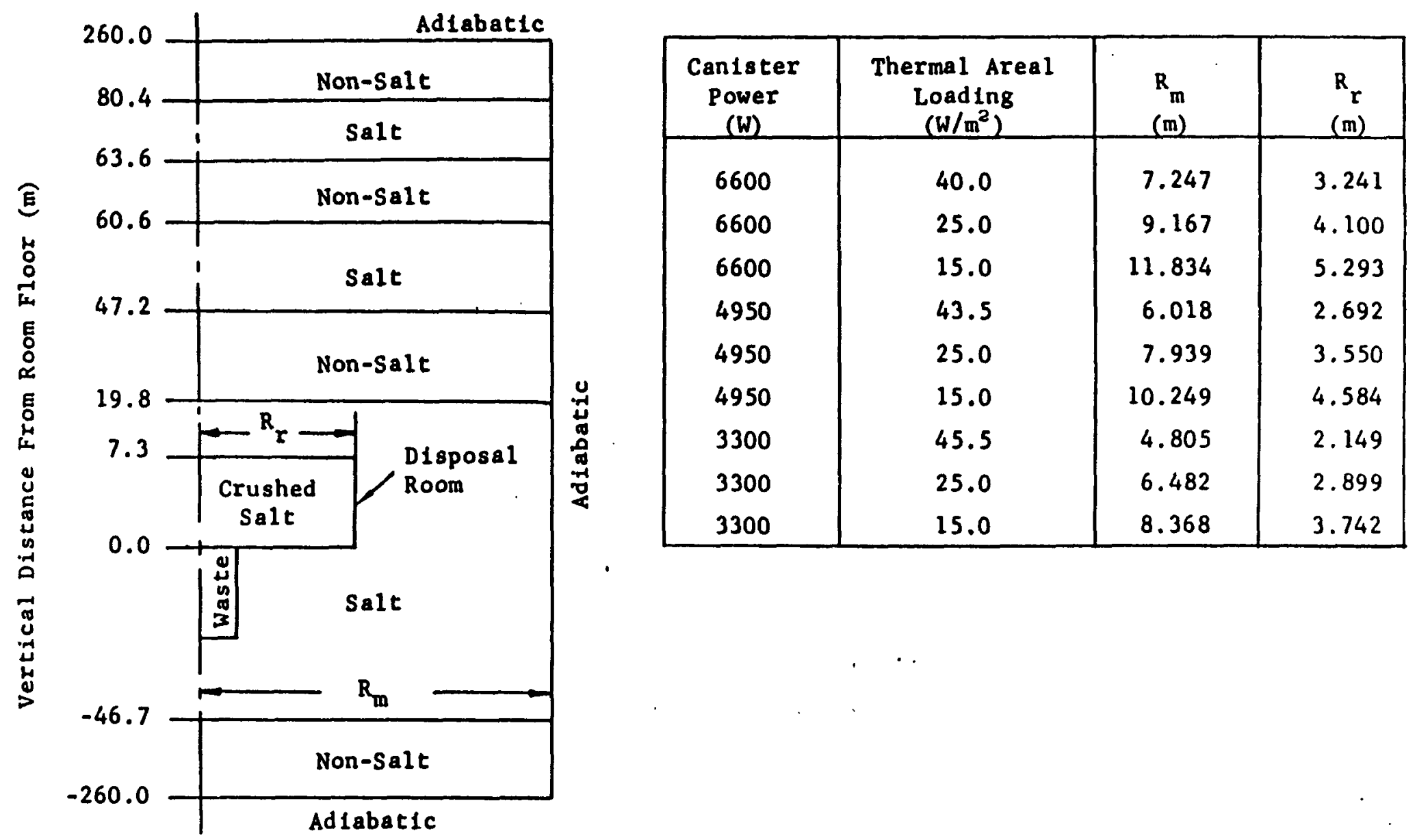




\section{Figure B-2 Peak Salt Temperature for Emplacement in a Vertical Borehole}

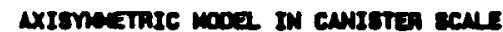
gert rud ompir 1000 in

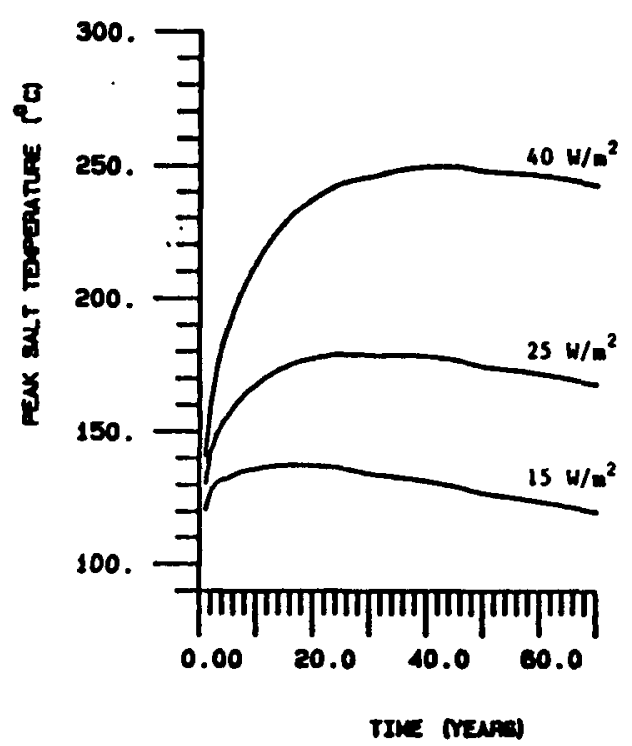

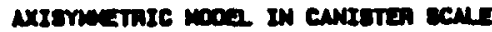
erort rut prota 4600 in

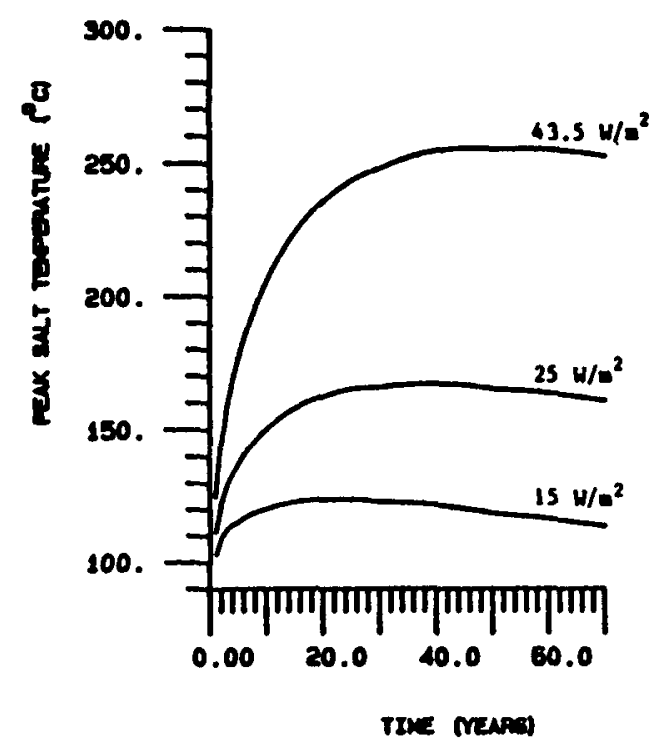

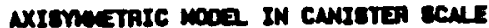
eper rua pune 3500 in

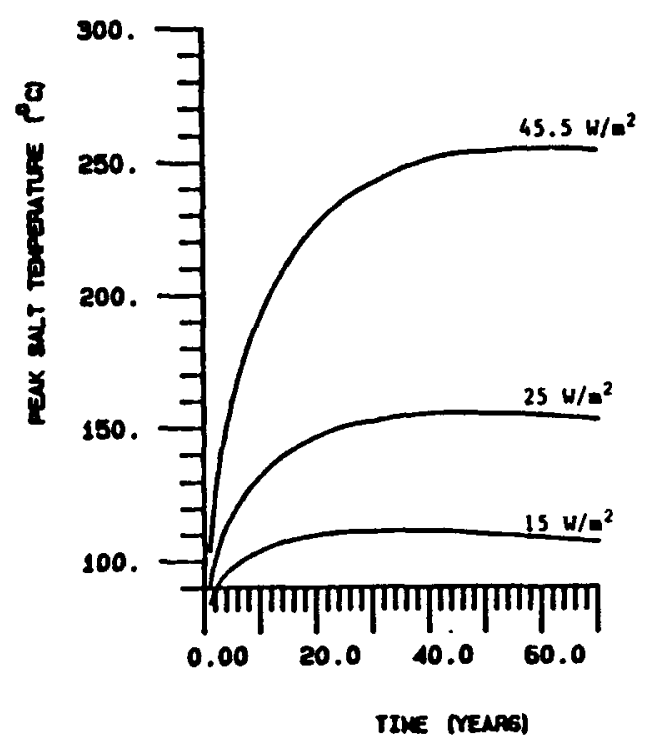


Figure B-3. Maximum Salt Temperature as a Function of Canister Spacing and Thermal Areal Loading for Emplacement in a Vertical Borehole

AXISYMETAIC MOOZI IN CANISTER SCNLE

spent fule (Pini-12, Pina-g, Pup-6)

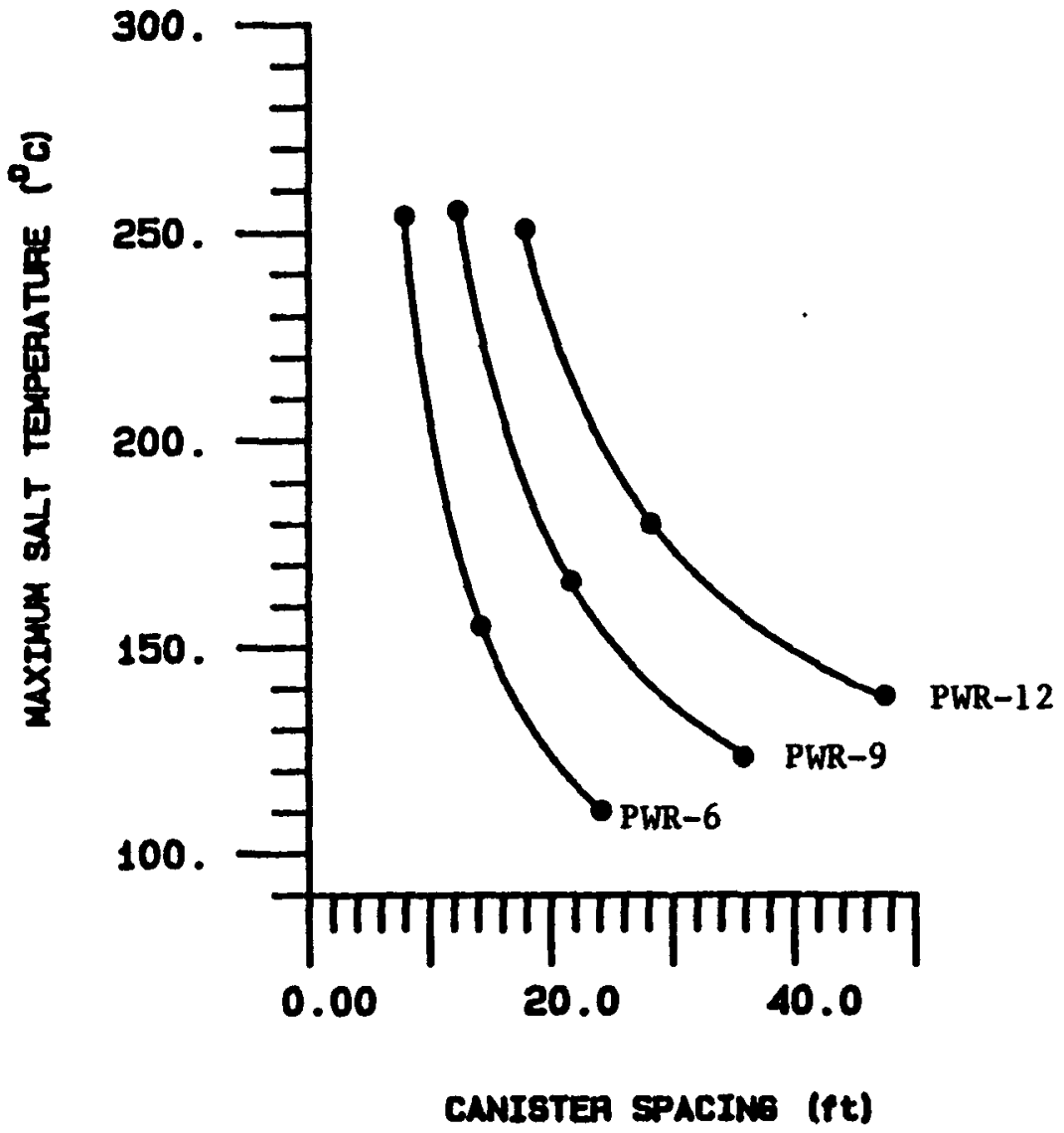

AXISYMETAIC MODZL IN CANISTEA SCALE

spent fü (PIA-12, Pin-8, PuA-6)

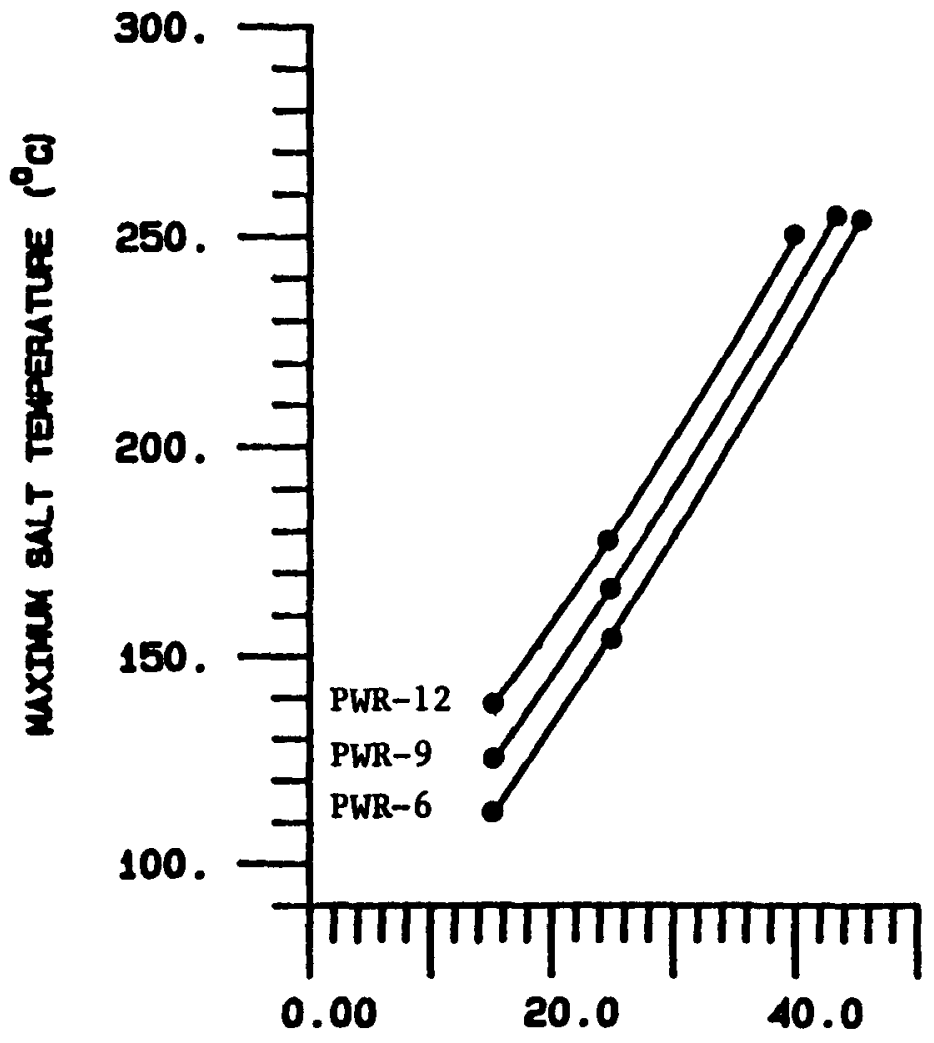

THERWAL AFEAL LOADINB $\left(W / \mathrm{m}^{2}\right)$ 
Figure B-4. Peak Salt Temperature for Emplacement in a Horizontal Slot

$3 \rightarrow$ NuLrtic Moda for spert fun

PUPS (10. IS and 24.2 w/ol

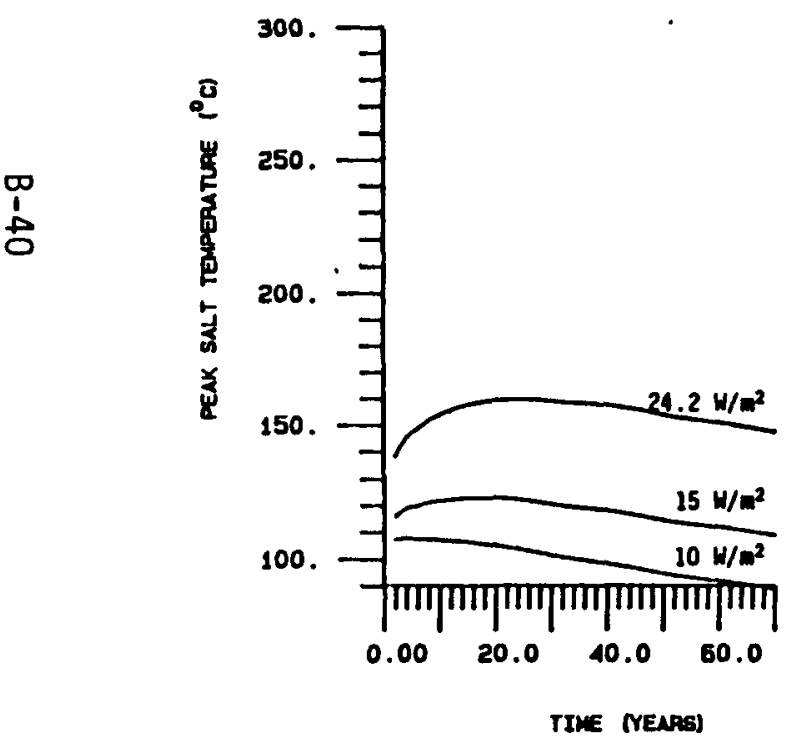

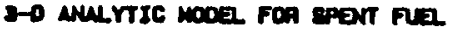

Pupo 1LE an and se.3 W/o?

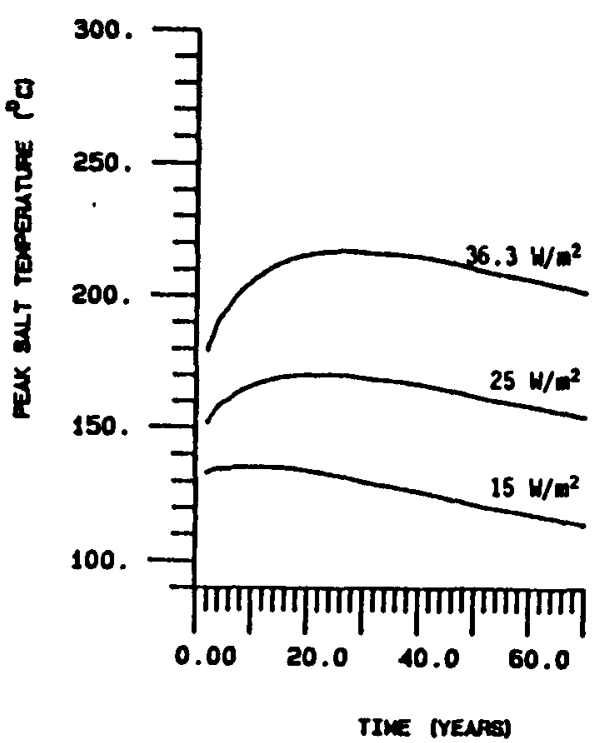

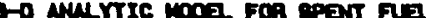

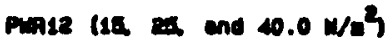

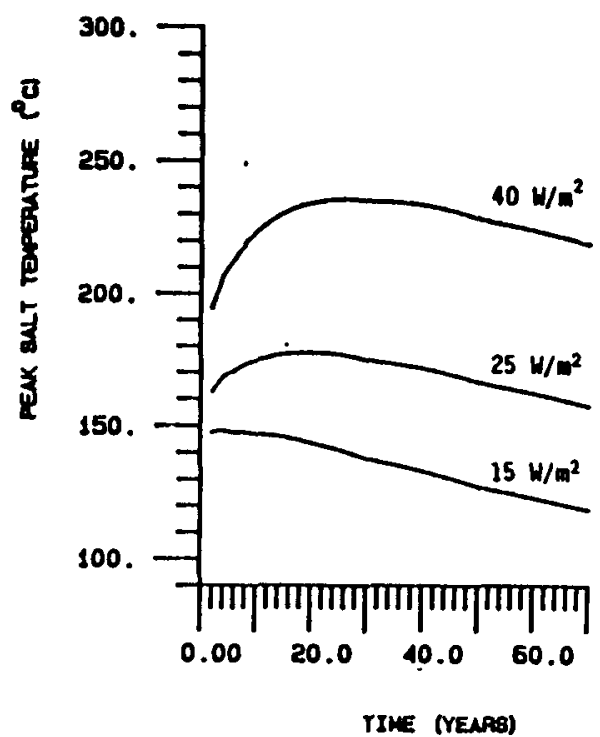


Figure B-5. Maximum Salt Temperature as a Function of Canister Spacing and Thermal Areal Loading for Emplacement in a Horizontal Slot

3-D ANALYTIC MODEL FOR SPENT FUEL

PWRG, PWR9, and PWR12

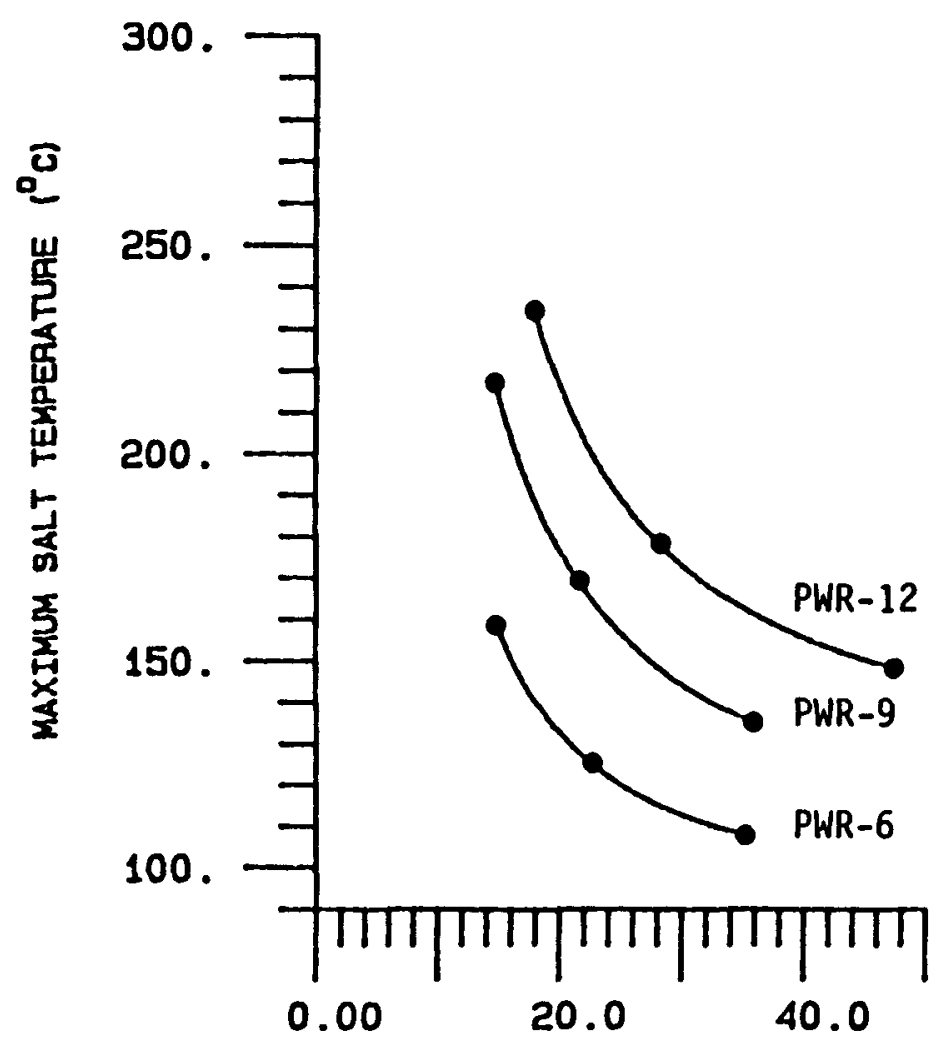

CANISTER SPACING (ft)
3-D ANALYTIC MODEL FOR SPENT FUEL

PWR6, PWR9, and PWR12

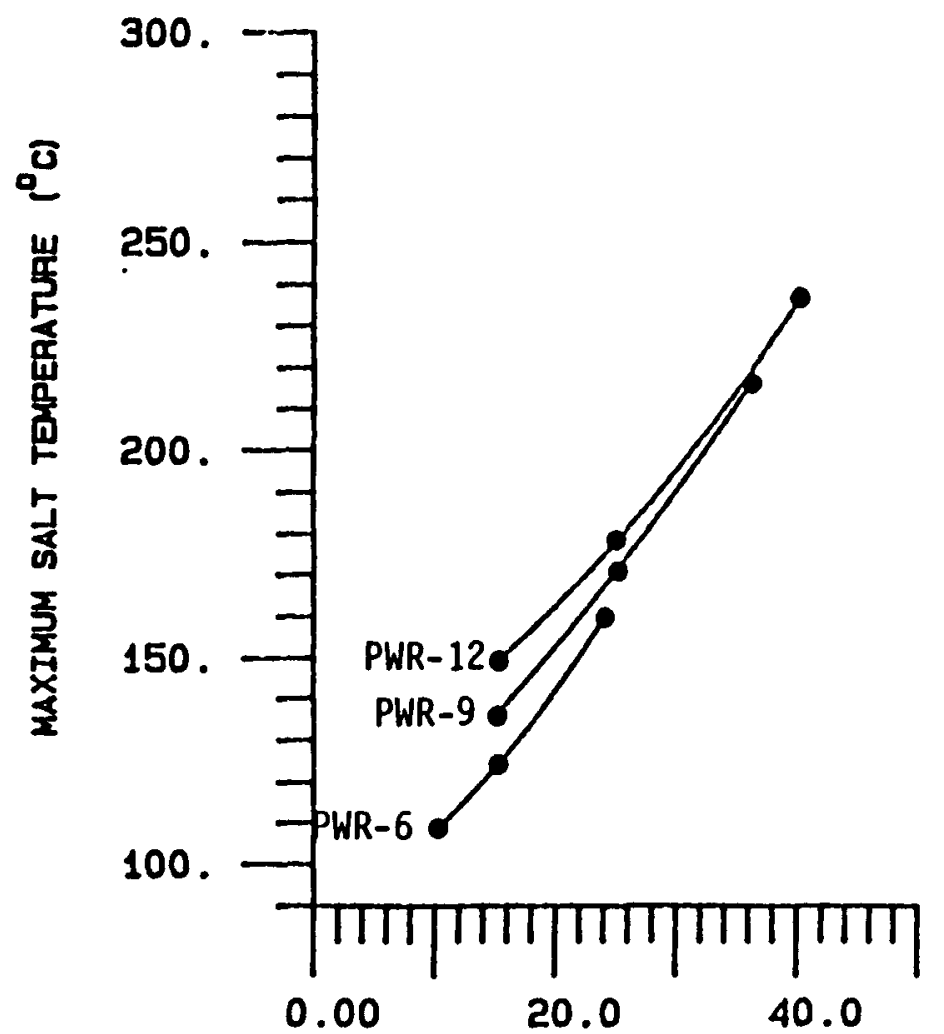

THEAMAL AREAL LOADING $\left(\mathrm{W} / \mathrm{m}^{2}\right)$ 
Figure B-6. Peak Salt Temperature for Emplacement in a Long Horizontal Borehole

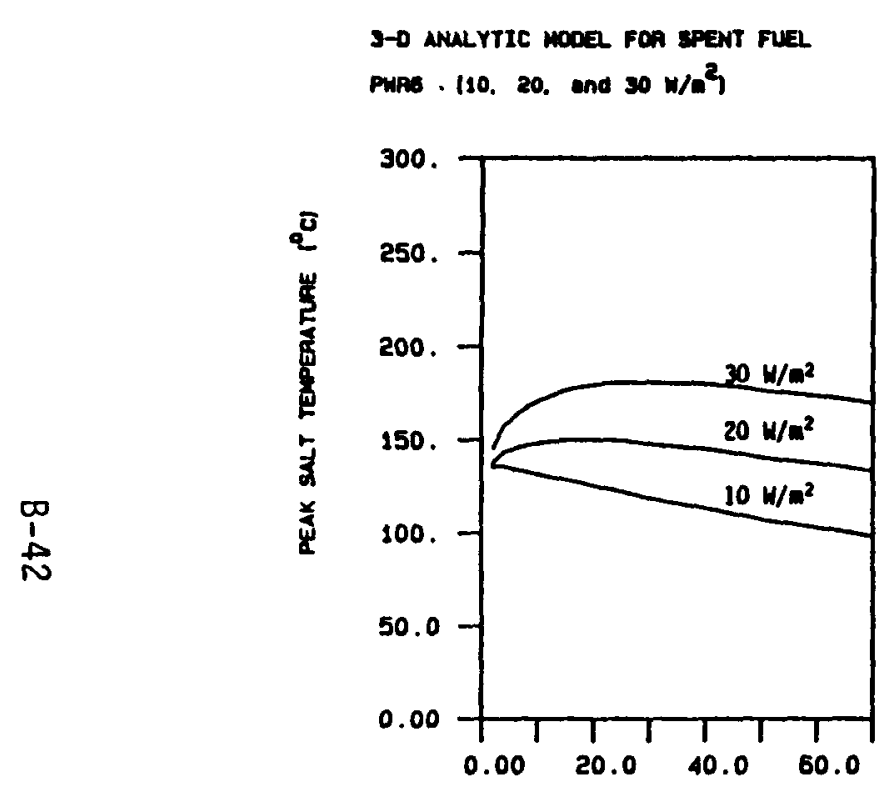

TIME (YEARS)

\section{3-0 MULYTIC MODEL FOA SPENT FUEL}

PuAs (20. 20. and $30 \mathrm{~m} / \mathrm{m}^{2}$ )

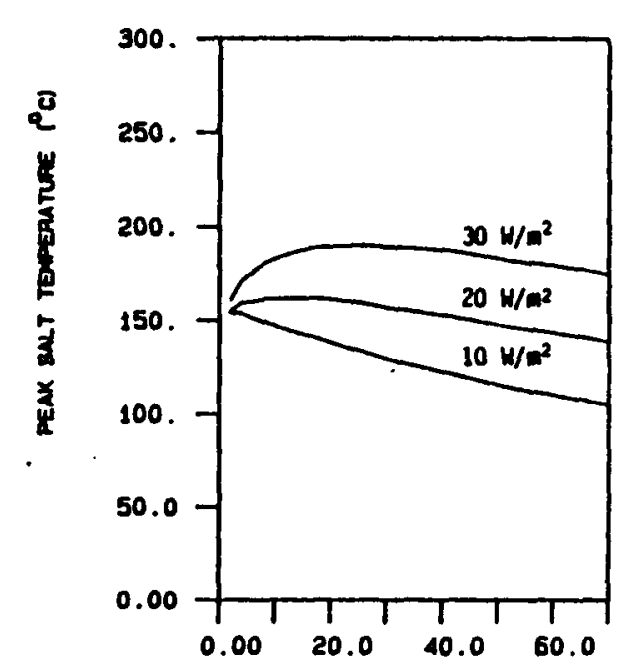

TIME (YEARS)
3-D ANULYTIC MOOEL FDA SPENT FUEL Pup1e (10. 20. and $30 \mathrm{~m} / \mathrm{m}^{2}$ )

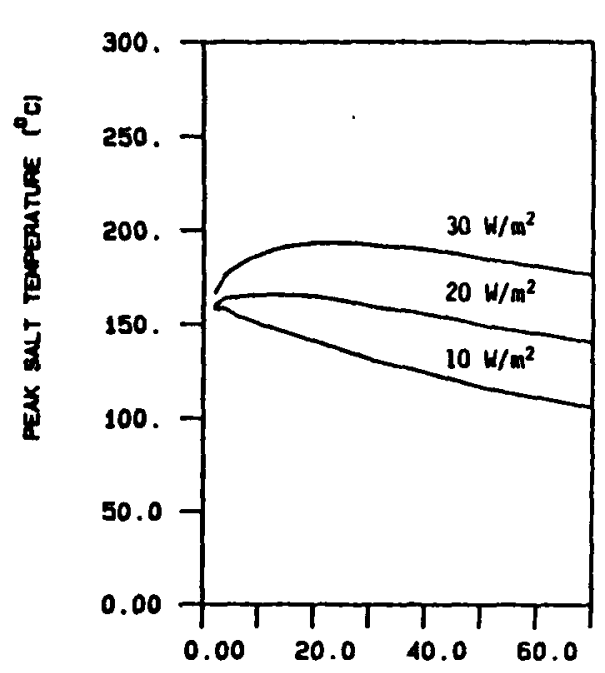

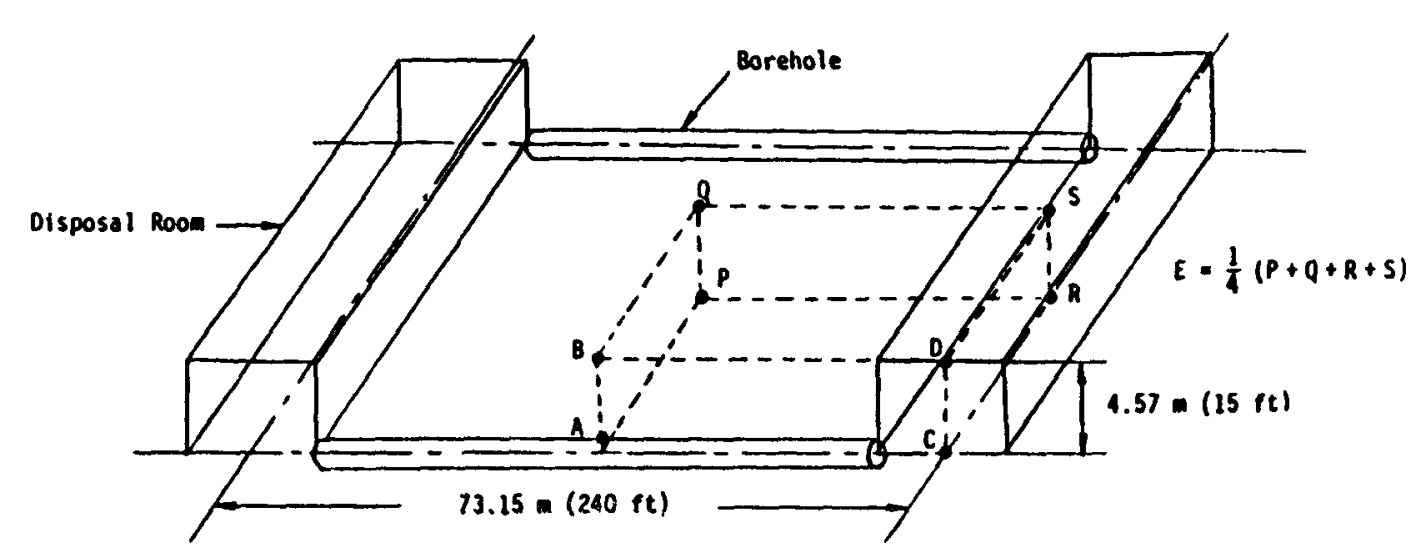

TIME (YEARS) 
Figure B-7. Maximum Salt Temperature as a Function of Borehole Spacing and Thermal Areal Loading for Emplacement in a Long Horizontal Borehole

3-D ANALYTIC MODEL FOA SPENT FUEL

PWR6, PWR9, and PWA12

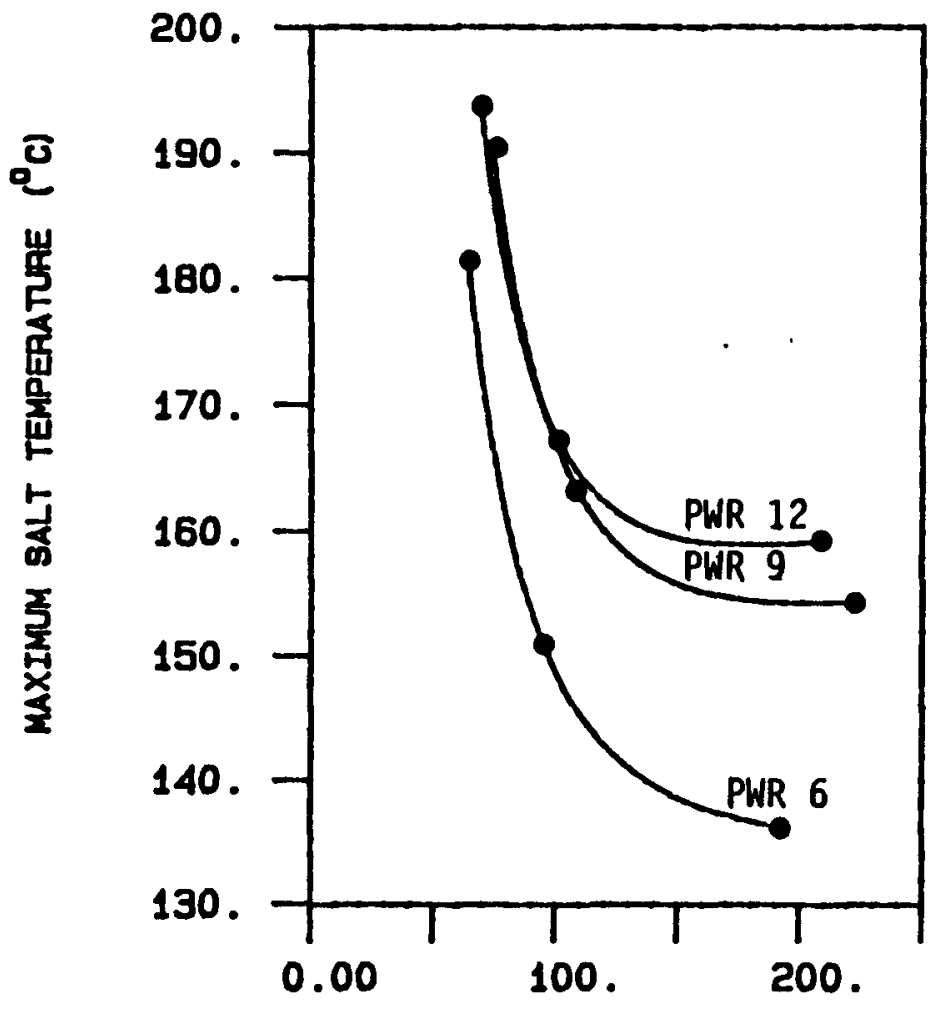

BOREHOLE SPACINB (ft)
3-D ANALYTIC MODEL FOR SPENT FUEL

PWR6, PWR9, and PWA12

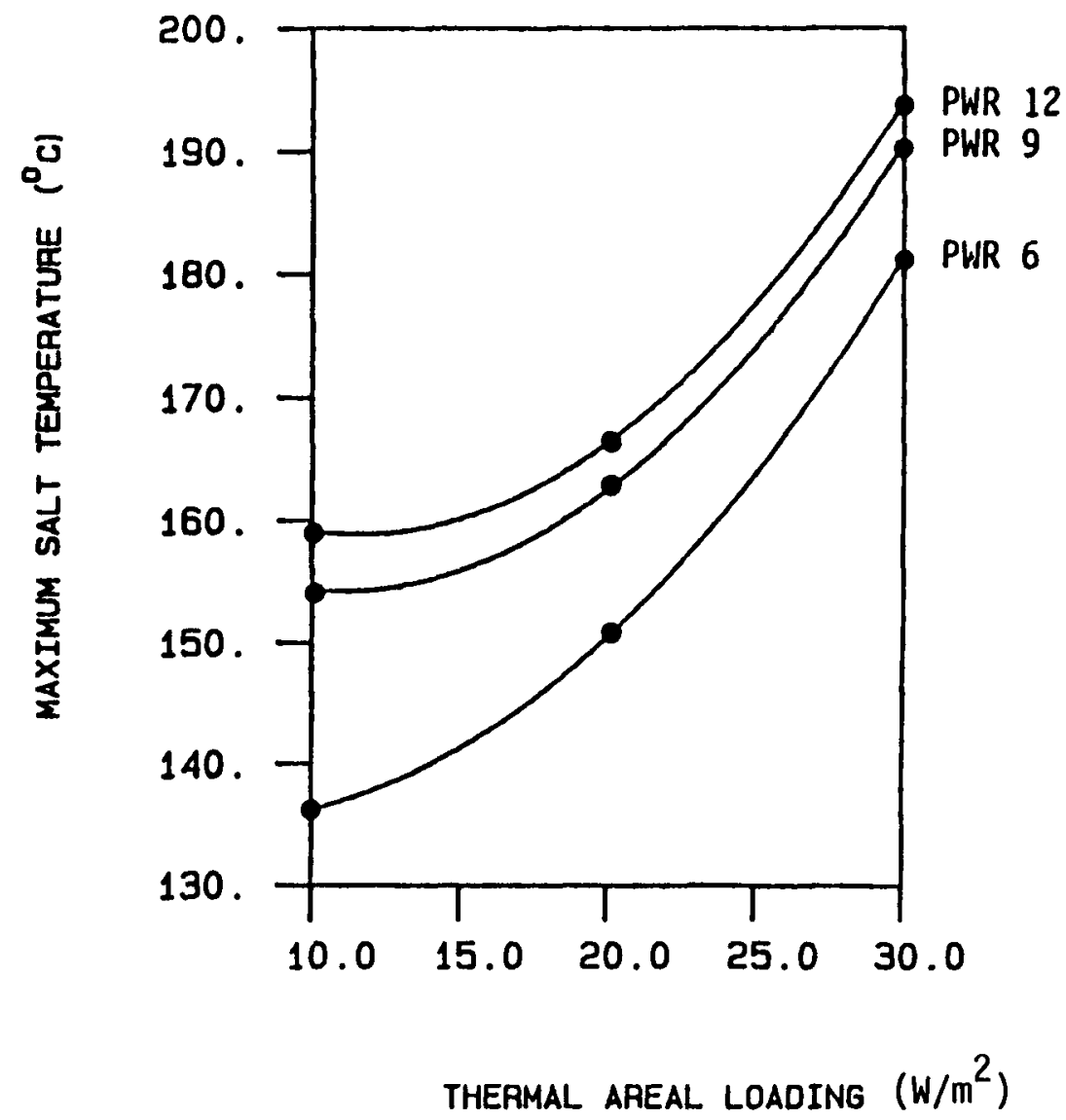


Figure B-8. Two-Dimensional Axisymmetric Model for Calculating Peak Salt Temperature with the Waste Package Surrounded by Crushed Salt

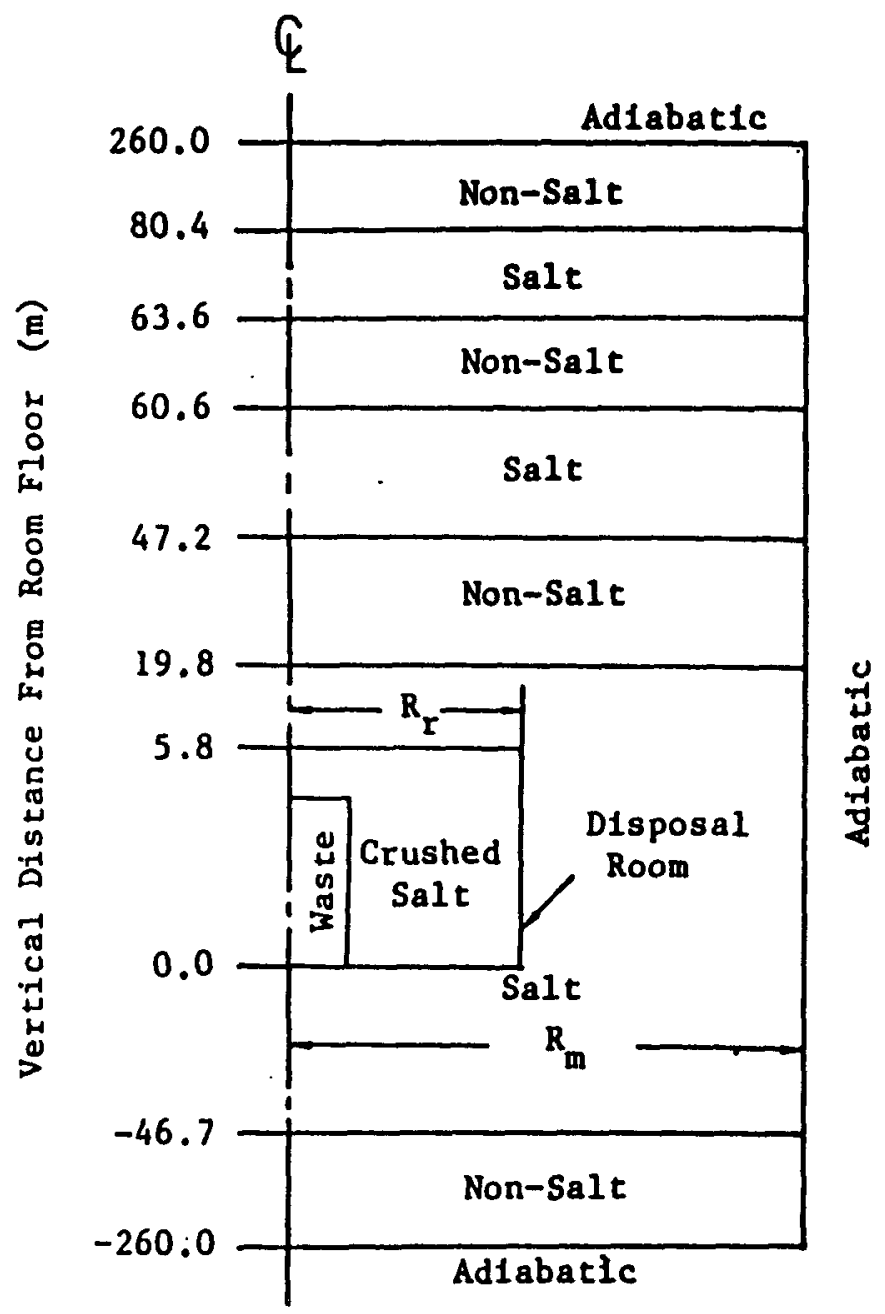

\begin{tabular}{|c|c|c|c|}
\hline $\begin{array}{c}\text { Thermal Areal } \\
\text { Load1ng } \\
\left(\mathrm{W} / \mathrm{m}^{2}\right)\end{array}$ & $\begin{array}{c}\text { Can1s ter } \\
\text { Power } \\
(\mathrm{W})\end{array}$ & $\begin{array}{c}\mathrm{R}_{\mathrm{m}} \\
(\mathrm{m})\end{array}$ & $\begin{array}{c}\mathrm{R}_{\mathrm{r}} \\
(\mathrm{m})\end{array}$ \\
\hline 15.0 & 6600 & 11.8 & 6.9 \\
10.0 & 5700 & 13.5 & 6.0 \\
20.0 & 2800 & 6.7 & 3.0 \\
6.4 & 2800 & 11.8 & 6.9 \\
\hline
\end{tabular}


Figure B-9. Peak Salt Temperature for a Waste Package Surrounded by Crushed Salt

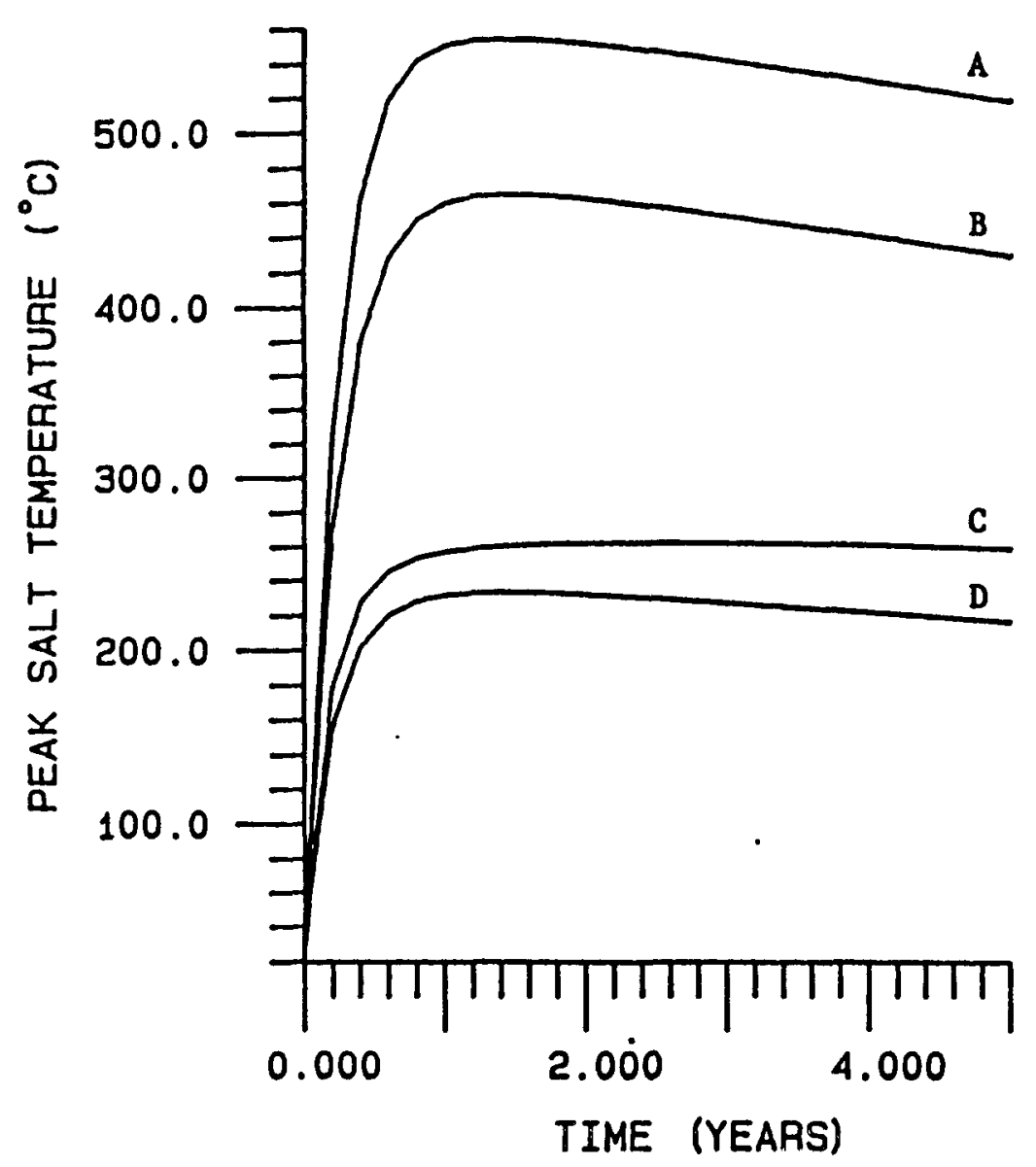

\begin{tabular}{|c|c|c|}
\hline & $\begin{array}{c}\text { Thermal Areal } \\
\text { Loading } \\
\left(\mathrm{W} / \mathrm{m}^{2}\right)\end{array}$ & $\begin{array}{c}\text { Canister } \\
\text { Power } \\
(\mathrm{W})\end{array}$ \\
\hline A & 15.0 & 6600 \\
B & 10.0 & 5700 \\
C & 20.0 & 2800 \\
D & 6.4 & 2800 \\
\hline
\end{tabular}

IME (YEARS) 
Figure B-10. Two-Dimensional Planar Model with the Waste Package Horizontally Emplaced at the Corner of a Room

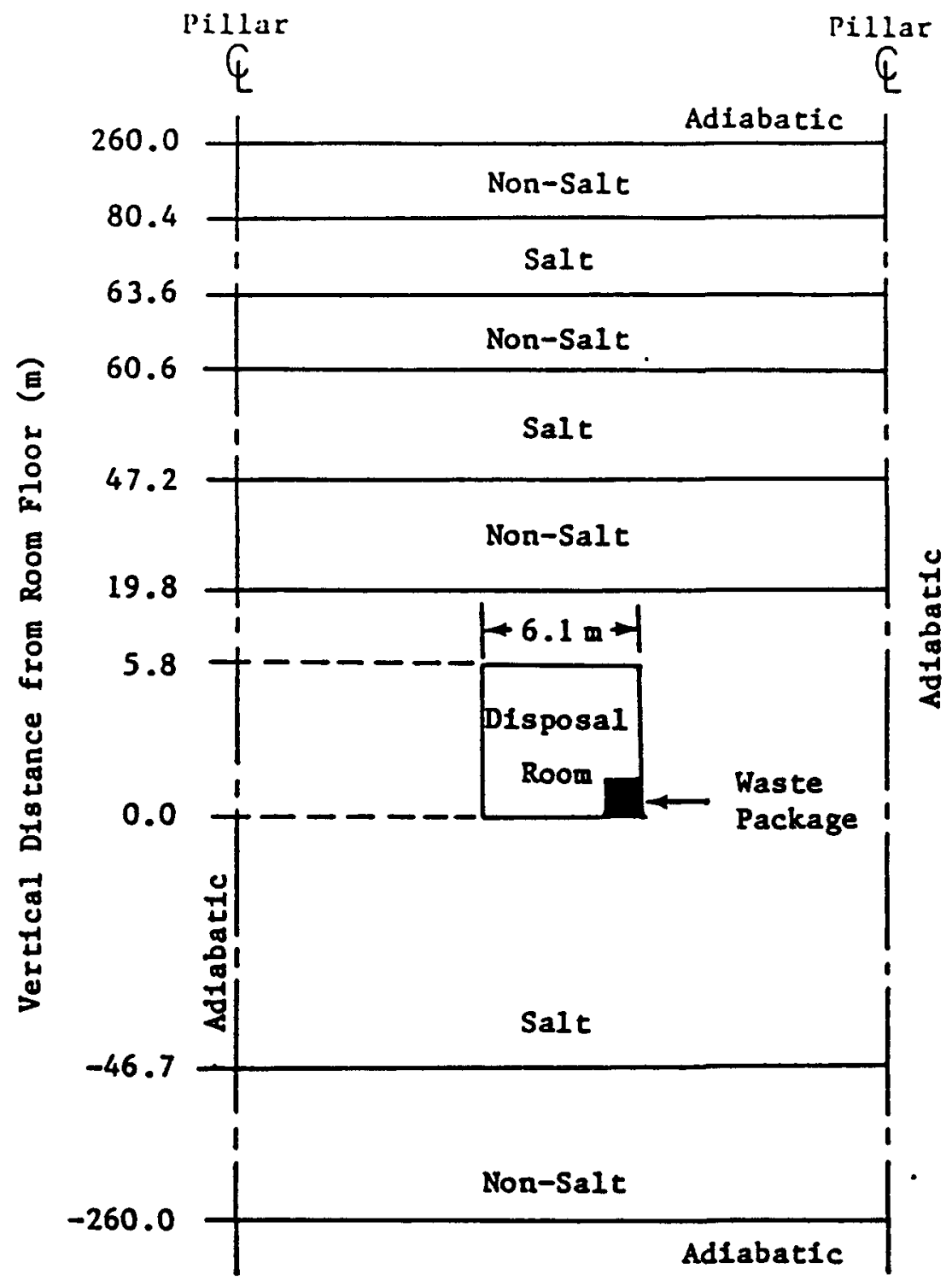


Figure B-11. Peak Salt Temperature with the Waste Package Horizontally Emplaced at the Corner of a Room; the Thermal Areal Loading is $25 \mathrm{~W} / \mathrm{m}^{2}$

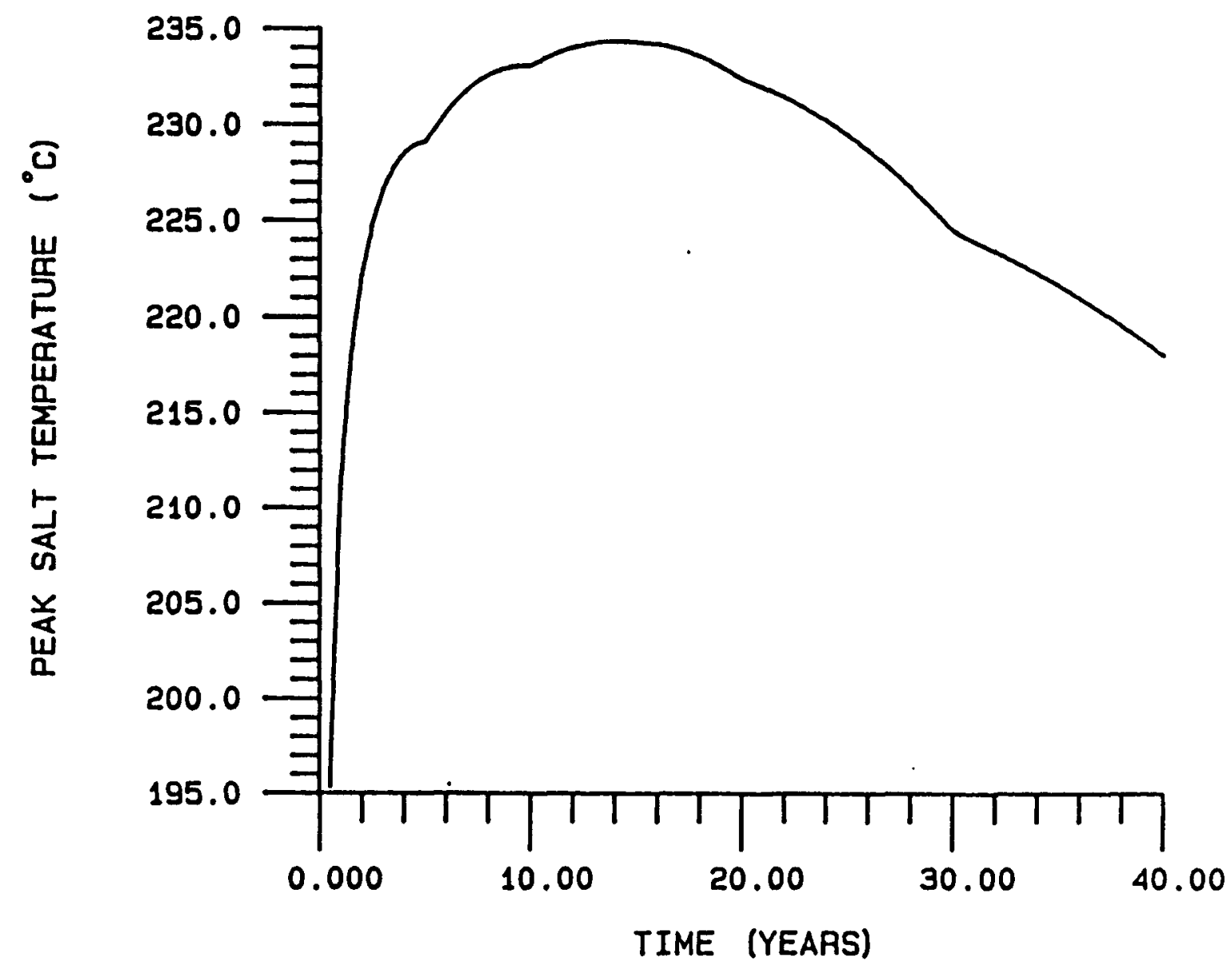


Figure B-12. Two-Dimensional Planar Model with the Waste Package Horizontally Emplaced in a Trench at the Corner of a Room

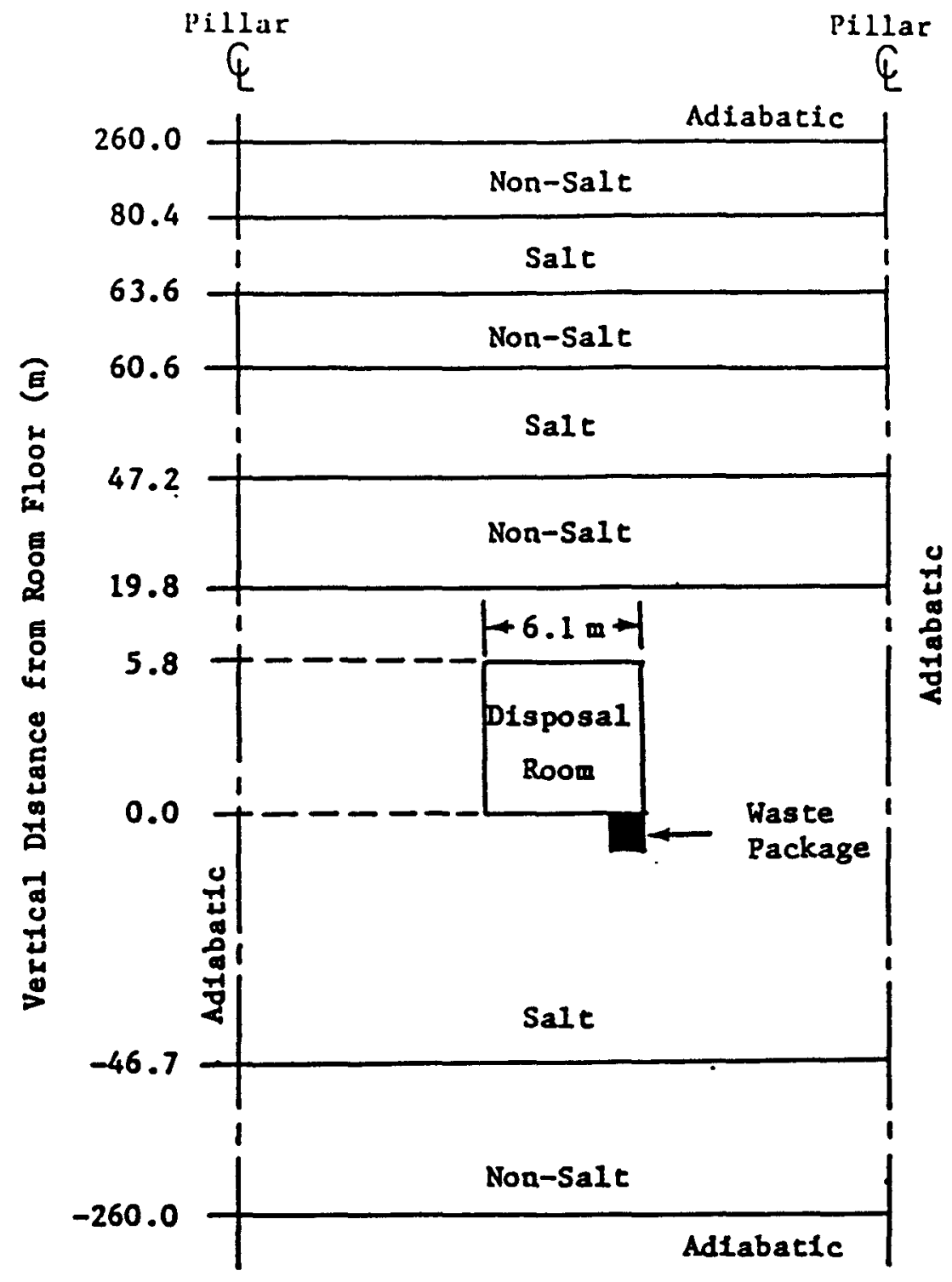


Figure B-13. Peak Salt Temperature with the Waste Package Horizontally Emplaced in a Trench at the Corner of a Room; the Thermal Areal Loading is $30 \mathrm{~W} / \mathrm{m}^{2}$

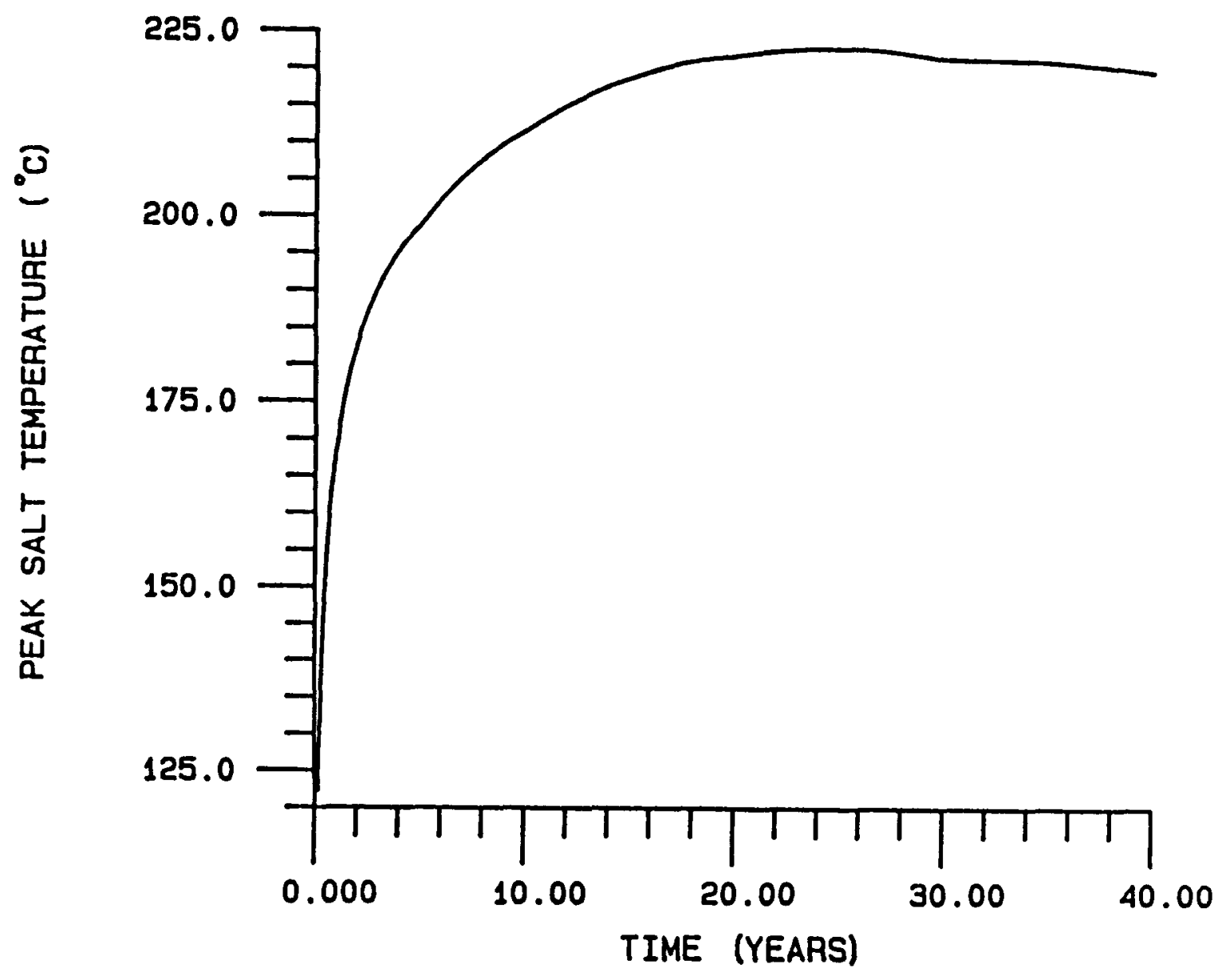


Figure B-14. Two-Dimensional Axisymmetric Model for Calculating Peak Salt Temperature for Emplacement in a Vertical Borehole Backfilled with Crushed Salt

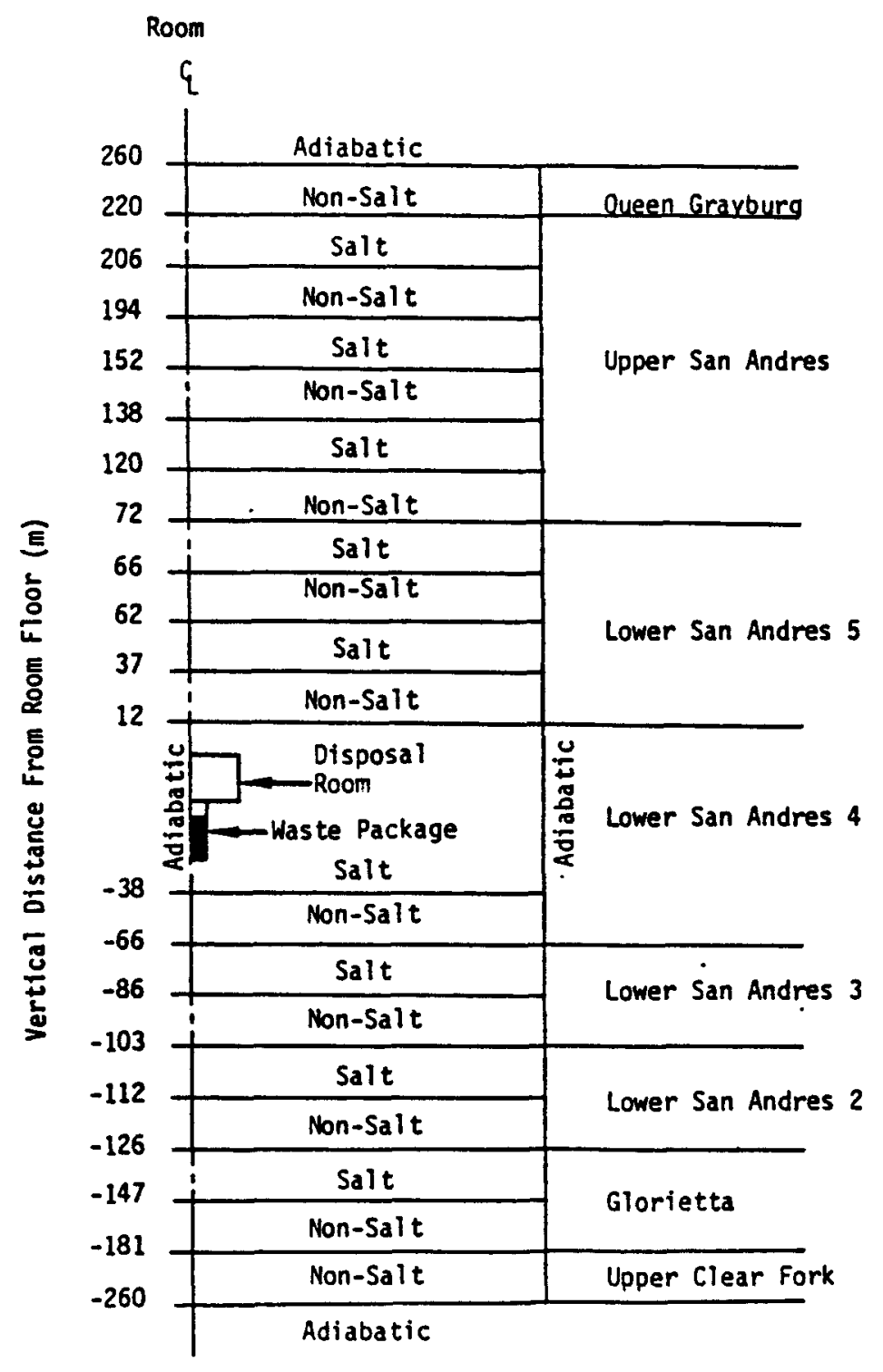


Figure B-15. Maximum Salt Temperature Versus Gap Size for Emplacement in a Vertical Borehole Backfilled with Crushed Salt

PIR-B MITH CPUEHED-8ALT BAP

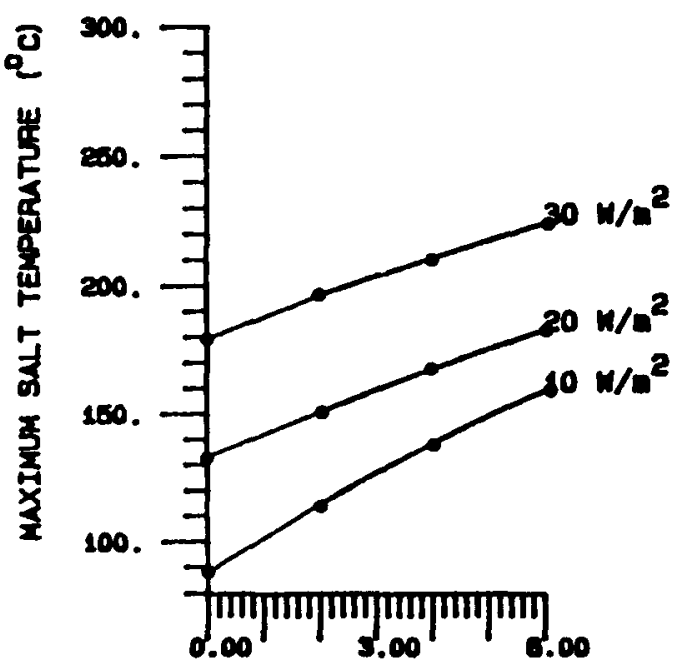

GAP SIZE IINCHO
PWA-Q MITH CRUSHED-EALT GAP

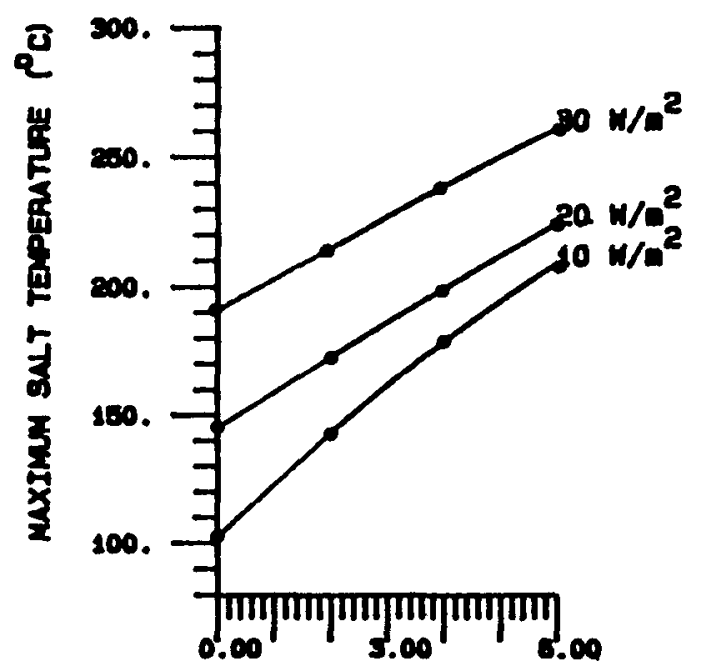

BAP SIZE (INCH)
PNA-12 UITH CRUSHED-EALT BAP

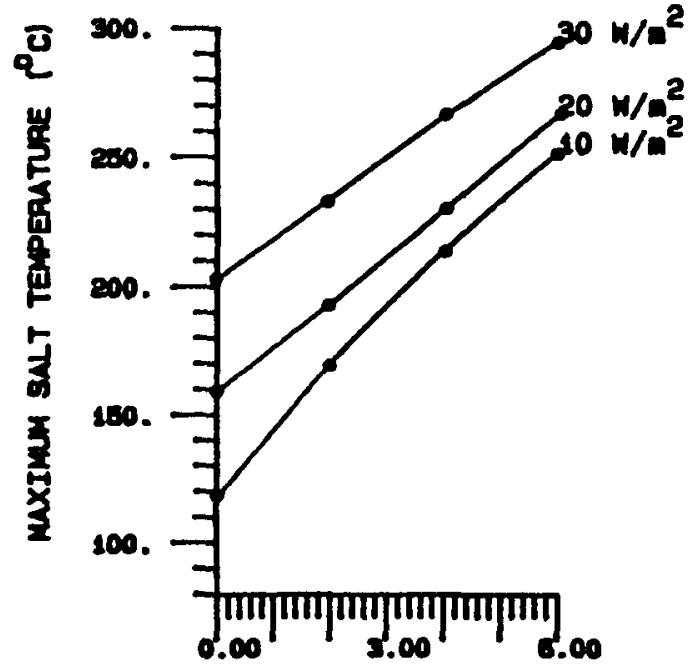

DAP SIZE (INCH) 
Figure B-16. Two-dimensional Planar Model for the Vertical and the Horizontal Emplacement Modes

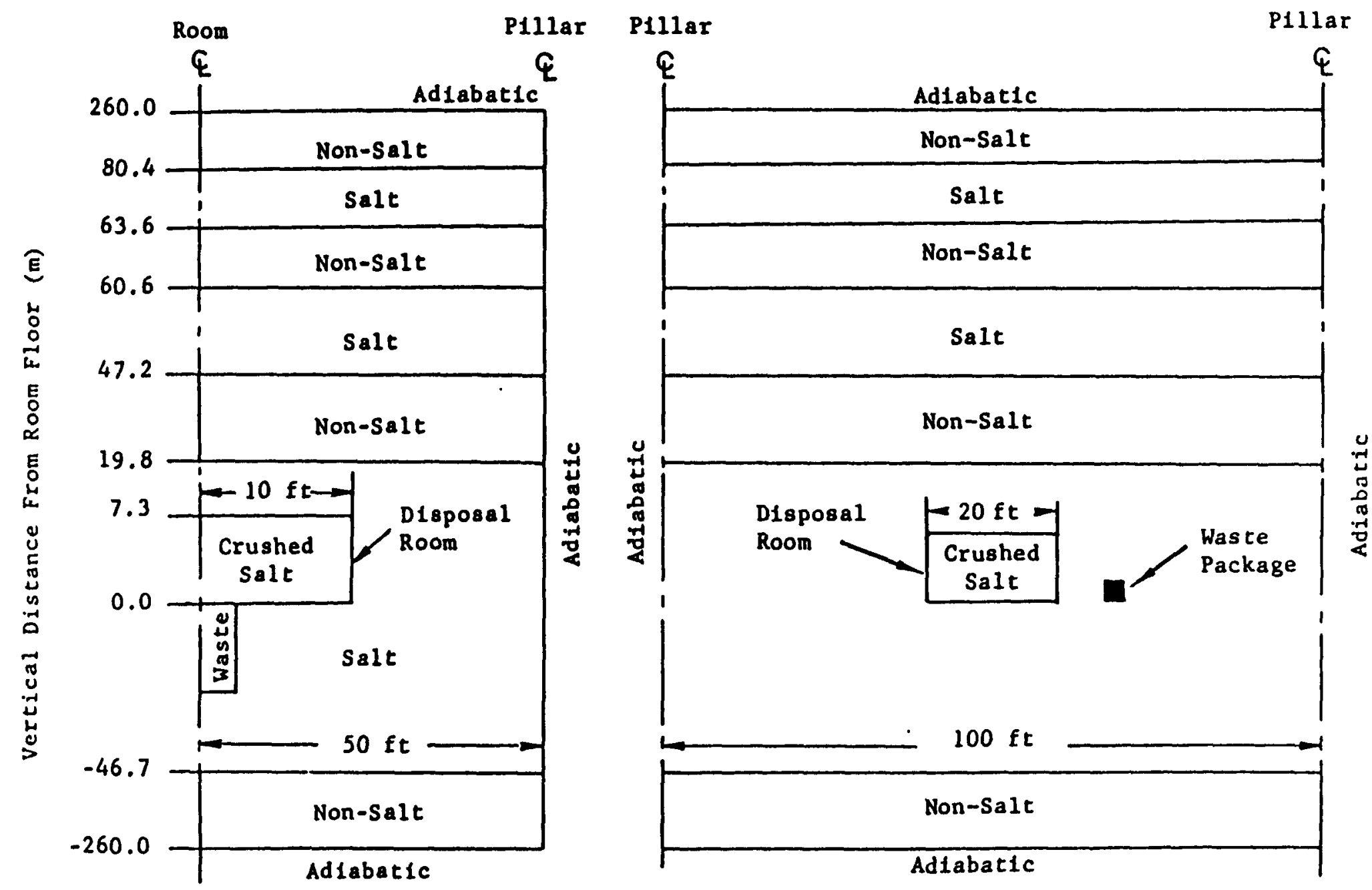

(a) Vertical Emplacement

(b) Horizontal Emplacement 
Figure B-17. Temperature Contours for Vertical Emplacement in the Room Floor with a Thermal Areal Loading of $20 \mathrm{~W} / \mathrm{M}^{2}$

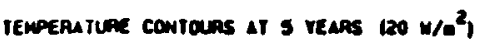

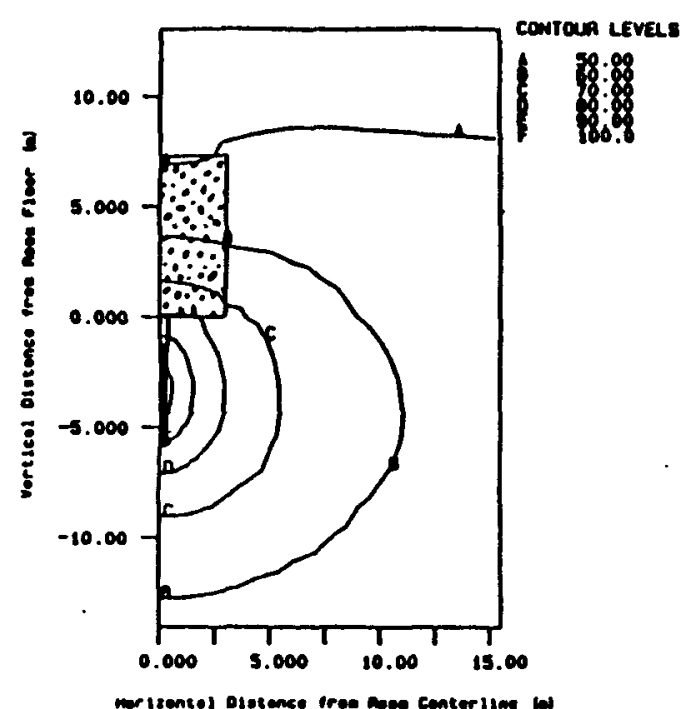

TEMPEALTUAE CONTOUAS AT 30 VEAAS $120 \mathrm{~m} / \mathrm{m}^{2}$ )

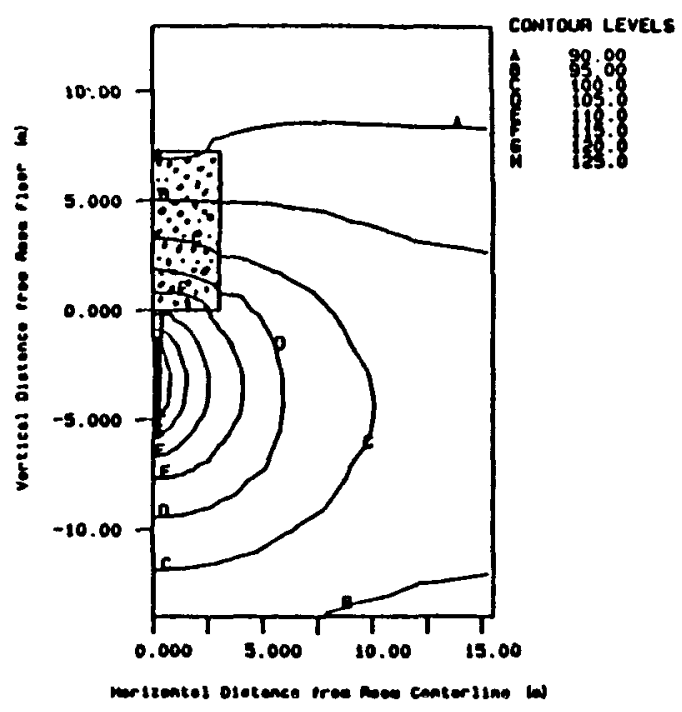

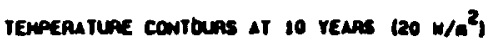

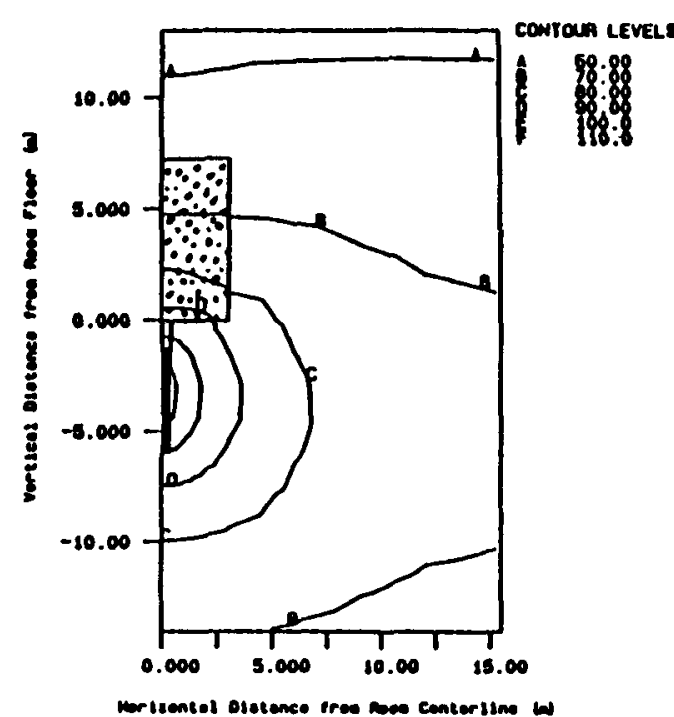

IENPERATURE CONTOUAS AT 10 reAAS $\left.120 \mathrm{~m} / \mathrm{s}^{2}\right)$

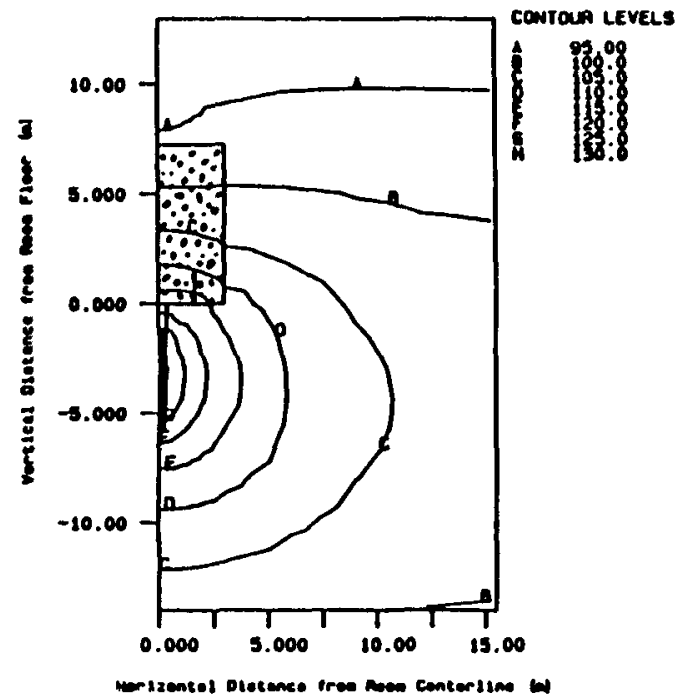

TEMPEAATURE CONTOUAS AT 20 YeARS $120 \mathrm{~m} / \mathrm{m}^{2}$

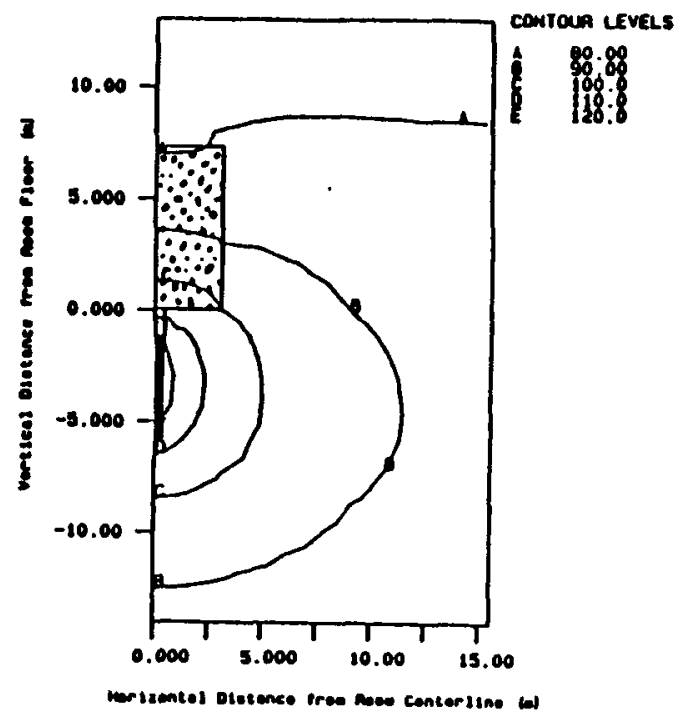

TENPEAATUEE CONTOUAS AT 50 VEAAS $120 \mathrm{~m} / \mathrm{m}^{2}$,

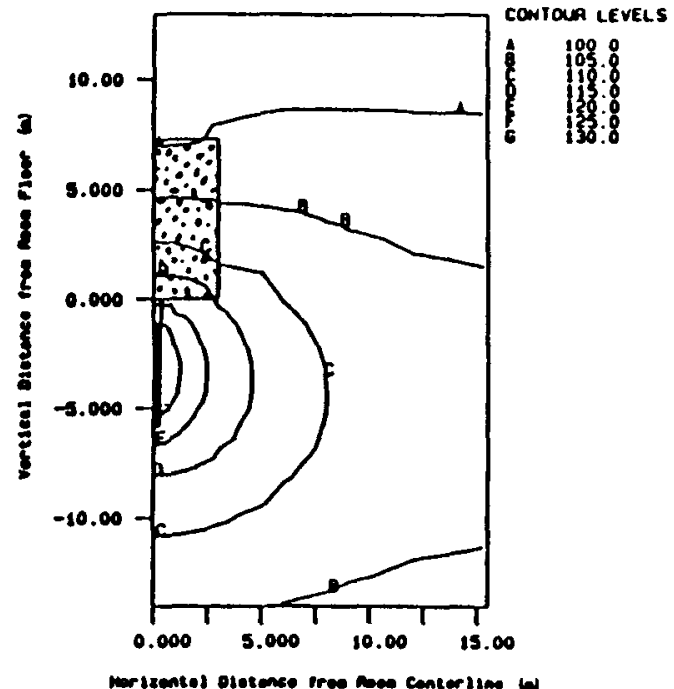


Figure B-18. Temperature Contours for Horizontal Emplacement in the Pillar Slot with a Thermal Areal Loading of $20 \mathrm{~W} / \mathrm{m}^{2}$

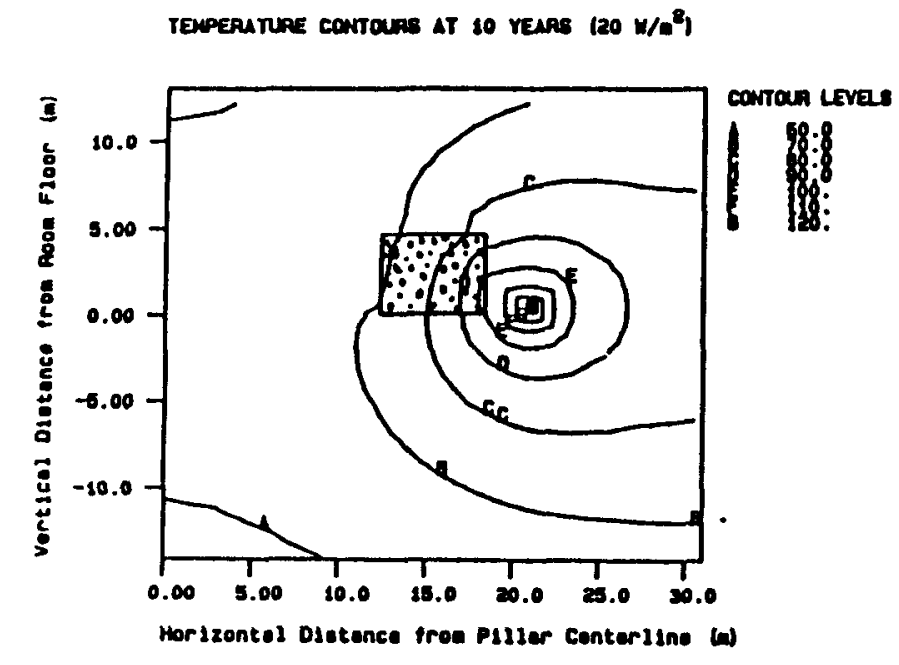

TEAPERATURE CONTOUAS AT 50 YEARS $\left(20 \mathrm{~m} / \mathrm{m}^{2}\right)$

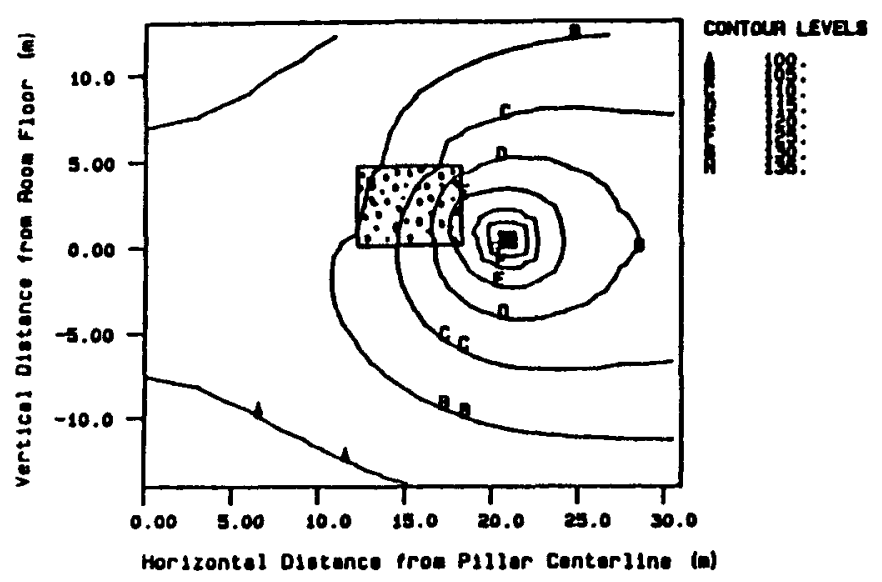

TEMPEATURE CONTOUAS AT 30 VEARS $\left(20 \mathrm{~m} / \mathrm{s}^{2}\right)$

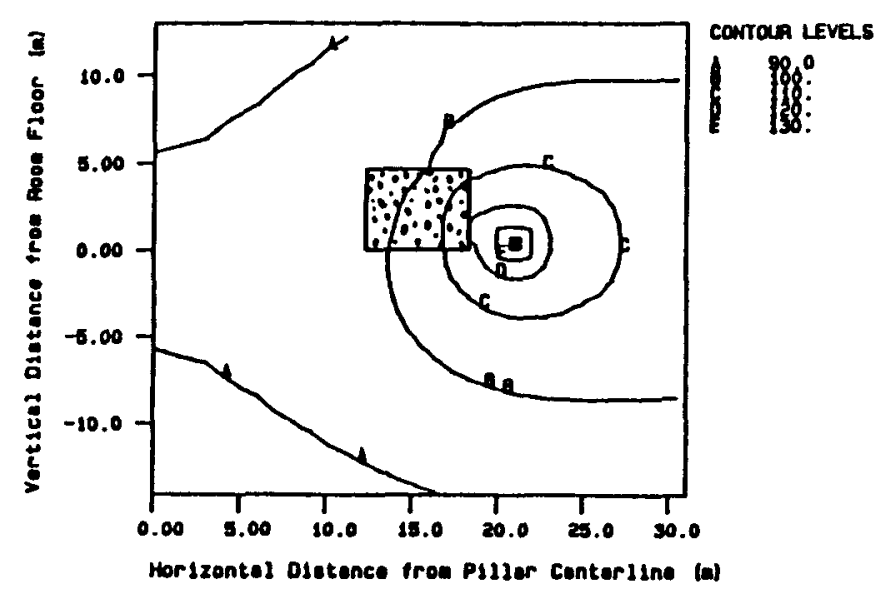

TEMPERTIRE CONTOURS AT 70 VENAS $\left(20 \mathrm{~m} / \mathrm{a}^{2}\right.$,

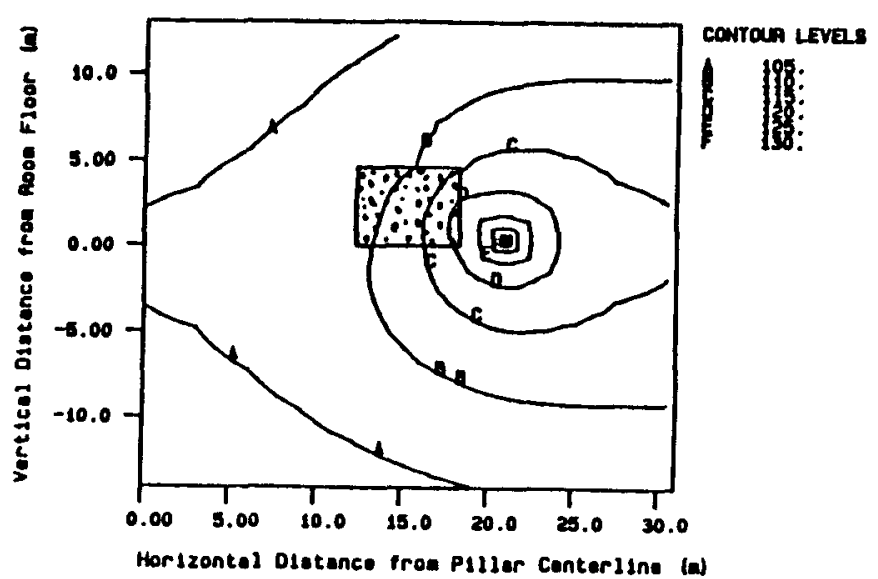


Figure B-19. Room and Pillar Temperatures for Emplacement in a Vertical Borehole

2-O PLANA Mooe IN ROON Scule FOA SPENT Tul W

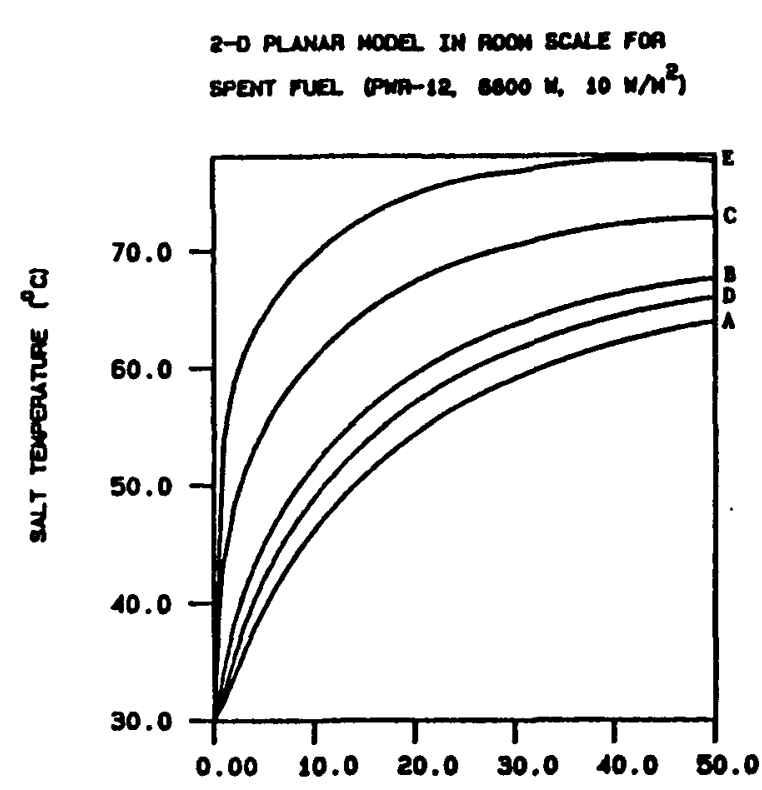

TIVE MENA)

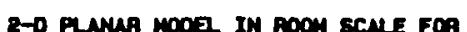

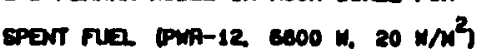

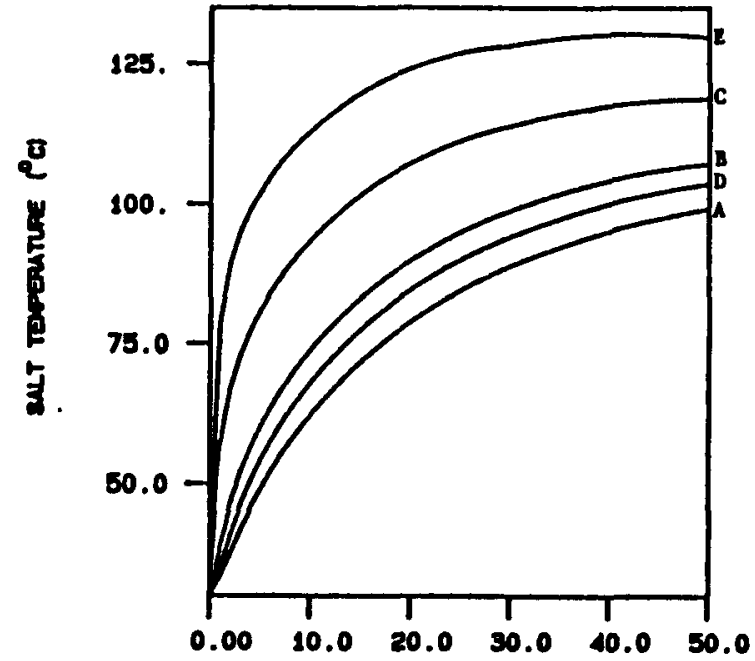

TINE MENas

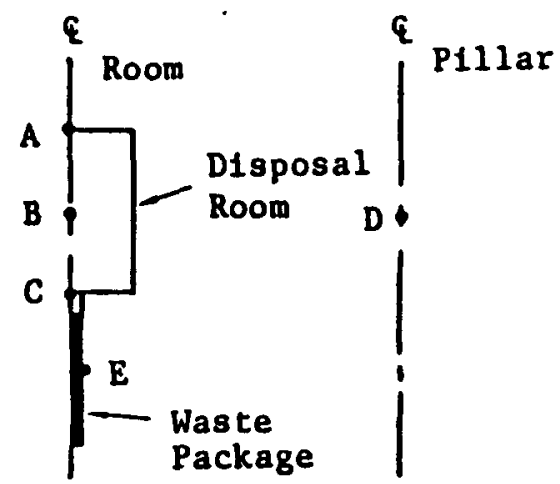

2-0 PLANLA MOOA. IN ROON SCALE FOR

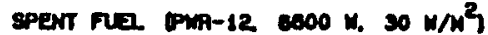

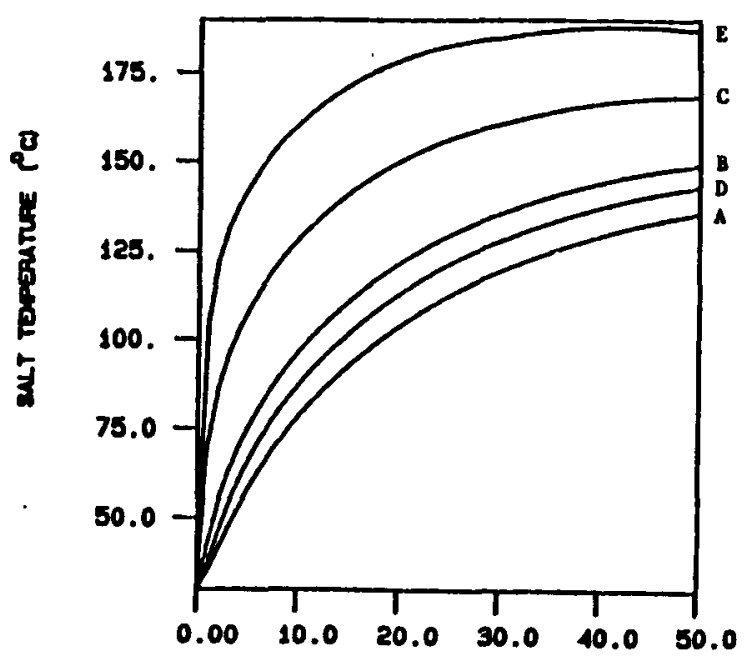

TINE MEaps)

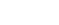


Figure B-20. Temperature Contours for Emplacement in a Vertical Borehole at $10 \mathrm{~W} / \mathrm{m}^{2}$

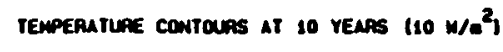

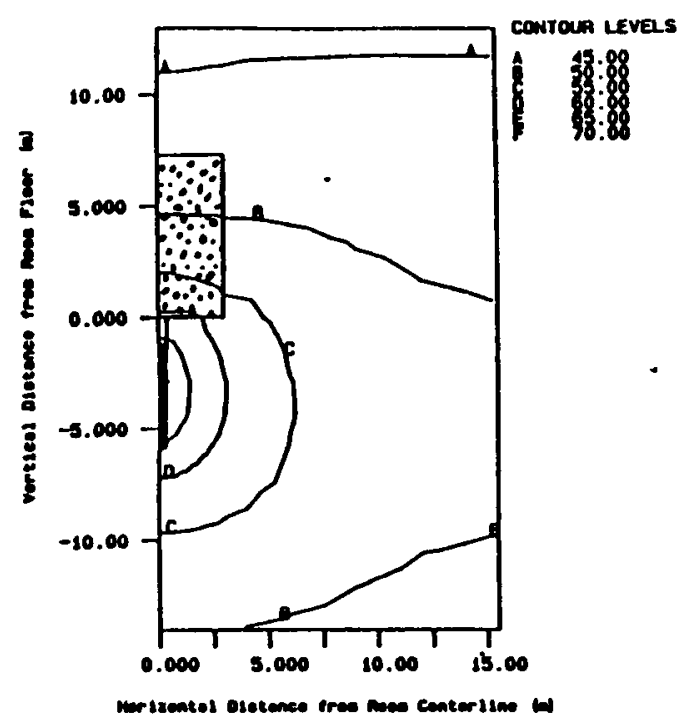

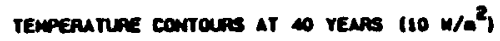

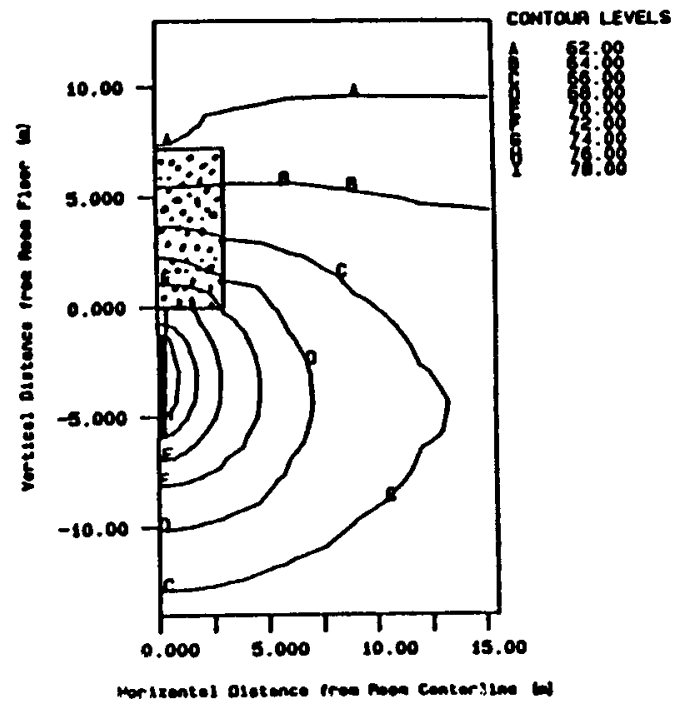

TEMPERA TURE CONTOUAS AT 20 VEARS $\left(10 \mathrm{~m} / \mathrm{m}^{2}\right)$

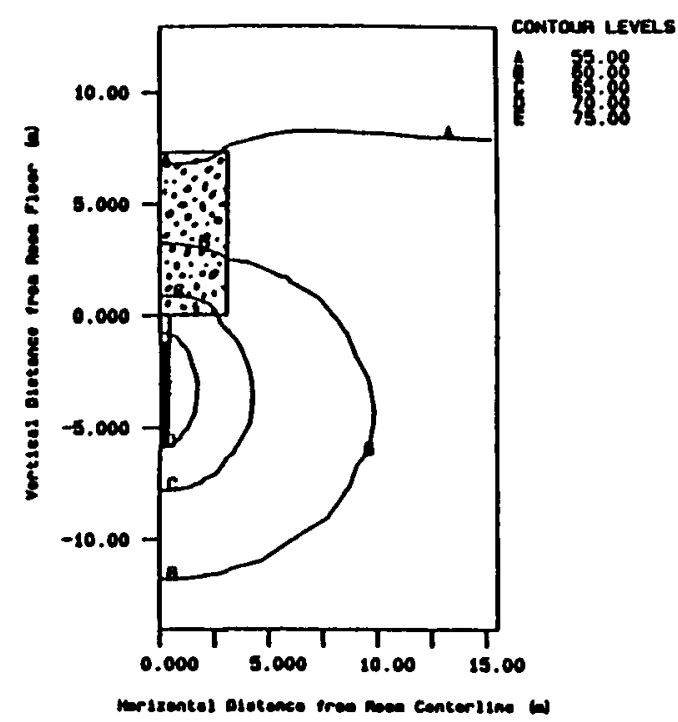

TEMPERTIUAE CONTOCAS AT 50 VEARS $\left(10 \mathrm{~m} / \mathrm{o}^{2}\right)$

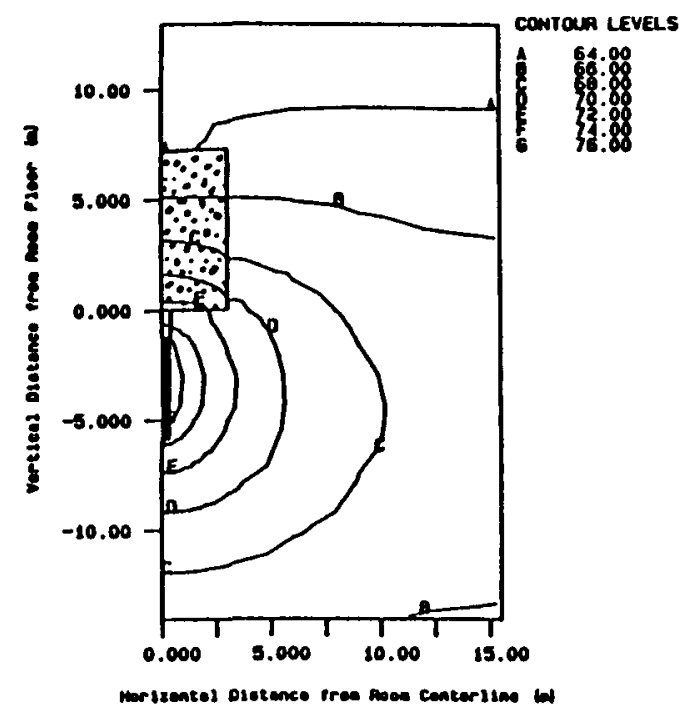


Figure B-21. Temperature Contours for Emplacement in a Vertical Borehole at $30 \mathrm{~W} / \mathrm{m}^{2}$

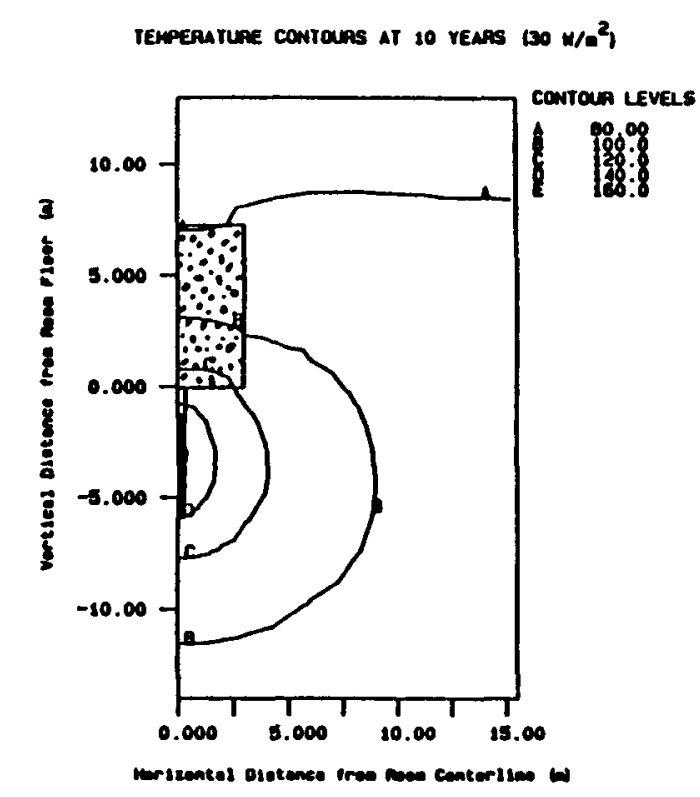

TEMPEAATURE CONTOUAS AT 10 YENAS $\left(30{\left.\mathrm{~m} / \mathrm{a}^{2}\right)}^{2}\right.$

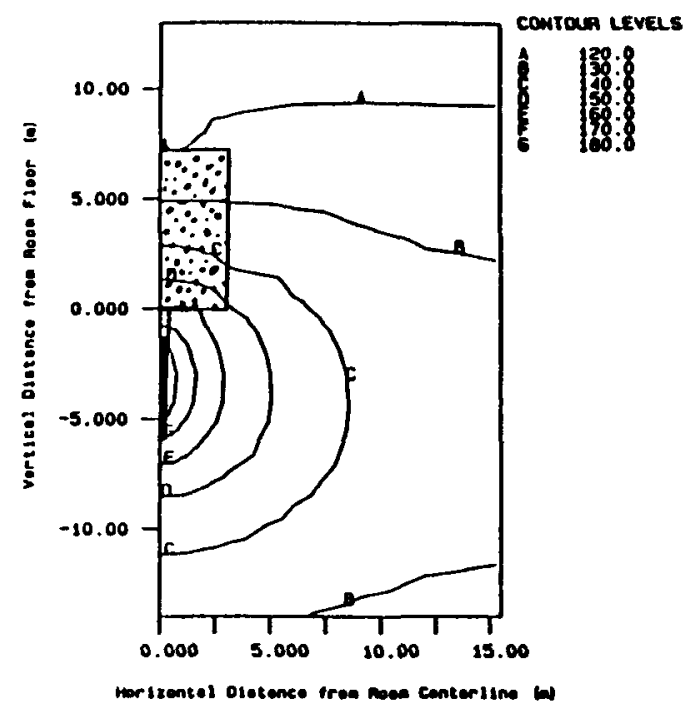

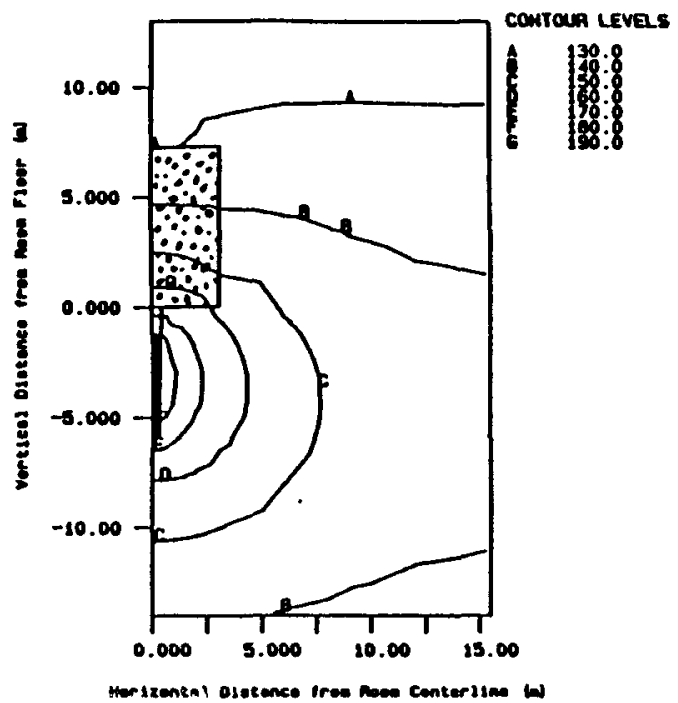

TEMPERATUFE COWTOURS AT 20 TEARS $130 \mathrm{~m} / \mathrm{m}^{2} \mathrm{I}$

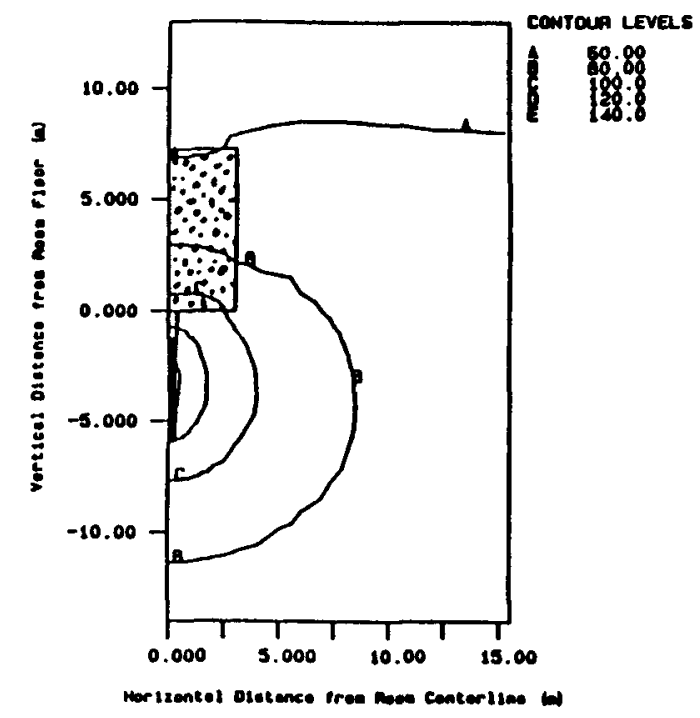

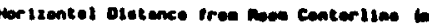

IEmPERATUAE contolas at 30 rears $130 \mathrm{~m} / \mathrm{O}^{4}$

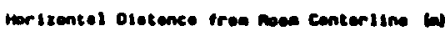

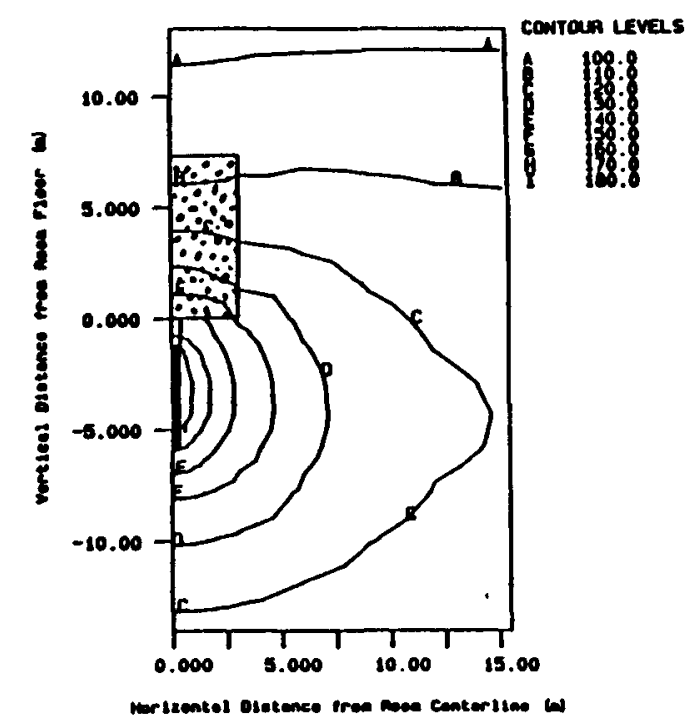

TEMPERTIURE CONTOUAS AT SO VEARS (30 $\mathrm{m} / \mathrm{s}^{2}$ )

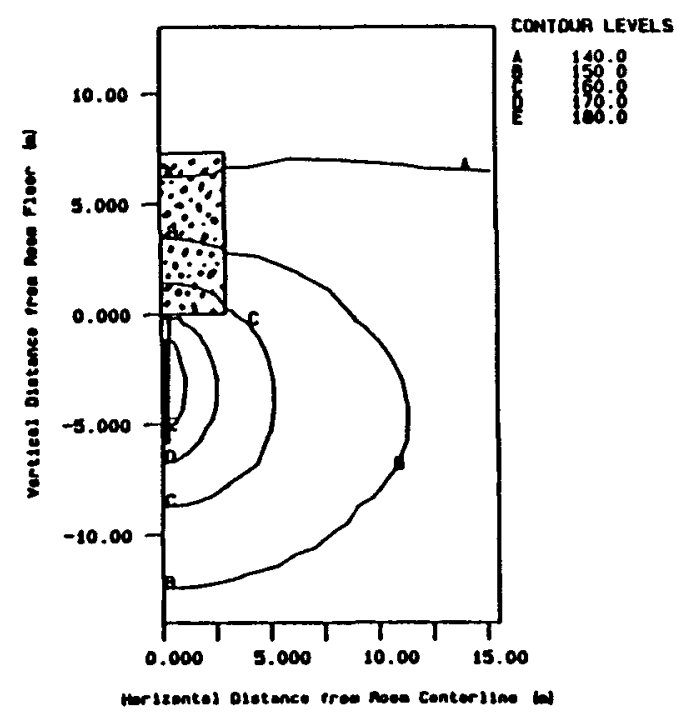


Figure B-22. Room and Pillar Temperatures for Emplacement in a Horizontal Pillar slot

2-O PLALA MOOE. IN ROON ECNE FOA

govi fua $110 \mathrm{~m} / \mathrm{m}$

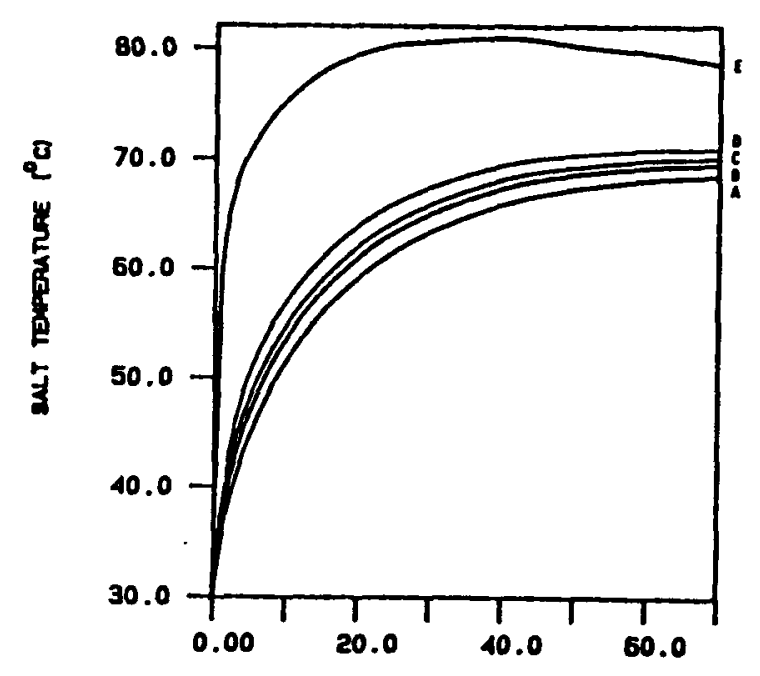

Tze meapas

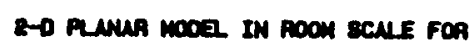

cort rue $\left(20 \mathrm{~m} / \mathrm{a}^{2}\right.$

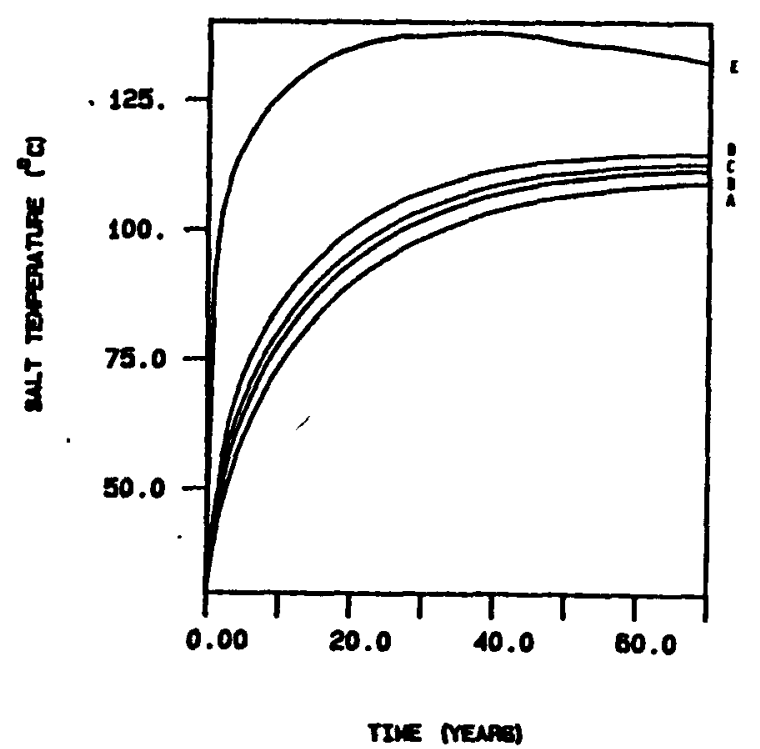

TuE Mesas

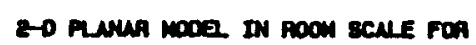
eart Fuz $60 \mathrm{~m} / \mathrm{h}$

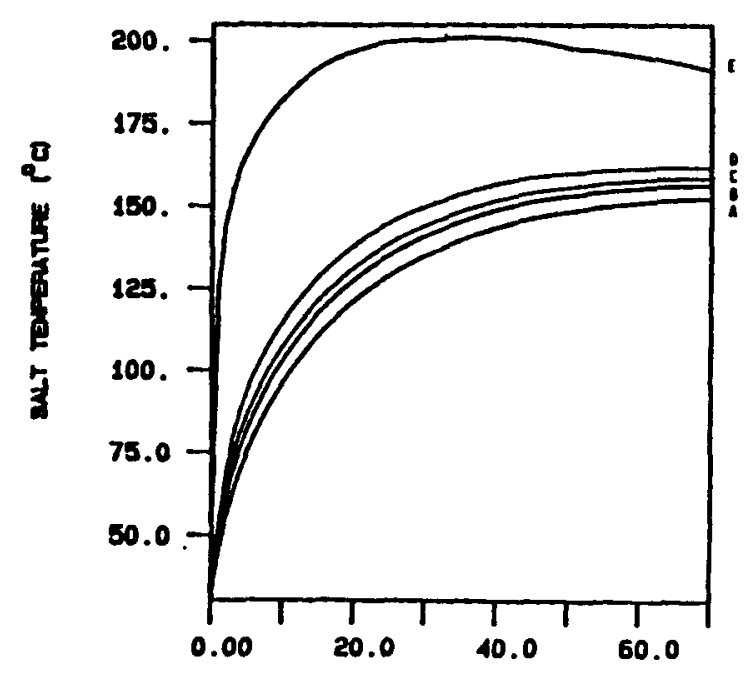

TIUE MEARS)

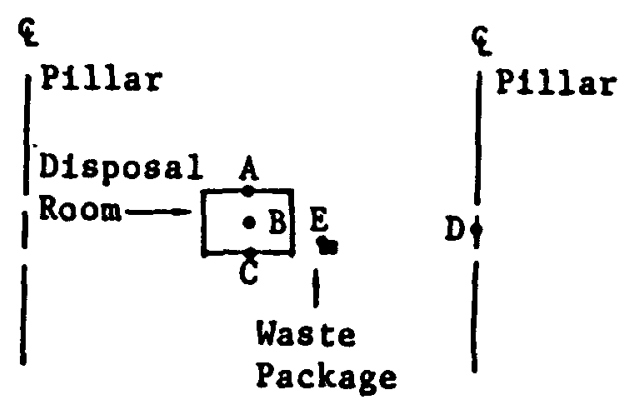


Table B-23. Temperature Contours for Emplacement in a Horizontal Pillar slot at $10 \mathrm{~W} / \mathrm{m}^{2}$

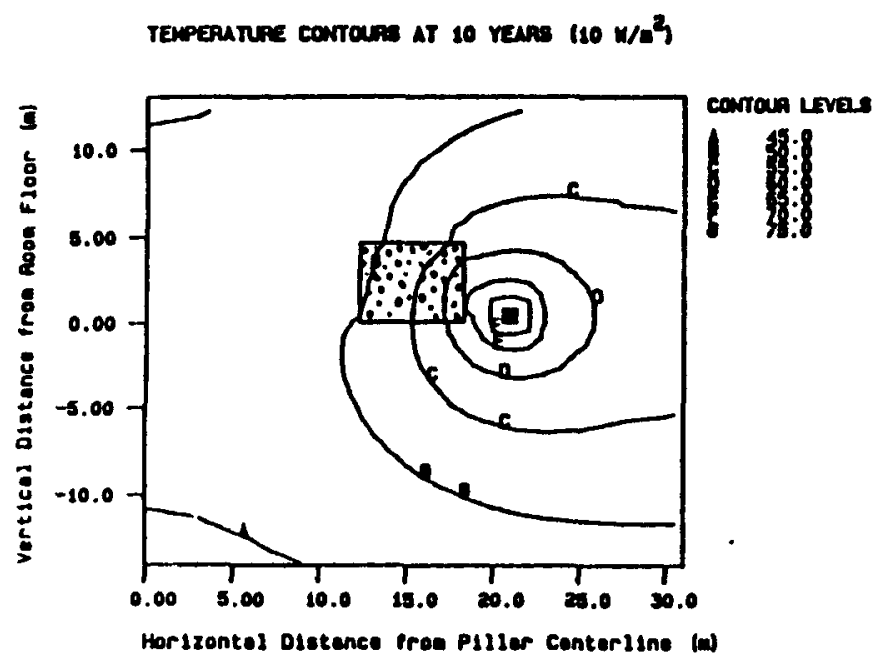

TEMPEAA TUFE CONTOUAS AT SO YEAAS $110 \mathrm{~W}$ W/4

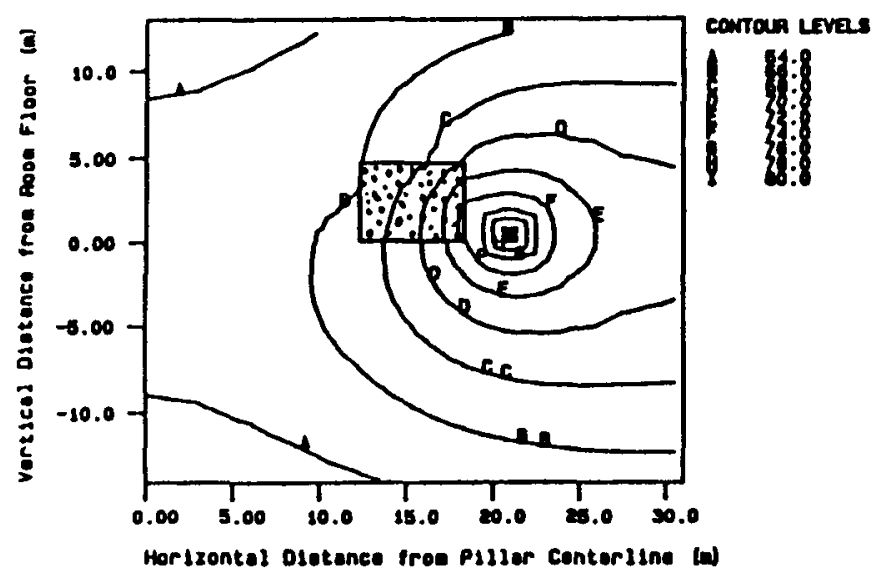

TEMPEAATIAE CONTOUAS AT 30 VELAS $120 \mathrm{~W} / \mathrm{a}^{2}$

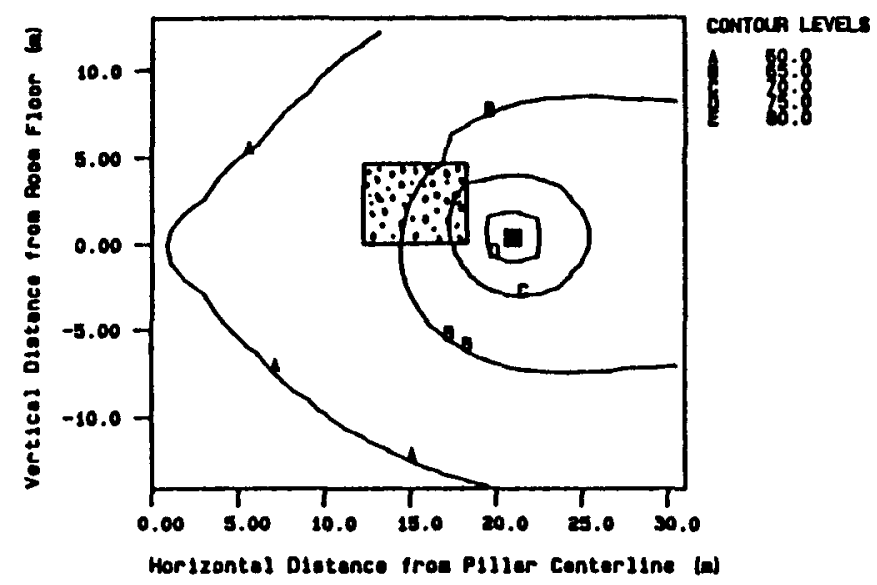

TEMPERATLAE CONTOLAS AT 70 VEARS $110 \mathrm{~m} / \mathrm{s}^{2}$

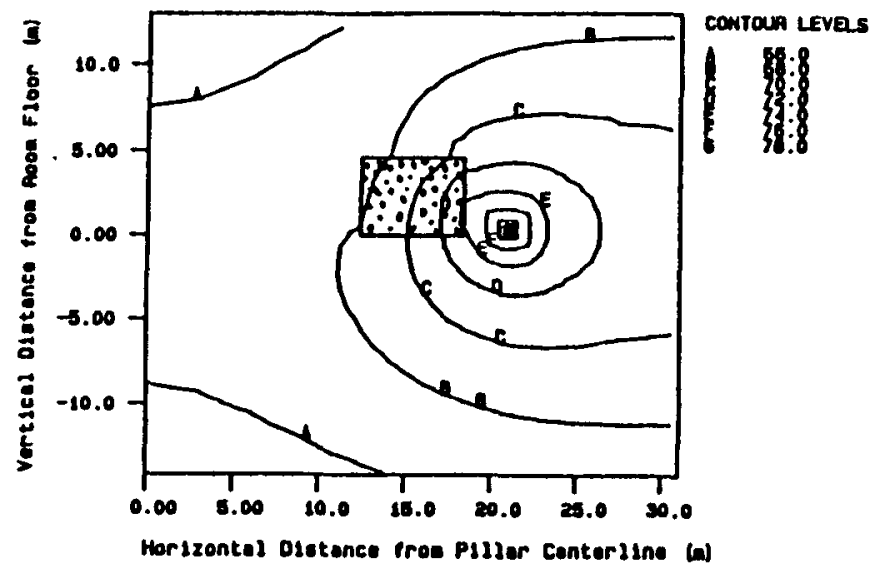


Figure B-24. Temperature Contours for Emplacement in a Horizontal Pillar slot at $30 \mathrm{~W} / \mathrm{m}^{2}$.
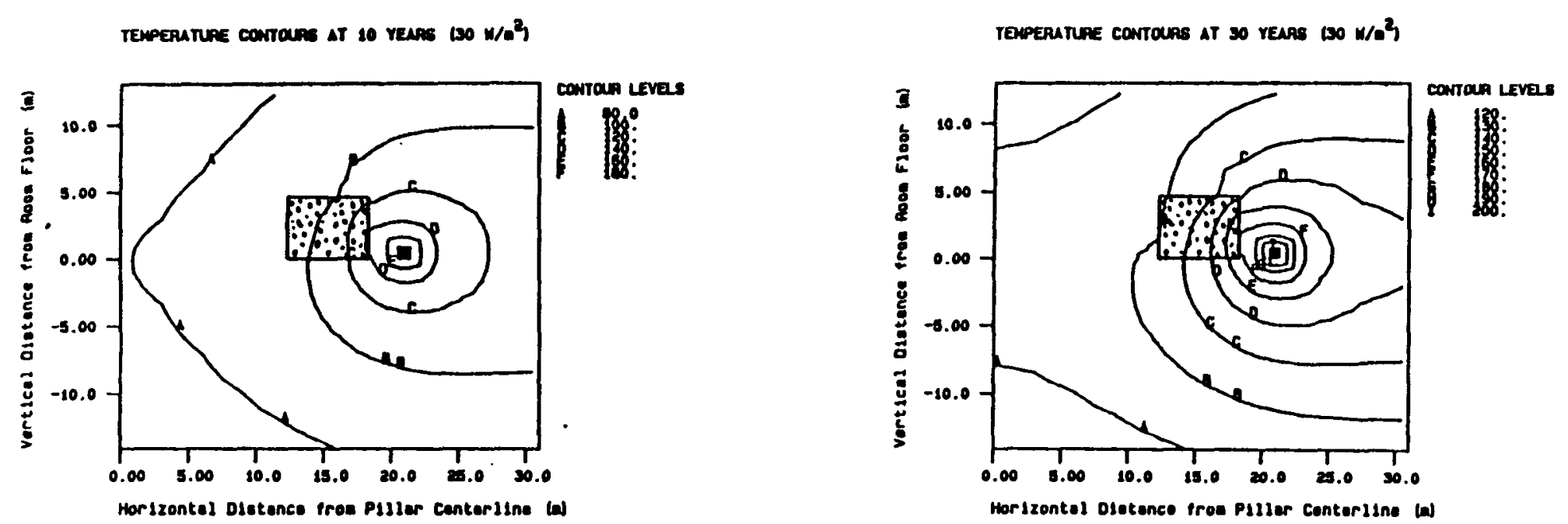

TEMPEATTURE CONTOUAS AT SO VELA $150 \mathrm{w/ \textrm {m } ^ { 2 }}$,

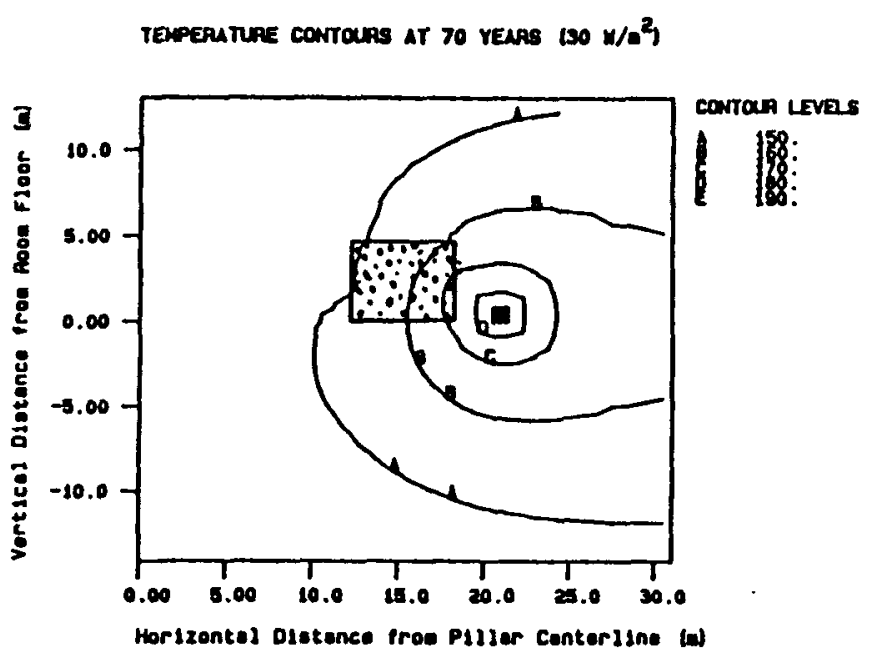


Figure B-25. Schematic Diagram of 8 Locations for Temperature-Time Histories for Horizontal Emplacement in a Long Borehole

0
1
$\stackrel{9}{\bullet}$

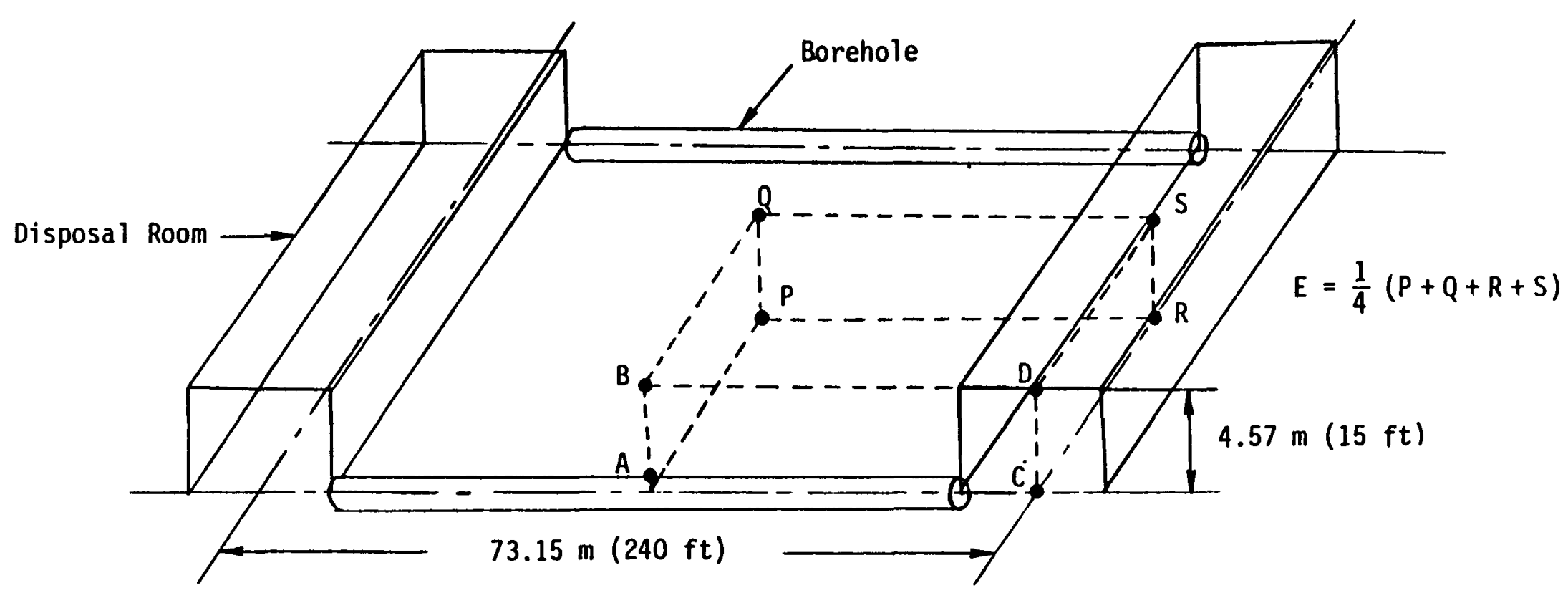


Figure B-26. Temperature Time Histories at Locations $P, Q, R$ and $S$ for Horizontal Emplacement in a Long Borehole. See Legend

for Explanation of Locations

3-D ANALYTIC MOOEL FOA SPENT FUEL

PUPB (120. 20. and $30 \mathrm{~m} / \mathrm{m}^{2}$ )

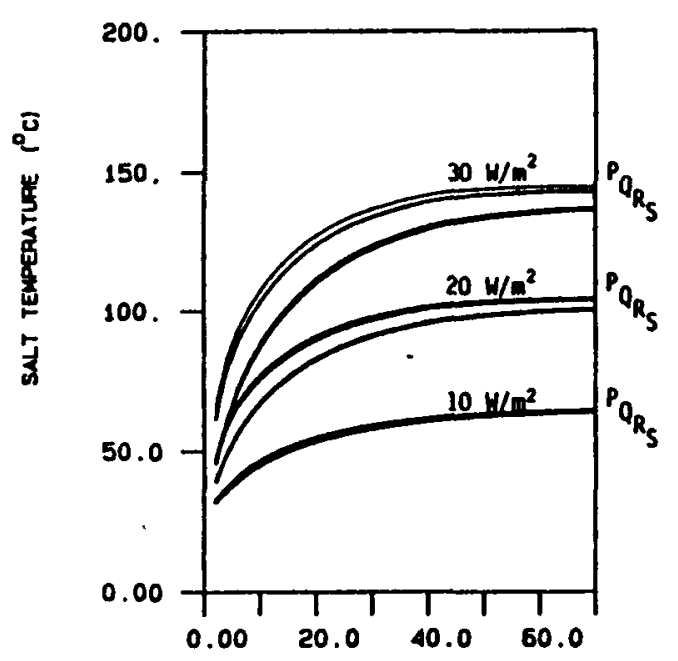

TIME IYEAASI
3-0 ANLLYYISC MOOEL FOA SPENT FUEL

PMAg (10. 20. and $30 \mathrm{~m} / \mathrm{a}^{2}$ )

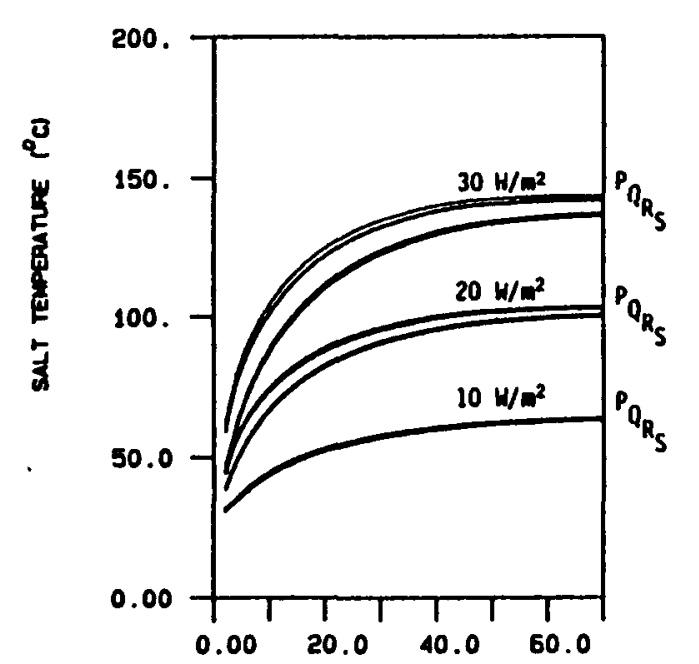

TIME (YEAAS)
3-D AMALYTIC MODEL FDA SPENT FUEL PMA12 (10, 20. and $30 \mathrm{~m} / \mathrm{m}^{2}$ )

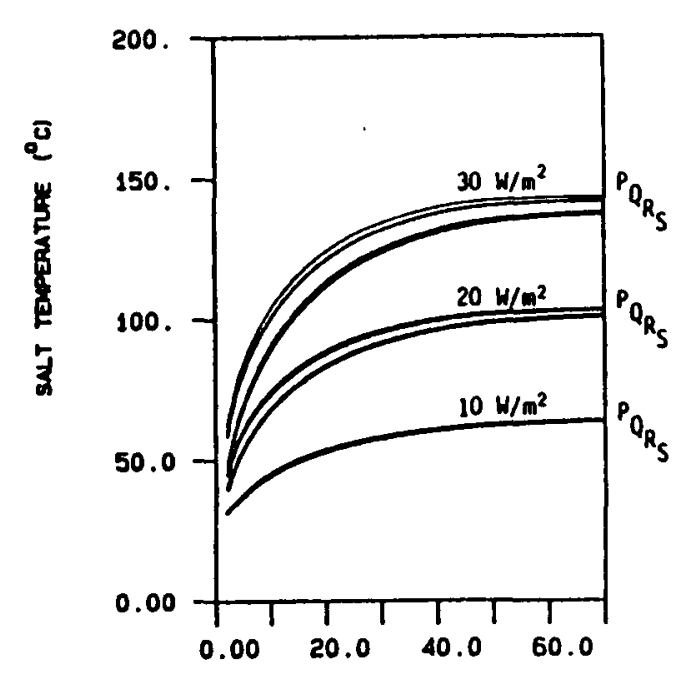

TIME (YEARS)

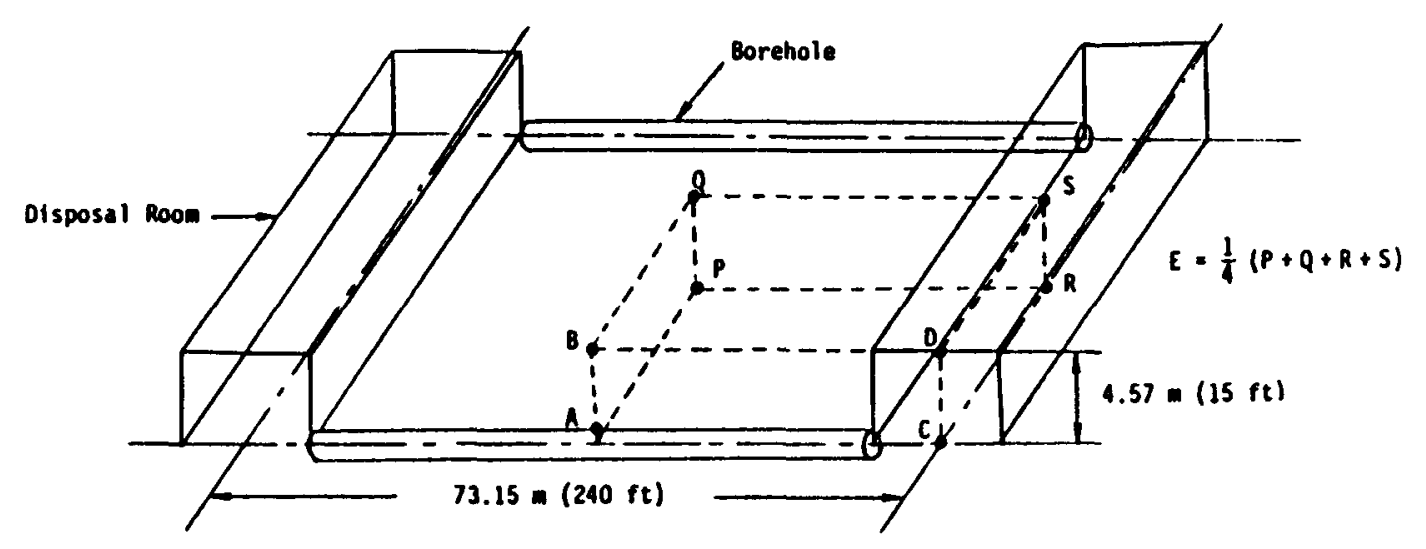


Figure B-27. Temperature Time Histories at Locations A, B, C, D and E for PWR 6 Waste Packages Horizontally Emplaced in a Long Borehole. See Legend for

Explanation of Locations
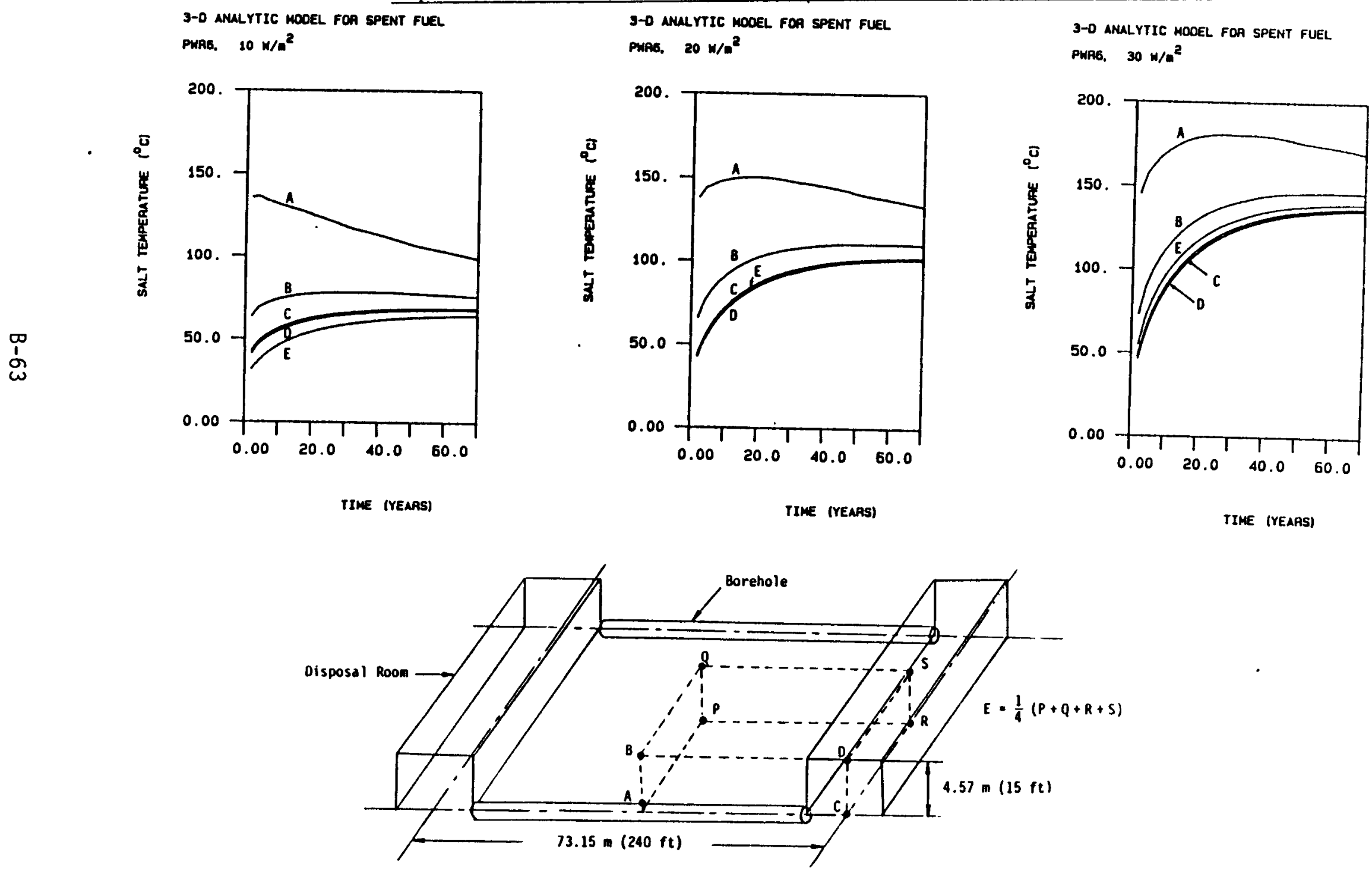
Figure B-28. Temperature Time Histories at Locations A, B, C, D, and E for PWR 6 Waste Packages Horizontally Emplaced in a Long Borehole. See Legend for

\section{Explanation of Locations}

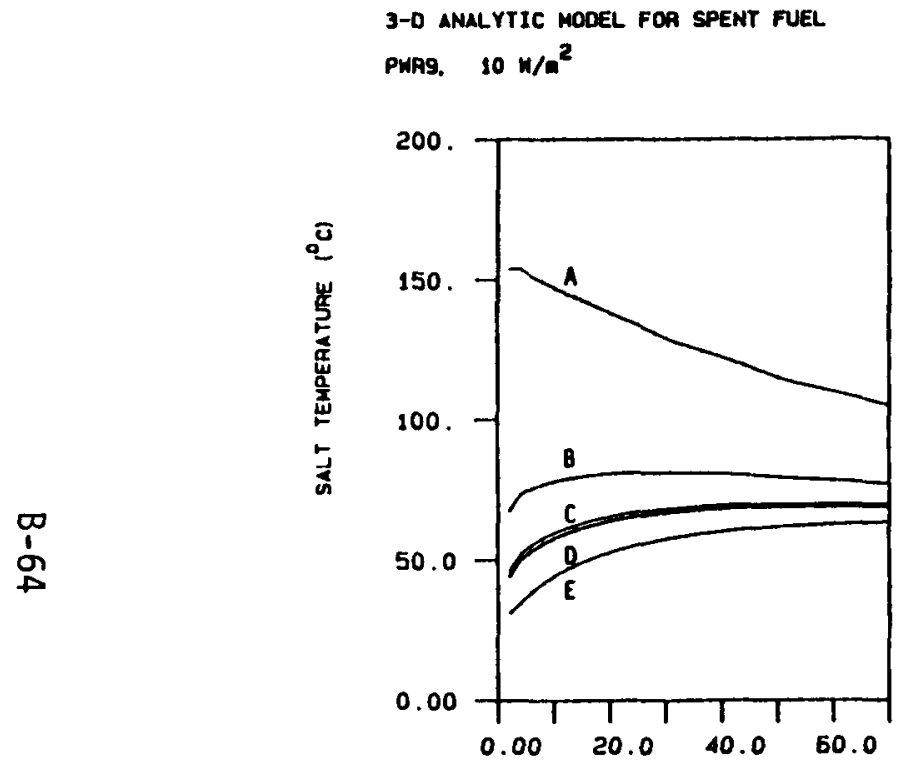

TIME (YEAAS)
3-D ANALYTIC MODEL FOR SPENT FUEL

PWA9. $20 \mathrm{~m} / \mathrm{m}^{2}$

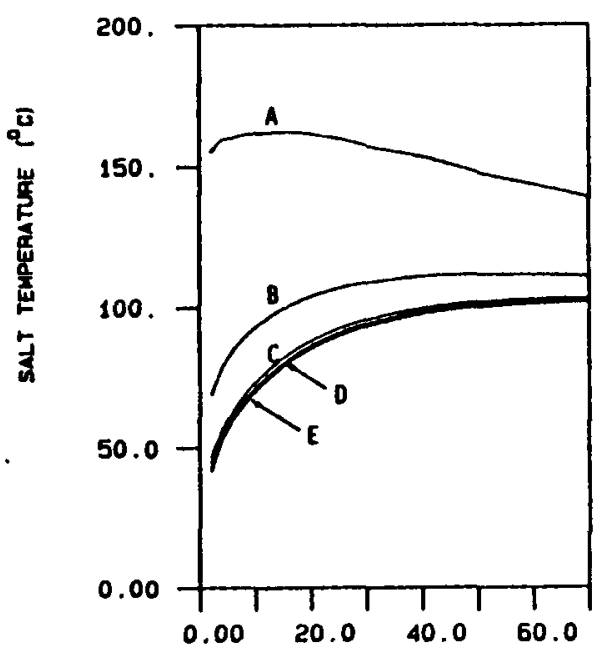

TIME (YEARS)
3-D ANALYTIC MOOEL FOA SPENT FUEL

PURS. $30 * / a^{2}$

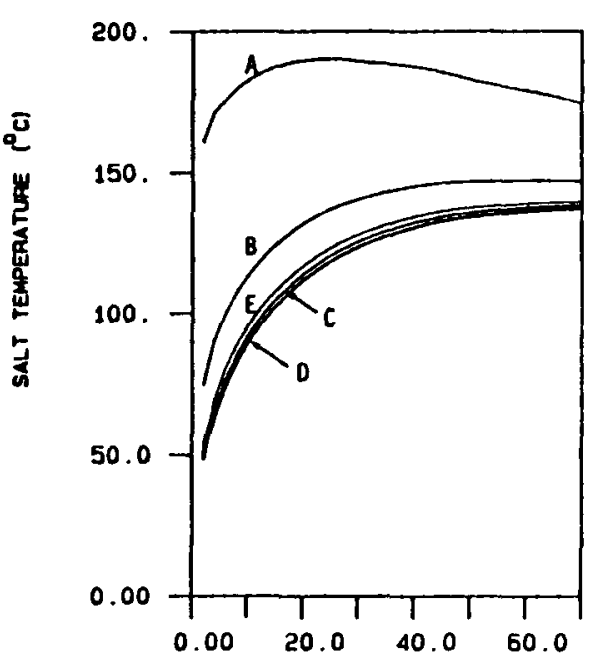

IIME (YEAPS)

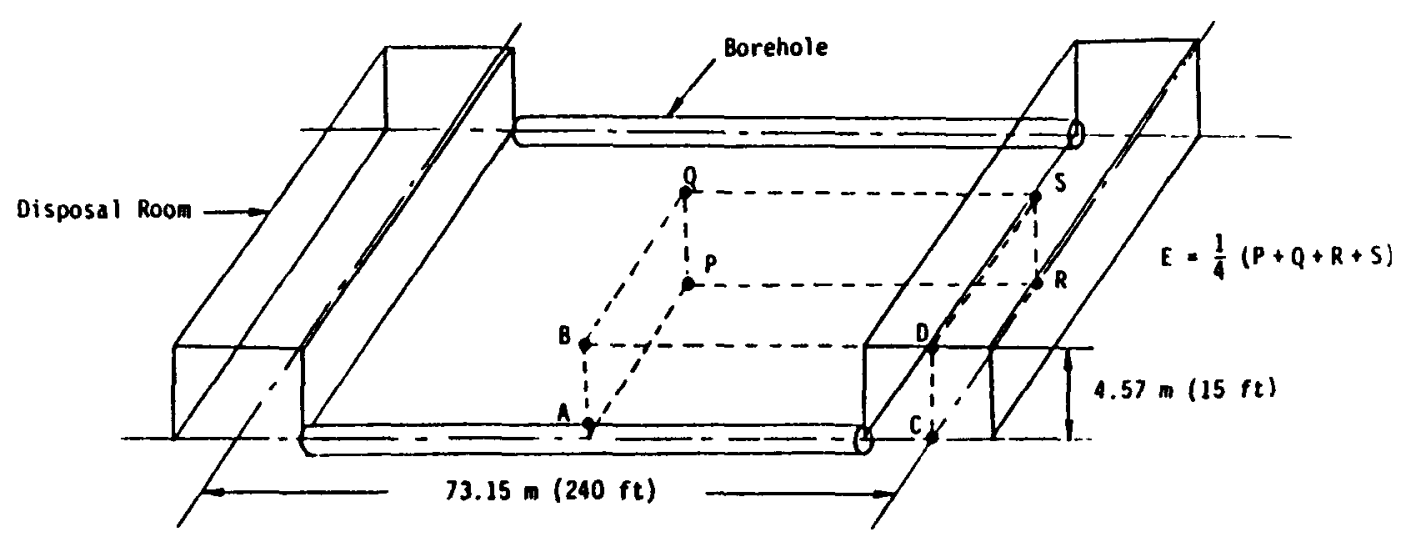


Figure B-29. Temperature Time Histories at Locations A, B, C, D, and E for PWR 12 Waste Packages Horizontally Emplaced in a Long Borehole. See Legend for

\section{Explanation of Locations}

3-0 ANALYTIC MODEL FOA SPENT FUEL

PพA12. $10 \mathrm{w} / \mathrm{m}^{2}$

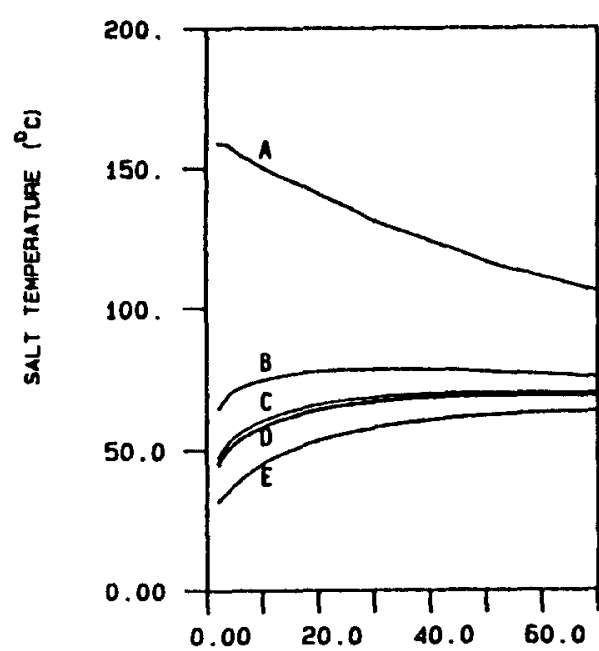

TIME (YEARS)
3-D AMLYYTIC MODEL FOR SPENT FUEL PWA12, $20 \mathrm{W/a^{2 }}$

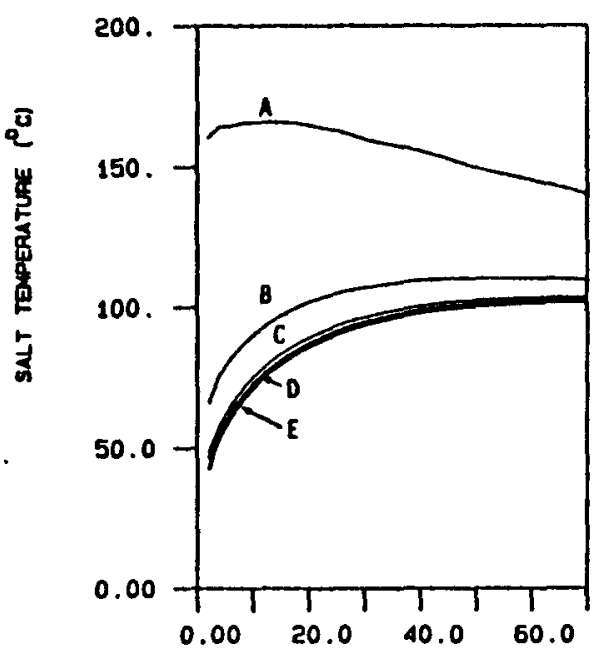

TIME (YEAAS)
3-D ANALYTIC MODEL FOR SPENT FUEL Pwa12, $30 \mathrm{~m} / \mathrm{m}^{2}$

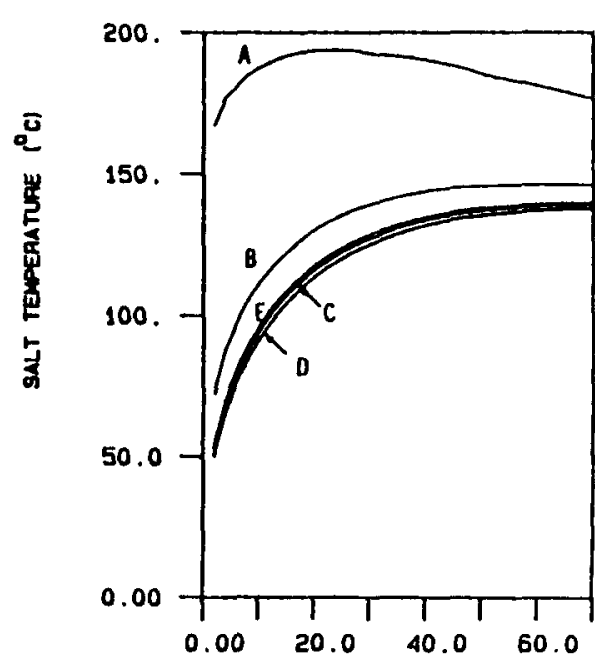

TIME (YEARS)

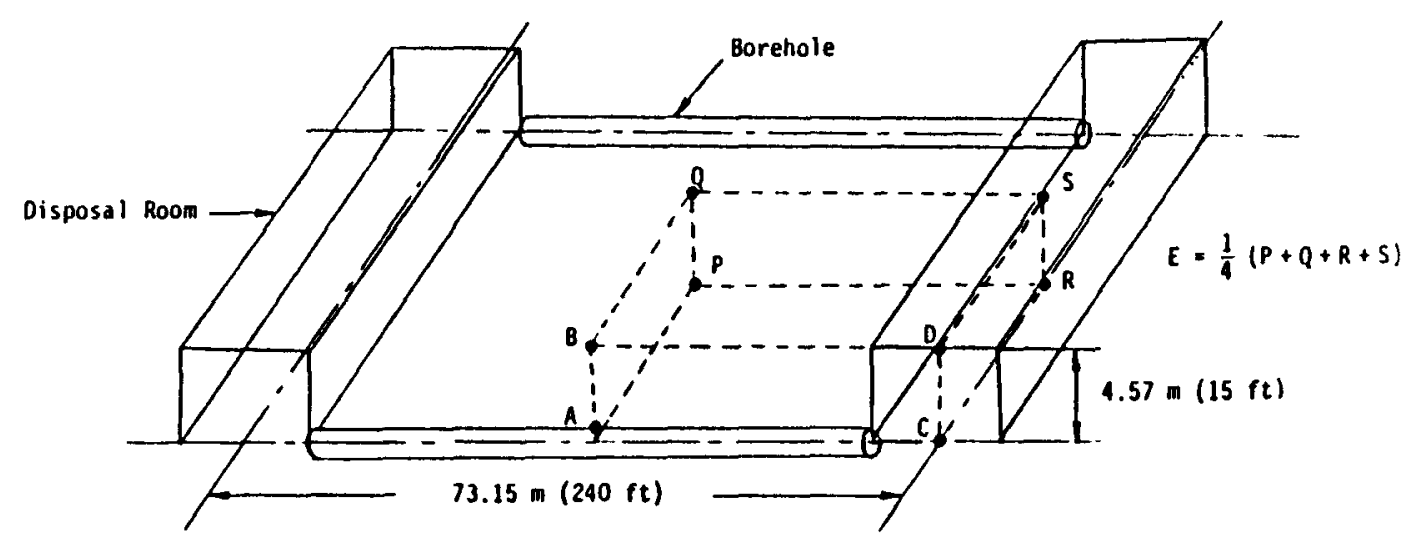


Figure B-30. Two-Dimensional Planar Model for Horizontal Emplacement in a Long Borehole in the Pillar

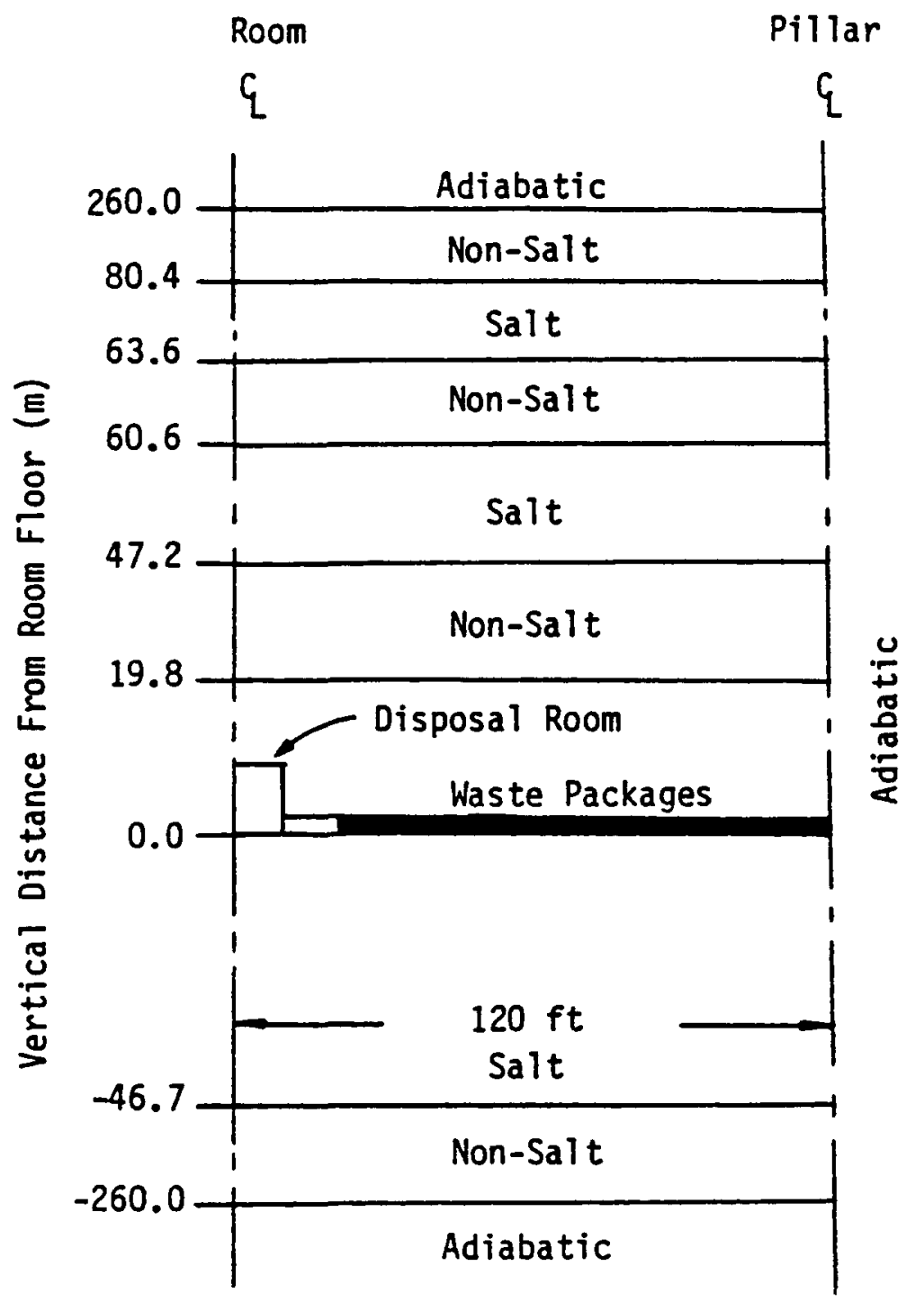


Figure B-31. Room and Pillar Temperatures for Emplacement in a Long Horizontal Borehole
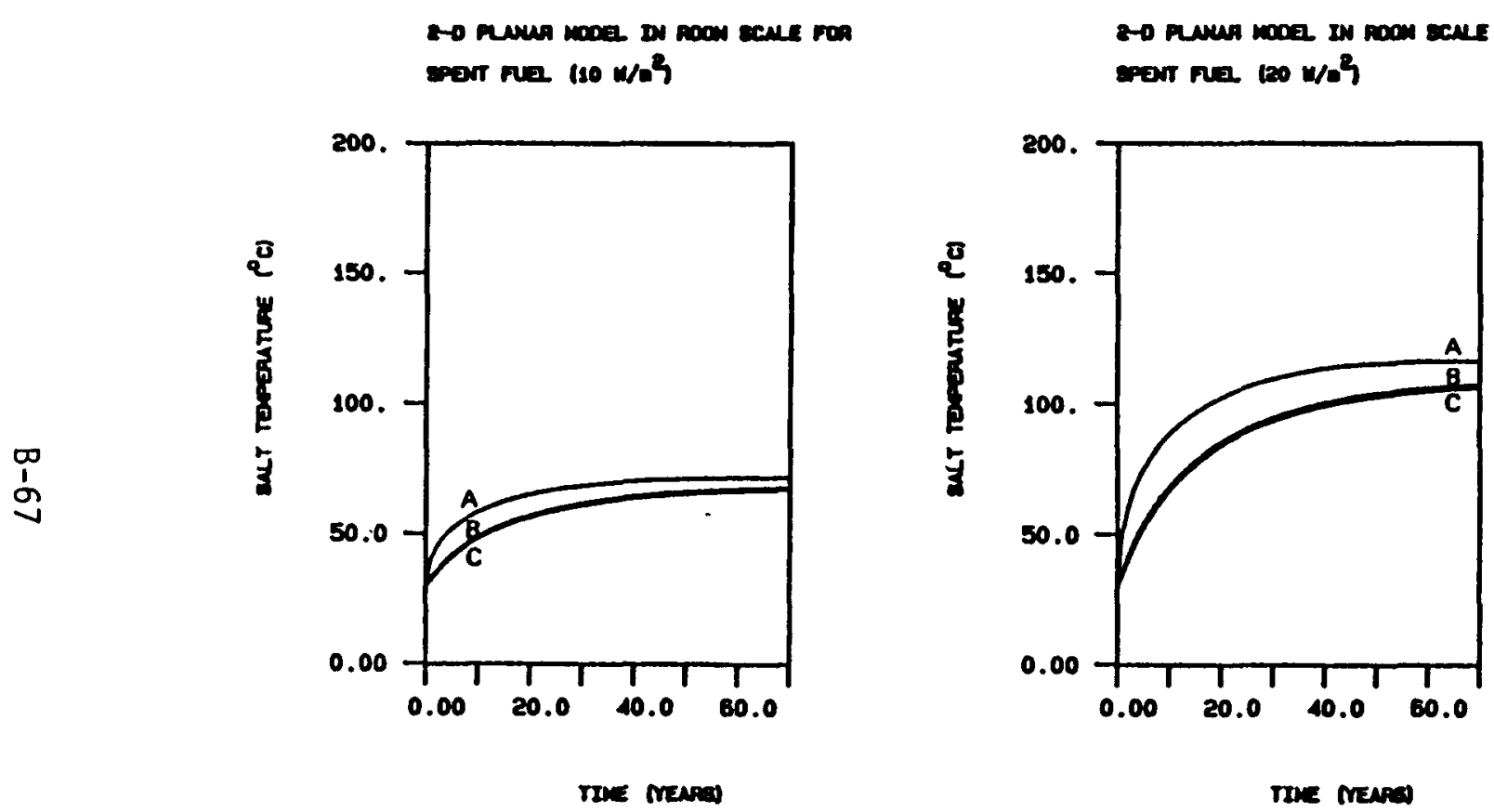

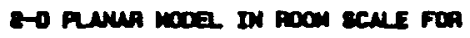
spar fua no wo'

True meapal
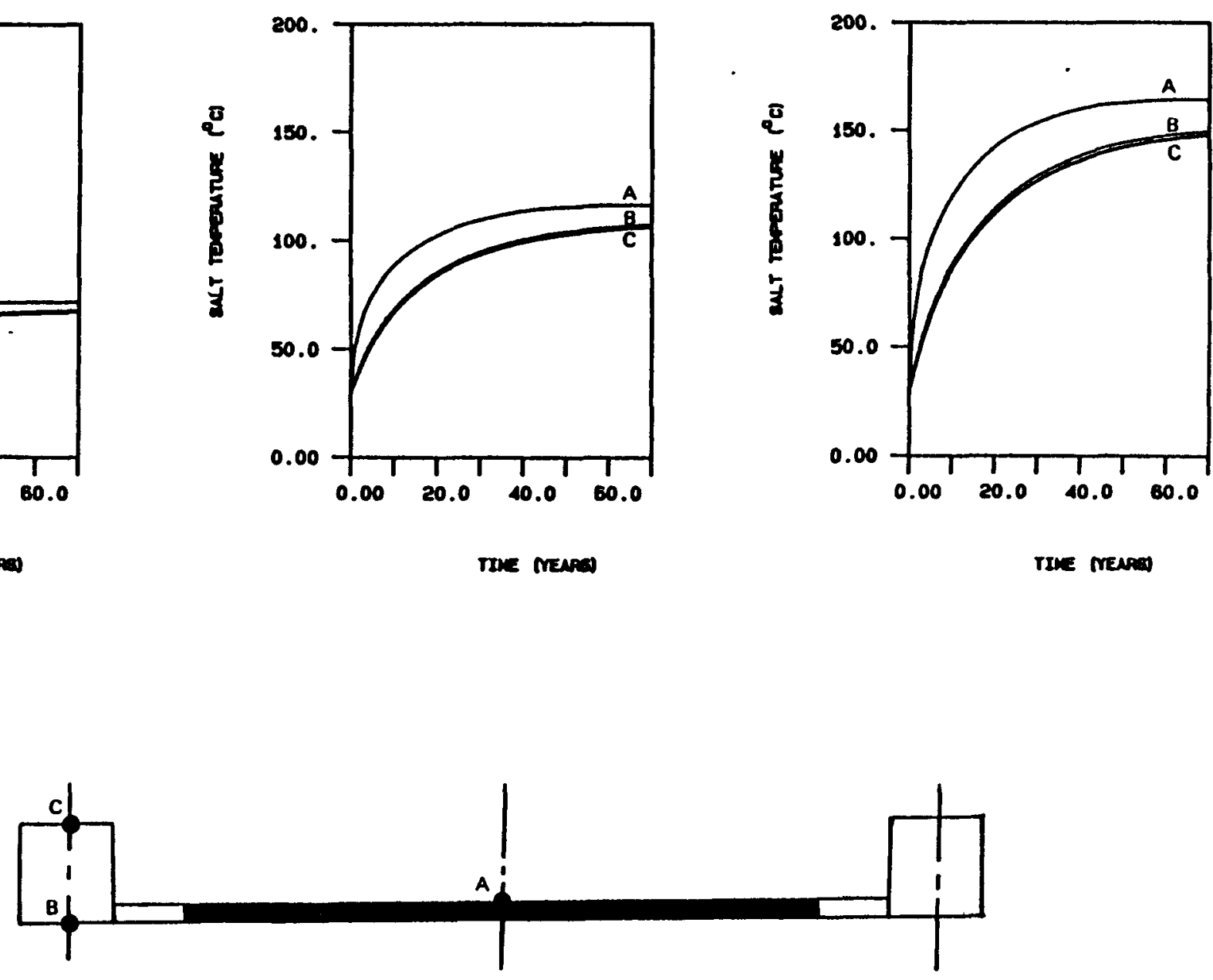
Figure B-32. Temperature Contours for Emplacement in a Long Horizontal Borehole at $10 \mathrm{~W} / \mathrm{m}^{2}$

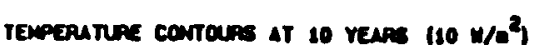

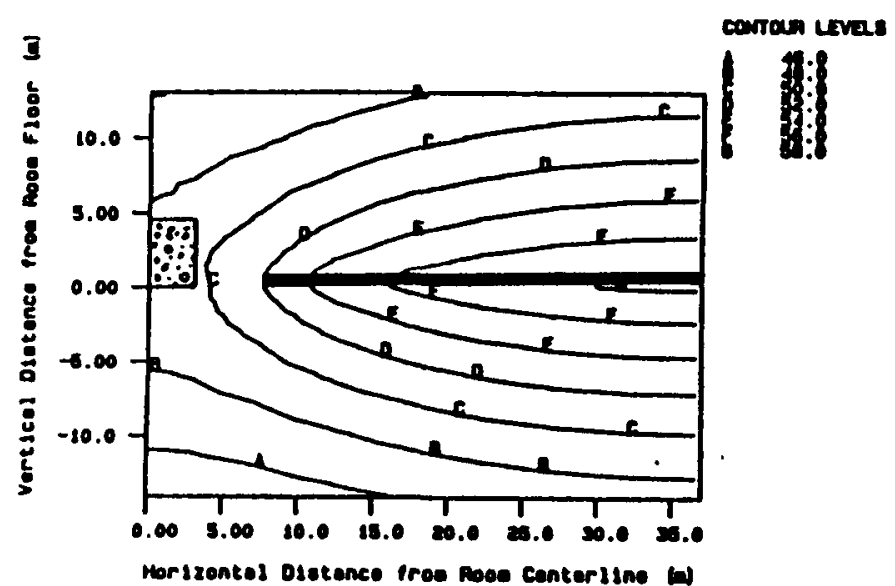

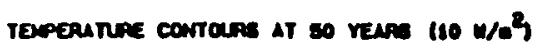

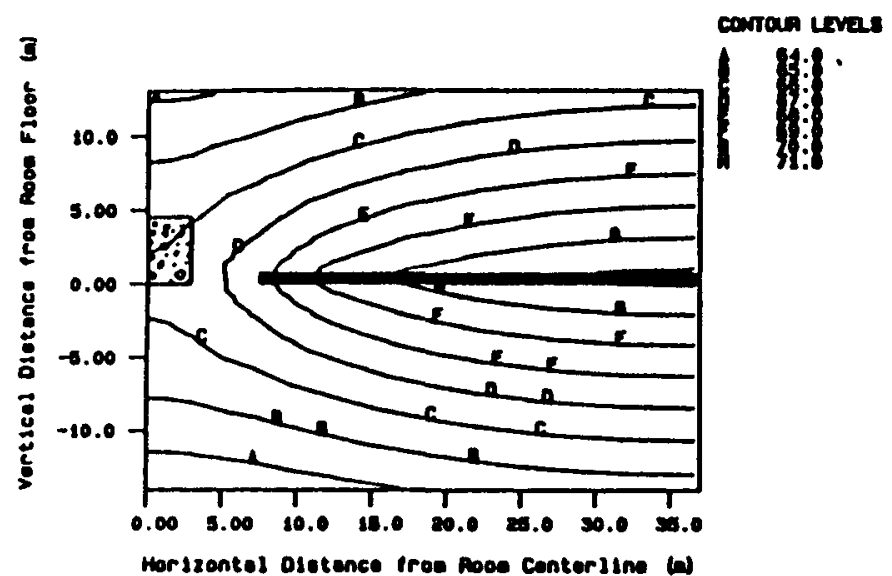

rewpenture contoups at so veats $110 \mathrm{w/0^{2 }}$

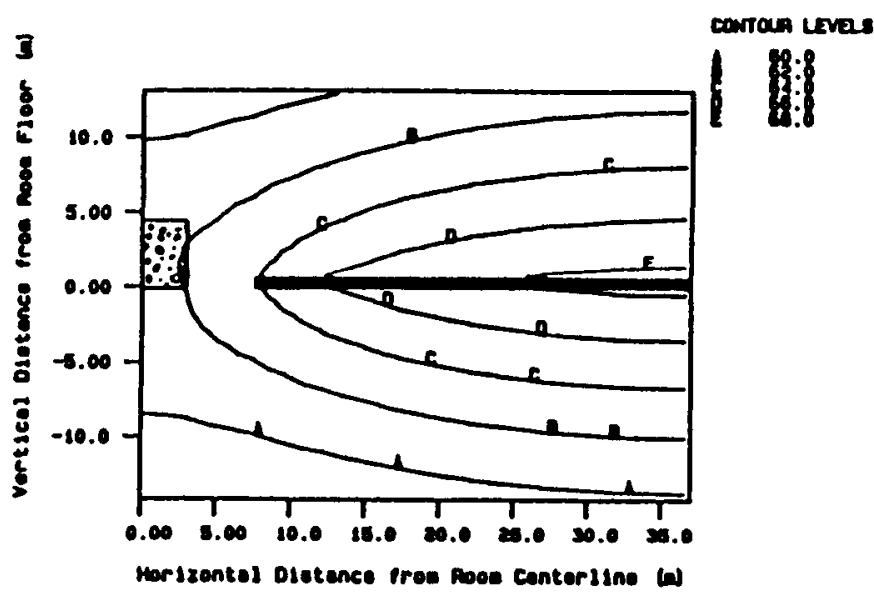

TEPERATRE Cowtous at 70 reass $\left(10 \mathrm{w} / \mathrm{o}^{2}\right)$

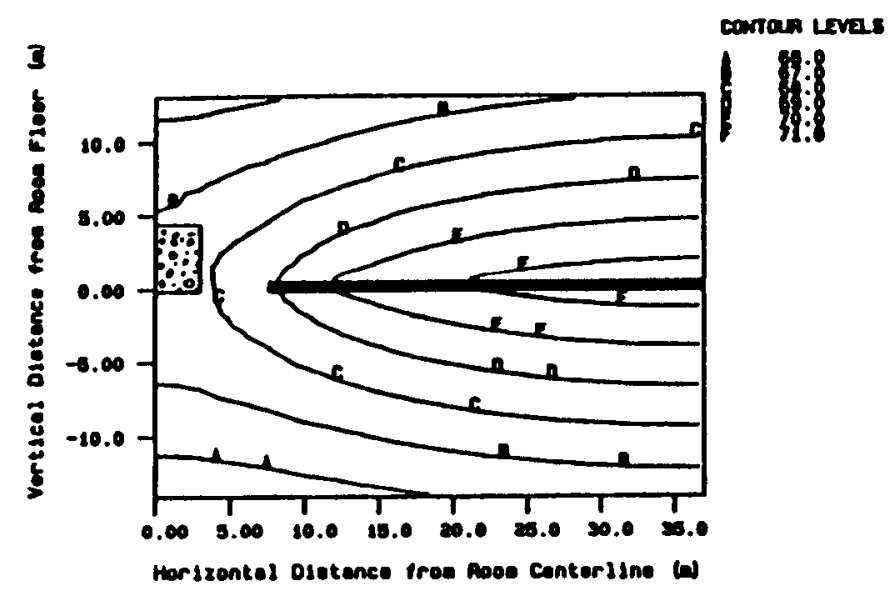


Figure B-33. Temperature Contours for Emplacement in a Long Horizontal Borehole at $20 \mathrm{~W} / \mathrm{m}^{2}$

Hordzontel ossetance iroe poou conterisino is

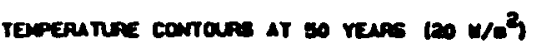

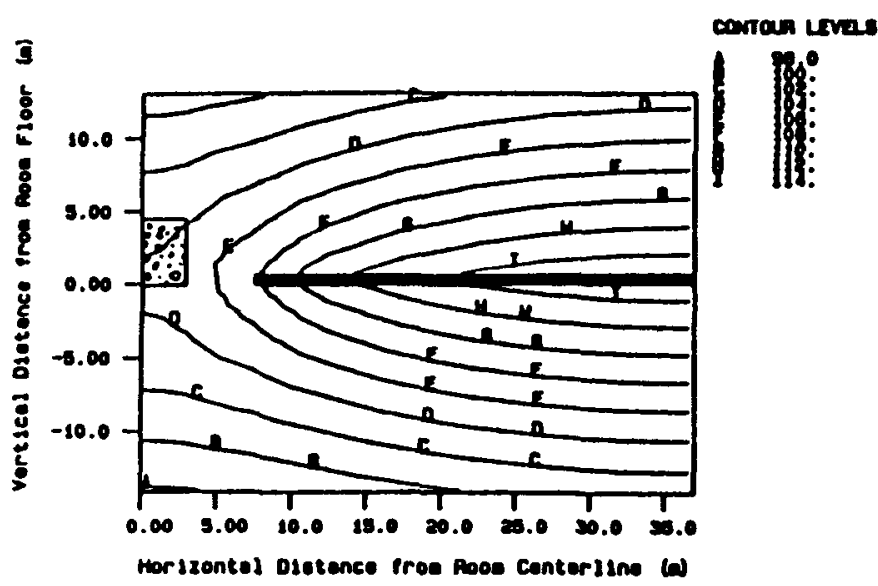

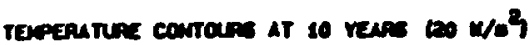

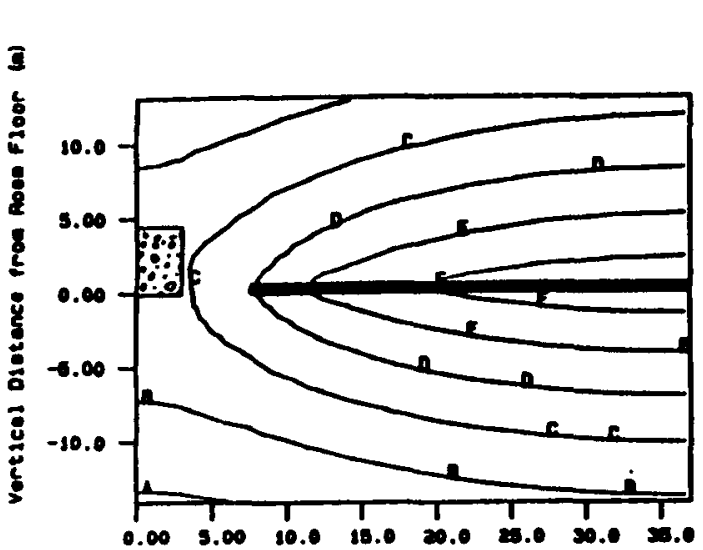

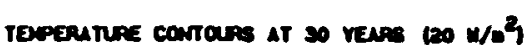

corran uves $1: 0$
8
$8:$

,

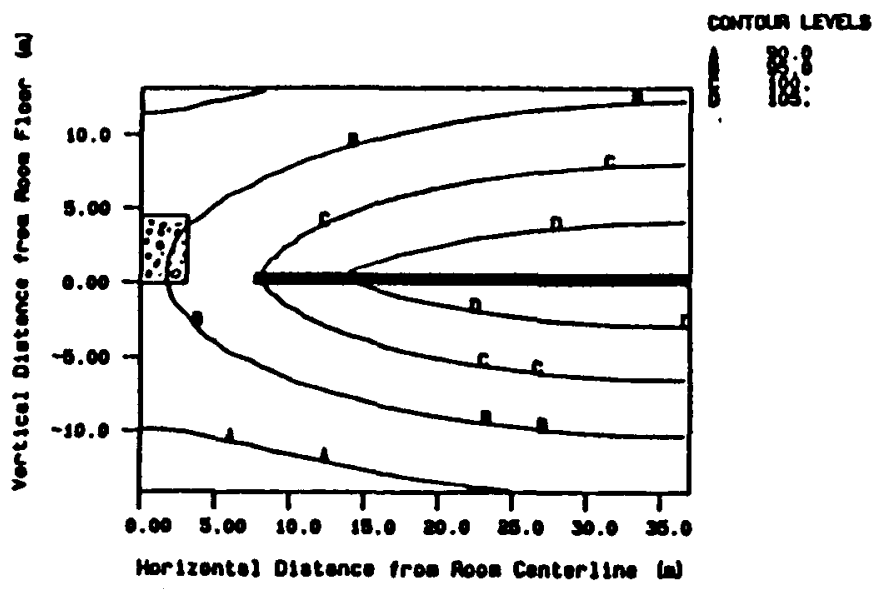

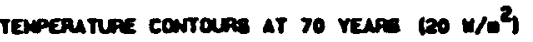

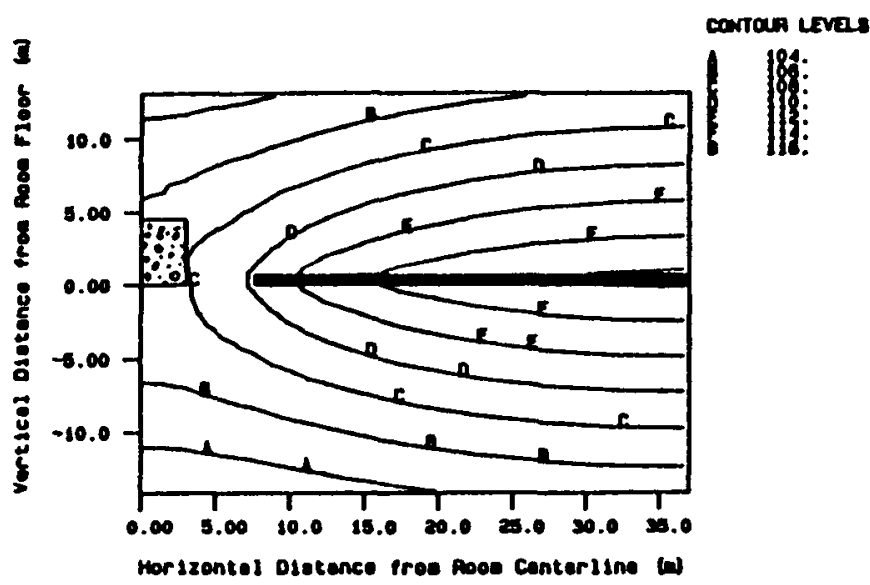


Figure B-34. Temperature Contours for Emplacement in a Long Horizontal Borehole at $30 \mathrm{~W} / \mathrm{m}^{2}$

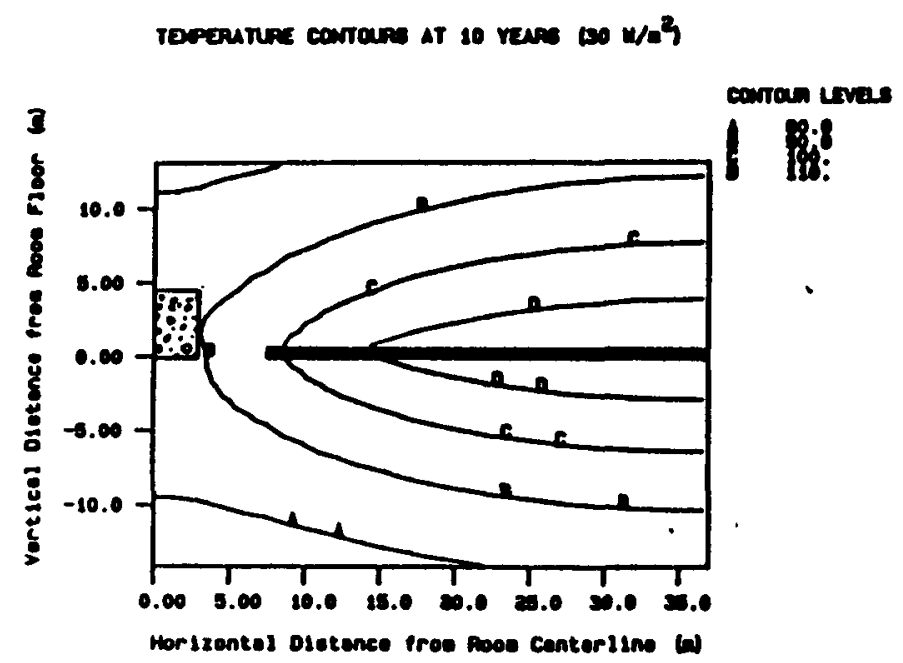

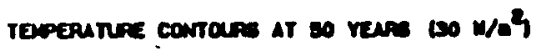

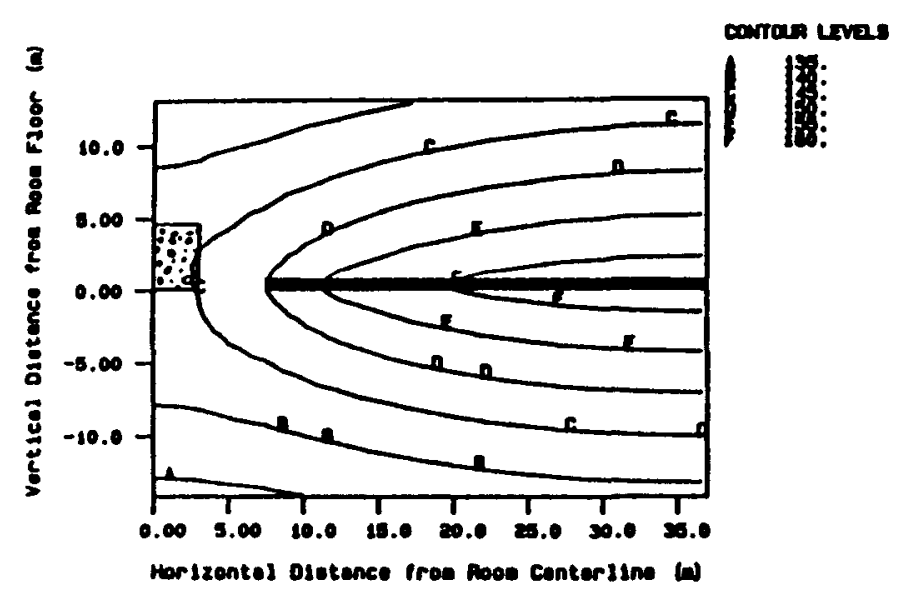

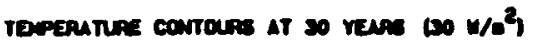

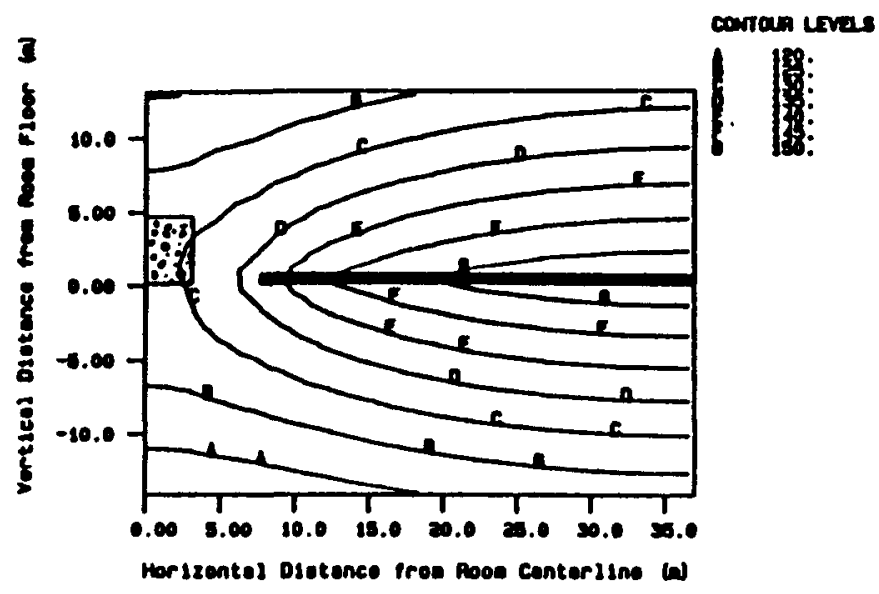

roperuture contoura at 70 veas $100 \mathrm{w/O}$

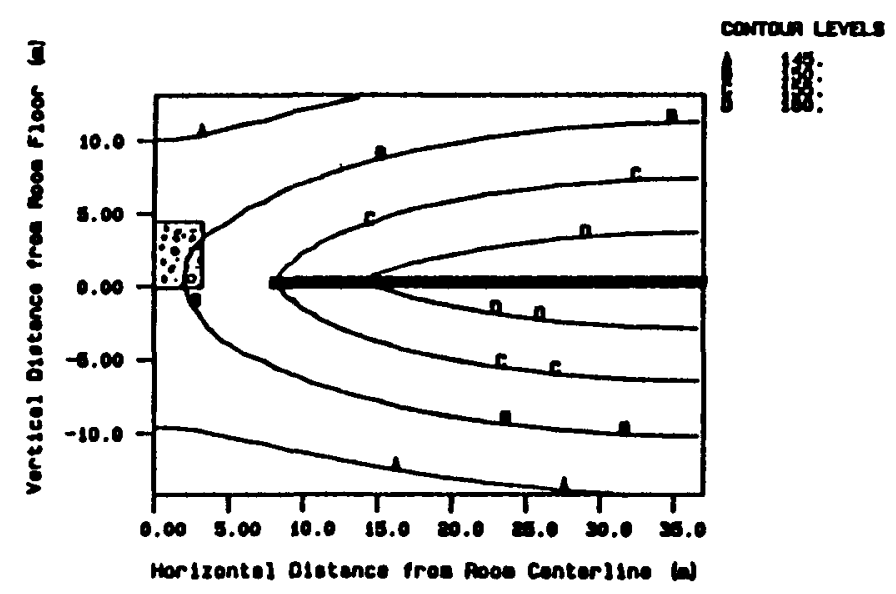


Figure B-35. Two-Dimensional Planar Model for the Thermal Calculation with an Alternate Stratigraphy (J. Friemel No. 1 Well)

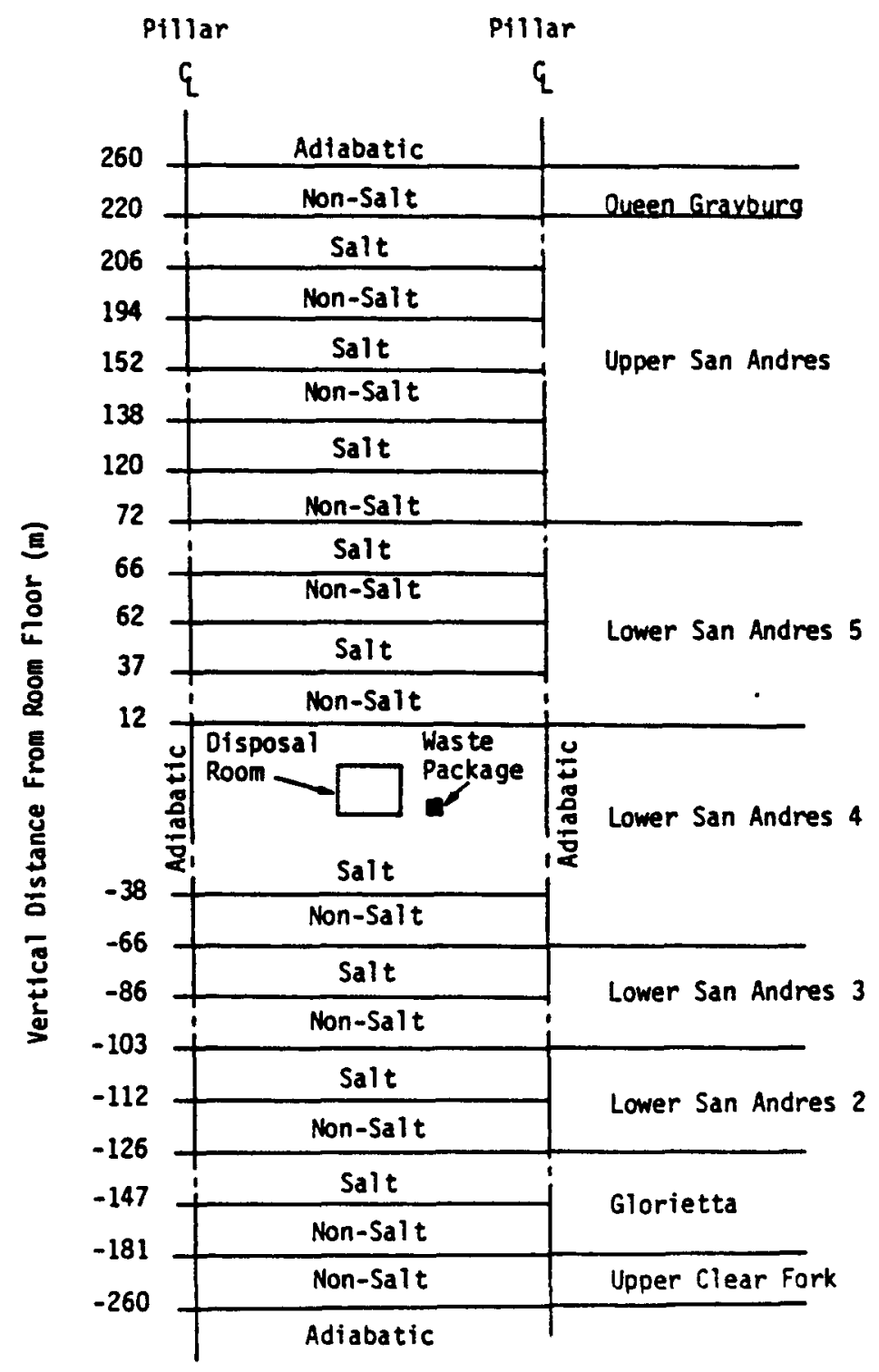


Figure B-36. Comparison of Temperature Contours at 50 Years After Emplacement for Calculations with the Detten and J. Friemel Stratigraphies

TEMPERATURE CONTOUAS AT 50 YEARS $\left(20 \mathrm{~W} / \mathrm{m}^{2}\right)$

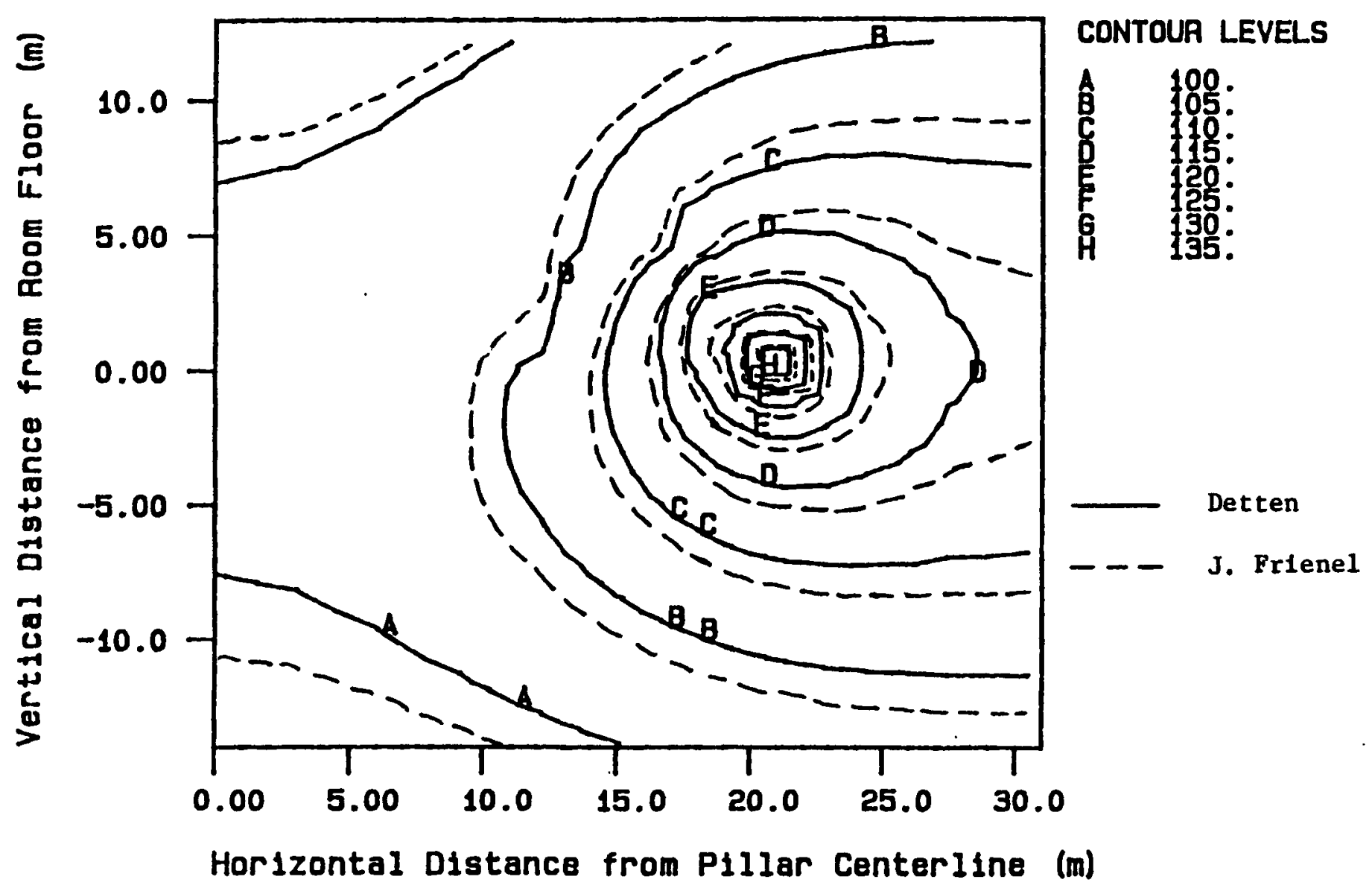


DOE, 1984. Draft Environmental Assessment, Deaf Smith County Site, Texas, DOE/RW-0014 U.S. Department of Energy, Washington, D.C., December.

INTERA, 1983. DOT: A Nonlinear Heat-Transfer Code for Analys is of TwoDimensional Planar and Axisymmetric Representations of Structures, ONWI-420, prepared for Office of Nuclear Waste Isolation, Battelle Memorial Institute, Columbus, $\mathrm{OH}$.

RE/SPEC, 1984. Thermomechanical Analyses of Conceptual Repository Designs for the Paradox and Permian Basins, RSI-0204, Draft Final Report prepared by $\mathrm{RE} / \mathrm{SPEC}$ Inc. for Office of Nuclear Waste Isolation, Battelle Memorial Institute, Columbus, $\mathrm{OH}$.

ONWI, 1984. Identification of Sites Within the Palo Duro Basin: Volume 1 Palo Duro Location A, BMI/ONWI-531, Volume 1, Office of Nuclear Waste Isolation, Columbus, Ohio, February.

ONWI, 1985. Waste Package Conceptual Designs for a Repository in Salt, Office of Nuclear Waste Isolation, Columbus, Ohio, ONWI-517.

Stearns-Roger, 1983. Deaf Smith and Swisher Counties, Texas: Repository Design Concepts and Costs, Denver, CO.

Stone and Webster, 1984. Geotechnical Log - J. Friemel No. 1 Well - Deaf Smith County, TX, OPBST-1173, pp. B-42 through B-47. 
APPENDIX C

WASTE PACKAGE STRESS FIELD ANALYSIS 
APPENDIX C

TABLE OF CONTENTS

$\underline{\text { Page }}$

C. 1 MECHANICAL ANALYSIS OF EMPLACEMENT IN A VERTICAL BOREHOLE $\ldots \ldots \ldots \ldots \ldots \ldots \ldots \ldots \ldots \ldots \ldots \ldots \ldots \ldots \ldots$ C-11

C.1.1 Description of Calculations ............. C-11

C.1.2 Results for Vertical Emplacement .......... C-17

C. 2 MECHANICAL ANALYSIS OF EMPLACEMENT IN A

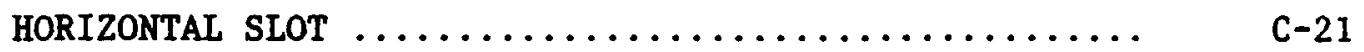

C.2.1 Description of Calculations ............. C-21

C.2.2 Results for Horizontal Slot Emplacement ..... C-23

C.3 SURVEY OF MECHANICAL FAILURE MODES FOR

THE WASTE PACKAGE ...................... c-25

C.3.1 Longitudinal Bending Loads ............. C-26

C.3.2 Estimates of Failure Stresses

for the Reference Package ............. c-27

C.3.2.1 Failure Under Uniform

Radial Stress ............... C

C.3.2.2 Failure Under Line Load ......... C-28

C.3.2.3 Failure Under Uniform

Lateral Stress .............. C -29

C.3.2.4 Summary .................. $\quad$ - 29 
APPENDIX C

TABLE OF CONTENTS

(Continued)

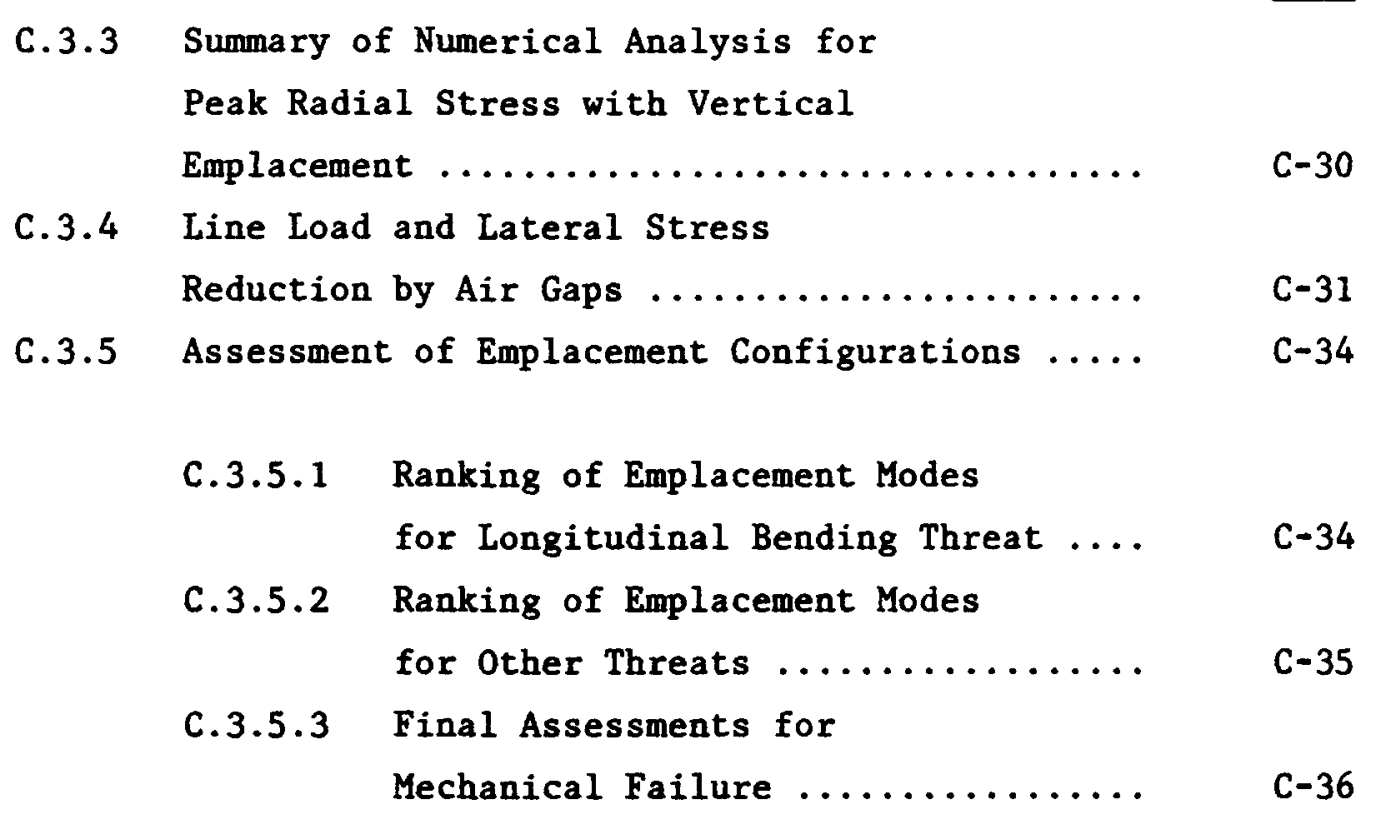

C.4 REFERENCES $\ldots \ldots \ldots \ldots \ldots \ldots \ldots \ldots \ldots \ldots \ldots \ldots \ldots \ldots \ldots \ldots$ 
APPENDIX C

LIST OF TABLES

$\underline{\text { Page }}$

C-1 Parameters for Vertical Emplacement

Calculations ......................... C-12

C-2 Material Properties for the Calculations

of Radial Stress ...................... C-14

C-3 Creep Law Parameters for Calculations

of Radial Stress ....................... c-15

C-4 Effective Material Properties for

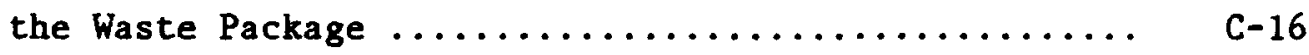

C-5 Initial Gap Closure Time (Years) $\ldots \ldots \ldots \ldots \ldots \ldots \ldots \ldots, c-19$

C-6 Peak Radial Stress on the Waste Package,

Time of Peak Radial Stress .................. C-20

C-7 Initial Air Gap Closure Time (Years) $\ldots \ldots \ldots \ldots \ldots \ldots \quad c-23$

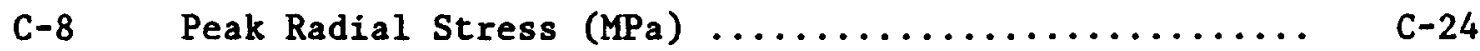

C-9 Assumed Package Properties $\ldots \ldots \ldots \ldots \ldots \ldots \ldots \ldots \ldots \ldots$ C-27

C-10 Summary of Failure Stress Estimates ............. c-29

C-11 Line Source Strength Cases $\ldots \ldots \ldots \ldots \ldots \ldots \ldots \ldots \ldots \ldots, c-30$ 
APPENDIX C

LIST OF FIGURES

$\underline{\text { Page }}$

C-1 Two-Dimensional Axisymmetric Model for

Calculating the Radial Stress for Emplacement

in a Vertical Borehole ..................... C-38

C-2 Boundary Conditions for Calculating

the Radial Stress for Emplacement in

a Vertical Borehole ......................... c-39

C-3 Two-Dimensional Planar Model for Calculating

the Radial Stress for Emplacement in

a Horizontal Slot

$\mathrm{C}-40$

C-4 Schematic Diagram of Cap Closure Algorithm

for Emplacement in a Vertical Borehole ............. C-41

C-5 Radial Stress Versus Time at Upper Third of

Waste Package in Vertical Emplacement Mode

with $20 \mathrm{~W} / \mathrm{m}^{2}$ and $0^{\prime \prime}$ Air Gap

$\mathrm{C}-42$

C-6 Radial Stress Versus Time at Mid-Height of

Waste Package in Vertical Emplacement Mode

with $20 \mathrm{w} / \mathrm{m}^{2}$ and $0 "$ Air Gap ....................

C-7 Radial Stress Versus Time at Lower Third of

Waste Package in Vertical Emplacement Mode

with $20 \mathrm{w} / \mathrm{m}^{2}$ and $1 "$ Air Gap $\ldots \ldots \ldots \ldots \ldots \ldots \ldots \ldots \ldots \ldots \ldots \ldots \ldots$ C-44

C-8 Radial Stress Versus Time at Upper Third of

Waste Package in Vertical Emplacement Mode

with $20 \mathrm{w} / \mathrm{m}^{2}$ and $1^{\prime \prime}$ Air Gap ...................... -45 
APPENDIX C

LIST OF FIGURES

(Continued)

$\underline{\text { Page }}$

C-9 Radial Stress Versus Time at Mid-Height of

Waste Package in Vertical Emplacement Mode

with $20 \mathrm{w} / \mathrm{m}^{2}$ and $1^{\prime \prime}$ Air Gap $\ldots \ldots \ldots \ldots \ldots \ldots \ldots \ldots \ldots \ldots$ C-46

C-10 Radial Stress Versus Time at Upper Third of

Waste Package in Vertical Emplacement Mode

with $20 \mathrm{~W} / \mathrm{m}^{2}, \mathrm{l}^{\prime \prime}$ Air Gap, and Low Salt

Thermal Conductivity .................... C-47

C-11 Radial Stress Versus Time at Upper Third of

Waste Package in Vertical Emplacement Mode

with $20 \mathrm{~W} / \mathrm{m}^{2}$, 1" Air Gap, and Low Salt

Thermal Conductivity .................... C-48

C-12 Radial Stress Versus Time at Mid-Height

of Waste Package in Vertical Emplacement Mode

with $20 \mathrm{~W} / \mathrm{m}^{2}$, $1^{\prime \prime}$ Air Gap, and Low Salt

Thermal Conductivity ..................... C-49

C-13 Radial Stress Versus Time at Upper Third

of Waste Package in Vertical Emplacement Mode

with $20 \mathrm{~W} / \mathrm{m}^{2}, 1^{\prime \prime}$ Air Gap, and Low Salt

Thermal Conductivity .................... c-50

C-14 Radial Stress Versus Time at Upper Third

of Waste Package in Vertical Emplacement Mode

with $20 \mathrm{~W} / \mathrm{m}^{2}$, 1" Air Gap, and Low Salt

Creep Rate ........................... C-51 
APPENDIX C

LIST OF FIGURES

(Continued)

Page

C-15 Radial Stress Versus Time at Mid-Height of Waste Package in Vertical Emplacement Mode with $20 \mathrm{~W} / \mathrm{m}^{2}, 1^{\prime \prime}$ Air Gap, and Low Salt Creep Rate ........................ C-52

C-16 Radial Stress Versus Time at Lower Third of Waste Package in Vertical Emplacement Mode with $20 \mathrm{~W} / \mathrm{m}^{2}, 1^{\prime \prime}$ Air Gap and Low Salt Creep Rate ......................... C-53

C-17 Radial Stress Versus Time at Upper Third of Waste Package in Vertical Emplacement Mode with $20 \mathrm{~W} / \mathrm{m}^{2}$ and $2 "$ Air Gap $\ldots \ldots \ldots \ldots \ldots \ldots \ldots$ C-54

C-18 Radial Stress Versus Time at Mid-Height of Waste Package in Vertical Emplacement Mode with $20 \mathrm{~W} / \mathrm{m}^{2}$ and $2 "$ Air Gap ............... C-55

C-19 Radial Stress Versus Time at Lower Third of Waste Package in Vertical Emplacement Mode with $20 \mathrm{w} / \mathrm{m}^{2}$ and $1 "$ Air Gap .............. c-56

C-20 Radial Stress Versus Time at Upper Third of Waste Package in Vertical Emplacement Mode

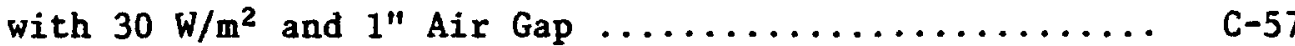




\section{APPENDIX C}

LIST OF FIGURES

(Continued)

$\underline{\text { Page }}$

C-21 Radial Stress Versus Time at Mid-Height

of Waste Package in Vertical Emplacement Mode

with $30 \mathrm{~W} / \mathrm{m}^{2}$ and $1^{\prime \prime}$ Air Gap $\ldots \ldots \ldots \ldots \ldots \ldots \ldots \ldots \ldots \ldots \ldots$

C-22 Radial Stress Versus Time at Lower Third

of Waste Package in Vertical Emplacement Mode

with $30 \mathrm{w} / \mathrm{m}^{2}$ and $1 "$ Air Gap $\ldots \ldots \ldots \ldots \ldots \ldots \ldots \ldots \ldots \ldots$. 59

C-23 Schematic Diagram of Gap Closure Algorithm

for Emplacement in a Horizontal slot ........... c-60

C-24 Radial Stress Versus Time at Left Side

of Waste Package in Horizontal Emplacement

Mode with Low Waste Package Heat

Energy Density $\ldots \ldots \ldots \ldots \ldots \ldots \ldots \ldots \ldots \ldots \ldots \ldots \ldots$. -61

C-25 Radial Stress Versus Time at Right Side

of Waste Package in Horizontal Emplacement

Mode with Low Waste Package Heat

Energy Density $\ldots \ldots \ldots \ldots \ldots \ldots \ldots \ldots \ldots \ldots \ldots \ldots \ldots \ldots$. -62

C-26 Radial Stress Versus Time at Bottom Side

of Waste Package in Horizontal Emplacement

Mode with Low Waste Package Heat

Energy Density

C -63 
APPENDIX C

LIST OF FIGURES

(Continued)

$\underline{\text { Page }}$

C-27 Radial Stress Versus Time at Top Side

of Waste Package in Horizontal Emplacement

Mode with High Waste Package Heat

Energy Density .......................... C 64

C-28 Radial Stress Versus Time at Left Side

of Waste Package in Horizontal Emplacement

Mode with High Waste Package Heat

Energy Density

C-65

C-29 Radial Stress Versus Time at Right Side

of Waste Package in Horizontal Emplacement

Mode with High Waste Package Heat

Energy Density

C-66

C-30 Radial Stress Versus Time at Bottom Side

of Waste Package in Horizontal Emplacement

Mode with High Waste Package Heat

Energy Density ........................... C-67

C-31 Radial Stress Versus Time at Top Side

of Waste Package in Horizontal Emplacement

Mode with High Waste Package Heat

Energy Density ........................ C-68

C-32 Room and Pillar Distortions for the

Low and High Energy Sources ................. C-69 


\section{APPENDIX C}

LIST OF FIGURES

(Continued)

$\underline{\text { Page }}$

C-33 Schematic Diagram of Package Failure Modes ......... C-70

C-34 Typical Distortions of 1 Meter Salt Zones

for a 50 percent Reduction in Room Volume ......... c-71

C-35 Peak Radial Stress Versus Air Gap Closure

Time for the Upper Third and Middle Third

of the Package ........................ c -72

C-36 Estimates of the Lateral Stress, $\sigma_{1}$,

Versus Time Based on a Simple, Analytic Model ....... c-73

C-37 Relative Ranking of Package Emplacement Modes

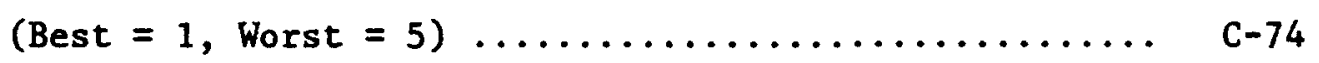

C-38 Schematic Diagram of a Scenario for

Generating a Concentrated Load from Sudden

Failure of The Room Wall .................. C-75 
APPENDIX C

WASTE PACKAGE STRESS FIELD ANALYSIS

A series of calculations and analyses have been performed to determine the mechanical response to an emplaced waste package. The specific objective of these studies is to determine the peak radial stress for the 17 candidate emplacement modes and to identify those emplacement modes that might result in a waste package stress failure. The technical approach to this study is to (1) perform numerical analyses of two representative modes, and (2) to extend these results to other emplacement modes by evaluating the potential failure mechanisms for a waste package.

The following subsection presents the numerical analyses for the horizontal and vertical emplacement modes. The results for the vertical emplacement mode show that, with an annular gap between package and borehole, the peak radial stress is below the $21.4 \mathrm{MPa}$ design limit of a package in the hoop mode (ONWI, 1985). This general result should be applicable to emplacement in any borehole. The results for the horizontal emplacement mode show a similar behavior: a gap will provide sufficient stress relief to keep the peak radial stress below $21.4 \mathrm{MPa}$.

The review of potential failure mechanisms considered a uniform radial loading (the hoop mode), a concentrated load on one side of a package, and a bending load normal to the package centerline. The response to these loads indicates that bending modes or stress concentrations from local geologic failures posed the greatest threat to a waste package, and that an air gap will eliminate the threat from a concentrated load on one side of a package.

\section{C.1 MECHANICAL ANALYSIS OF EMPLACEMENT IN A VERTICAL BOREHOLE}

\section{C.1.1 Description of Calculations}

A series of calculations with the STEALTH 2D computer program (Hofmann, 1981) was performed to compute the stress field surrounding an emplaced waste 
package in salt. The objective of these calculations is to determine the magnitude of the peak radial stress on an emplaced waste package. The peak radial stress is important because excessive radial stress may cause failure of the waste package.

A series of calculations was performed to determine the peak radial stress for emplacement in a vertical borehole as a function of initial conditions and material properties. More specifically, the radial stress was determined as a function of the areal heat loading, the gap size between the borehole and the package, the thermal conductivity of the salt, and the creep rate of the salt. A summary of the six calculations that were performed is given in Table C-1. The stratigraphy for the simulations was the Deaf Smith site at a repository depth of $792 \mathrm{~m}(2600 \mathrm{ft})$. The initial lithostatic overburden stress was $17.58 \mathrm{MPa}$, with an initial ambient temperature of $30^{\circ} \mathrm{C}$.

Table C-1. Parameters for Vertical Emplacement Calculations

\begin{tabular}{cccc}
\hline \hline Case & $\begin{array}{c}\text { Air Gap } \\
\text { (inch) }\end{array}$ & $\begin{array}{c}\text { Areal Heat } \\
\text { Loading }\left(\mathrm{W} / \mathrm{m}^{2}\right)\end{array}$ & Special Materials \\
\hline 1 & 0 & 20 & N/A \\
2 & 1 & 20 & N/A \\
3 & 1 & 20 & Low salt conductivity \\
4 & 1 & 20 & Low salt creep rate \\
5 & 2 & 20 & N/A \\
6 & 1 & 30 & N/A \\
\hline \hline
\end{tabular}

Calculations 1,2 , and 5 analyze the variation of radial stress with air gaps of 0,1 , and 2 inches, respectively. Calculations 2,3 , and 4 analyze the variation of radial stress with thermal conductivity and with the creep rate of salt. Calculations 2 and 6 analyze the variation of radial stress with areal loadings of 20 and $30 \mathrm{~W} / \mathrm{m}^{2}$, respectively. 
Figure C-1 is a schematic diagram of the computational model for these calculations. The locations of the upper and lower boundaries are far enough above and below the room so that the thermal boundary conditions do not influence the temperature field near the room during the time frame of the calculation. The top portion of the mesh is the $25 \mathrm{~m}$ thick Lower San Andres Unit 5 anhydrite and the bottom portion is the $50 \mathrm{~m}$ thick Lower San Andres Unit 4 Cycle 4 salt.

Figure C-2 shows the boundary conditions for the vertical emplacement calculations. The left, right, and bottom boundaries are adiabatic roller boundaries. The top boundary is an adiabatic constant pressure boundary. The constant pressure is the initial lithostatic overburden stress (17.58 $\mathrm{MPa})$. The walls of the room are allowed to transport heat by radiation. The emissivity of the walls is assumed to be 0.8 (RE/SPEC, 1984). Thermal conduction within the room is neglected.

In all cases, the vertically emplaced package was the PWR12 spent fuel waste package. The results with the PWR12 package are conservative, in the sense that the peak radial stress will be greater with the PWR12 package than with the PWR9 or PWR6 packages.

Figure C-3 summarizes the physical dimensions of the models for areal heat loadings of 20 and $30 \mathrm{~W} / \mathrm{m}^{2}$. The outer radius of the model is selected so that the cross-sectional area of the computational model is equal to the crosssectional area per package in the repository layout. Similarly, the radius of the room in the model is selected so that the cross-sectional area of the room matches the room cross-sectional area per packages in the repository layout.

The material properties for the calculations are given in Tables $\mathrm{C}-2$ and $\mathrm{C}-3$. The individual materials in the actual waste package are blended into a single material for computational efficiency. Table $c-4$ lists the effective material parameters for the model of the package. The specific heat density in the table is based on a mass weighted average of the specific heat densities of 
Table C-2. Material Properties for the Calculations of Radial Stress

(Source: RE/SPEC, 1984)

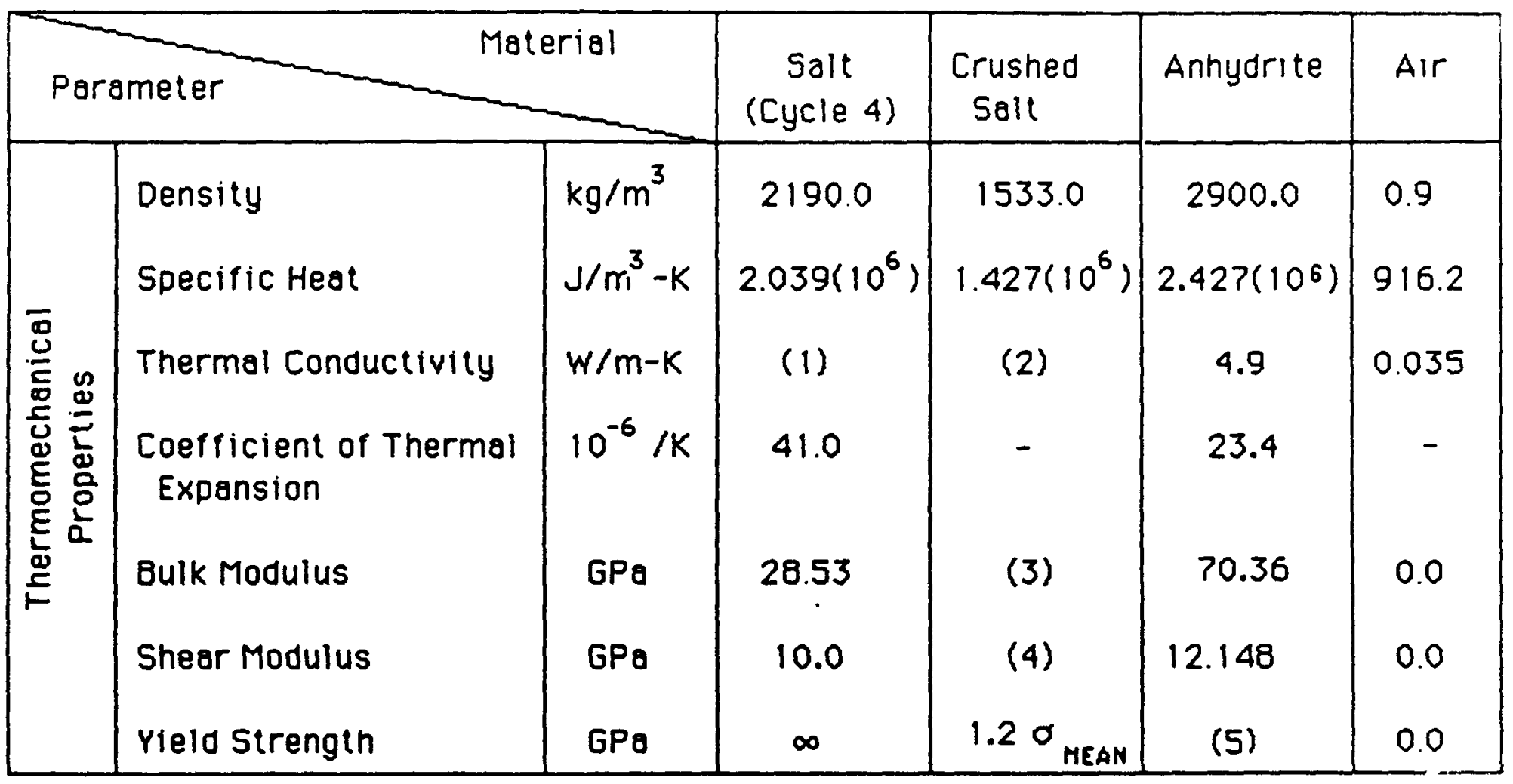

(1) $k(T)=6.02-1.84\left(10^{-2}\right) T+3.20\left(10^{-5}\right) T^{2}$

$K(T)=4.3(300.0 / T(K))^{0.988}$ [Low Conductivity Case]

(2) $K(T)=0.60-1.84\left(10^{-3}\right) T+3.20\left(10^{-6}\right) T^{2}$

(3) $K=6.99\left(10^{6}\right)+17.9 \sigma_{\text {MEAM }}$

(4) $G=4.194\left(10^{6}\right)+10.74 \sigma_{\text {MEAN }}$

(5) $Y=9.25\left(10^{7}\right)+1.13 \sigma_{\text {MeAN }} \begin{aligned} & \text { (Mohr-Coulomb Yield } \\ & \text { Model) }\end{aligned}$ 
Table C-3. Creep Law Parameters for Calculations of Radial Stress (Source: RE/SPEC, 1984)

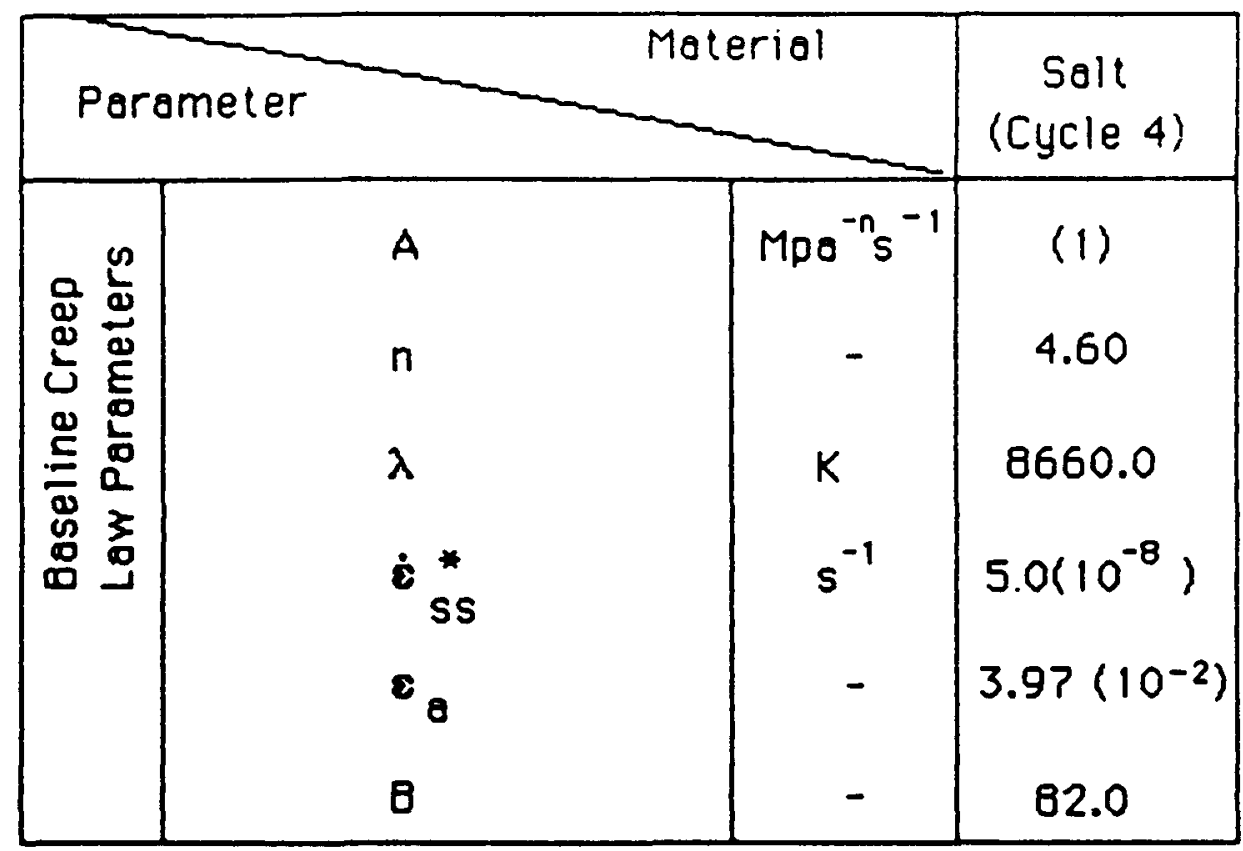

(1) $\quad A=4.66\left(10^{-3}\right)$

$A=2.33\left(10^{-3}\right)$ (Low Creep Case]

Baseline Exponential-Time

Creep Lam

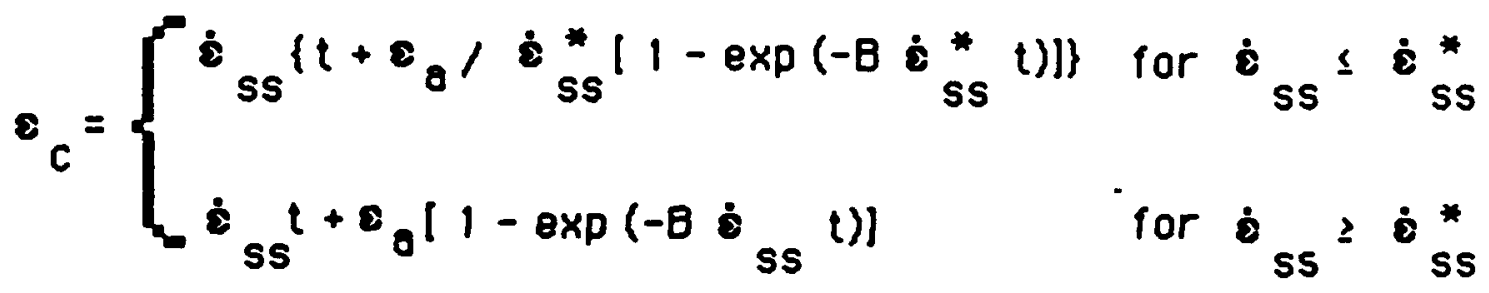

where, $\quad \dot{\varepsilon}_{\text {ss }}=A \sigma^{n} \exp (-Q / R T)$

ond,

$$
\begin{aligned}
\dot{s}_{\text {ss }}= & \text { Steody-State Stroin Rate } \\
8_{\text {s }} & \text { Asymptotic Transient Strain } \\
\dot{8}_{\text {ss }}^{*}= & \text { Critical Strain Rate dividing low and high } \\
& \text { steody-state regions }
\end{aligned}
$$

$A, B, n, Q / R=$ Fitting Porometers 
Table C-4. Effective Material Properties for the Waste Package (Source: RE/SPEC, 1984)

\begin{tabular}{|l|c|c|}
\hline \multicolumn{2}{|c|}{ Material } & $\begin{array}{c}\text { Waste } \\
\text { Package }\end{array}$ \\
\hline Porometer & $\mathrm{kg} / \mathrm{m}^{3}$ & 8790.0 \\
Specific Heat & $\mathrm{J} / \mathrm{m}^{3}-\mathrm{K}$ & $3.7358\left(10^{6}\right)$ \\
Thermol Conductivity (Axiol) & $w / \mathrm{m}-\mathrm{K}$ & 5.5 \\
Thermol Conductivity (Radial) & $w / m-K$ & $(1)$ \\
\hline
\end{tabular}

(1) $k(T)=0.865+4.02\left(10^{-5}\right) \mathrm{T}+3.17\left(10^{-6}\right) \mathrm{T}^{2}$ 
the individual components. The thermal conductivity of the package is anisotropic. The axial conductivity is the conductivity of steel and the radial conductivity is the effective series conductivity for the materials in the radial direction.

A gap closure algorithm is used to simulate the movement of the walls of the borehole coming into contact with the package. The waste package is modeled as three STEALTH $2 \mathrm{D}$ zones stacked vertically along the axis (Figure $\mathrm{C}-4$ ). The initial radius of each zone is the radius of the borehole. That is, this radius represents the sum of the package radius and the gap that exists between the package and the borehole.

Before contact, each of the four grid points that defined the three package zones are allowed to move freely. When the radial position of a grid point is less than or equal to the radius of the package, then that point is considered to be in contact with the package. Once in contact, the grid point is allowed to move only in the vertical direction; the radial position of the grid point is fixed at the radius of the package. When two adjacent grid points both come in contact with the package, the gap for the corresponding zone is defined as closed.

\section{C.1.2 Results for Vertical Emplacement}

The time duration varied for each of the six vertical emplacement cases. The one-inch air gap cases were computed for two years. The no-gap case and the two-inch gap case were carried out to one year and five years, respectively. These durations are sufficient to determine the peak radial stress.

Plots of the radial stress as a function of time were made for each of the three package zones. These plots are shown in Figures $\mathrm{C}-5$ through $\mathrm{C}-22$. The typical behavior of radial stress is that the peak stress occurs when a salt zone first contacts the package, followed by a slow decay in stress as the salt creep relieves the stress concentration near the package. The stress-time history plots frequently have a constant value of zero because the radial 
stress is assumed to be zero until the air gap closes for a zone. For example, the time histories for the bottom zone with a one-or two-inch gap are zero because the bottom gap does not close during the calculations. Table C-5 summarizes the closure times for all the case.

Table C-6 summarizes the peak radial stress and the associated time of occurrence for each of the cases. The no-gap case has the highest value of peak radial stress, $34.7 \mathrm{MPa}$. However, this value is unrealistic unless the packages are press-fit into the salt. With a minimum gap that is realistic, say one inch, the peak radial stress is below $20 \mathrm{MPa}$. The value for the two-inch case was even less at $11.8 \mathrm{MPa}$. The effect of the lower salt thermal conductivity or the lower salt creep rate is very small. The peak radial stress in those cases increased by less than 18 percent over the value for the standard material properties.

The magnitude of the peak radial stress for all cases, except the zero gap case, is less than the design limit of the package in the hoop mode. This design limit has been estimated to be about $21.4 \mathrm{MPa}$ (ONWI, 1985). The maximum value of peak stress for the five cases with a finite gap is $19.5 \mathrm{MPa}$ (for a one-inch gap at $30 \mathrm{~W} / \mathrm{m}^{2}$ ). There is, therefore, a substantial factor of safety for package failure in the hoop mode with vertical emplacement.

These analyses also demonstrate that the size of the air gap is the key factor for determining peak radial stress on the waste package; material properties and thermal areal loading play a relatively minor role in determining the peak radial stress.

These general results are expected to be valid for any emplacement mode with an air gap because the thermal and mechanical process of stress relief, thermal expansion, and salt creep will be present for all modes. Note that these results do assume uniform response without any sudden failures, such as on a bedding plane, that could lead to intense stress concentrations. These latter phenomena must be considered carefully for each emplacement mode. 
Table C-5. Initial Air Gap Closure Time (Years).

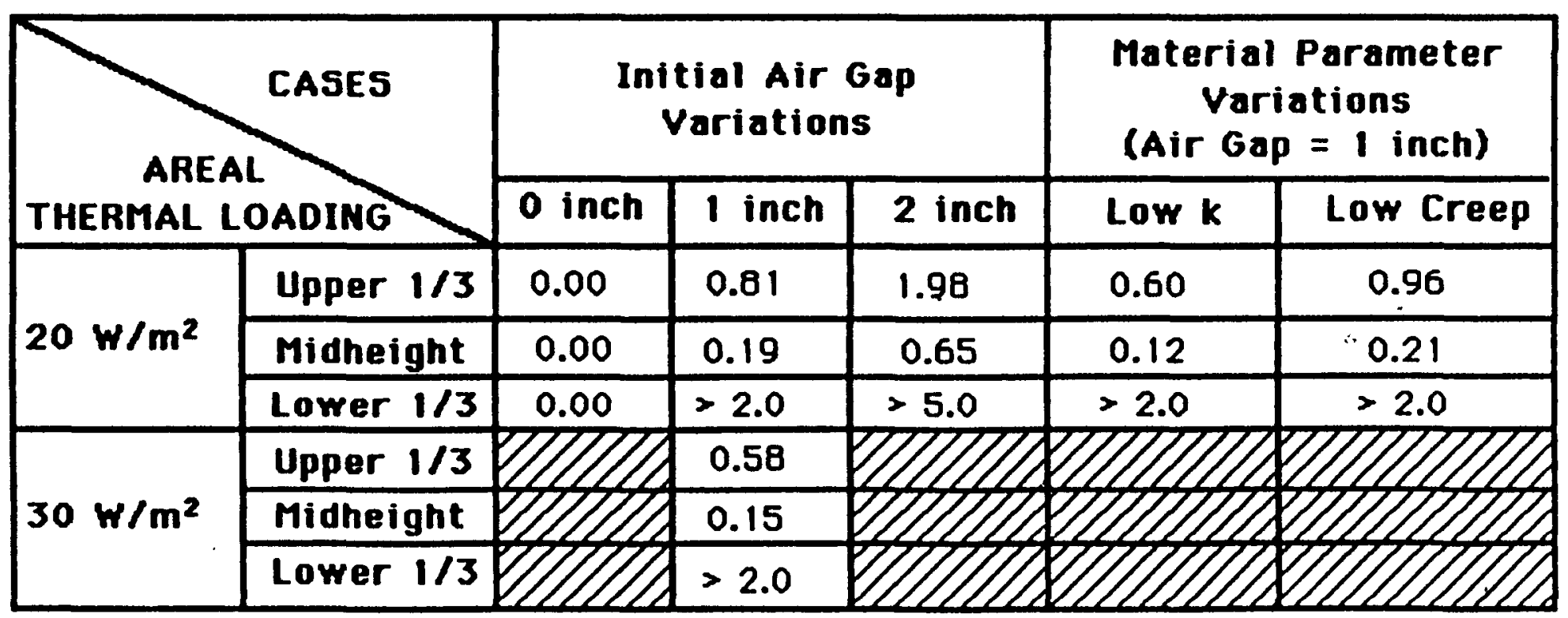


Table C-6. Pegk Radial Stress on Waste Package

Time of Peak Radial Stress

\begin{tabular}{|c|c|c|c|c|c|c|}
\hline \multirow{2}{*}{\multicolumn{2}{|c|}{$\overbrace{\text { AREAL }}^{\text {CASES }}$}} & \multicolumn{3}{|c|}{$\begin{array}{c}\text { Initial Air Gap } \\
\text { Variations }\end{array}$} & \multicolumn{2}{|c|}{$\begin{array}{c}\text { Material Parameter } \\
\text { Variations } \\
\text { (Air Gap = } 1 \text { inch) }\end{array}$} \\
\hline & & 0 inch & 1 inch & 2 inch & Low $k$ & Low Creep \\
\hline \multirow{2}{*}{$20 \mathrm{~W} / \mathrm{m}^{2}$} & MPa & 34.7 & 15.2 & 11.8 & 17.9 & 16.8 \\
\hline & Years & 0.03 & 0.25 & 0.73 & 0.13 & 0.31 \\
\hline \multirow{2}{*}{$30 \mathrm{~W} / \mathrm{m}^{2}$} & MPa & 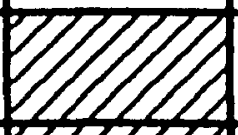 & 19.5 & \multirow{2}{*}{\multicolumn{3}{|c|}{ 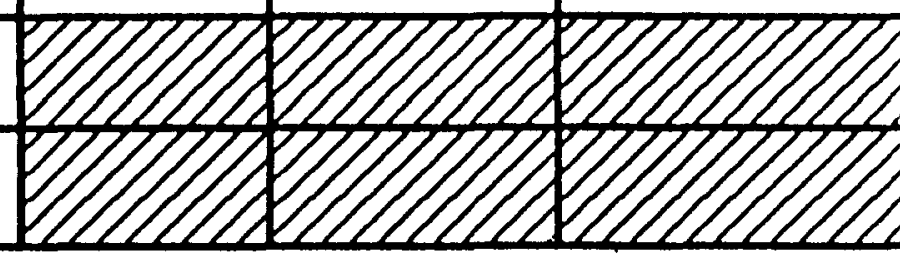 }} \\
\hline & Years & 111119 & 0.21 & & & \\
\hline
\end{tabular}


Finally, crushed salt backfill may be required around each waste package. This backfill should not pose a problem, provided that the annular gap is expanded to accommodate the backfill. For example, the typical porosity of backfill is on the order of 50 percent, so a 2-inch air gap should be mechanically equivalent to a 4-inch gap with filled crushed salt.

\section{C.2 MECHANICAL ANALYSIS OF EMPLACEMENT IN A HORIZONTAL SLOT}

\section{C.2.1 Description of Calculations}

The horizontal emplacement mode for this study is emplacement in a horizontal slot at the mid-height of the room pillar with the package parallel to the length of the drift. Mechanical analyses of this geometry require a three-dimensional calculation to accurately represent the finite length of the package. However, three-dimensional calculations were beyond the scope of this study, and two-dimensional analyses are adequate to bound the mechanical response for initial selection of emplacement mode.

Two horizontal emplacement calculations were therefore performed using a two-dimensional, planar model. The two calculations are similar in every respect except for the amount of heat energy density (per unit length) produced by the emplaced packages. The two values for the heat energy density corresponded to bounding cases for simulating the mechanical response to the package.

As a lower bound, the heat energy of the finite length package is uniformly distributed along the distance between two emplaced packages. This lower bound corresponds to a two-dimensional line source with an average value for the source strength. This is a lower bound because the actual value of the power per unit length near the package mid-height would be greater than this average value. As the upper bound, the heat energy per unit length of the computational model is the actual value in the package. This case represents an upper bound because the resultant areal heat loading corresponds to an infinite number of packages emplaced end-to-end. 
The stratigraphy for the horizontal emplacement calculations is the same as the stratigraphy for the vertical emplacement cases. The initial ambient temperature and lithostatic overburden stress are also identical.

Figure $\mathrm{C}-3$ is a schematic diagram of the two-dimensional, planar model for the calculations. Unlike the vertical emplacement cases, there is no axis (or plane) of symmetry through the centerline of the room. As a result, the computational model must span the full region between mid-pillars.

At the mid-height of the room pillar is a 3.353-meter (11-foot) slot where the package is emplaced. The slot is assumed to be backfilled with solid salt blocks. Note that the room dimensions for horizontal emplacement are slightly smaller than for vertical emplacement.

Boundary conditions are similar to the boundary conditions for the vertical emplacement case. The package is again a PWR12 spent fuel waste package, and the nominal areal loading is $20 \mathrm{~W} / \mathrm{m}^{2}$.

The material properties for this analysis are identical to the properties used in the analysis of vertical emplacement, with a few exceptions. The axial thermal conductivity of the blended package material was not applicable in this case. In addition, no calculations were made using the lower thermal conductivity and the lower creep rate models for the salt.

The cross section of the waste package is modeled with four STEALTH zones (See Figure C-23). After emplacement, the open slot is assumed to be backfilled with salt blocks and the package is assumed to be touching the back wall of the slot and the inner surface of the salt blocks. A two-inch air gap is assumed between the package and the top and bottom of the slot, similar to the vertical emplacement case. 
The central grid point (of the package) represents the center of mass of the package. It is allowed to move freely to simulate the translation of the package due to the creep of the salt. The outer points are allowed to move inward towards the center point. Gap closure occurs when the outer points move past the circle representing the outside circumference of the package.

\section{C.2.2 Results for Horizontal Slot Emplacement}

The low energy density case for the horizontal emplacement mode was computed to three years. The high energy density case was stopped at 1-1/2 years due to large distortions of the room walls and the high potential for rock failure.

Radial stress-time history plots were made at four package locations. These were the left, right, bottom and top sides of the package. Figures $\mathrm{C}-24$ through $\mathrm{C}-31$ are the plots for the two bounding cases. As in the case of the vertical emplacement mode, the stress was assumed to be zero until gap closure occurred. As noted above, the left and right sides have no air gap, and the top and bottom sides each have a two-inch air gap. Table $C-7$ summarizes the air gap closure times and Table $\mathrm{C}-8$ summarizes the peak radial stress.

Table C-7. Initial Air Gap Closure Time (years)

\begin{tabular}{lcc}
\hline $\begin{array}{l}\text { Side of } \\
\text { Canister }\end{array}$ & $\begin{array}{c}\text { Low Heat } \\
\text { Energy }\end{array}$ & $\begin{array}{c}\text { High Heat } \\
\text { Energy }\end{array}$ \\
\hline & & \\
Left & 0.0 & 0.0 \\
Right & 0.0 & 0.0 \\
Bottom & 1.86 & 0.12 \\
Top & 1.90 & 0.12 \\
\hline
\end{tabular}


Table C-8. Peak Radial Stress (MPa)

\begin{tabular}{lcc}
\hline \hline $\begin{array}{l}\text { Side of } \\
\text { Canister }\end{array}$ & $\begin{array}{c}\text { Low Heat } \\
\text { Energy }\end{array}$ & $\begin{array}{c}\text { High Heat } \\
\text { Energy }\end{array}$ \\
\hline & & \\
Left & 12.6 & 25.5 \\
Right & 34.6 & 34.6 \\
Bottom & 18.9 & 16.2 \\
Top & 20.4 & 18.0 \\
\hline
\end{tabular}

The peak radial stress is $34.6 \mathrm{MPa}$ on the right side of the waste package for both bounding cases. This result is similar to the no-gap vertical emplacement case. The peak stress is lower on the left side because of the presence of the salt blocks, with an initial lithostatic overburden stress of zero.

At the top and bottom sides, where there are two-inch gaps, the peak stresses are less than $20.4 \mathrm{MPa}$. Curiously, the high energy density case produced lower peak values. This effect is probably the result of the extra stress relief from the higher salt creep rate in the hotter temperature field. As was the case for vertical emplacement, a modest (two-inch) air gap can substantially reduce the peak radial stress below the maximum allowable load stress of about $21.4 \mathrm{MPa}$.

Figure C-32 compares the distortions of the room and package area for the two cases. For the low energy density case, the right wall has an inward displacement of $0.2 \mathrm{~m}$ after 3 years. In contrast, the same wall has an inward displacement of $1.3 \mathrm{~m}$ after $1-1 / 2$ years for the high energy density case. In addition to the displacement, several of the zones at the surface of the right wall are in tension. A peak tension of $5.5 \mathrm{MPa}$ is observed for the high energy case, and a peak tension of $1.5 \mathrm{MPa}$ is observed for the low energy case. These tensile stresses are generally beyond the elastic limit for rock 
salt, so some failure of the pillar is expected; however, more accurate three-dimensional analyses are required to better define the extent and magnitude of the tensile stress field.

\section{C.3 SURVEY OF MECHANICAL FAILURE MODES FOR THE WASTE PACKAGE}

The second part of this study investigates the potential mechanical failure of the carbon steel package with respect to waste package emplacement modes. This study is preliminary because the analyses are based on scoping data; however, the results are useful for identifying general trends and for providing preliminary recommendations.

Figure $\mathrm{C}-33$ is a schematic of the four failure modes that are considered. These are:

1. longitudinal bending

2. uniform radial stress

3. line load

4. uniform lateral stress

The longitudinal bending mode is associated with the large bending loads that may develop on a package in the room pillar during room convergence. The uniform radial stress mode corresponds to uniform compression from the lithostatic pressure. The line load scopes a potential stress concentration from an inclusion of non-salt (hard) rock. The uniform lateral stress case approximates a shallow emplacement trench where the backfill supports the lateral stress (parallel to the room wall), while the stress normal to the room wall is negligible.

Subsection C.3.1 deals with the longitudinal bending mode and identifies relatively safe and relatively dangerous emplacements.

Subsection C.3.2 considers a baseline carbon steel package and scopes the salt stresses that promote package failure for (a) uniform radial stress, (b) line loads, and (c) uniform lateral stress. 
Subsection C.3.3 summarizes the computed results of STEALTH code parametric calculations of the axisymmetric radial stress on packages with vertical emplacement. It is seen that an initial air gap of one inch or more reduces the peak stress to very safe levels for all of the cases.

Subsection C.3.4 deals both with the line load and the uniform lateral stress case. In the absence of better data, this section employs an oversimplified model to estimate the thermomechanical stresses. Though the model is not accurate, it is believed that the trend of the data is correct. They show that the threat of failure is rapidly reduced as the package air gap is increased.

Subsection C.3.5 provides recommendations based on the results of the study.

\section{C.3.1 Longitudinal Bending Loads}

The crushed salt in a backfilled disposal room will originally occupy about 90 percent of the room volume. Assuming a 40 percent porosity for this backfill, the total void space is then about half of the room volume. Thus, the room will close to about 50 percent of its original volume when the crushed salt is reconsolidated.

Figure $\mathrm{C}-34$ displays the distortions in the solid salt surrounding the room due to the room closure. The left side shows half of an original room surrounded by 1-meter square zones of salt. The right side shows the distortion when the room volume has halved. This figure has been interpolated from averaged computational data without regard to the location of the package. The distortions near a package can be expected to be larger.

A package with its axis in the plane of Figure C-34 is subjected to longitudinal bending due to the salt distortion. Detailed three-dimensional analyses would be required to properly assess the potential for package failure. However, the symmetry about horizontal and vertical lines through the room center provides several safe emplacement modes. These are (a) a 
vertical borehole in the center of the floor, and (b) a horizontal borehole or horizontal slot at the room mid-height.

\section{C.3.2 Estimates of Failure Stresses for the Reference Package}

The reference package is a thick-walled carbon steel cylinder with the assumed properties of Table $\mathrm{C}-\mathrm{g}$.

Table C-9. Assumed Package Properties

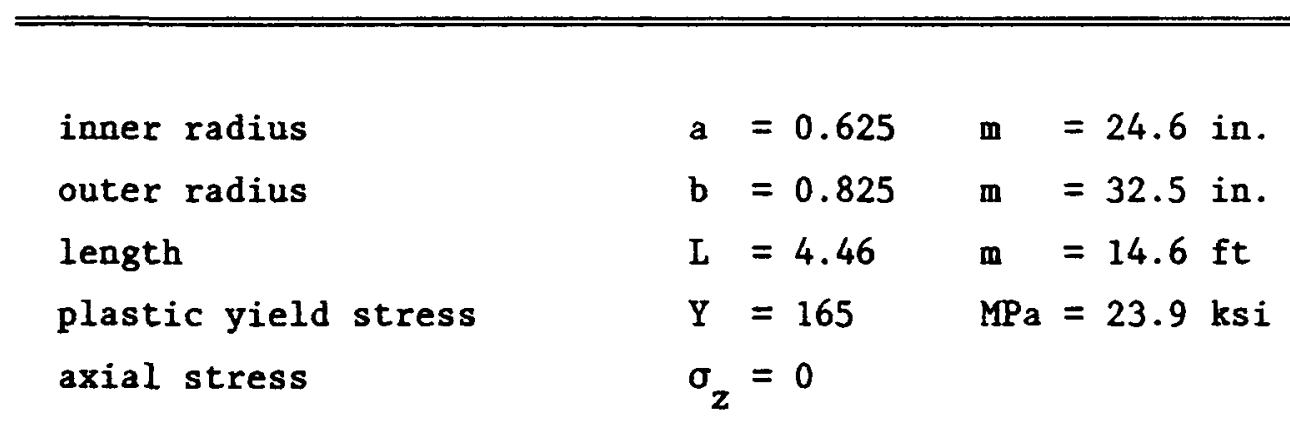

The zero axial stress condition is selected for conservatism, i.e., plastic yielding is accentuated by this condition. In addition, the assumed plastic yield stress is in the lower range for carbon steels. Though the tensile strength is about twice the plastic yield stress, tensile failure will be treated as plastic failure. In other words, failure is always assumed when the second invariant of stress deviation exceeds the plastic yield stress. This additional conservatism could account for fabrication defects that can greatly reduce the tensile strength of a thick-walled cylinder. 


\section{C.3.2.1 Failure Under Uniform Radial Stress}

It can be shown that the second invariant of stress deviation is maximum on the steel inner surface and that this maximum value is

$$
\sqrt{3 J_{2}}=2 \sigma_{1} /\left(1-a^{2} / b^{2}\right)
$$

where

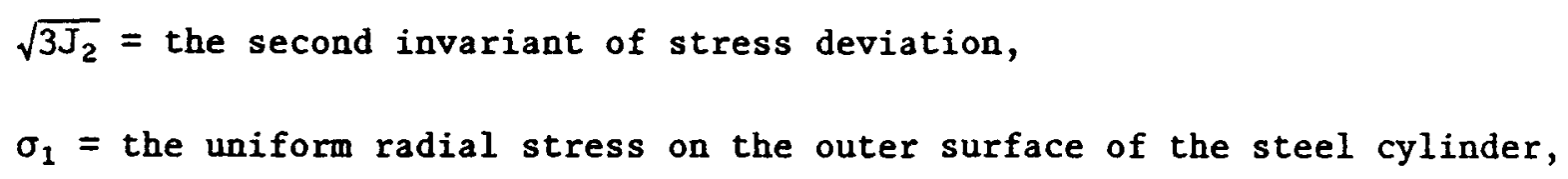
and

$a, b=$ the inner and outer radii of the steel cylinder, respectively. Plastic failure occurs when $\sqrt{3 J_{2}}$ reaches the plastic yield stress, Y. For the package of Table $C-9$, the failure value of $\sigma_{1}$ is

$$
\sigma_{1}^{\text {FAIL }}=\mathrm{Y}\left(1-\mathrm{a}^{2} / \mathrm{b}^{2}\right) / 2=34.4 \mathrm{MPa} \text {. }
$$

\section{C.3.2.2 Failure Under Line Load}

The methods of Marks Handbook (Baumeister, 1978) are employed to estimate the salt stress, $\sigma_{1}$, that produces failure in the baseline package for the line load case of Figure C-33. For this case, the maximum stress in the steel is

$$
\sigma^{\mathrm{MAX}}=39.5 \sigma_{1}
$$

Then, employing the plastic yield stress for the reason previously noted, the failure value of $\sigma_{1}$ is

$$
\sigma_{1}^{\text {FAIL }}=Y / 39.5=4.2 \mathrm{MPa} \text {. }
$$


This case corresponds to an integration of distributed line loads, and results in the following maximum stress in the steel:

$$
\sigma^{\mathrm{MAX}}=17.5 \sigma_{1}
$$

Then, employing the plastic yield stress for the reason previously noted, the failure value of $\sigma_{1}$ is

$$
\sigma_{1}^{\text {FAIL }}=Y / 17.5=9.4 \mathrm{MPa} .
$$

\section{C.3.2.4 Summary}

The geometries of Figure $\mathrm{C}-33(\mathrm{~b}),(\mathrm{c})$, and (d) have been applied to the carbon steel cylinder of Table $\mathrm{C}-9$ to obtain the following estimates of the failure stress $\sigma_{1}$.

Table C-10. Summary of Failure Stress Estimates

\begin{tabular}{llc}
\hline \hline Case & Figure & $\sigma_{1}(\mathrm{MPa})$ \\
\hline & & \\
Uniform radial stress & $\mathrm{C}-33(\mathrm{~b})$ & 34.4 \\
Line load & $\mathrm{C}-33(\mathrm{c})$ & 4.2 \\
Uniform lateral stress & $\mathrm{C}-33(\mathrm{~d})$ & 9.2 \\
\hline
\end{tabular}

These estimates are not necessarily conservative since many effects have been ignored; however, the estimates do include the effects of degradation of the yield stress due to temperature, radiation damage, corrosion, etc. 


\section{C.3.3 Summary of Numerical Analyses for Peak Radial Stress with Vertical Emplacement}

A series of STEALTH 2D axisymmetric calculations has been performed to obtain the (uniform) radial stress at different elevations along the height of a package emplaced vertically below the room floor. The repository floor is at a depth of 792 meters where the in-situ overburden stress is $17.58 \mathrm{MPa}$. The baseline salt model corresponds to Permian Basin cycle 4 salt. The package dimensions are those of Table C-9. Section C.I provides detailed descriptions of the computations and of the results.

The PWR12 package $(6.6 \mathrm{~kW})$ and the cross-sectional area of the grid provide a baseline thermal areal loading of $20 \mathrm{~W} / \mathrm{m}^{2}$. This area is decreased in one of the variations to provide a $30 \mathrm{~W} / \mathrm{m}^{2}$ case. The leading coefficient of the steady-state creep model is halved in another variation to scope the effect of a reasonable error in the creep model. The thermal conductivity of the salt is decreased in another variation to approximate the lower bound of the experimental data. This case scopes the effect of a reasonable error in the conductivity.

The baseline case has an initial one-inch air gap around the package which must close before the package is compressed by the salt. Variations include a two-inch air gap and no air gap. Typical plots of the radial stress versus time on the package are in Figure $\mathrm{C}-5$ to $\mathrm{C}-31$. The rise time to peak stress is always rapid after gap closure. Therefore, the time of peak stress can be approximated by the gap closure time.

Figure C-35 shows that the peak stress is controlled mainly by the gap closure time and that other variations produce lesser effects. The dashed lines apply to the baseline case with varying air gap size. The small scatter of points around the dashed lines indicates that the effects of the variations are small. (Individual points are not identified because the scatter is small.) Figures $\mathrm{C}-35(\mathrm{a})$ and $\mathrm{C}-35(\mathrm{~b})$ show almost the same behavior for the upper third and middle third of the package. This is remarkable in view of the observation that the gap closing time is a strong function of (a) the original 
gap size, (b) the location (upper or middle third of the package), and (c) other variations in material properties and thermal areal loading.

Although these results are interesting, it may not be necessary to pursue them further. It appears that a modest initial air gap of one inch or more will reduce the peak stress to a value well below the failure value of $34.4 \mathrm{MPa}$ that is estimated for this package in Table $\mathrm{C}-10$.

\section{C.3.4 Line Load and Lateral Stress Reduction by Air Gaps}

This section investigates the mechanical response to a package in a shallow trench in the floor or wall of the room. The trench is backfilled with solid salt blocks to help support the lateral stress $\sigma_{1}$ that is parallel to the room wall. The other lateral stress is $\sigma_{2}$, which is normal to the room wall; $\sigma_{2}$ is small for shallow burial and is neglected. These conditions approximate the idealized line load case and the uniform lateral stress case of Figures $\mathrm{c}-33(\mathrm{c})$ and $\mathrm{c}-33(\mathrm{~d})$. The failure stresses, $\sigma_{1}$, for these cases are given in Table C-10 for the baseline package of Table C-9.

Since the results of detailed computations are not available for these cases, it is necessary to employ a simplified model to estimate the lateral stress, $\sigma_{1}$, acting on the package. This simple model applies the following assumptions to the local region of salt surrounding the package:

1. The deviatoric stress relaxation rate from creep is approximated by the steady-state part of the creep model.

2. The thermally induced deviatoric stress rate is approximated by the thermally induced mean stress rate for the case of zero salt total strain rate (i.e., rigid salt boundaries).

3. The boundary motion of the salt region is neglected. 
These assumptions are incorporated in Equation C-1:

$$
\frac{d}{d t}\left(\sqrt{3 J_{2}}\right)=-2 g\left[A\left(3 J_{2}\right) N^{N} \operatorname{EXP}(-\lambda / T)\right]=3 k \alpha \frac{d T}{d t}+0
$$

where

$$
\begin{array}{ll}
\sqrt{3 J_{2}} & =\text { deviatoric stress } \\
\mathbf{g} & =\text { salt shear modulus } \\
\mathrm{A}, \mathrm{N}, \lambda & =\text { salt creep model parameters } \\
\mathrm{T} & =\text { Kelvin temperature } \\
\mathbf{k} & =\text { salt bulk modulus } \\
\alpha & =\text { salt thermal expansivity }
\end{array}
$$

The left side of Equation $\mathrm{C}-1$ is the total deviatoric stress rate in the salt around the package. The first term on the right is the deviatoric stress decay rate due to the steady-state part of the salt creep model. This decay rate is underestimated because the primary creep rate is not included. The middle term on the right is the rate of thermally induced pressure for rigidly confined salt. This term greatly overestimates the thermally induced deviatoric stress for any realistic combination of fixed and free boundary conditions in the room region. The zero term on the right estimates the externally applied deviatoric stress rate. It is difficult to assess the potential errors in this latter assumption. However, it is not expected that the errors will alter the general trends of the stress response.

Because $\sigma_{z}$ and $\sigma_{2}$ are assumed to be negligible, the value of $\sigma_{1}$ corresponds to the value of $\sqrt{3 J_{2}}$ Thus, Equation $c-1$ describes the rate of $\sigma_{1}$ and must be integrated. This requires a temperature time history in the salt surrounding the package. This temperature is estimated by the application of the following assumptions:

1. An infinite line heat source of $6.6 \mathrm{~kW}$ per 4.46 meters corresponds to the PWR12 package of Subsection C.3.3. 
2. A constant thermal conductivity of $5.4 \mathrm{~W} / \mathrm{m}-\mathrm{K}$ to approximate the baseline Permian Cycle 4 salt of Subsection C.3.3.

3. Solid salt everywhere, i.e., the detailed geometry of room and air gap is ignored.

4. The temperature-time history is calculated at 1.5 radii, or 0.63375 meters, from the line source.

Under these approximations, the salt temperature can be evaluated with the analytic solution given by Carslaw and Jaeger (1978).

The integration of Equation $\mathrm{C}-1$ for the baseline Permian Basin Cycle 4 salt is performed with a small computer program. The variations include the line source strengths of Table $\mathrm{C}-11$.

Table C-11. Line Source Strength Cases

\begin{tabular}{lcc}
\hline \hline Package & Watts/Package & Watts/Meter \\
\hline & & \\
PWR12 & 6600 & 1480 \\
PWR9 & 4950 & 1180 \\
PWR6 & 3300 & 740 \\
\hline
\end{tabular}

The line source is turned on at zero time, corresponding to package emplacement. The initial stress in the salt is negligible due to the proximity of the air gap. The air gap closing time is varied by turning on Equation $\mathrm{C}-1$ at selected times during the heating of the salt.

The resulting response of $\sigma_{1}$ in the salt is displayed in Figure $\mathrm{C}-36$ for the PWR12, PWR9, and PWR6 packages for selected air gap closure times. The 
circle and square points correspond to the failure conditions in Table C-10 for the line load and uniform lateral stress cases, respectively. Thus, it again appears that small delays in the gap closing time will remove the threat of package failure in these modes.

\section{C.3.5 Assessment of Emplacement Configurations}

An unambiguous nomenclature is presented to identify various emplacement configurations. The diagrams of Figure $\mathrm{C}-37$ provide schematic illustrations.

1. Borehole emplacement refers to packages in boreholes that are perpendicular to the direction of the room corridor. The narrow rectangles in the diagrams of Figure $c-37(a)$ and $C-37(b)$ display these packages.

2. Corridor slot emplacement refers to packages that are placed in backfilled slots that extend in the direction of the corridor. The circles in the diagrams of Figure $c-37(d)$ and c-37(d) display end-on views of these packages.

3. Section slot emplacement refers to slot emplacement with the slot length in the section plane of the room. The narrow rectangles in the bottom diagrams of Figure $\mathrm{C}-37(\mathrm{c})$ and $\mathrm{C}-37(\mathrm{~d})$ display the side views of these packages.

\section{C.3.5.1 Ranking of Emplacement Modes for the Longitudinal Bending Threat}

The large distortions in the salt during room closure can induce package failure in the longitudinal bending mode. This is the basis for the relative ranking of borehole emplacements and section slot emplacement. The boreholes in the floor centerline of Figures $c-37(a)$ and $c-37(b)$ are ranked 1 (the best) because the symmetric flow of salt in this location does not induce longitudinal bending of the packages. The horizontal boreholes at the mid-height of the walls are ranked 2 (next best). This position is not quite as desirable because of the possibility that the layered material properties may 
vary with height and skew the otherwise symmetric flow of the salt in this location. The other borehole emplacements are not recommended. The shallow boreholes in the corner regions are subjected to large bending and are rated 5 (dangerous). The deep borehole emplacements in the corner regions are rated 4 (suspect) to indicate that the bending strains decrease with increasing distance from the room.

The section slot emplacements are shown as narrow rectangles in the bottom diagrams of Figure C-37. These emplacements are particularly dangerous with respect to longitudinal bending. The assigned rankings of 4 and 5 , respectively, for the deep and shallow burial cases are due to the fact that the bending strains increase closer to the room wall. Section slot emplacements in the floor (not shown) have the same rankings as the corresponding section slot emplacements in the walls.

The corridor slot emplacements are shown as circles in the bottom diagrams of Figure $\mathrm{C}-37$. The salt flow does not induce longitudinal bending for these emplacements, and the indicated rankings are based on other considerations given later. However, longitudinal bending can occur in special cases of non-uniformity in the direction of the corridor. As an extreme example, one-half of the package might be imbedded in an anhydrite lens, with the other half in salt. A more marginal case can occur for corridor slot emplacements near a cross-drift intersection. The two ends of the corridor slot package are at different distances from the intersection and can be subjected to different salt flows during room convergence. This case requires detailed analysis for proper assessment.

\section{C.3.5.2 Ranking of Emplacement Modes for Other Threats}

It is assumed that an initial one-inch or larger air gap will be used for all emplacements to obtain the beneficial stress reductions that are described 
in the previous Subsection. Then the baseline package is expected to remain intact under
1. uniform radial stress
2. line load
3. uniform lateral stress

for all emplacements in uniform salt.

However, these cases do not consider defects or inclusions in the salt that can lead to sudden failure. In certain situations, the bearing load in the failed salt can shift to the package, as shown schematically in Figure C-38 for the case of a shallow burial in a corridor slot. This failure is similar to wall scabbing of non-salt rock. The threat to the package is diminished as the burial depth is increased.

The above considerations are the basis for the relative ranking of the corridor slot emplacements (the circles) of Figures $\mathrm{c}-37(\mathrm{c})$ and $\mathrm{C}-37(\mathrm{~d})$. The higher numbers for the room corner regions reflect the stress concentrations around the corners that can promote fracturing.

\section{C.3.5.3 Final Assessments for Mechanical Failure}

The preliminary assessments from this study are somewhat subjective, and may be revised when better computational data are available. The present conclusions apply only to the mechanical failure of the package.

1. An initial air gap of one inch or more should be present for all emplacements. Ignoring thermal considerations, the air gap can be replaced by a thicker gap filled with crushed salt to provide an equivalent delay of the stress build-up on the package.

2. A vertical borehole at the room center and a horizontal borehole at the wall mid-height have the lowest stress levels. 
3. In-floor trench emplacements are satisfactory if the burial depths are not shallow. However, a safe minimum depth has not been established.

4. In-floor trench emplacements should be backfilled with solid salt blocks with a fit-up clearance that is smaller than the equivalent air gap around the package. This will reduce the possibility of the salt failure shown in Figure $\mathrm{C}-34$.

5. Shallow corridor slot emplacements are undesirable because of the possibility of salt failure, as shown in Figure C-34.

6. All of the other emplacement modes are expected to result in package failures in the longitudinal bending mode unless they are buried deeply. 
Figure C-1. Two-Dimensional Axisymmetric Model for Calculating the Radial Stress for Emplacement in a Vertical Borehole

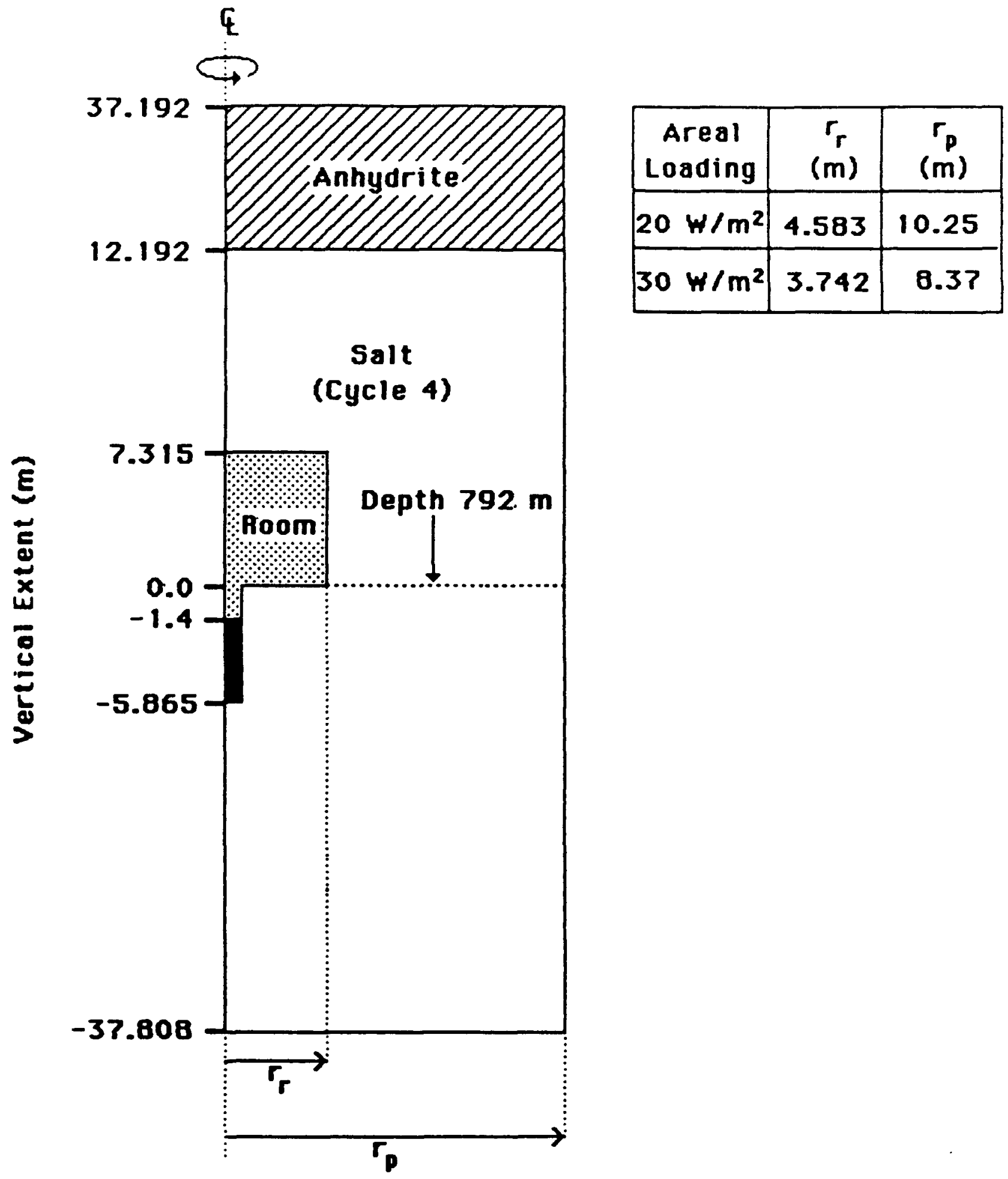

Radial Extent 
Figure C-2. Boundary Conditions for Calculating the Radial Stress for Emplacement in a Vertical Borehole

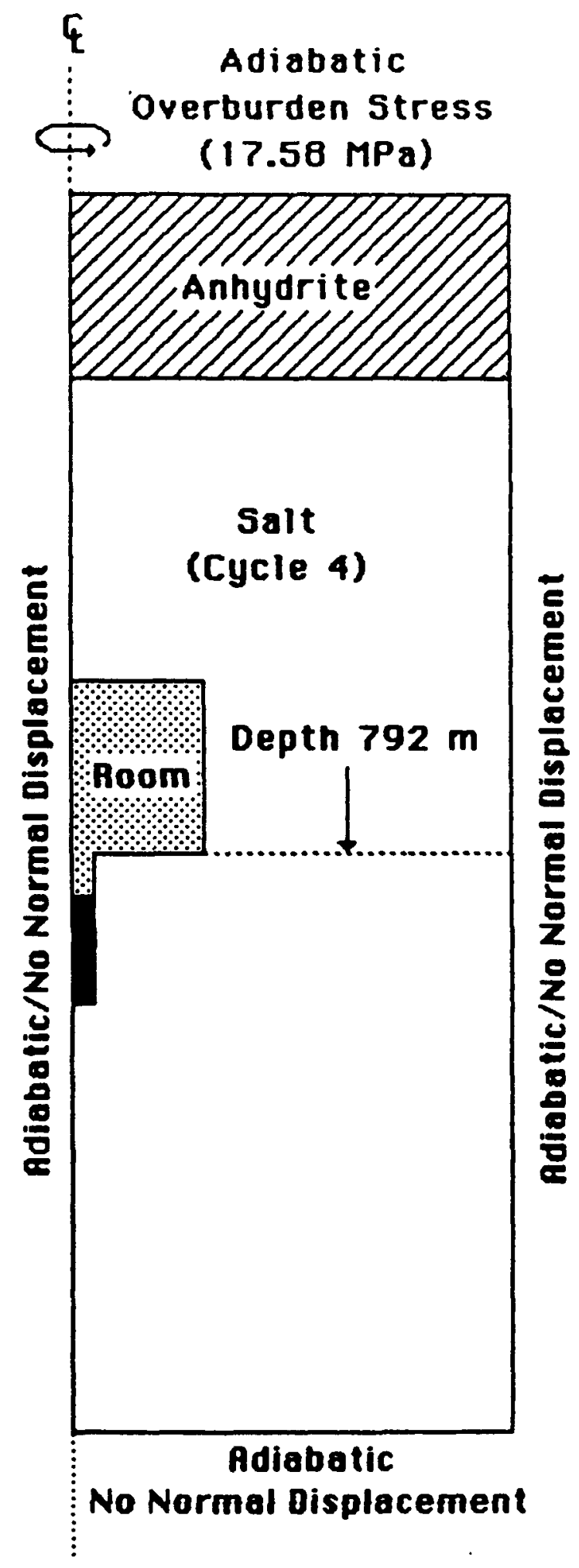


Figure C-3. Two-Dimensional Planar Model for Calculating the Radial Stress for Emplacement in a Horizontal slot

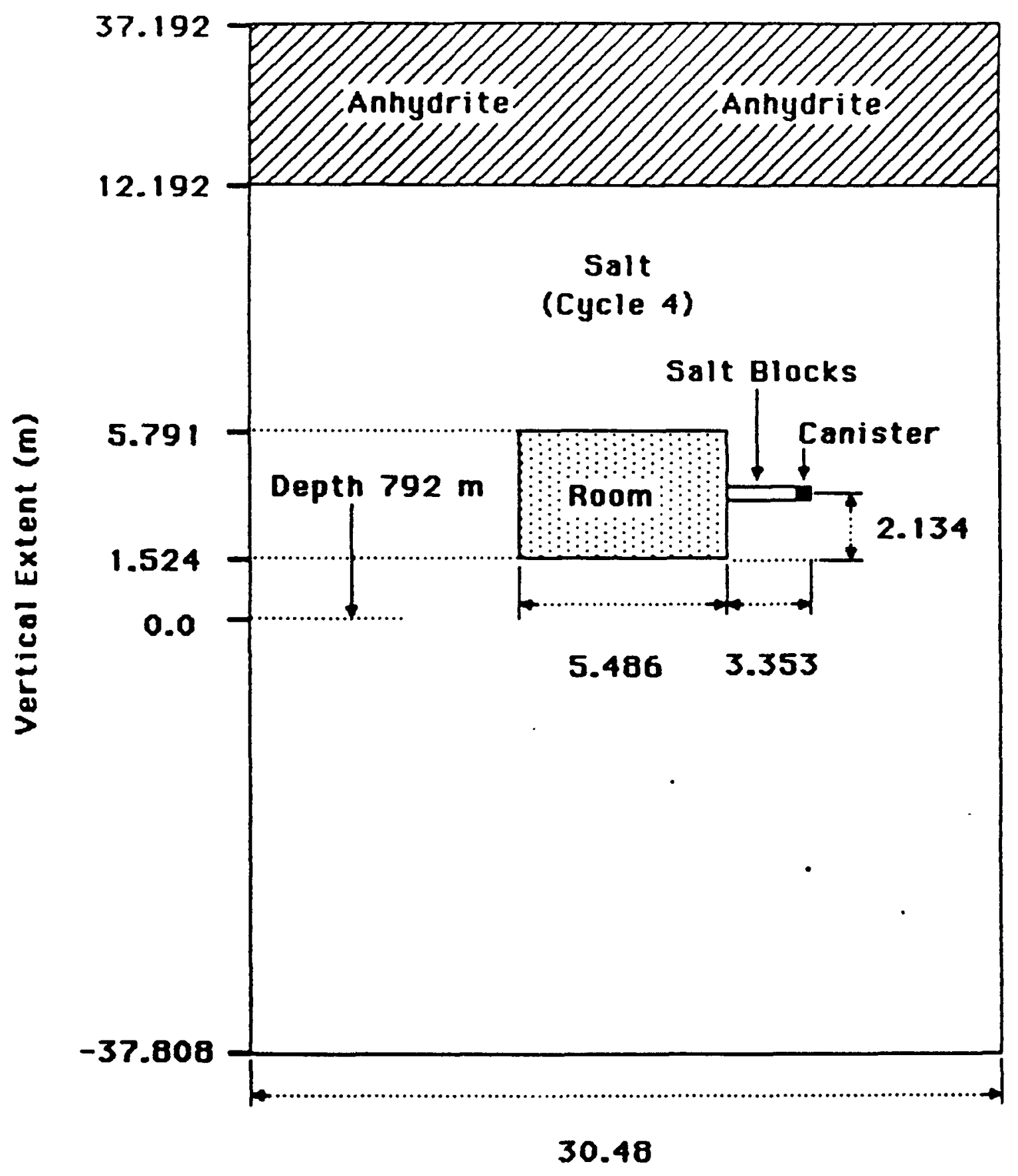


Figure C-4. Schematic Diagram of Gap Closure Algorithm for Emplacement in a Vertical Borehole

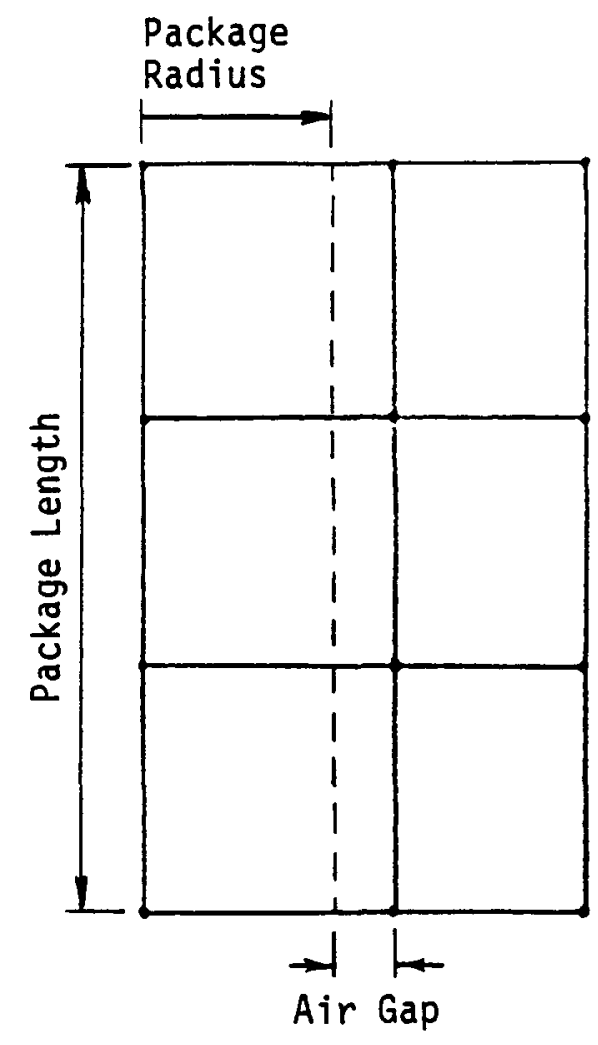

(a) Initial Orientation

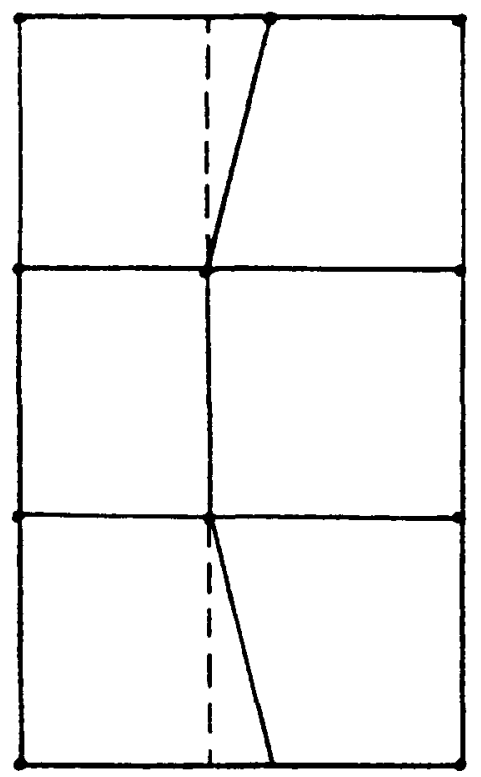

(c) Gap in Middle Zone Closed

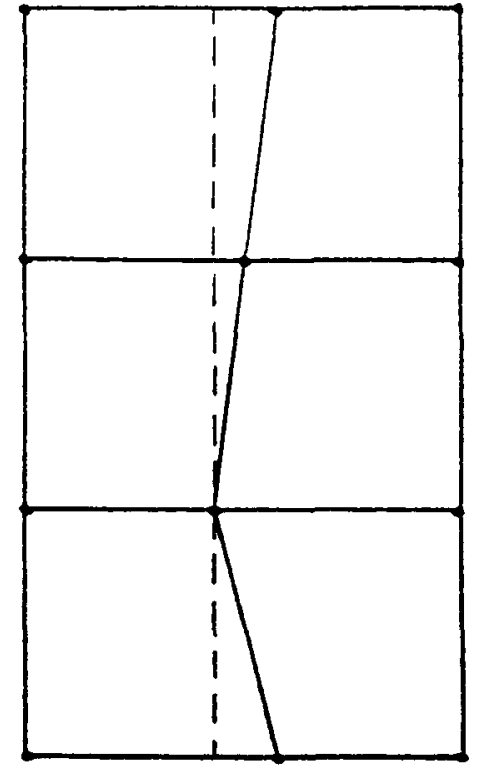

(b) Single Point Contact

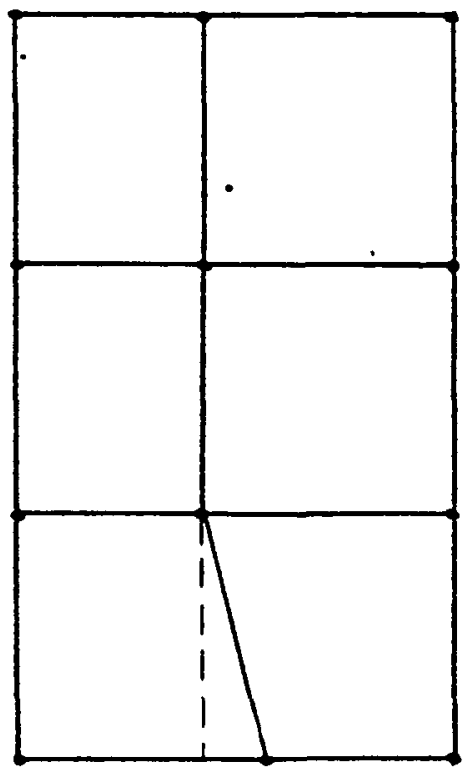

(d) Gaps in Top and Middle Zones Closed 
Figure C-5. Radial Stress Versus Time at Upper Third of Waste Package in Vertical Emplacement Mode with $20 \mathrm{~W} / \mathrm{m}^{2}$ and "0" Air Gap

VEATICAL EMPLACEMENT - 20 W/MMMR - O' AIR GAP

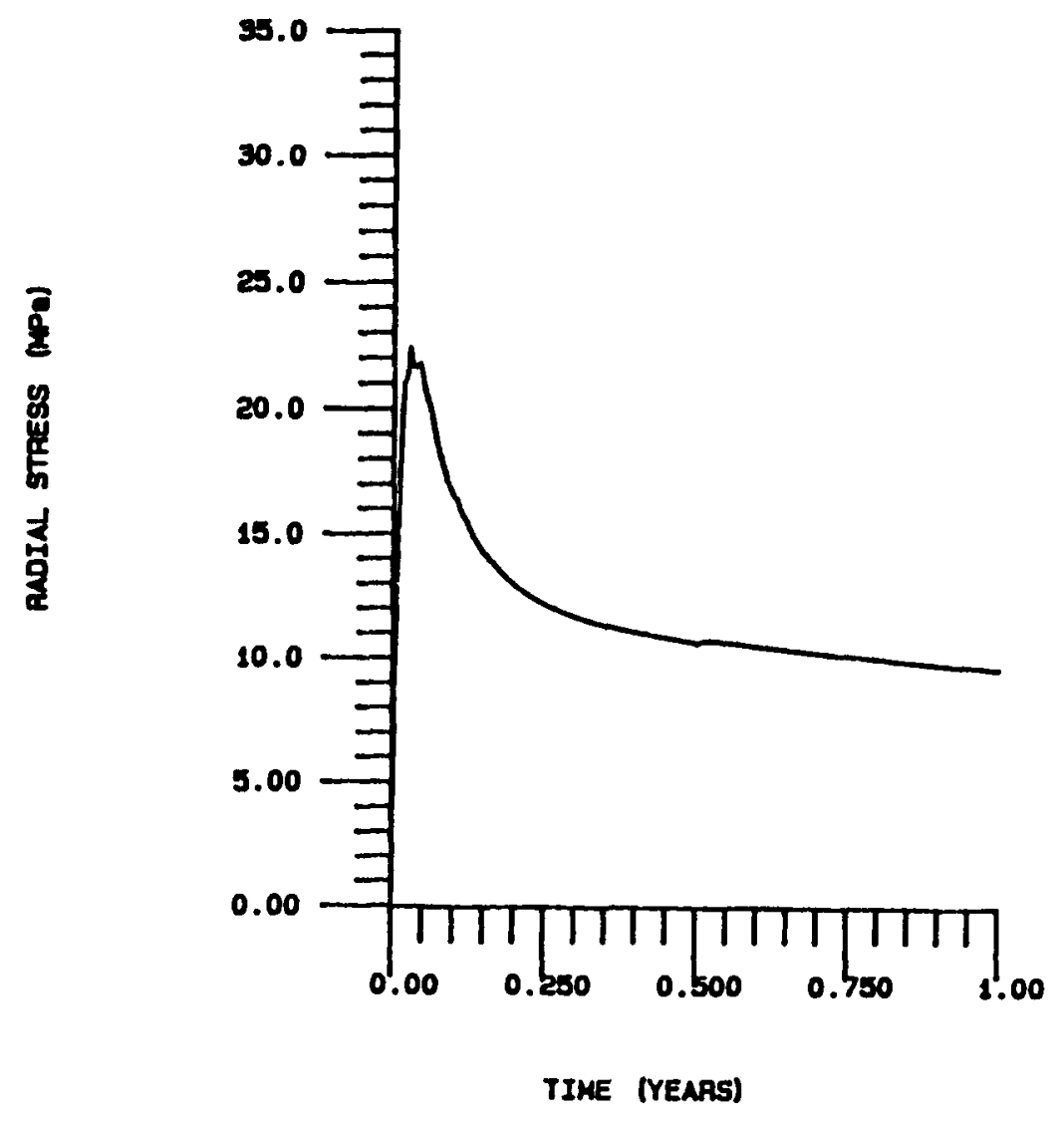

STRESS EXERTED ON MASTE PACKage versus tIME UPPER THIRD OF WASTE PACKAGE 


\section{Figure C-6. Radial Stress Versus Time at Mid-Height of Waste Package in Vertical}

Emplacement Mode with $20 \mathrm{~W} / \mathrm{m}^{2}$ and "0" Air Gap

VERTICAL EMLACEMENT - 20 MMUUR - O" AIA GAP

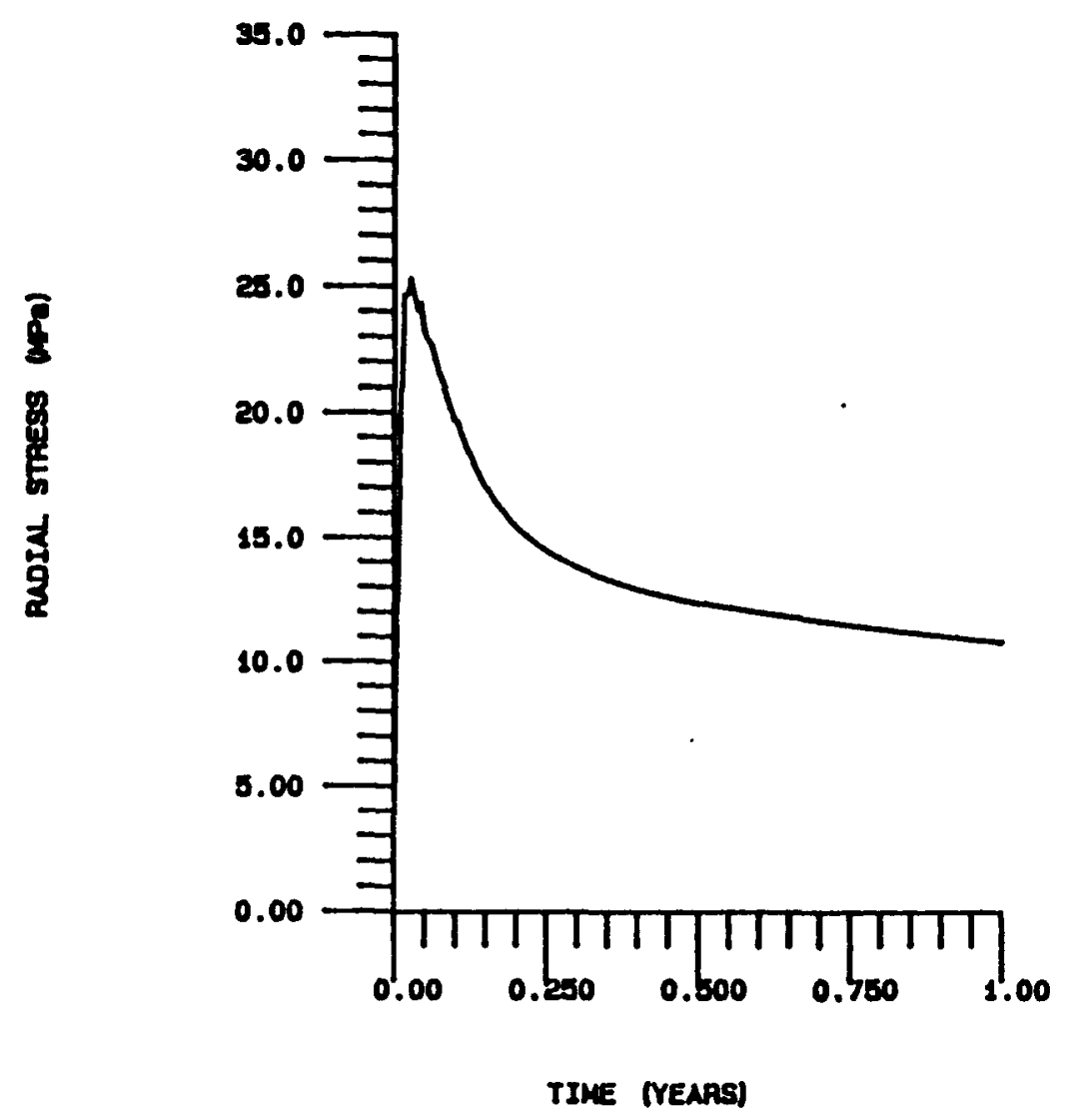

STRESS EXERTED ON MASTE PACKABE VERSUS TIME MID-HEIEHT OF MASTE PACKAGE 
Figure C-7. Radial Stress Versus Time at Lower Third of Waste Package in Vertical Emplacement Mode with $20 \mathrm{~W} / \mathrm{m}^{2}$ and "0" Air Gap

VERTICAL EMPLACEMENT - 20 W/MMMR - 0' AIR GAP

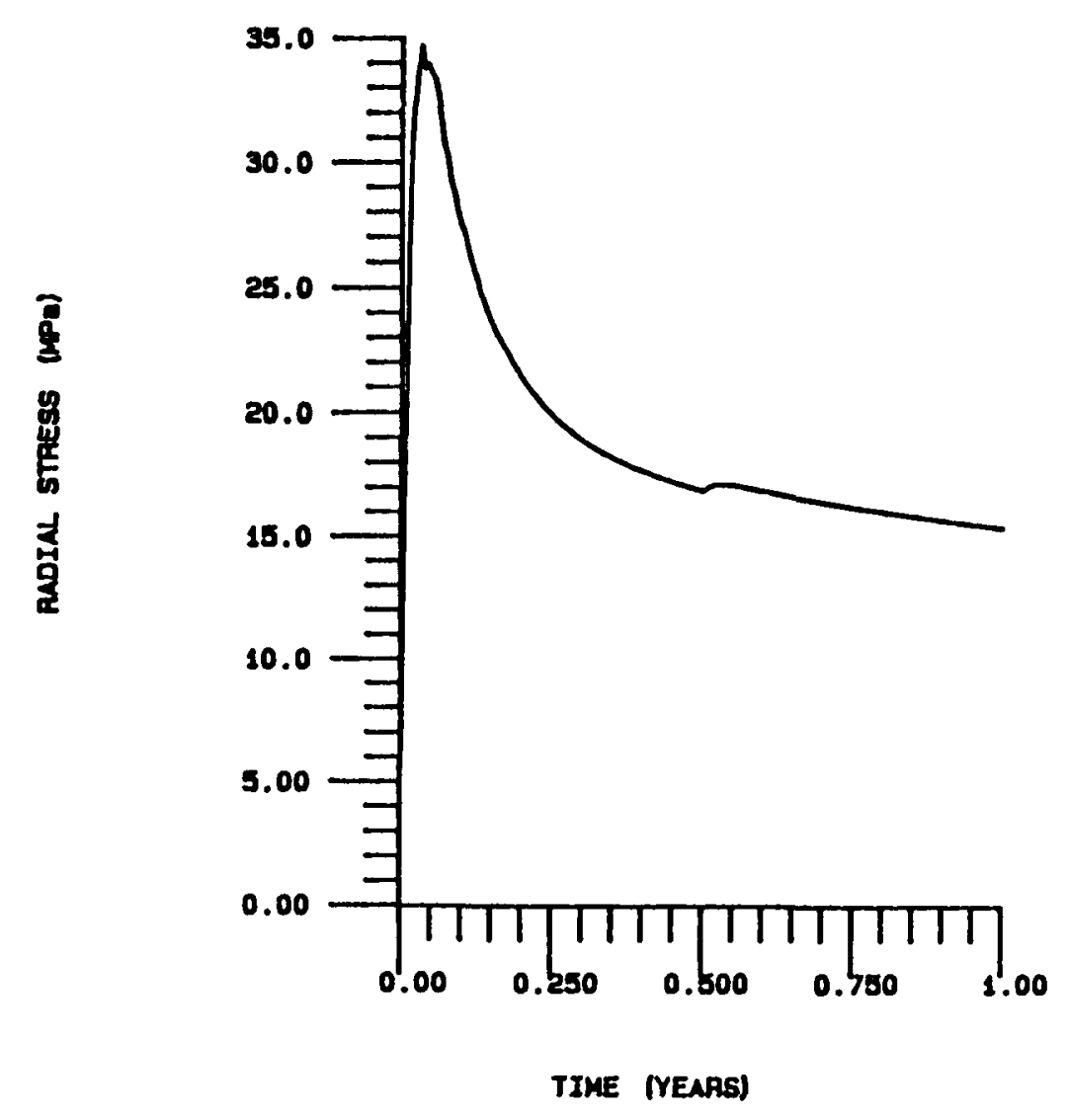

STRESS EXERTED ON MASTE PACKAGE VERSUG TIME LOWER THIRD OF MASTE PACKAGE 
Figure C-8. Radial Stress Versus Time at Upper Third of Waste Package in Vertical Emplacement Mode with $20 \mathrm{~W} / \mathrm{m}^{2}$ and 1" Air Gap

VERTICAL EXPLACENENT - 20 M/MMMR - 1' AIA GAP

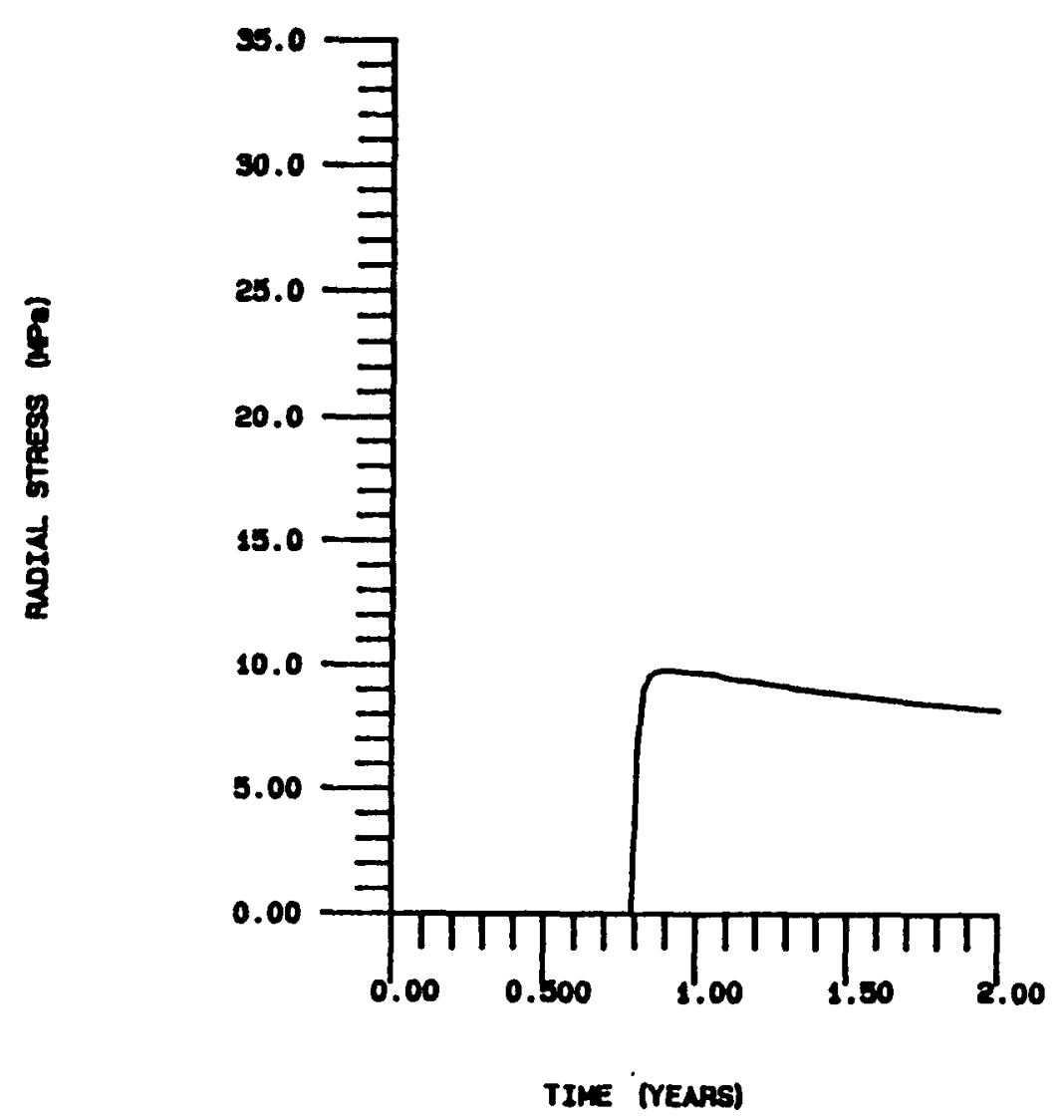

STRESS EXERTED ON MASTE PACKAGE VERSUS TIME UPPER THIPO OF MASTE PACKABE 
Figure C-9. Radial Stress Versus Time at Mid-Height of Waste Package in Vertical Emplacement Mode with $20 \mathrm{~W} / \mathrm{m}^{2}$ and 1" Air Gap

VERTICAL ENPLACEMENT - 20 W/NWME - 1" AIA EAP

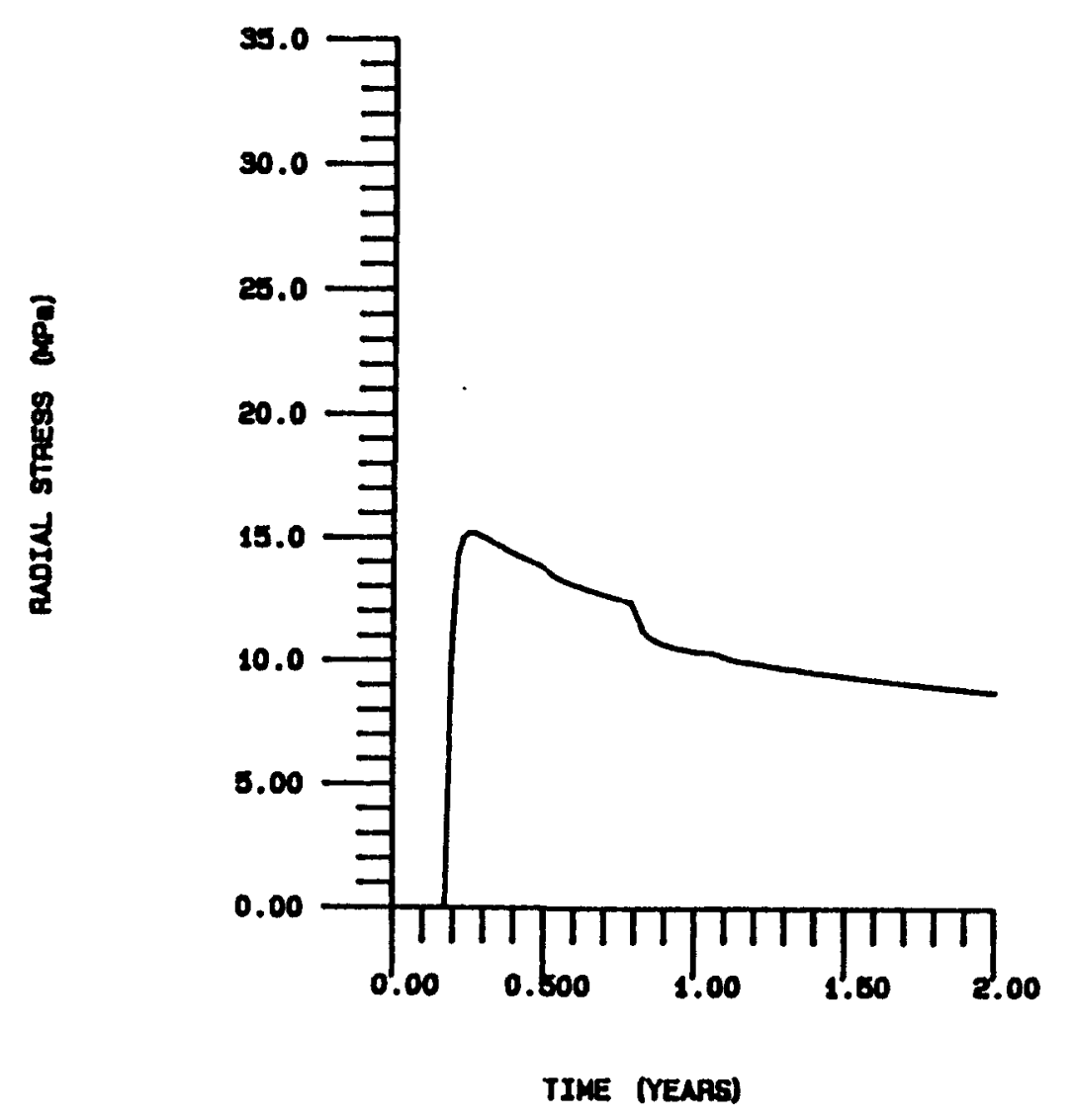

STRESS EXERTED ON MASTE PACKAGE VERSUS TIME MID-HEJEHT OF MASTE PACKAGE 
Figure C-10. Radial Stress Versus Time at Lower Third of Waste Package in Vertical Emplacement Mode with $20 \mathrm{~W} / \mathrm{m}^{2}$ and 1" Air Gap

\section{VERTICAL EMPLACEUENT - 20 W/MMMR - 1" AIA CAP}

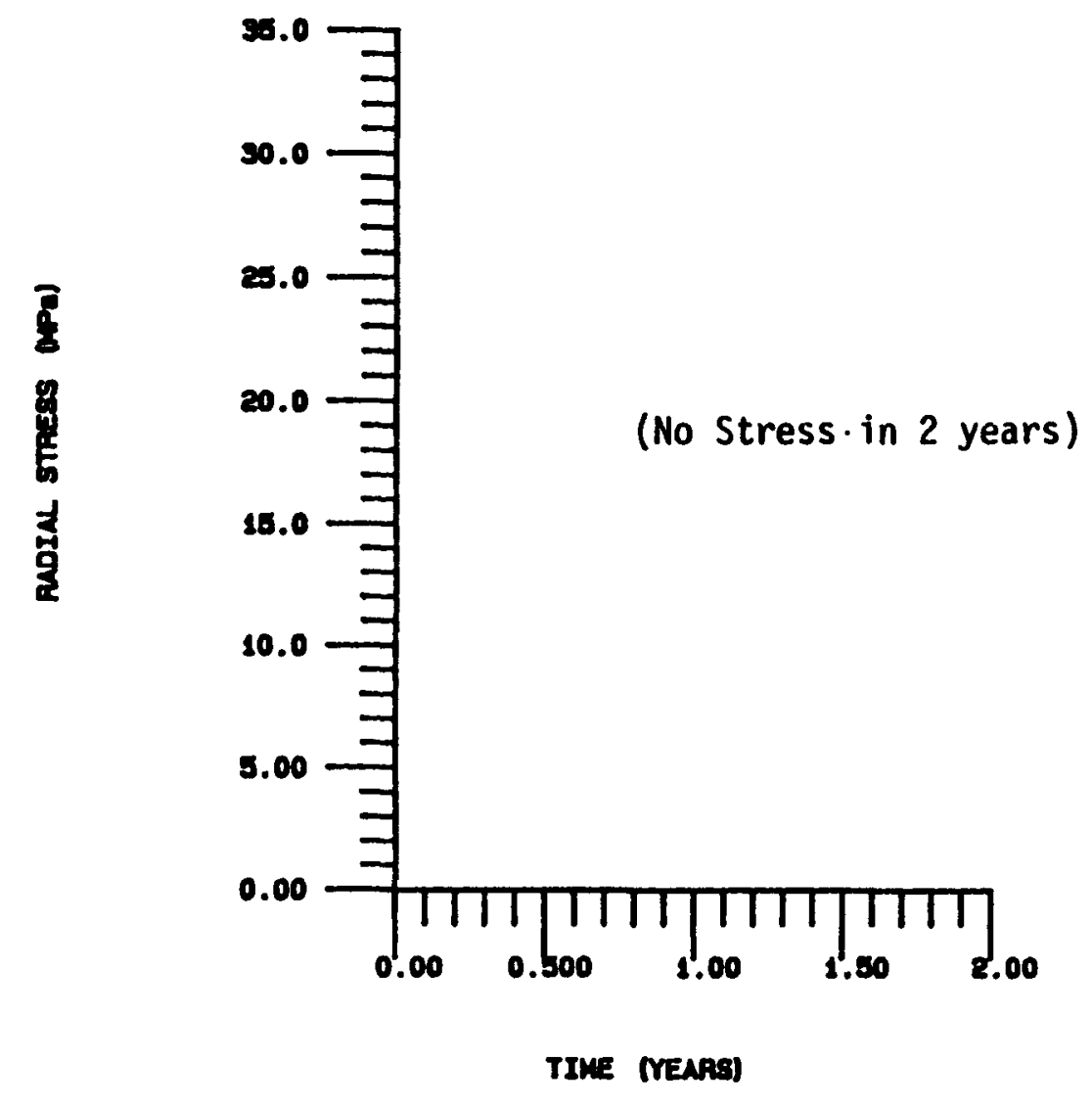

STRESS EXEATED ON MASTE PACKABE VERSUS TIME LONER THIFO OF WASTE PACKABE 
Figure C-11. Radial Stress Versus Time at Upper Third of Waste Package in Vertical Emplacement Mode with $20 \mathrm{~W} / \mathrm{m}^{2}$, 1" Air Gap, and Low Salt Thermal Conductivity

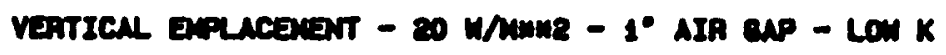

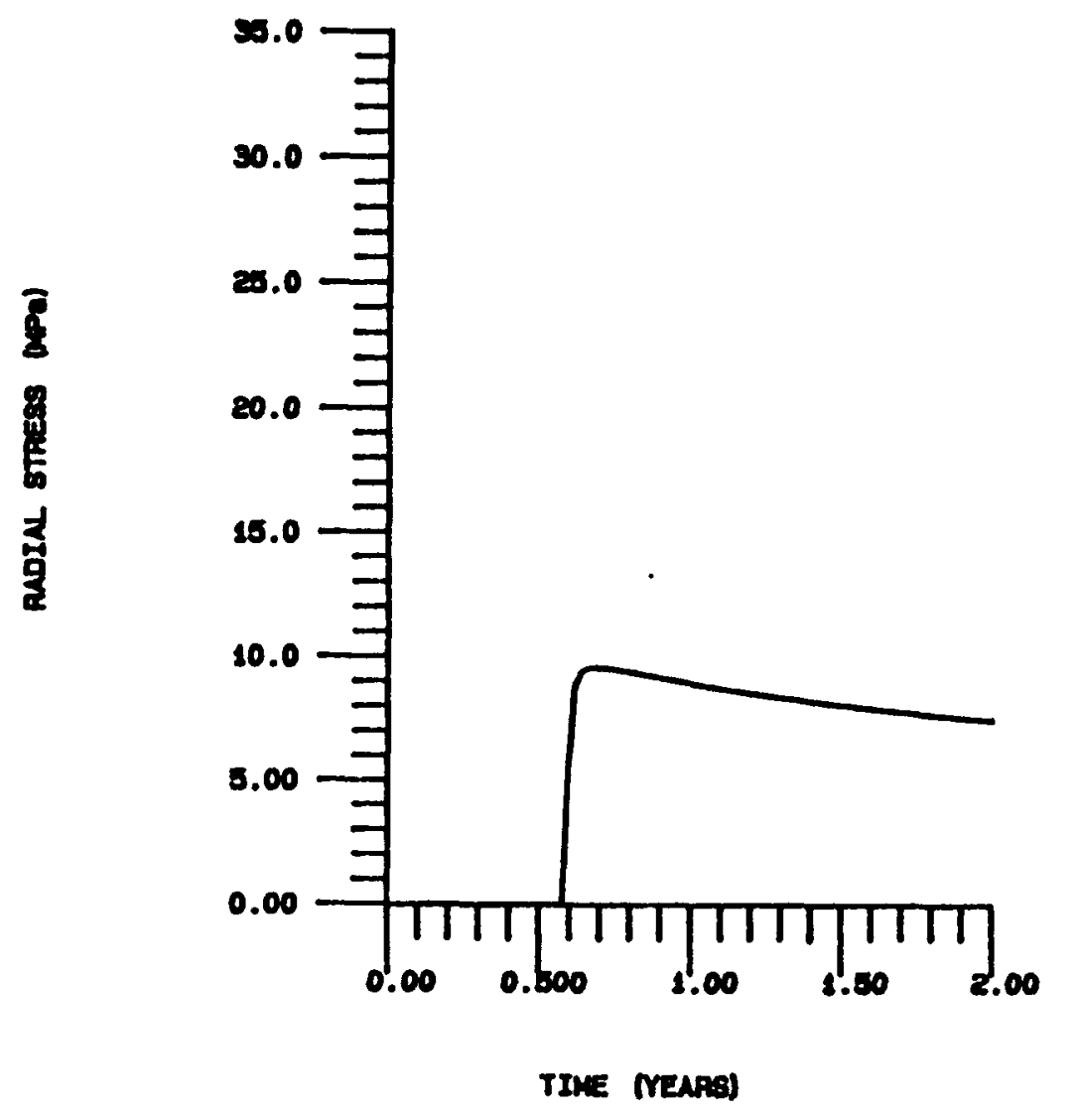

STRESB EXERTED ON MASTE PACKACE VERBUS TIME UPPER THIRD OF MASTE PACKADE 
Figure C-12. Radial Stress Versus Time at Mid-Height of Waste Package in Vertical Emplacement Mode with $20 \mathrm{~W} / \mathrm{m}^{2}, 1 "$ Air Gap, and Low Salt Thermal Conductivity

VERTICAL EMPLACEVEN - 20 W/MMME - 1" AIP OAP - LOW K

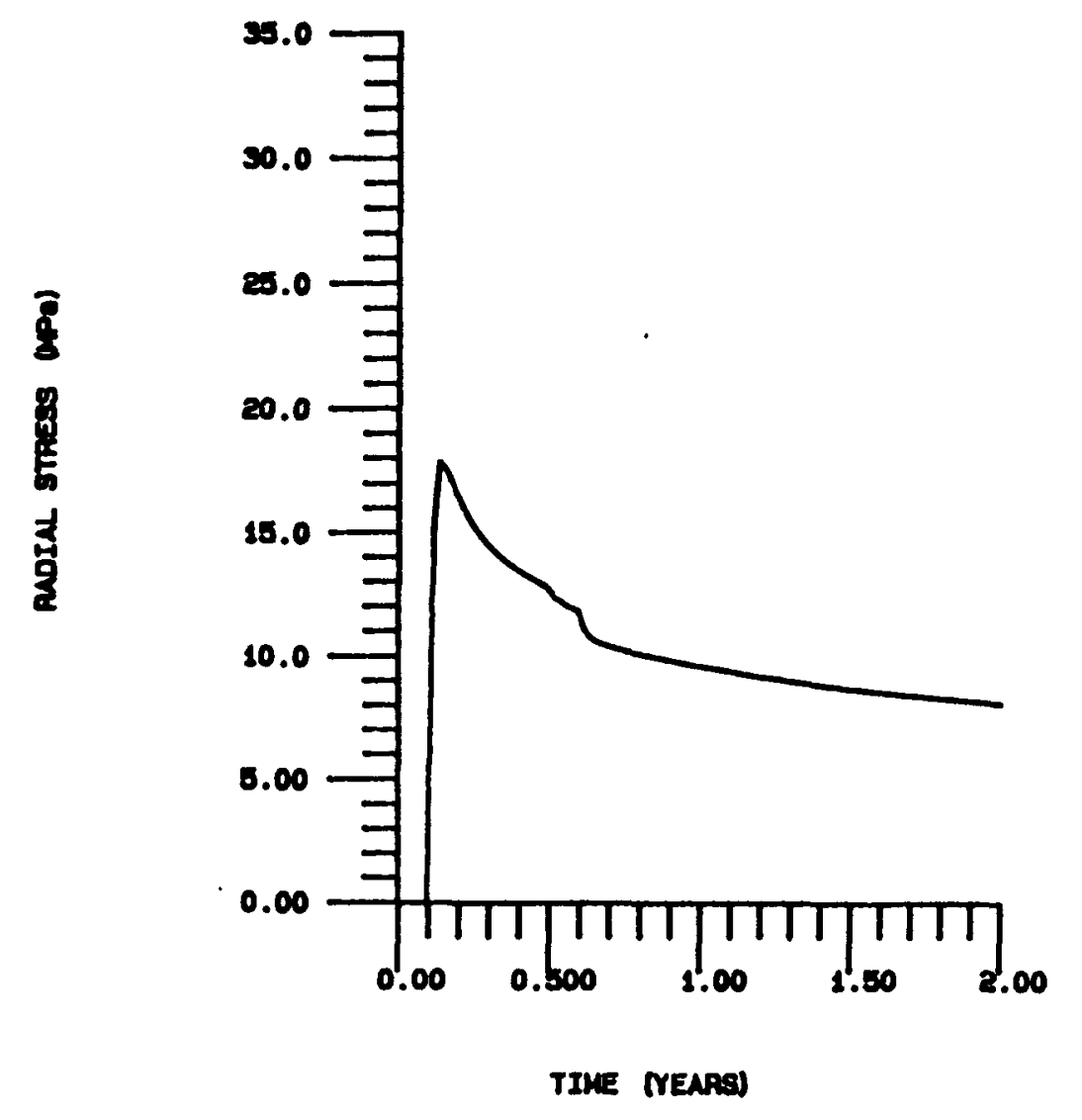

STRESS EXERTED ON MABTE PACKaGE VERSUS TIME MID-HEIEHT OF MASTE PACKABE 
Figure C-13. Radial Stress Versus Time at Lower Third of Waste Package in Vertical Emplacement Mode with $20 \mathrm{~W} / \mathrm{m}^{2}$, 1" Air Gap, and Low Salt Thermal Conductivity

VEATICAL EMPLACEMENT - 20 WMNME - 1" AIA CAP - LON K

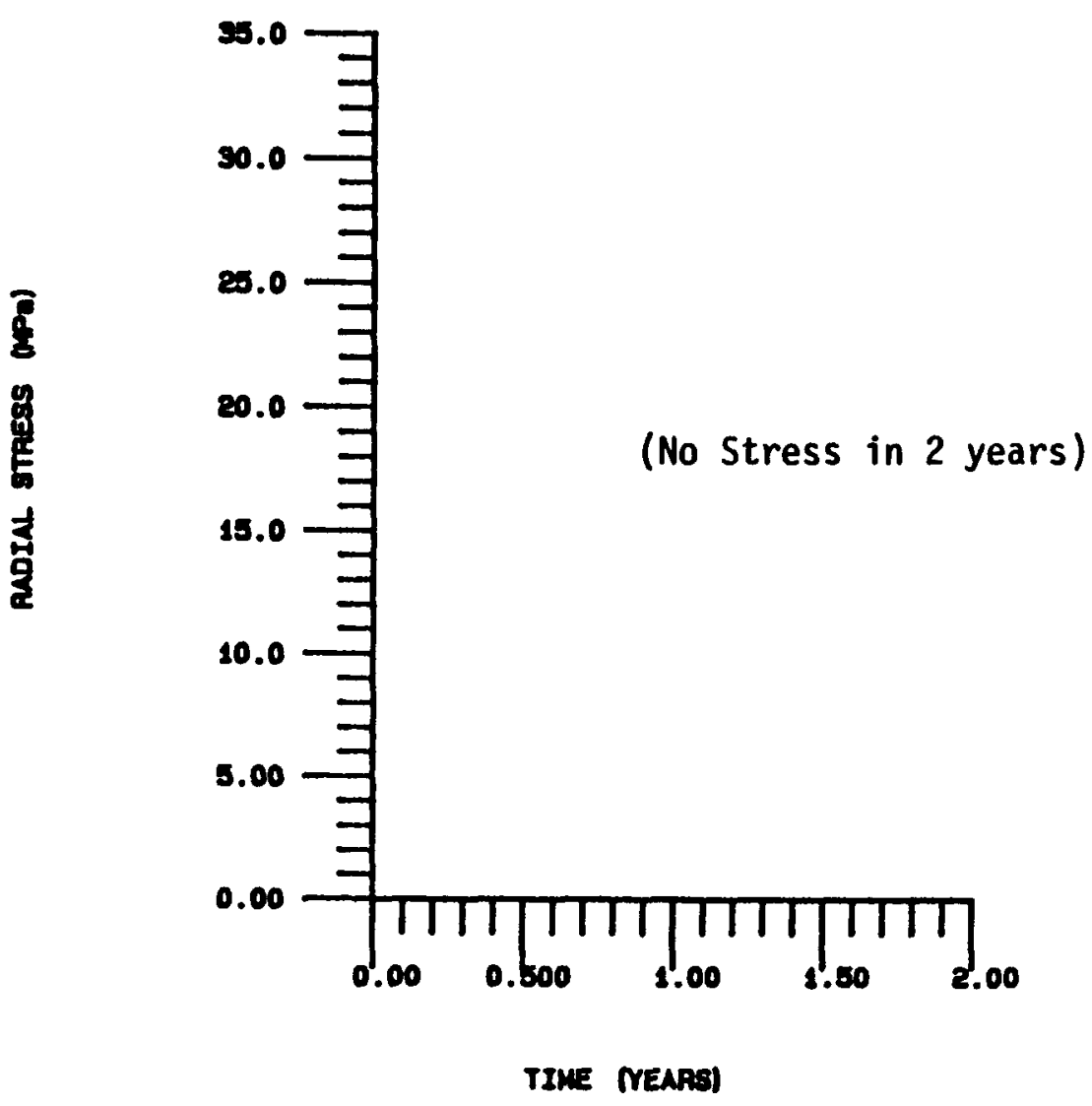

8TRESS EXERTED ON WASTE PACKABE VERSUS TIME LOWER THIPO OF MASTE PACKABE 
Figure C-14. Radial Stress Versus Time at Upper Third of Waste Package in Vertical Emplacement Mode with $20 \mathrm{~W} / \mathrm{m}^{2}$, 1" Air Gap, and Low Salt Creep Rate

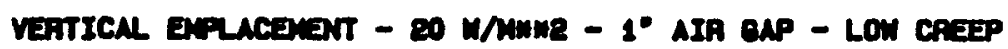

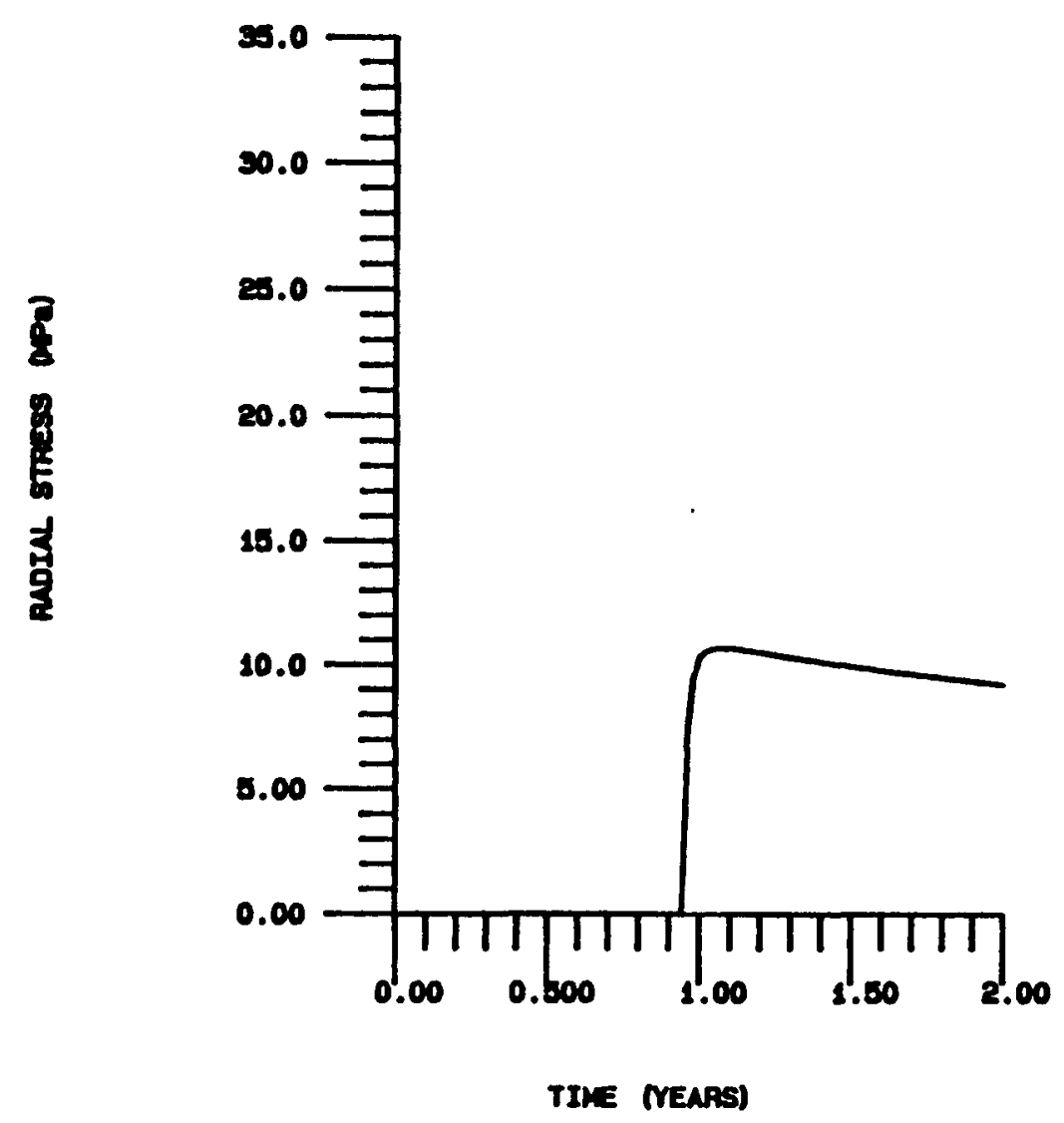

STRESS EXERTEO ON WASTE PACKCARE VERSUS TIME UPPER THIFO OF WASTE PACKAEE 
Figure C-15. Radial Stress Versus Time at Mid-Height of Waste Package in Vertical Emplacement Mode with $20 \mathrm{~W} / \mathrm{m}^{2}$, 1" Air Gap, and Low Salt Creep Rate

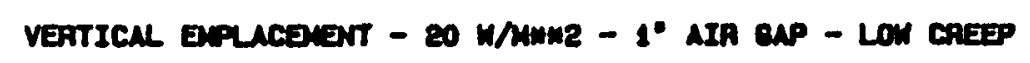

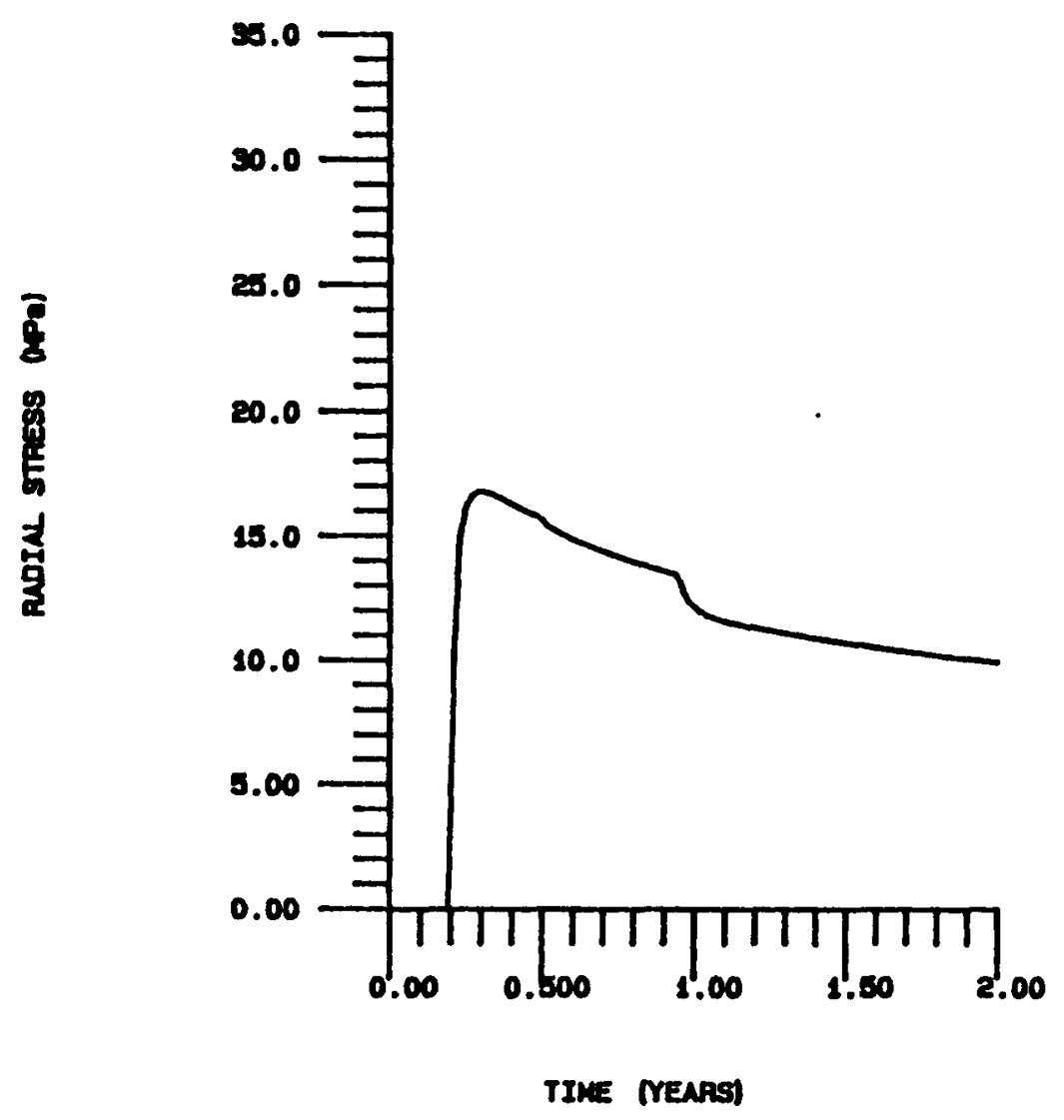

STRESS EXEATED ON WASTE PACKACE VERSUS TIME MIO-FEIET OF MASTE PACKABE 
Figure C-16. Radial Stress Versus Time at Lower Third of Waste Package in Vertical Emplacement Mode with $20 \mathrm{~W} / \mathrm{m}^{2}$, 1" Air Gap, and Low Salt Creep Rate

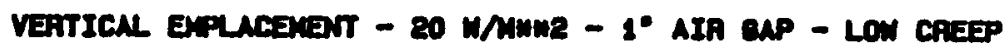

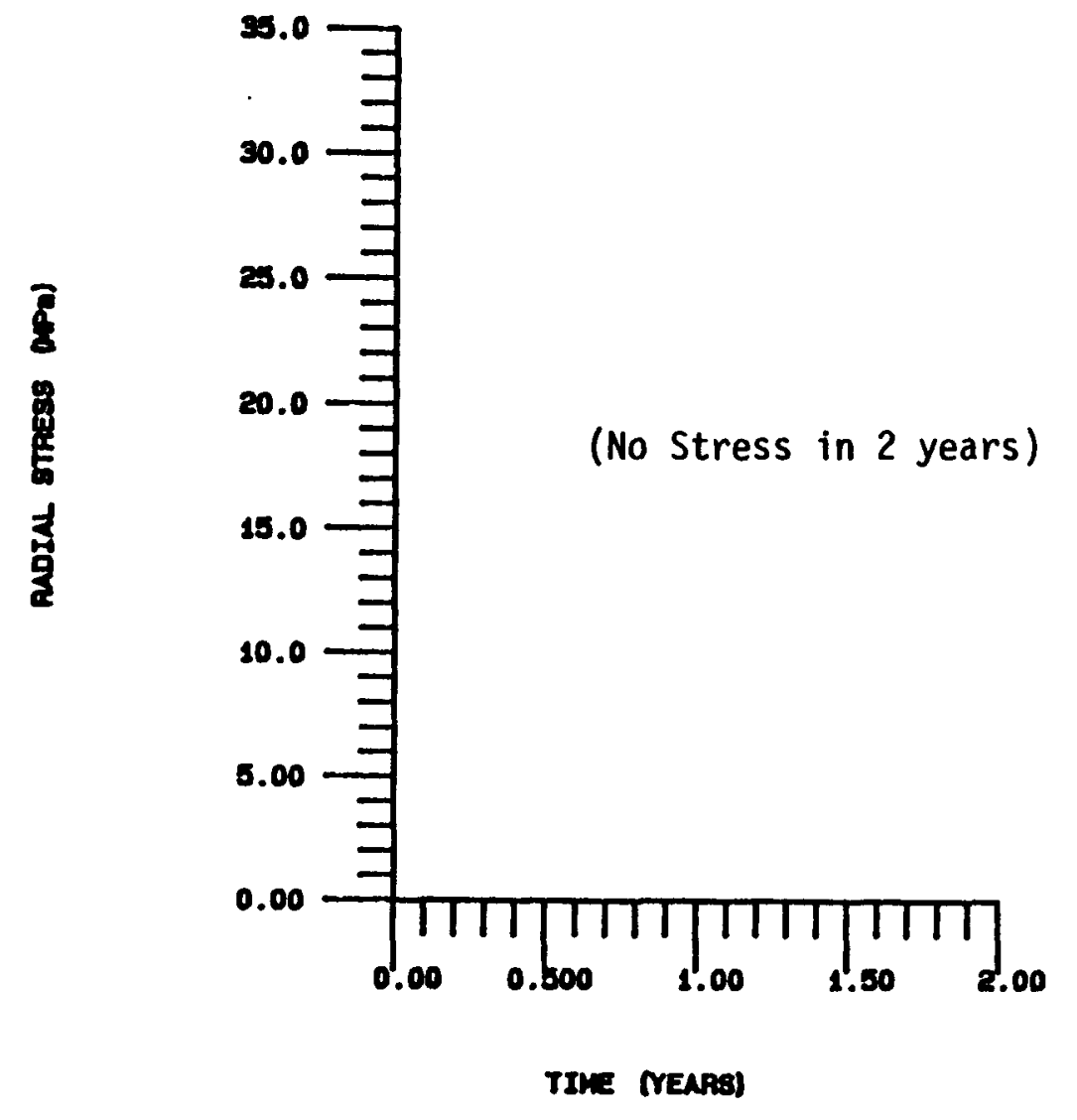

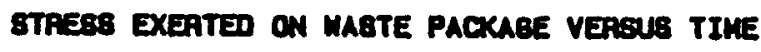
LOWEA THIFD OF MASTE PACKAGE 
Figure C-17. Radial Stress Versus Time at Upper Third of Waste Package in Vertical Emplacement Mode with $20 \mathrm{~W} / \mathrm{m}^{2}$ and 2" Air Gap

VERTICAL EMPACEMENT - 20 W/MWHE - 2' AIR BAP

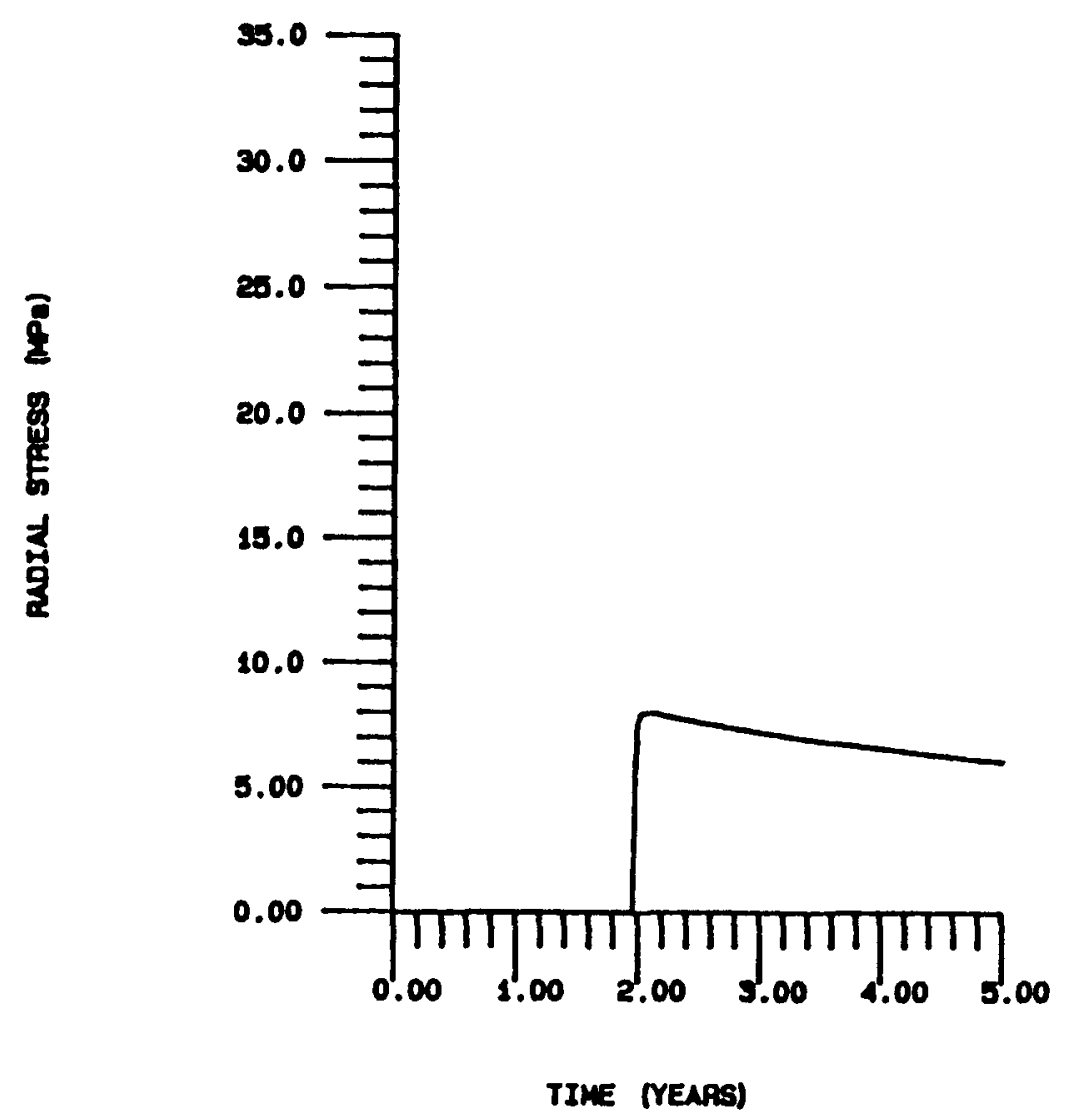

STRESS EXERTED ON WASTE PACKABE VERSUS TIME LPPEP THIRO OF MASTE PACKAGE 
Figure C-18. Radial Stress Versus Time at Mid-Height of Waste Package in Vertical Emplacement Mode with $20 \mathrm{~W} / \mathrm{m}^{2}$ and $2 "$ Air Gap

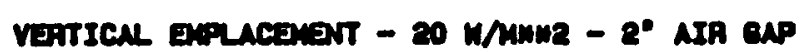

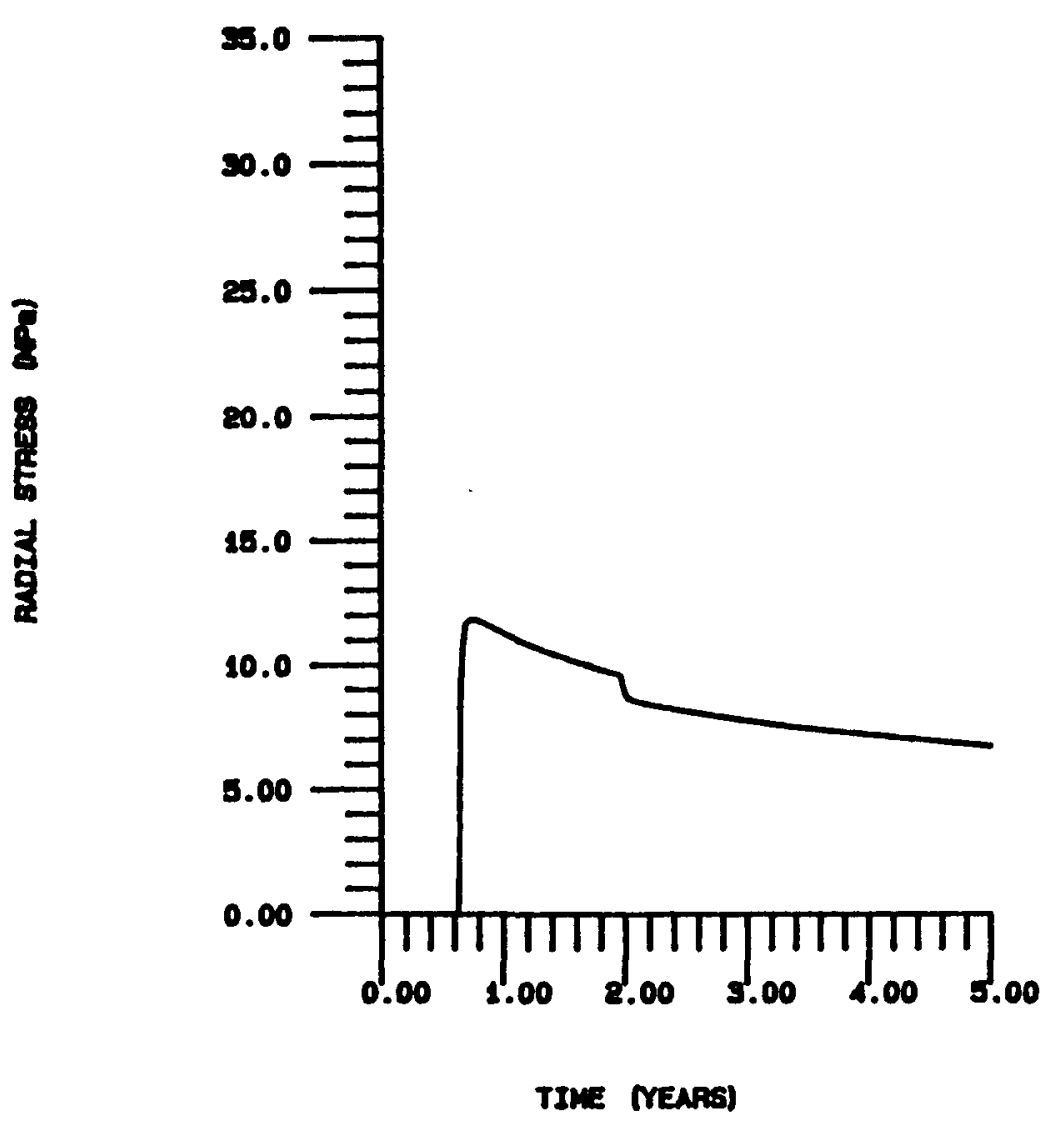

8TRESS EXERTED ON MASTE PACKACE VERSUS TIME MID-tEIGT OF MASTE PACGCAOE 
Figure C-19. Radial Stress Versus Time at Lower Third of Waste Package in Vertical Emplacement Mode with $20 \mathrm{~W} / \mathrm{m}^{2}$ and $2 "$ Air Gap

VERTICAL EMPLACEMENT - 20 W/MMMR - 2" AIA GAP

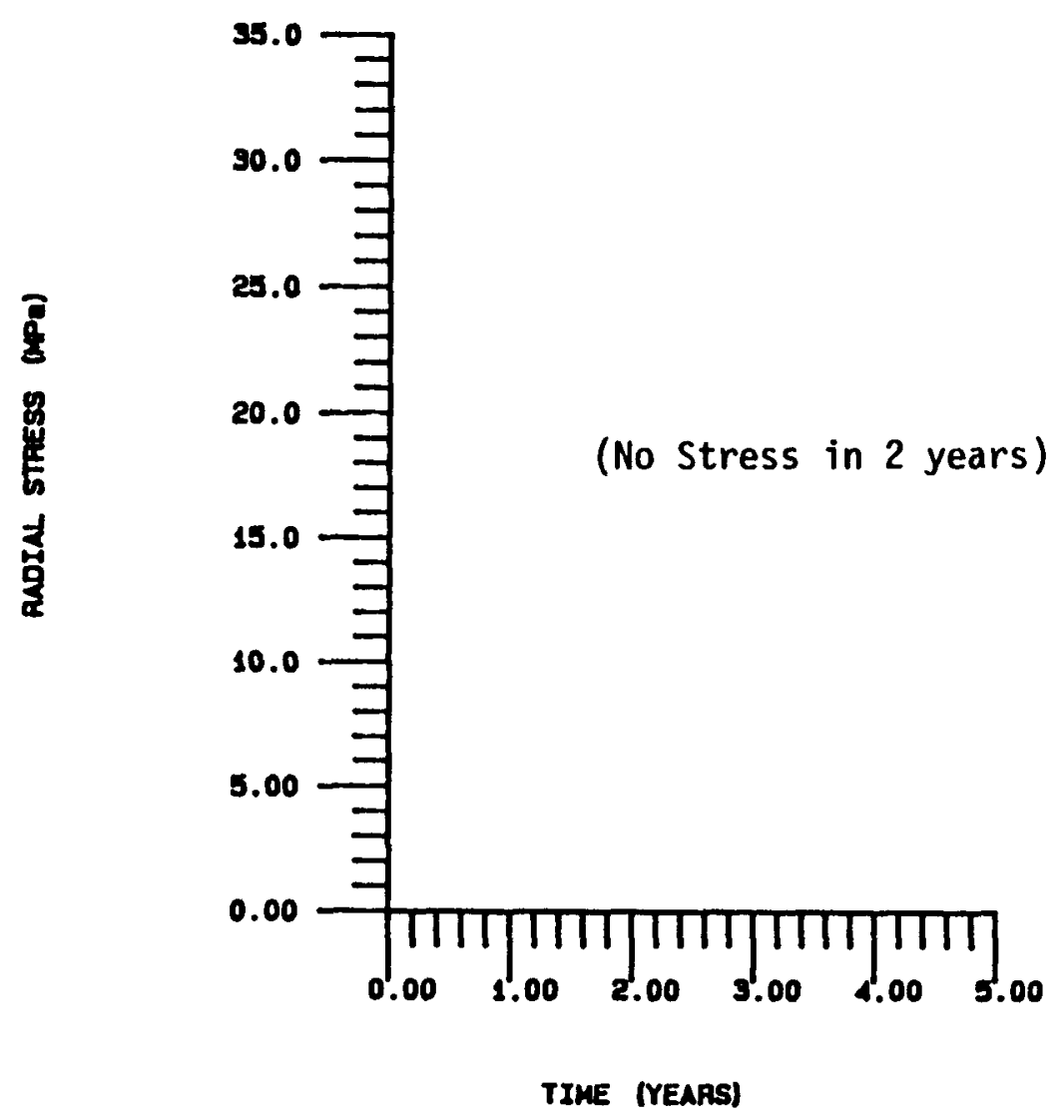

STRESS EXEATED ON WASTE PACKAGE VERSUS TIME LONER THIRO OF MASTE PACKAGE 
Figure C-20. Radial Stress Versus Time at Upper Third of Waste Package in Vertical Emplacement Mode with $30 \mathrm{~W} / \mathrm{m}^{2}$ and 1" Air Gap

VERTICAL ERLACDENT - 30 W/AMUR - 1" AIR BAP

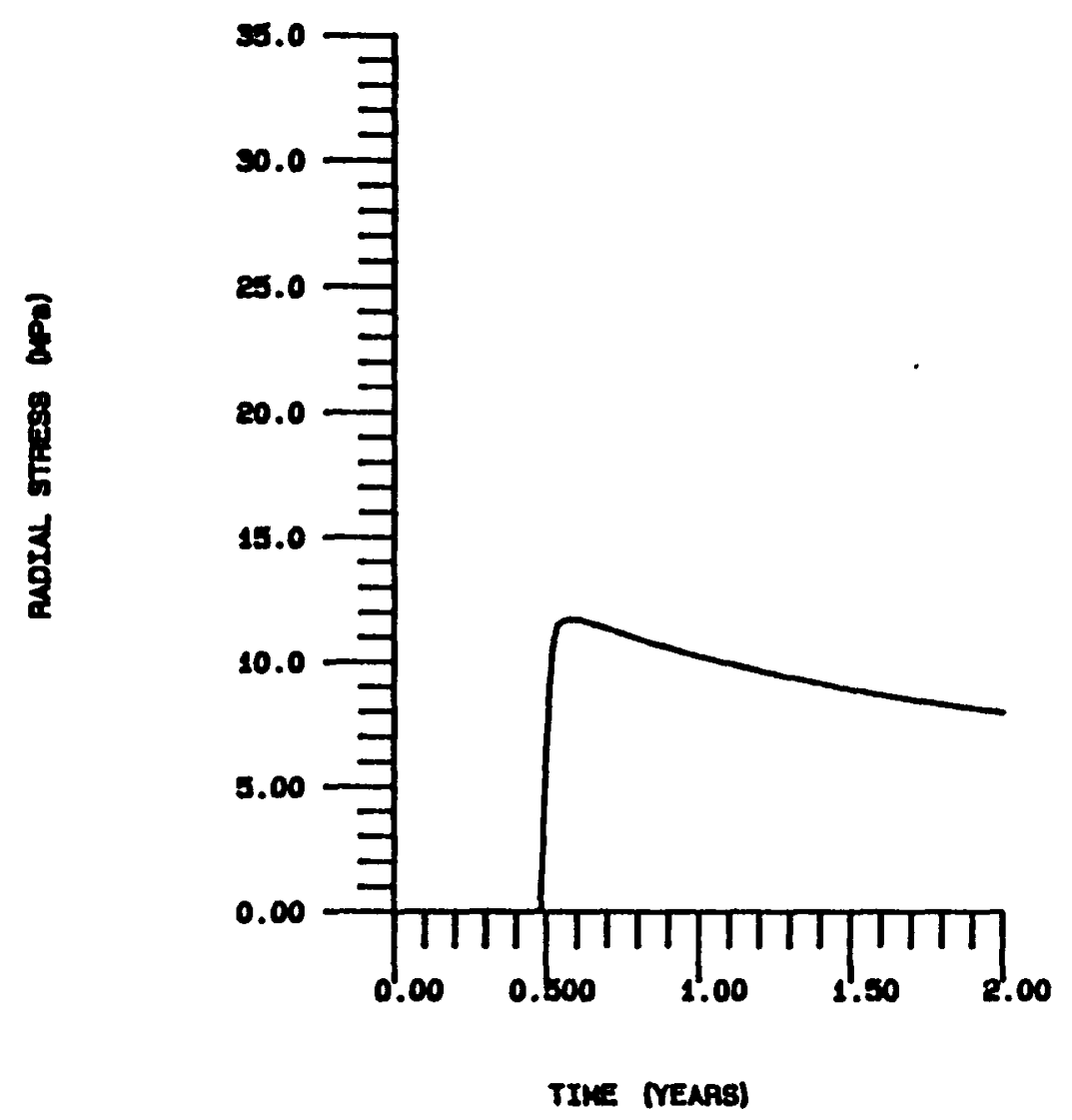

STRESS EXERTED ON MASTE PACKAGE VERSUS TIME UPPEA THIFO OF MASTE PACKABE 
Figure C-21. Radial Stress Versus Time at Mid-Height of Waste Package in Vertical Emplacement Mode with $30 \mathrm{~W} / \mathrm{m}^{2}$ and 1" Air Gap

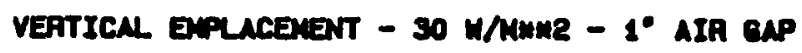

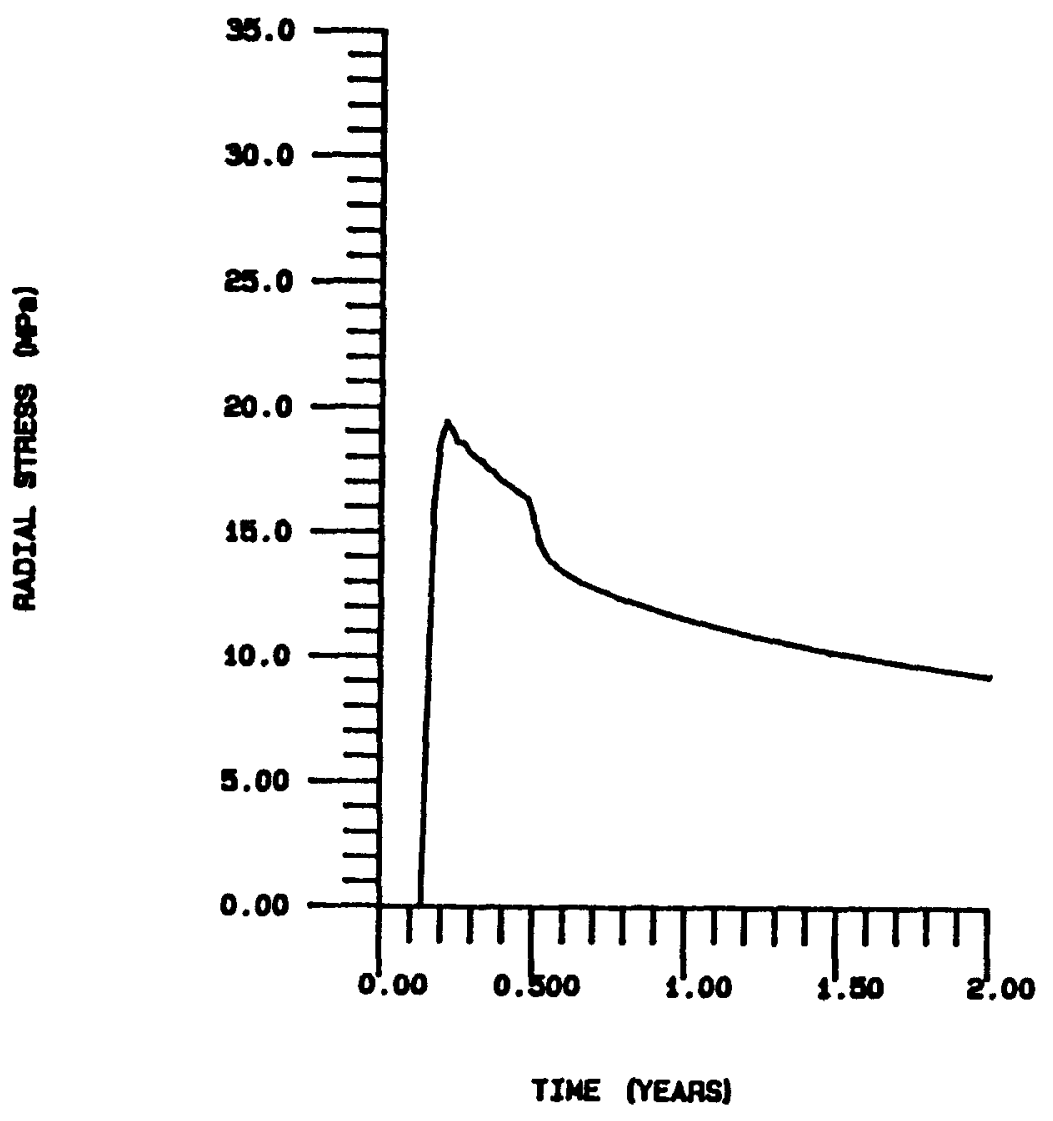

STRESS EXEATED ON WASTE PACKAEE VERSUS TIME MIO-HEIGHT OF MASTE PACKABE 
Figure C-22. Radial Stress Versus Time at Lower Third of Waste Package in Vertical Emplacement Mode with $30 \mathrm{~W} / \mathrm{m}^{2}$ and 1" Air Gap

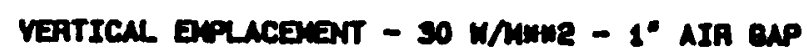

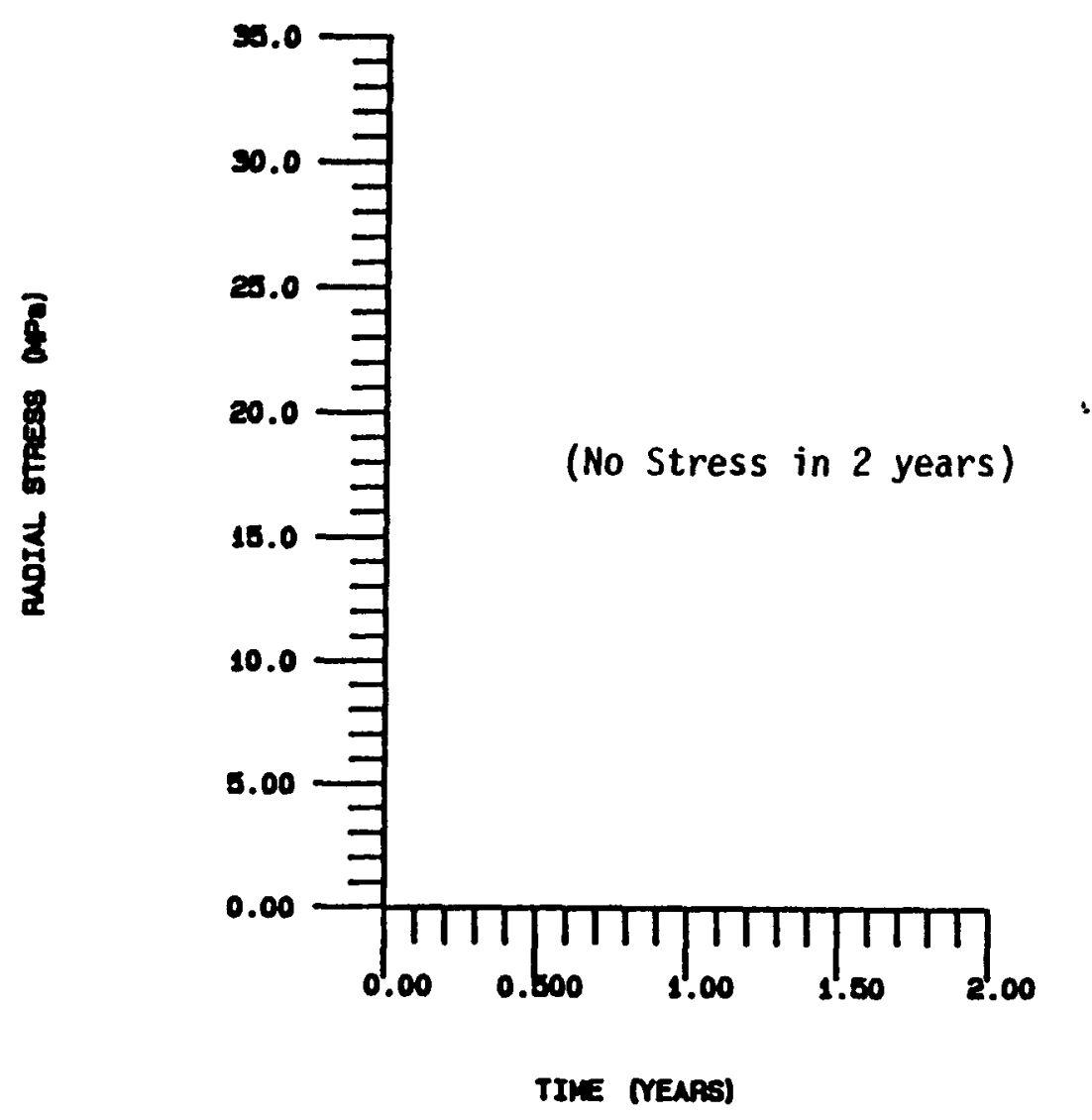

STFESS EXERTED ON MASTE PACKAGE VERSUS TIME LOUEA tHIFO OF MASTE PACKaEE 
Figure C-23. Schematic Diagram of Gap Closure Algorfthm for Emplacement in a Horizontal slot

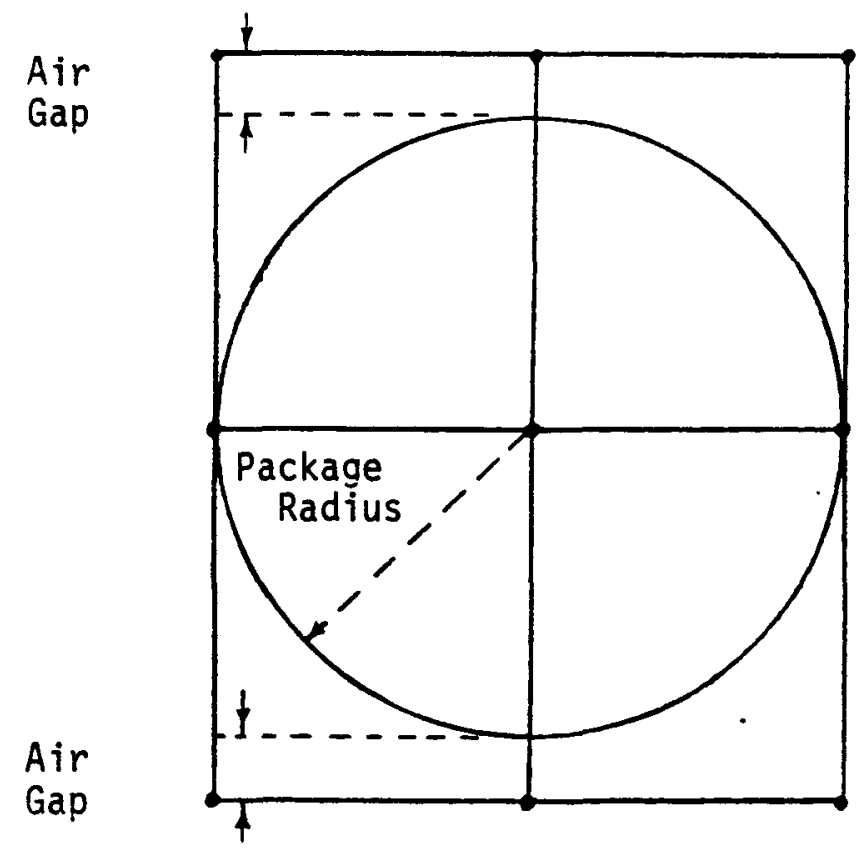


Figure C-24. Radial Stress Versus Time at Left Side of Waste Package in Horizontal Emplacement Mode with Low Waste Package Heat Energy Density

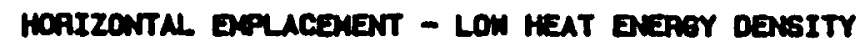

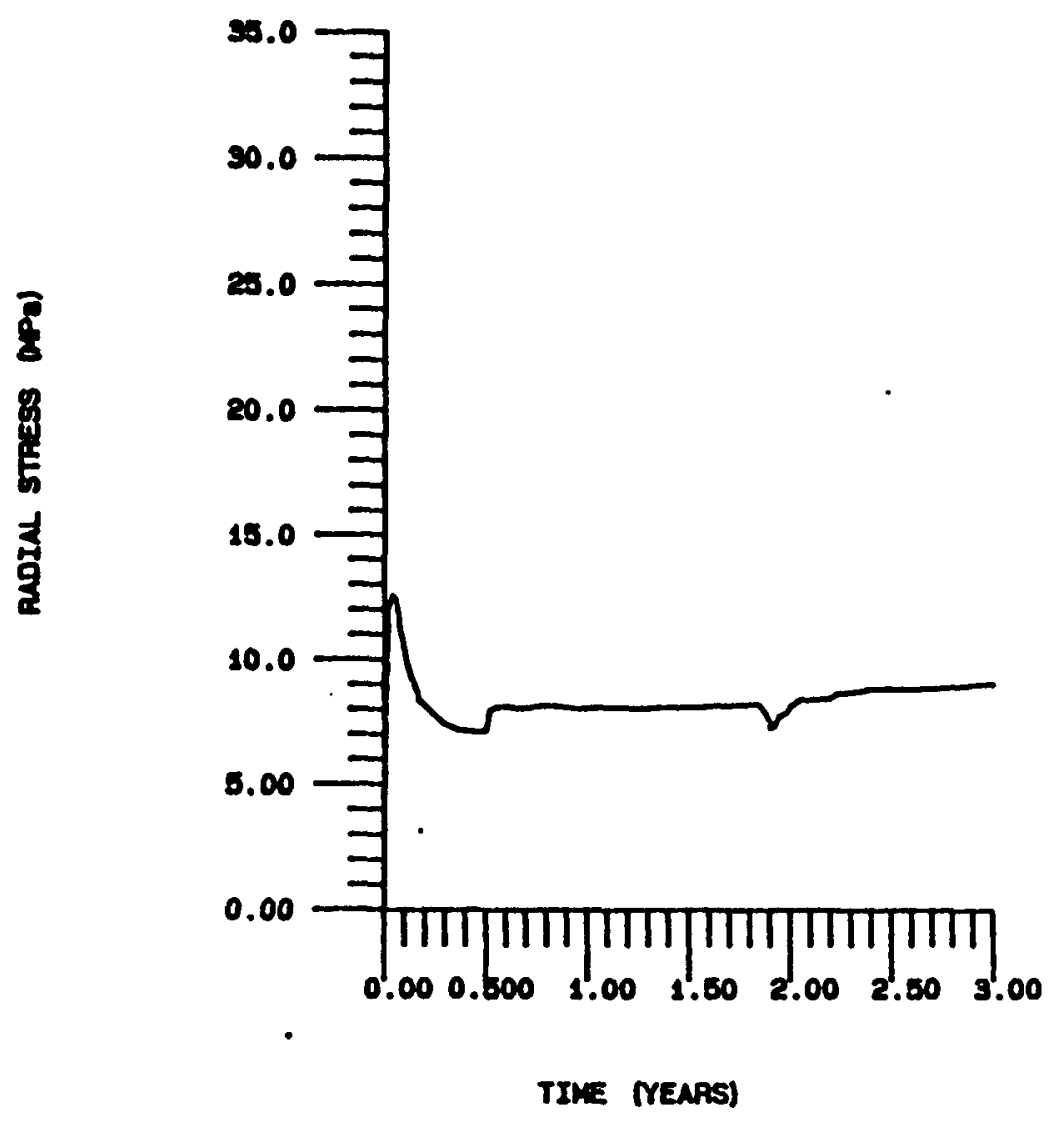

STRESS EXERTED ON MASTE PACKAGE VERSUS TIME LeFT SIOE OF MASTE PACKAGE 
Figure C-25. Radial Stress Versus Time at Right Side of Waste Package in Horizontal Emplacement Mode with Low Waste Package Heat Energy Density

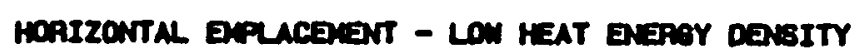

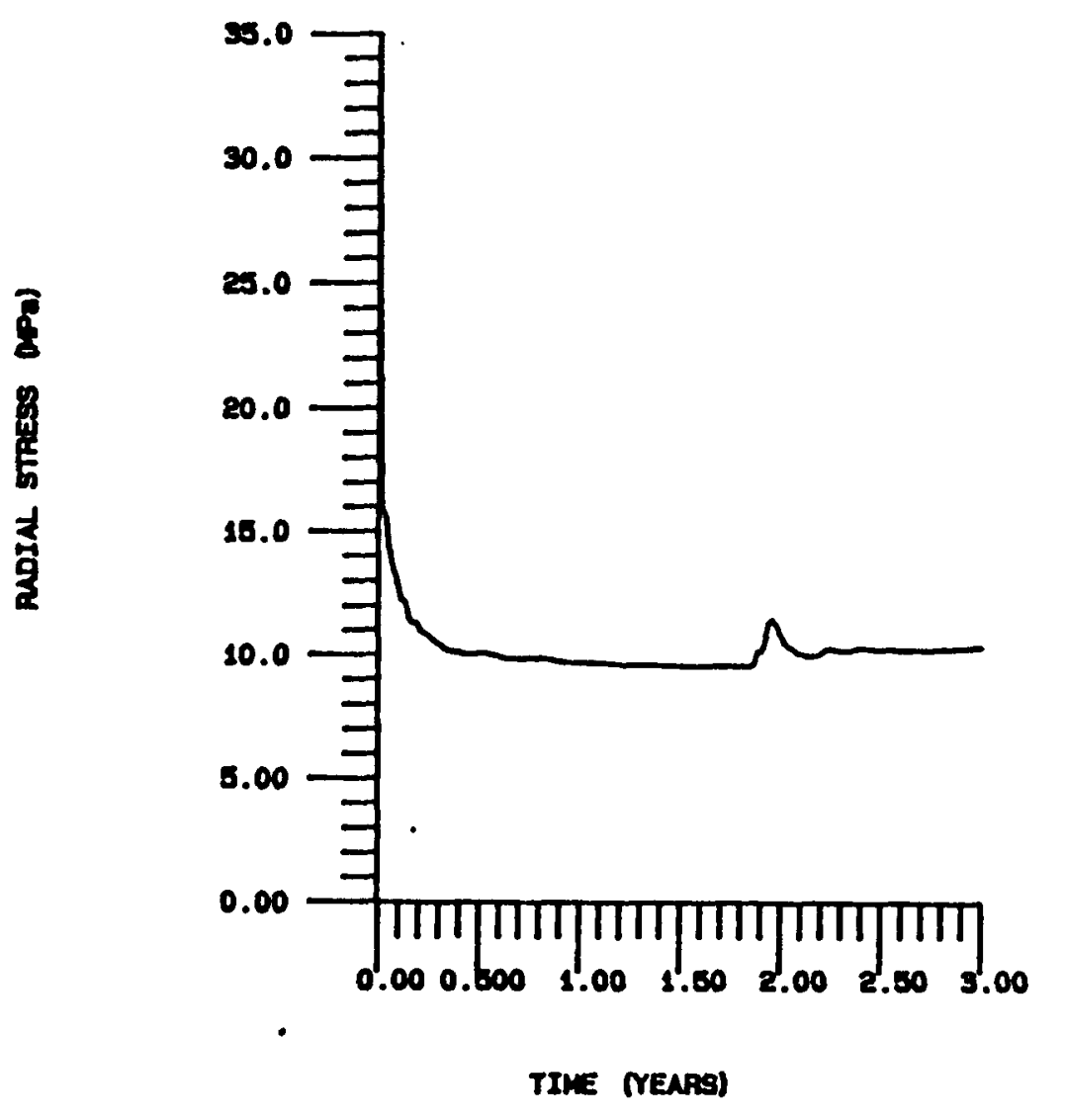

STRESS EXERTED ON WASTE PACKAGE VERSUS TIME AIGH SIDE of MAgTE PACKAGE 
Figure C-26. Radial Stress Versus Time at Bottom Side of Waste Package in Horizontal Emplacement Mode with Low Waste Package Heat Energy Density

HOAIZONTAL EMPLACEUENT - LOU HEAT ENEREY DENSITY

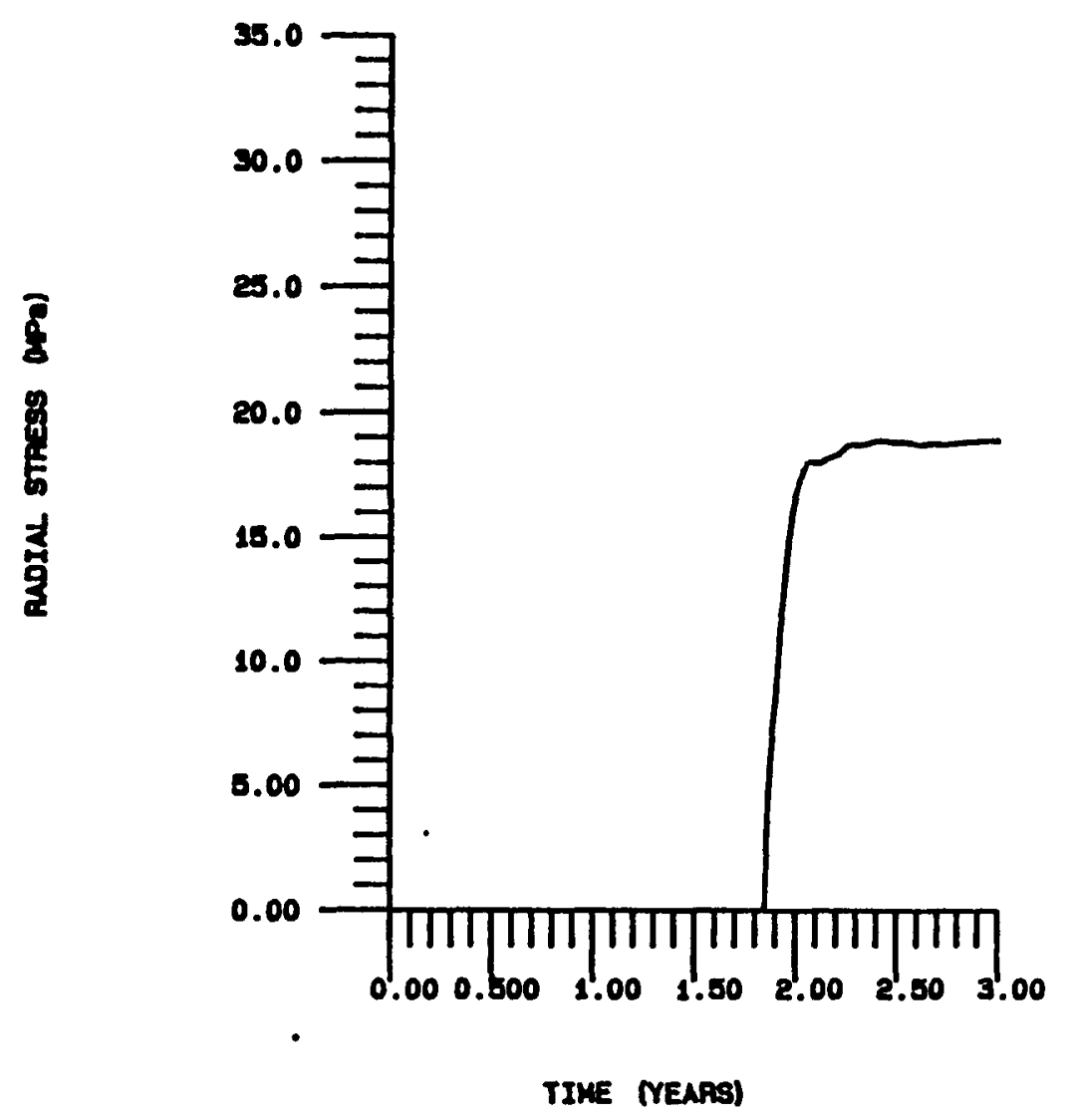

STREsS EXERTED ON MASTE PACKage versus tIME BOTTON SIDE OF WASTE PACKABE 
Figure C-27. Radial Stress Versus Time at Top Side of Waste Package in Horizontal Emplacement Mode with Low Waste Package Heat Energy Density

\section{HOAIZONTAL EPLACEVIT - LOM HEAT EMEROY DENSITY}

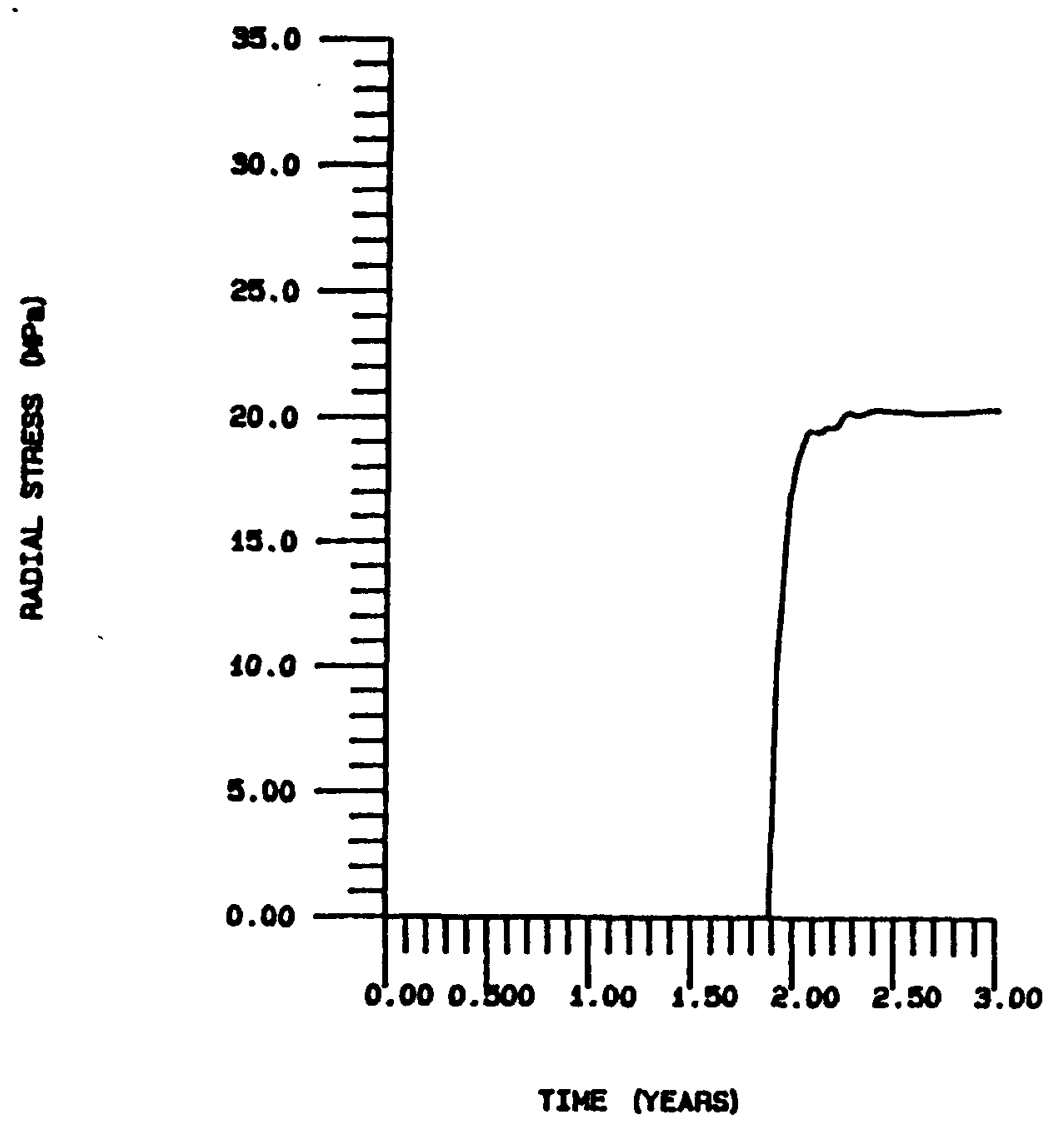

STRESS EXERTED ON MAGTE PACKAGE VERSUS TIME TOP STDE OF WASTE PACKAOE 
Figure C-28. Radial Stress Versus Time at Left Side of Waste Package in Horizontal Emplacement Mode with High Waste Package Heat Energy Density

hoAizontAl ERLACEMENT - HIEH hEAT ENERGY DENGITY

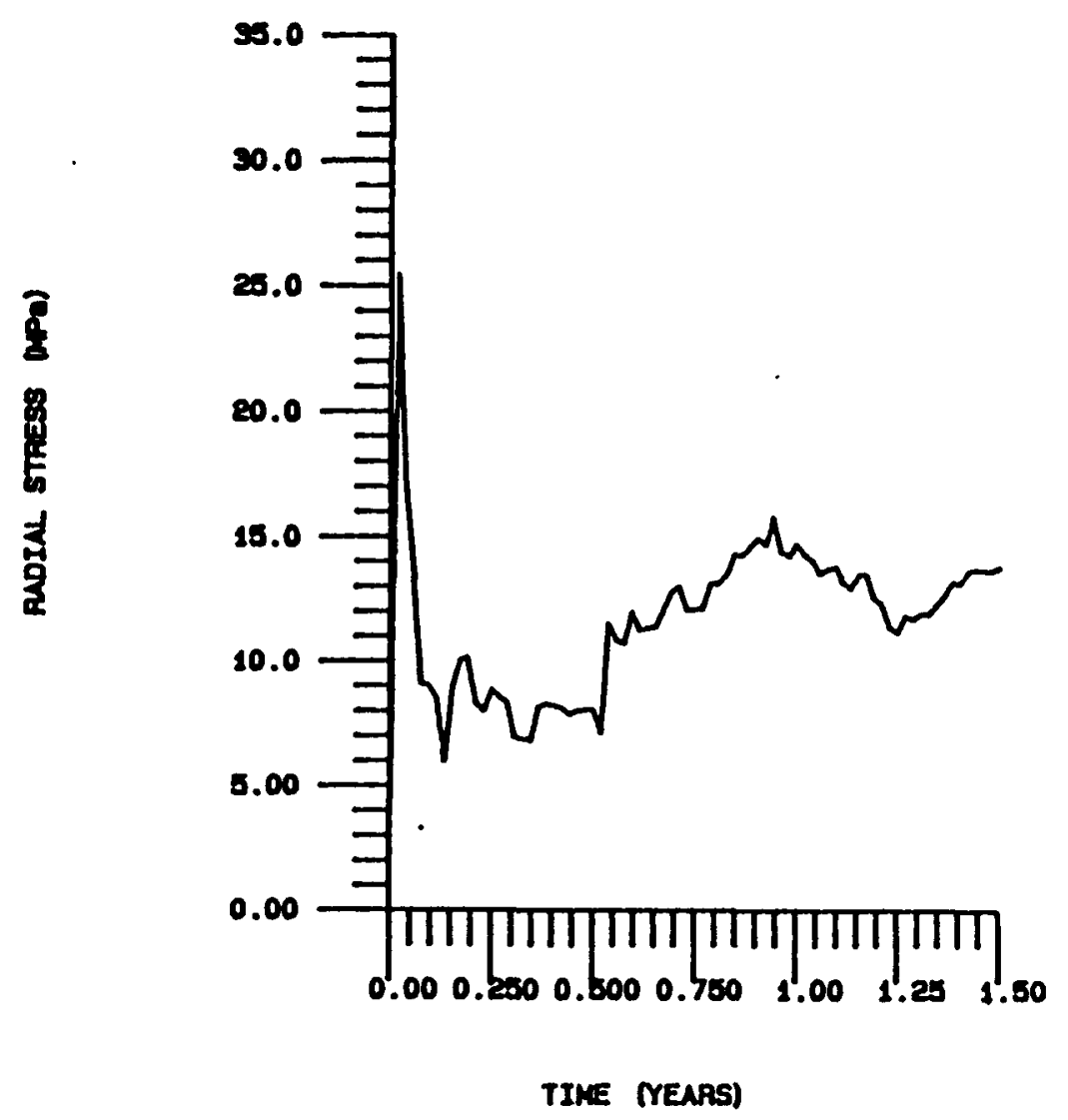

STRESB EXERTED ON WASTE PACKAGE VERSUS TIME LEFT SIDE OF MASTE PACKABE 
Figure C-29. Radial Stress Versus Time at Right Side of Waste Package in Horizontal Emplacement Mode with High Waste Package Heat Energy Density

MORIZONTAL ERLACEMENT - HIEH MEAT ENEROY DENSITY

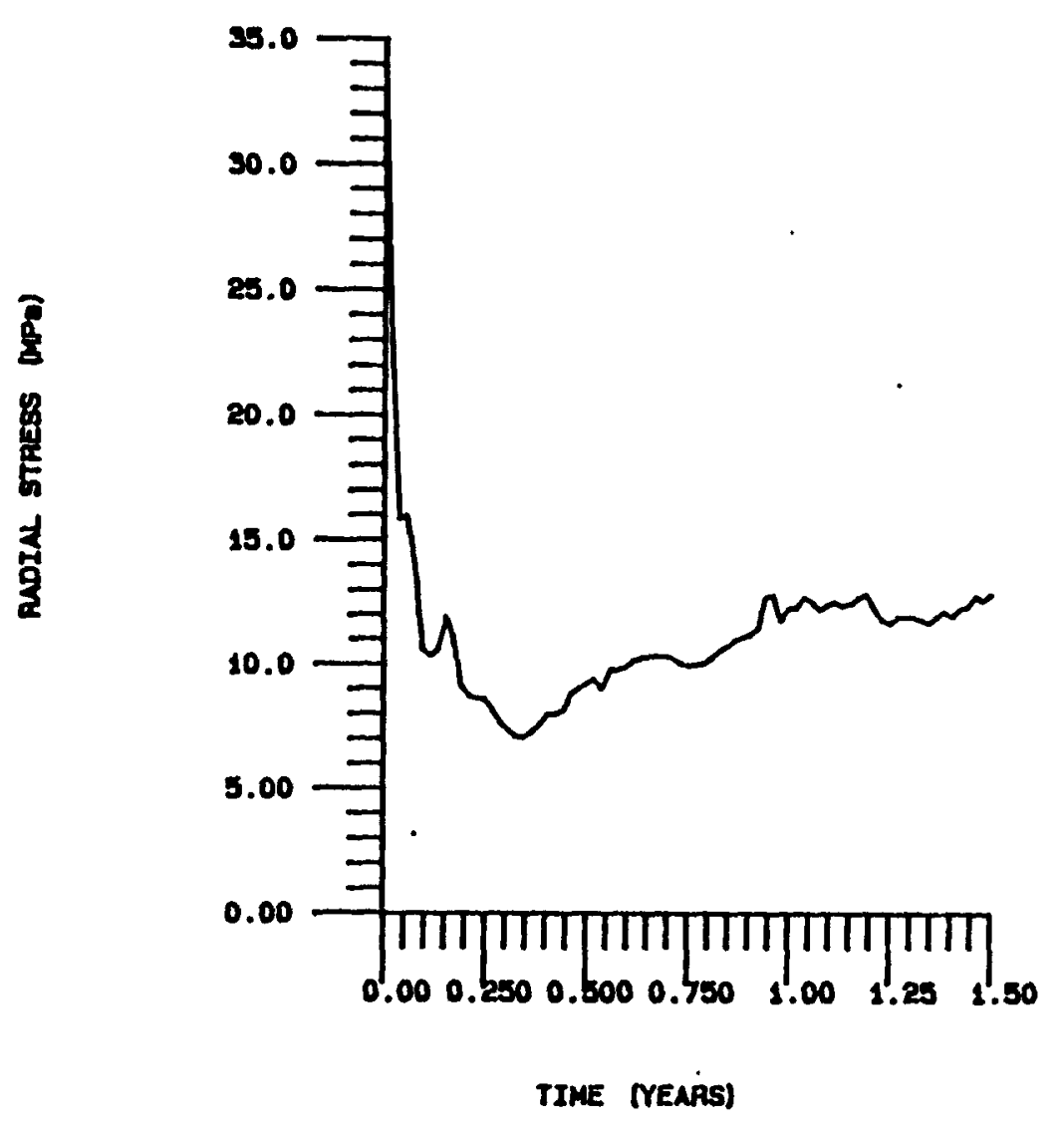

STRESS EXERTED ON MASTE PACKAGE VERSUS TIME RIGT SIDE OF WASTE PACKABE 
Figure C-30. Radial Stress Versus Time at Bottom Side of Waste Package in Horizontal Emplacement Mode with High Waste Package Heat Energy Density

hOAIZONTAL EMPACENaNT - HIGH HEAT ENERGY DENSITY

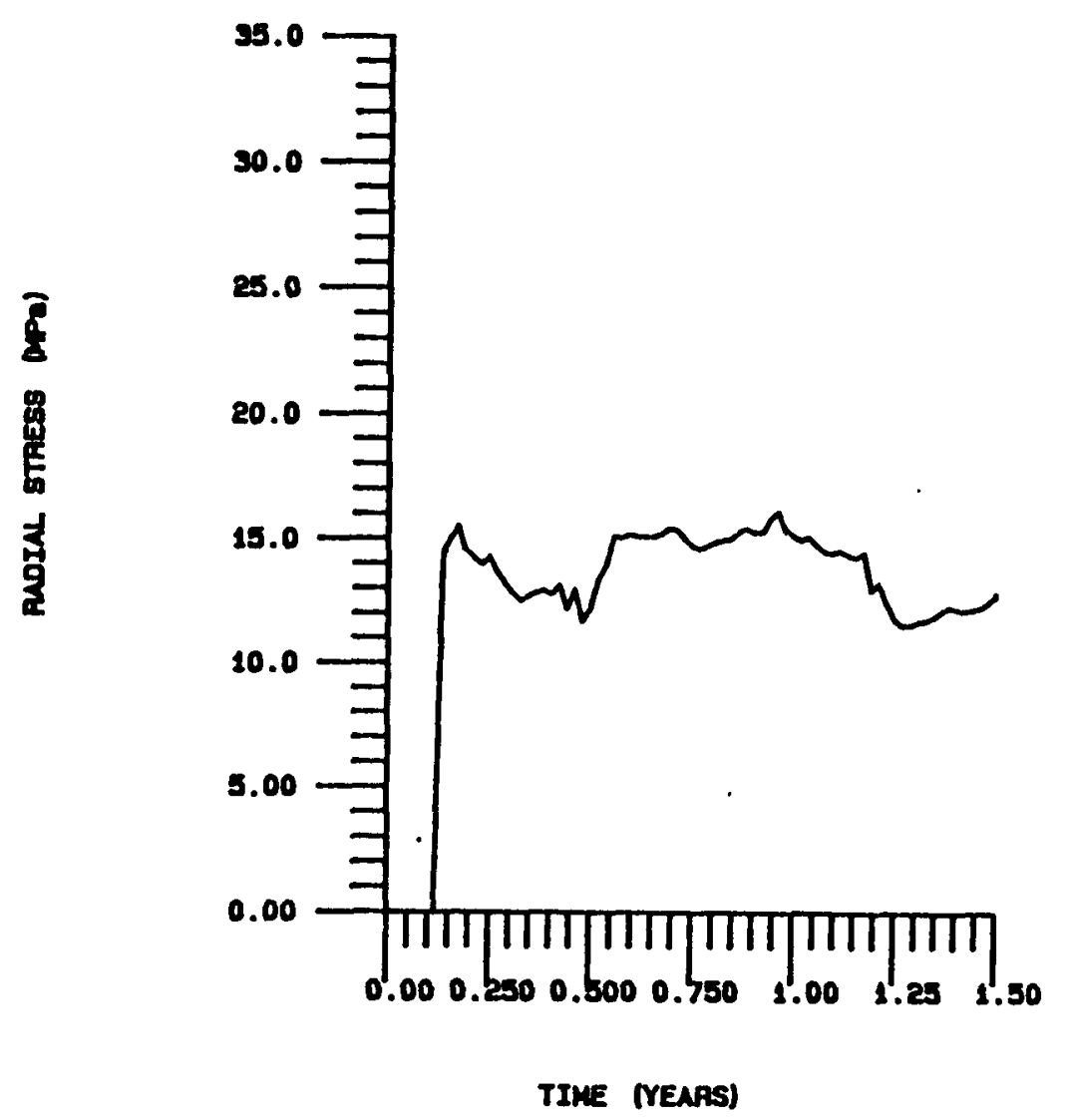

STAESS EXEATED DN MABTE PACKABE VERSUS TIME BOTTON SIDE OF MAGTE PACKAGE 
Figure C-31. Radial Stress Versus Time at Top Side of Waste Package in Horizontal Emplacement Mode with High Waste Package Heat Energy Density

HOAIZONTAL EMPLACENENT - HIEH HEAT ENEROY DENBITY

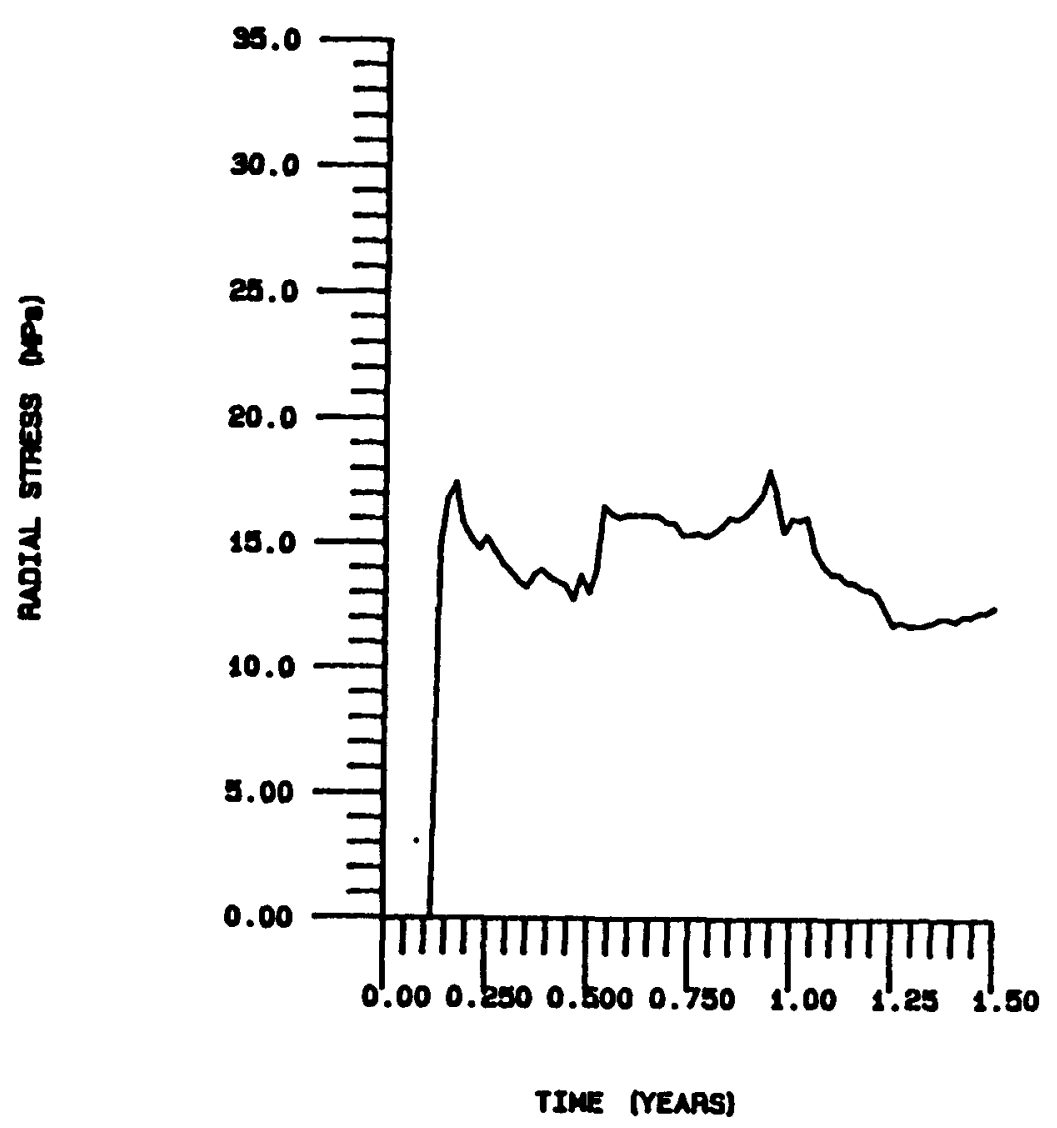

STRESS EXERTED ON MASTE PACKAGE VERSUS TIME TOP SIDE OF MASTE PACKABE 
Figure C-32. Room and Pillar Distortions for the Low and High Energy Sources

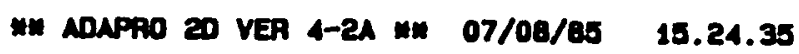

HOAITZONTAL ERLACEMENT

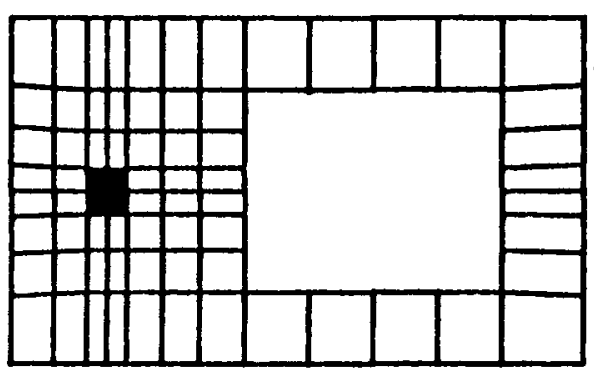

(a) Initial view of room and canister area.

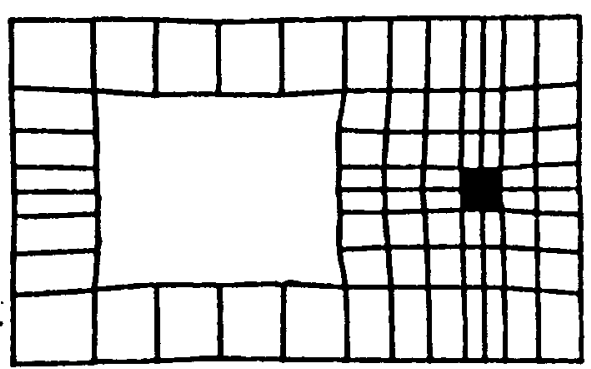

(b) View of room and canister area after 3 years. (low energy density calculation)

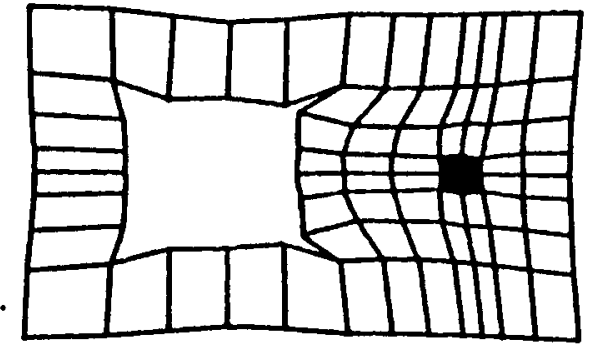

(c) View of room and canister area after $1 \frac{1}{2}$ years.

(High energy density calculation)

. 1.

TIME - 4.73E+07 CYCLE -2578 
Figure C-33. Schematic Diagram of Package Failure Modes

(a) Longitudinal Bending

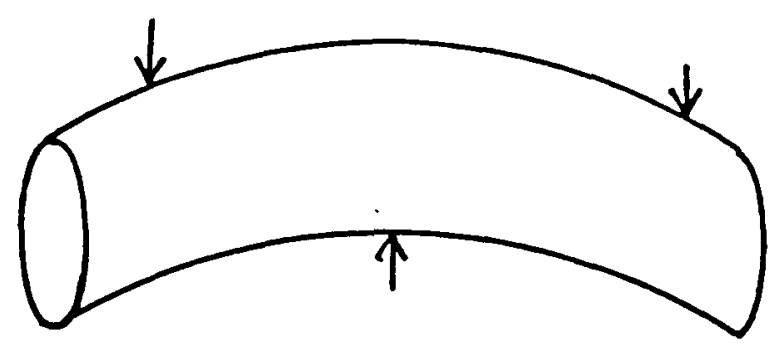

(b) Uniform Radial Stress

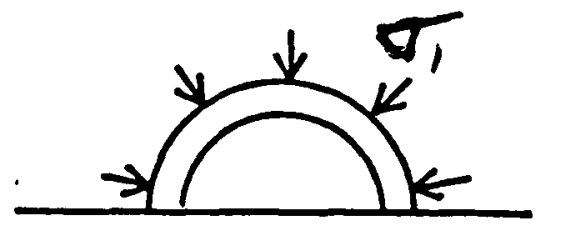

(c) Line Load, $F=2 b \sigma_{\text {, }}$

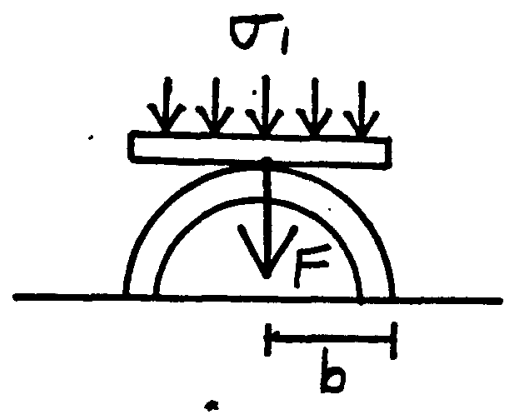

(d) Uniform Lateral Load

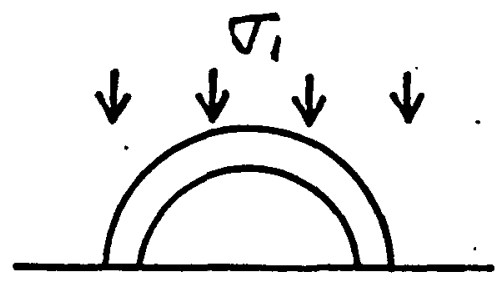


Figure C-34. Typical Distortions of 1 Meter Salt Zones for a $50 \%$ Reduction in Room Volume

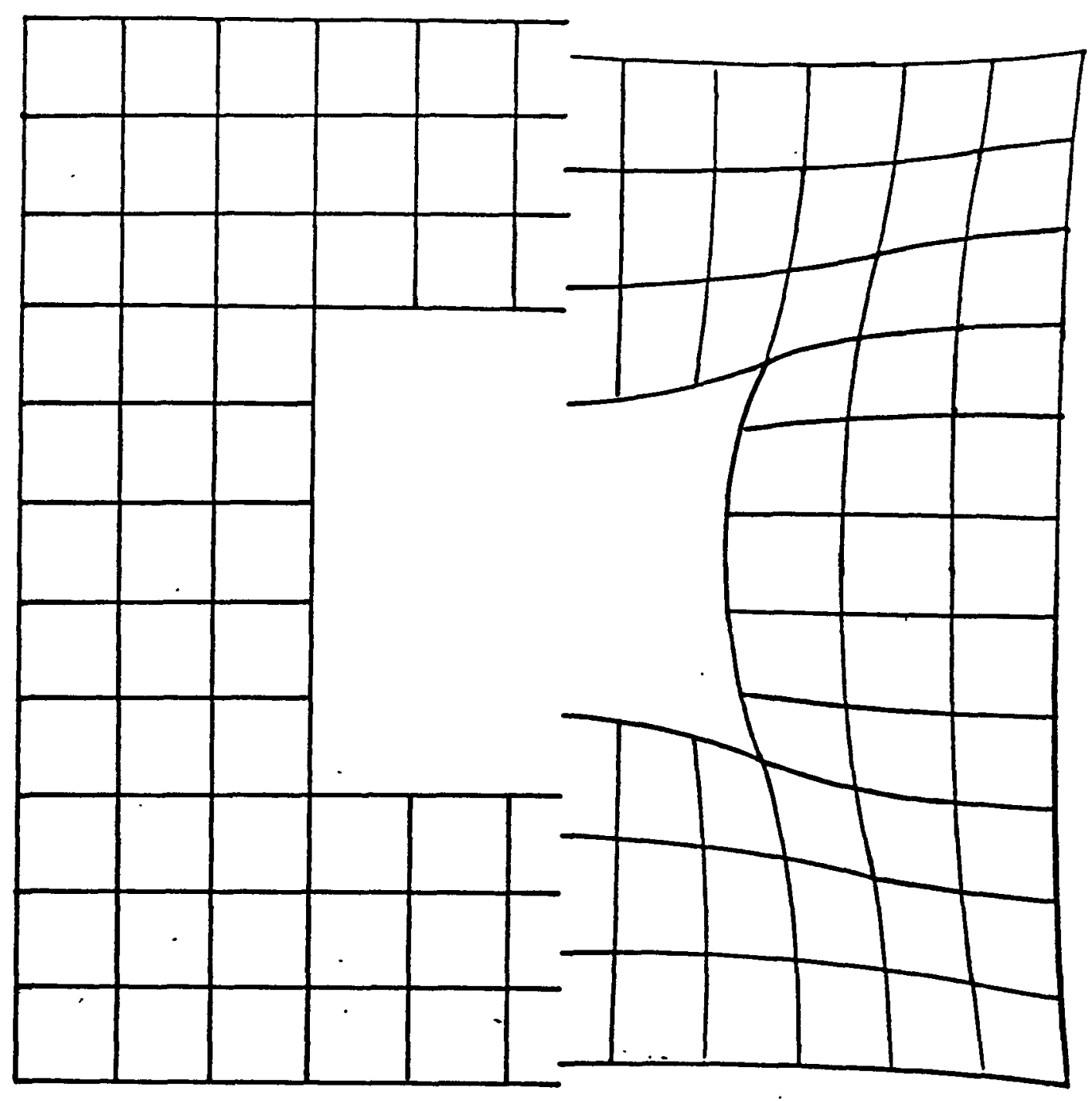

(a) Before Closure

(b) After clösure 
Figure C-35. Peak Radial Stress vs Air Gap Closure Time for the Upper Third and Middle Third of the Package

(a) Upper Third

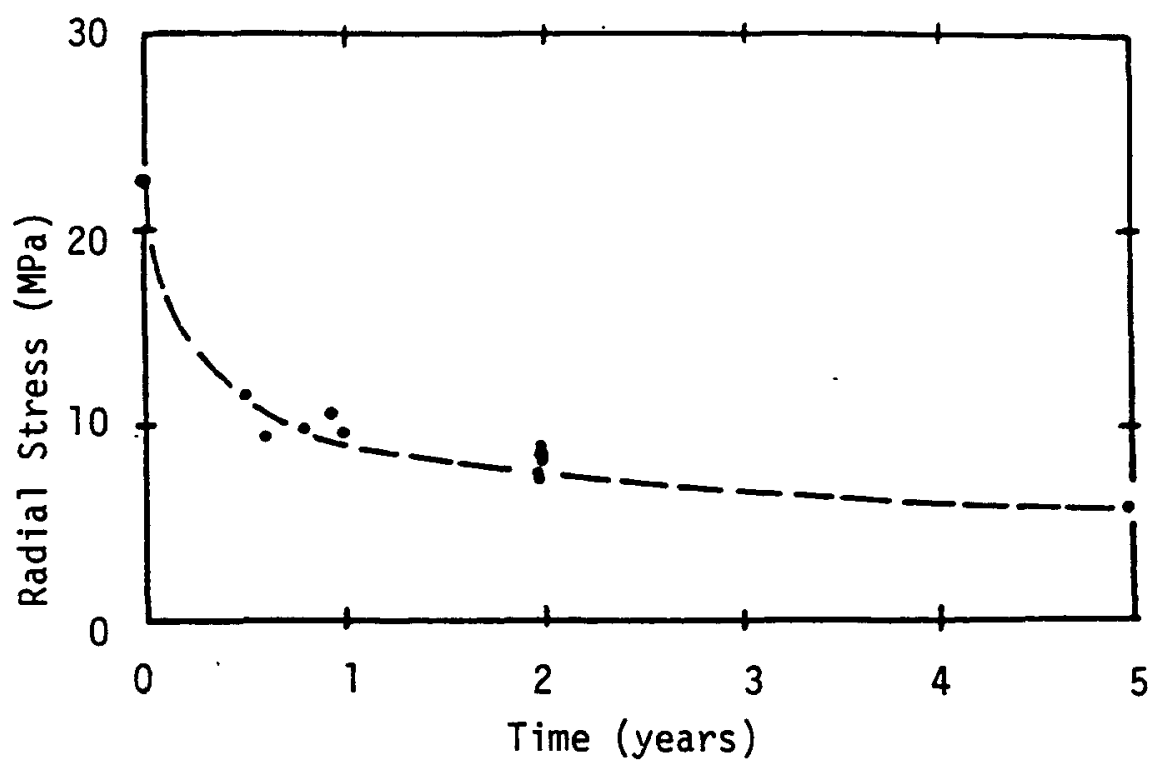

(b) Middle Third

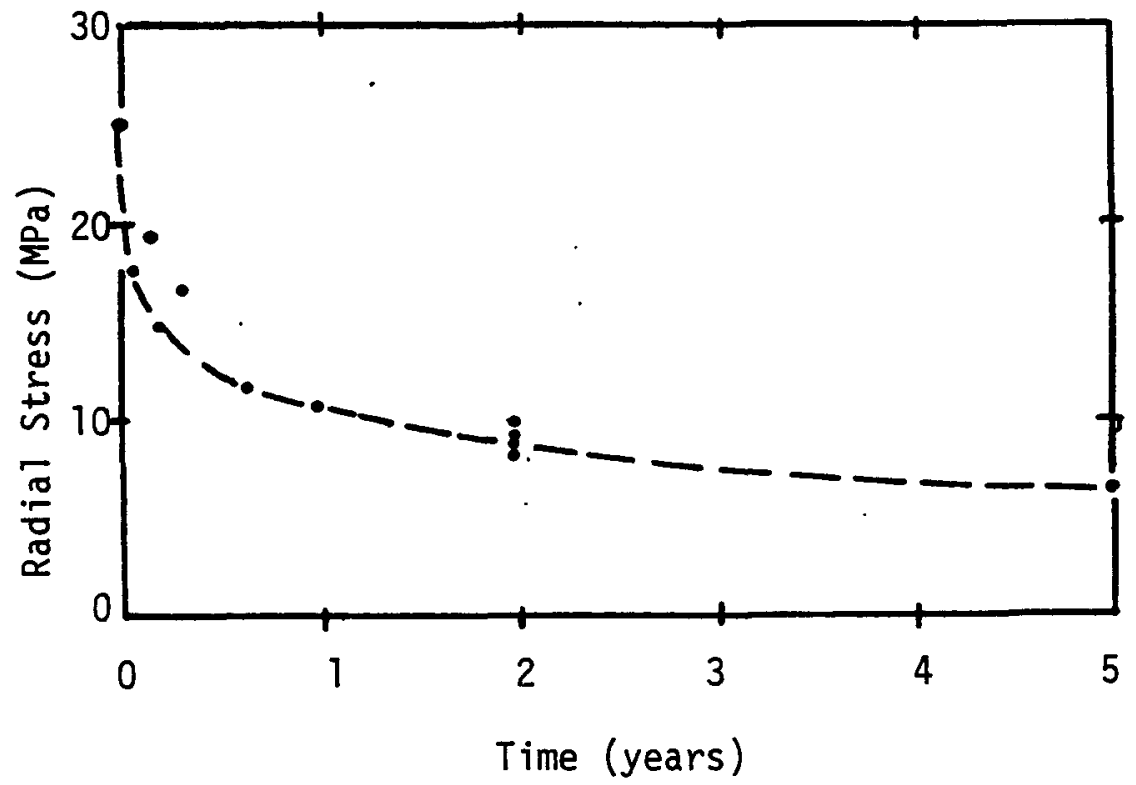


Figure $\mathrm{C}-36$. Estimates of the Lateral Stress, $\sigma_{1}$, vs Time (based on a simple analytic model)

from 22.4

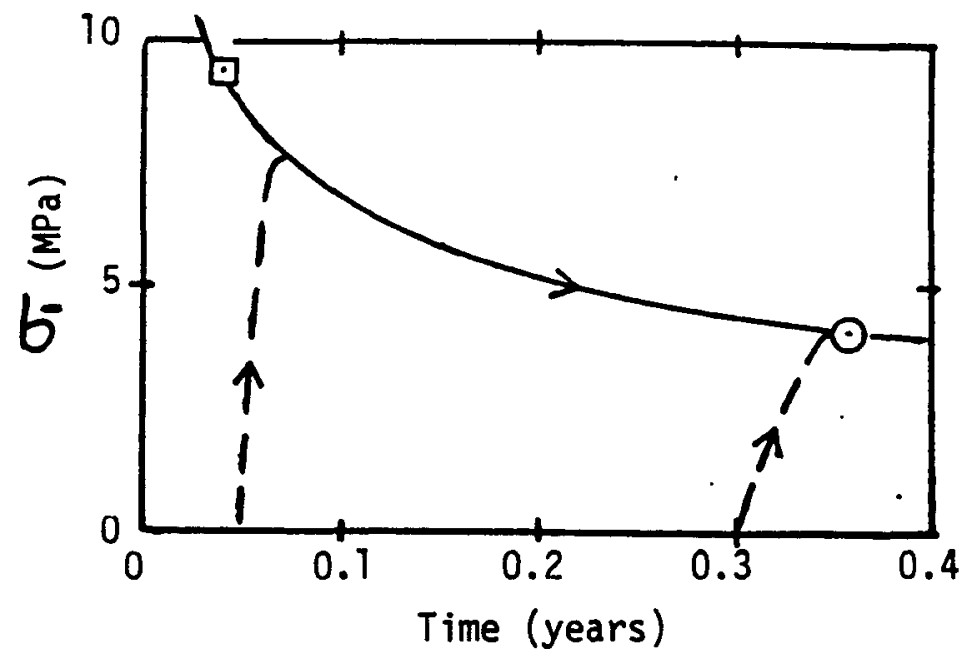

(a) PWR6 (3300 watts)

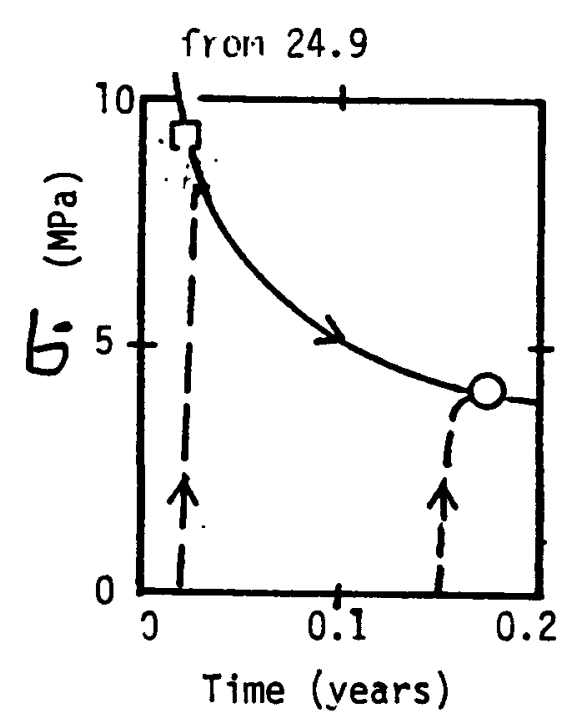

(b) PWR9 (4950 watts)

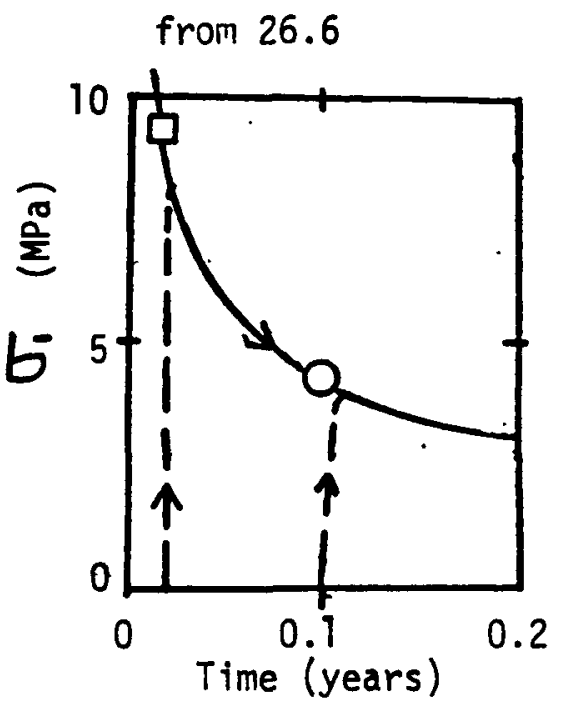

(c) PWR12 (6600 watts)

Note: The dashed lines show the effect of a delay in closure - due to an air gap.

The squares and circles are the estimated failure stresses for a uniform lateral stress and for a line load, respectively.

C-73 
Figure C-37. Relative Ranking of Package Emplacement Modes ( 1 = best $; 5$ = worst $)$

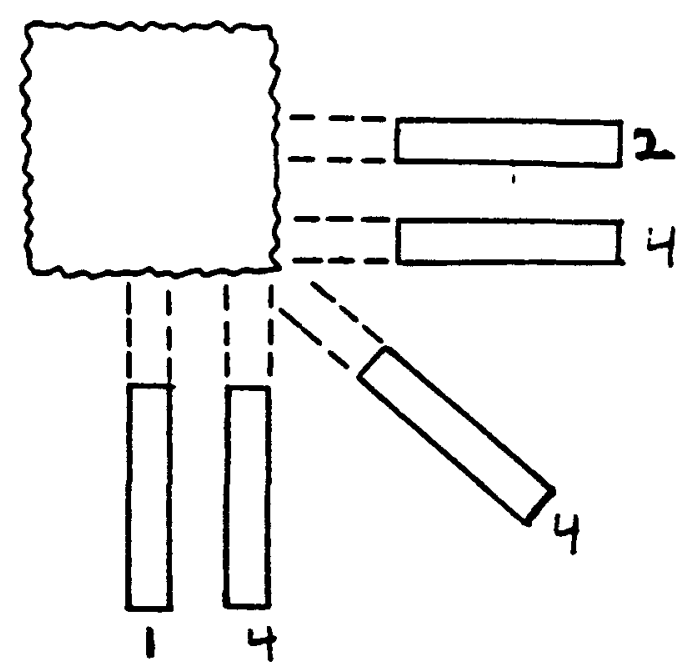

(a) Deep Borehole

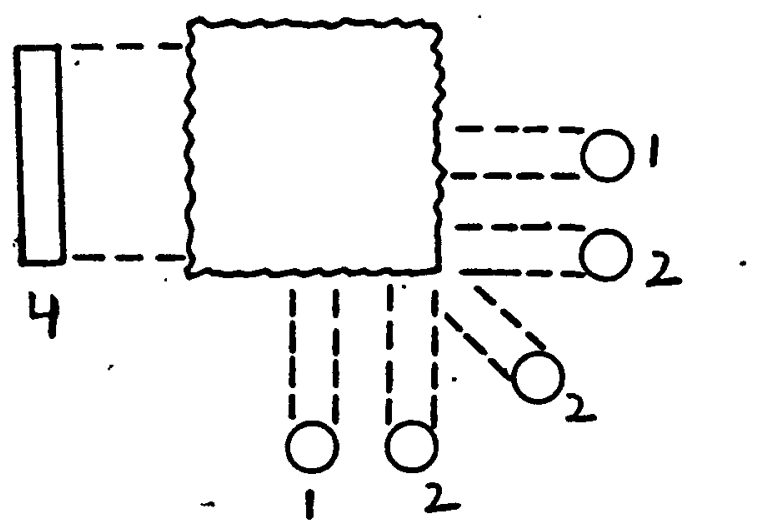

(c) Deep Slots

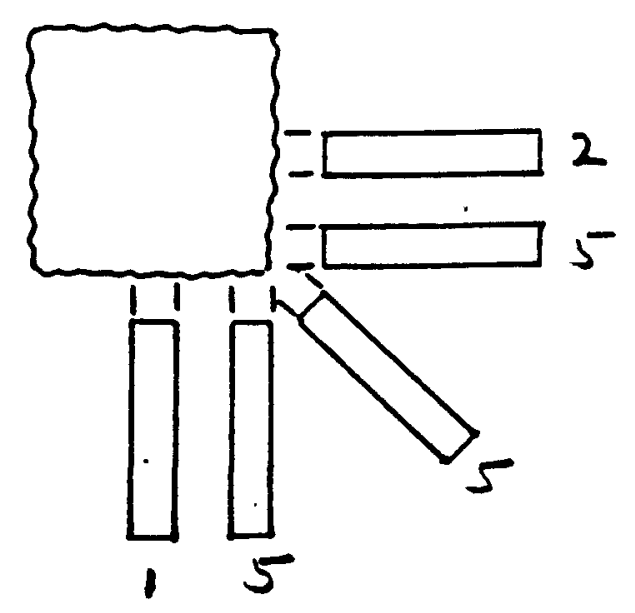

(b) Shallow Borehole

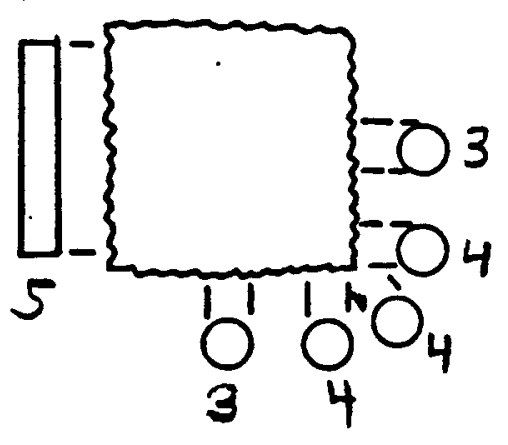

(d) Shallow Slots 
Figure C-38. Schematic Diagram of a Scenario for Generating a Concentrated Load From Sudden Failure of a Room Wall

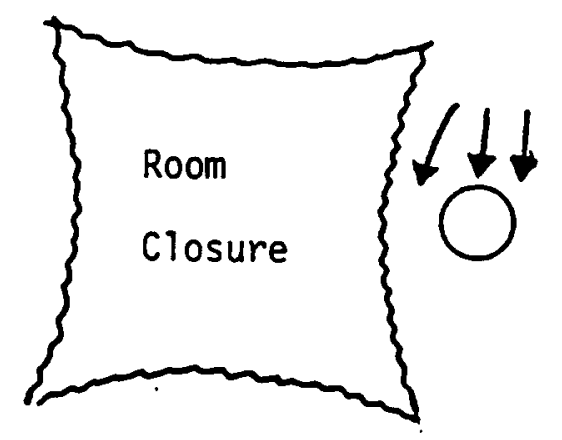

(a) Modest lateral stresses on a shallow slot emplaced package

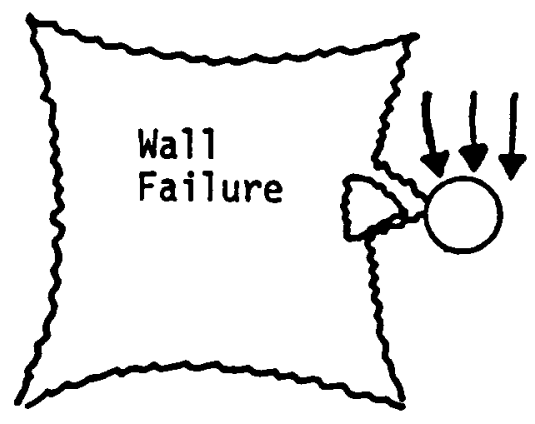

(b) Local wall failure shifts a potentially damaging load onto the emplaced package 


\section{4 REFERENCES}

Baumeister, 1978; Marks Standard Handbook for Mechanical Engineers, 8th edn., McGraw-Hill Book Company, New York, NY.

Carlslaw, and Jaeger, 1978; Conduction of Heat in Solids, Oxford University Press, Oxford, Great Britain.

Hofmann, 1981; STEALTH - A Lagrange Explicit Finite Difference Code for Solids, Structural, and Thermohydraulic Analysis, EPRI NP-2080, Volumes 1A, 1B, 2, and 3, prepared by Science Applications Company for Electric Power Research Institute, Palo Alto, CA.

RE/SPEC, 1984; Thermo mechanical Analyses of Conceptual Repository Designs for the Paradox and Permian Basins, RSI-0204, Draft report for Office of Nuclear Waste Isolation, Columbus, Ohio.

ONWI, 1985; Waste Package Reference Conceptual Desigas for a Repository in Salt, ONWI-517, Office of Nuclear Waste Isolation, Columbus, Ohio. 
APPENDIX D

EMPLACEMENT MODE SELECTION 
APPENDIX D

TABLE OF CONTENTS

Page

D.1 Emplacement Mode Selection ..................... D-3

ATTACHMENT 1 - Emplacement Mode Analysis Evaluation of Alternatives 
APPENDIX D

\section{LIST OF FIGURES}

$\underline{\text { Page }}$

D.1 Emplacement Mode Illustrations $\ldots \ldots \ldots \ldots \ldots \ldots \ldots \ldots \ldots$ D-5 


\section{D.1 EMPLACEMENT MODE SELECTION ANALYSIS}

This appendix presents the documentation for the emplacement mode selection analysis. The Kepner-Tregoe (K-T) decision analysis method was used for the selection. This documentation has been included here to show the tentative selection of the preferred emplacement mode for the salt repository. The preferred mode has been used in feasibility assessments on the reference waste package. This appendix is not meant to substantiate the emplacement mode selection and submit it for SRPO approval. That will be done through other salt conceptual design project documentation.

The following documentation reflects the use of the $K-T$ approach. The $\mathrm{K}-\mathrm{T}$ methodology is given, for information on its use, in Appendix $\mathrm{H}$. 


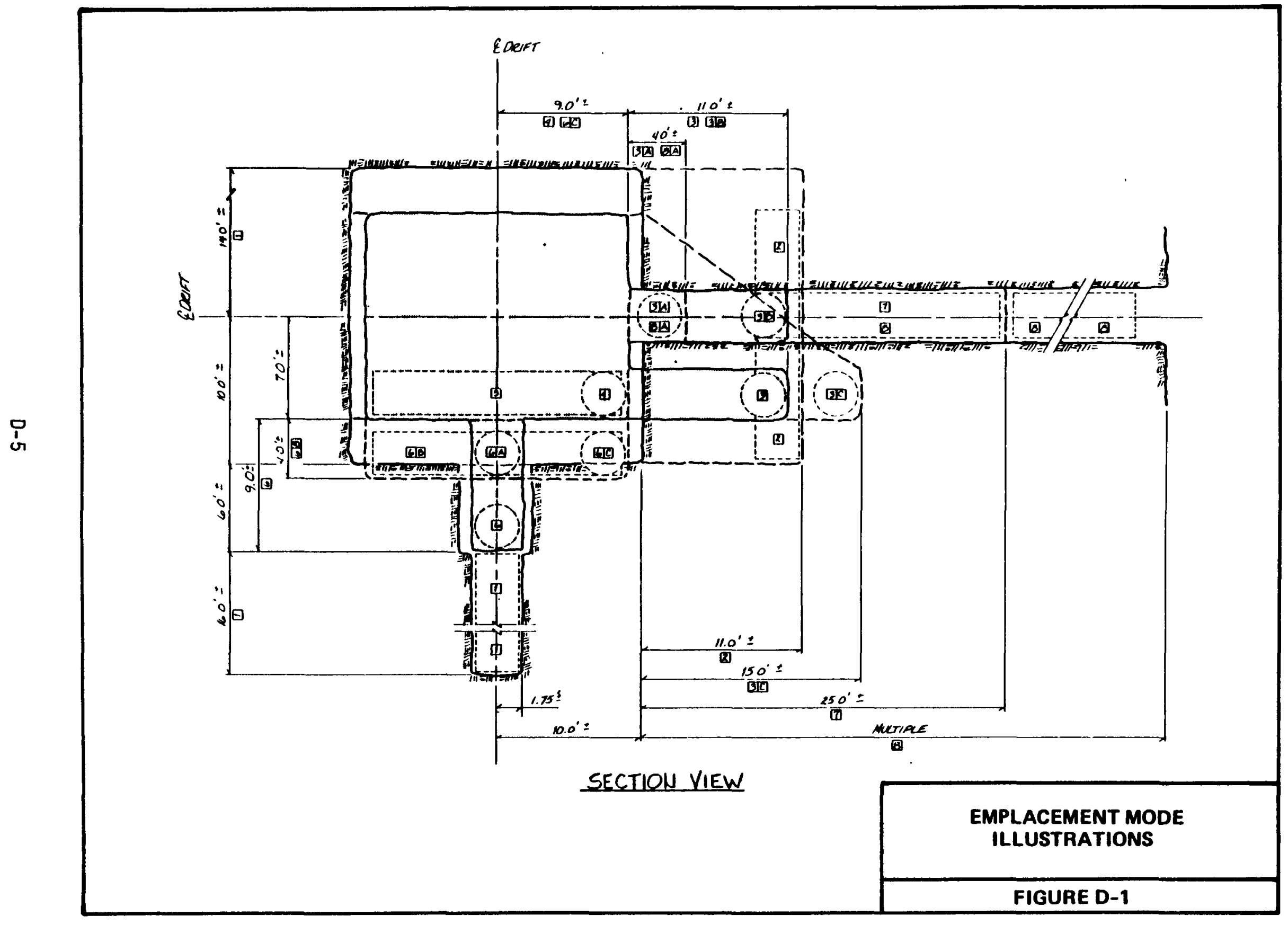


FIGURE D-1

EMPLACEMENT MODE ILLUSTRATIONS 


\section{ATTACHMENT 1}

EMPLACEMENT MODE ANALYSIS

EVALUATION OF AL. TERNATTVES

$6-1:-95$

\section{DECTSION STATEMENT :}

Select the emplacement mode for coriceptual design of the nuc lear waste repository in salt.

ASSUMPTIONS arid DEFINITIONS:

1. Assume the salt media - bedded salt at Deaf Smith site.

2. Assume the only disposal packages to be handled are as follows:

- Spent Fuel (SF)

- Defense High Level Waste (DHLW)

- West Valley High Level Waste (WVHLW)

3. Assume a disposal package geometry similiar to PWR 12 described in section J.1.

4. Assume no constraint on lateral flexibility in the emplacement horizon.

5. Assume the retrievability position stated in DOE draft paper on retrievability dated Jurie $14,1985$.

6. Disposal package temperature limits as follows: 175 degrees $C$ at the waste package surface. This reflects a maximum cladding temperature of 375 degree $C$. A 200 degree $C$ gradient between package surface and centerline for a $6.0 \mathrm{~kW}$ package is currently being corisidered by ONWI.

7. Maximum 6.6 kW heat load disposal package (reflects 12 PWR fuel assembly capacity).

8. Assume thermal/mechanical properties based on Deaf Smith properties in RE/SPEC, 1984 (RSI-0204).

7. Aralysis is based on gassy mine regulations now existing in Mirie Safety \& Health Administration regulations (MSHA, 1984 ).

10. Assume the same emplacement mode will be used for all package types (see assumption no. 2). Spacing of packages 
will be adjusted for heat load.

11. Assume backfill will be close-coupled with emplacement as determiried by mode alternative.

12. Definitions:

- Main Entries - major corridors in the subsurface leading froin the waste shaft area to the emplacement areas

- Emplacement Eritries - Short corridors or rooms (excavated off the main entries) in which emplacemont openings (see below) are made for disposal packages

- Emplacement openings - openings (boreholes, slots, trenches, etc.) in the emplacement entries into which are placed the disposal packages

13. If and when retrieval takes place all packages in an effected emplacement entry will be removed and the entry will rot be reused for emplacement.

14. Decommissioning is independent of the emplacement mode.

15. Credit for long term integrity will not be considered within this emplacement. inode evaluation.

16. Definition of "reasoriably available techrology" Includes techrology that will be demoristrated by 1700 .

17. Definitions:

- Near field - Emplacement entry and plliar region

- Far field - Repository host formation and surrounding strata

13. Definition: Package, waste package, and disposal package are used interchangeably in the discussions following.

\section{PROCEDURE :}

The following steps were taken in this emplacement mode arialysis:

- Identify decision criteria

- MUST'S (Constraints)

- WANT'S (Desired Characteristics)

- Group the WANT criteria. These cruteria were grouped irito sub-level categories representing the major tasks in the repository life cycle: Exc avation, 
Emplacement, and Remining/retrieval. (See SUBCATEGORY WEIGHTING).

- Assign relative weights to the sub-level categories.

- Assign relative weights to the WANT's within each sub-level category using the method of "PairedComparison" - see Note on page 5 for description of this method.

- Identify alternative emplacement modes.

- Screen the alternatives against. MUST criteria.

- Evaluate the alternatives using WANT criteria in each sub-level category.

- Combirie the weighted scores for each altermative in each sub-level category.

- Consider adverse consequences of top alternatives.

- Make balanced choice (select alternative).

\section{SUB-CATEGORY WEIGHTING:}

The emplacement mode alternatives were evaluated in three separate "sub-level" analyses resulting in weighted scores for each alterrative in each sub-level category. The scores for each alternative were then added together to arrive at a consolidated sc:ore for each alternative. The sub-level categories used focused on the major elements in the overall repository life cycle: excavation stage (excavation of main entries and before waste handling; excavation of emplacement. ent.ries and openings assimed to occur in the emplacement stage), emplacement stage (pre-emplacement excavation, waste package movement. and emplacement.), and remining/retrieval stage (removal of the waste package).

Each sub-level category was assigned a partial weight in line with its importarice to the overall emplacement mode decision. The following category weights were derived through group consensus by the atteridees at this emplacement. mode meetirig:

Sub-level Category

Excavation

Emplacement

Remining/retrieval

$$
\begin{aligned}
& \text { Weight } \\
& \hline 20.9 \% \\
& 50.0 \\
& 21.2 \\
& 100.0 \%
\end{aligned}
$$


A separate list of WANT criterla were developed for each sub-level category and are listed below. A sirigle set of MUST criteria were developed and were considered only once agalnst each alternative - before going into the sub-level analyses. The MUST and WANT criteria are listed below.

The scores of WANT's for each emplacement mode alternative ir each sub-category were multiplied by the above weights before the final totaling of the scores. Hence, the different stages in the repository life cycle coritributed different significance in selecting a best emplacement mode.

\section{DECISION CRITERIA:}

\section{MUSTS (Constraints)}

- Must handle a minimum of $3000 \mathrm{MTU} / \mathrm{yr}$ SF and $400 \mathrm{MTU} / \mathrm{yr}$ High Level Waste (DHLW, WVHLW).

- Must preserve the option to retrieve emplaced waste within 50 years of start of emplacement operation.

- The emplacement mode must not result in the spent fuel rod cladding from exceeding 375 degrees $c$ (center line temperature).

- Reasonably available techrology must be used in the emplacement inode selected.

- Worker radiation exposure must be 1 imited to $750 \mathrm{mrem} / \mathrm{yr}$ including any radiation exposure from the emplacement operation.

- Must meet MSHA and OSHA requirements (worker safety).

- Must meet requirement for waste package integrity (300 1000 years).

- Mirie development and emplacement operations must be able to be conducted simultaneously.

- Must be able to decommission the repository.

- Must maintain geologic integrity 1 n the far field.

- Must be able to verify quality coritrol (oC) of the waste package emplacement. 
WT. WANTS (Desired Characteristics)

5.6 - To maximize áfety of excavation personnel

5.2 - To maximize flexibility to locate repository horizon (eg., floor elevation) within the salt stratum.

4.t - To maximize stabllity of subsurface entries (near field)

4.1 - To maximize flexibility to accomodate localized geologir variations

3.t, - To maximize use of technologically conservativa emplacement design (handling equdpment, etc) to account for geologic uncertainties

3.1 - To maximize ease of excavation of enplacement entriea

2.t - To minimize volume of excavated material

(1)

The above WANT criteria and their pelative weights were used to evaluate the alternative emplacement modes discussed in the rext section. other WANT criteria were also considered but were rot used in the evituations bec ause their combined weights pepresented only about $15 \%$ of the total catagory weight and would therefore not havis a bearing on the end result. These other criteria are 1 isted here:

- To maximize use of prover techrology for excavation equipment.

- To maximize excavation rate

- To manimize direct excavation costs

- To minimize capital costs of excavation equipment

- To mirimize design and development costs

NOTES :

(1) The WANT criteria were weighted using Paired-Compat ison Evaluation. Thas method comparas each criterion against every other craterion arid then weights the criteria based on tallies of "better than" evaluations. The weight for any given criterion was derived in the following mariner: 1) first, the percentage of the total palpod-comparlson tally pontis was calculated (eg 7.e\%), then 2) the number in step 1 is divided by the cumulative ferchat 
Sub-Level category: EMPLACEMENT

WT. WANTS (Desired Characteristics)

7.2 - To minimize non-uniform forces on the waste package
- To maximize ability to loc ate the package horizon (most
sultable salt surrounding package along the entire length
of the package).

5.8 - To maximize radiation protection for workers during emplacemerit. (ALARA)

5.3 - To maximize stability of emplacement opening

5.3 - To maximize simplicity of emplacement operations (transport, pre-emplacement excavatıon, emplacement, arıd backfill)

4.9 - To maximize flexiblity to vary package spacing to accomodate waste packages with different heat loadings

4.8 - To maximize safety of emplacement personnel (industrial safety). Radiation safety is covered under the 3rd criteria in this category.

4.3 - To minimize risk of package damage during emplacenent

3.4 - To maximize ease of recovery from an operational malfuriction

2.4 - To maximize flexibility of waste package dimensions (ie., allow for different dimensions in the future)

The above WANT criteria and their relative weights were used to evaluate the alternative emplacement modes discussed in the rext section. Other WANT criteria were also considered but were not used in the evaluations bec ause their combined weights represented only about $15 \%$ of the total catagory weight and would therefore not have a bearing on the end result. These other criteria are listed below:

(1) - coritirued

of the (top) criteria being used in the decision analysis (eg.

34. 9\%)-generally, only the top criteria accounting for approximately a5\% were used in the numer 1 cal evaluation of alternatives, and 3$)$ the quotient of step 2 is then multiplied by the weight assigned the respective sub-category (eg $29.9 \%$ for the "Excavation" sub-cat(sgory). To illustrate this calculation, the :eventh chiterion listed above was calculated as follows: Weight $=(7.6 / 84.7)(29.8)=2.0$ 
- To minimize interference of pre-emplacement operations with emplacement.

- To minimize radiation field in post emplacement openings

- To maximize use of prover technology

- To minimize direct emplacement costs (operation and mairiteriarice)

- To minimize capital costs of emplacement equipment

- To minimize design and development costs

Sub-Level Category: REMINING/RETRIEVAL

WT. WANTS (Desired Characteristics)

-- - - -

3.8 - To maximize preservation of waste package integrity during retrieval

3.5 - To maximize radiation protection for worker during retrieval (ALARA)

J.2 - To maximize ability to control contamination (in case of breached package)

2.5 - To maximize rear field geologic: stability

2.5 - To maximize ability to handle off-normal petrieval operations (ie., breached package)

2.2 - To maximize simplicity of retrieval operations

1.9 - To naxinize industrial safety of worker

1.6 - To maximize far field geologic integrity during retrieval

The above WANT criteria ard their relative weights were used to evaluate the alterrative emplacement. modes discussed in the next section. nther WANT criter ia were also considered but were not used in the evaluations because their combined weights represented only about $15 \%$ uf the total catagory weight and would therefore not have a bearing on the end result. These other criteria are listed here:

- To maximize use of proven tectirology

- To maximize retrieval rate 
- To minimize direct retrieval costs (operation and maintenance)

- To mirimize capital costs of petrieval equipment

- To minimize design and development costs

\section{AL.TERNATIVE EMPLACEMENT MODES:}

Seventeen emplacement modes (configur ations) are llited irı the table on the following page.

These modes were evaluated usirig the MUST

arid WANT criteria listed above. Relative scoring of the

modes against the criteria is shown in the "Scoring Matrix" for each sub-level category analysis.

Headings in Table 1 are defined below:

- Vertical/Horizontal - Orientation of the waste package

- Openirig - Emplatcement opening excavated from the emplacement entry (if any) into which the waste package is placed

- Lo ation - Where the opening (if applicable) is locatod relative to emplacement entry/piliar

- Sleeved - Whether or not the emplacement operiing is sleeved before emplacemerit.

- Number - Whether or not orie (1) or multiple packages are inserted in each emplacement. npening 
Table 1.

AL TERNATIVE EMPLACEMENT MODES

\begin{tabular}{|c|c|c|c|c|c|c|}
\hline No. & VERT/HORIZ & OPENING & LOCATION & SLFEEVED & NUMBER & COMMENTS \\
\hline 1 & Vertical & Hole & Enitry floor & No & Orie & (2) \\
\hline$Z A$ & Vertical & Hole & Entry floor & Yes & Grie & $(2)$ \\
\hline 2 & Vertical & Slot & Entry pillar & Ho & Grie & $(2)$ \\
\hline 3 & Horizontal & slot & Entry pillar & No & one & $(2)$ \\
\hline$\Xi A$ & Horizontal & slot & $\begin{array}{c}\text { Eritry mid- } \\
\text { pillar }\end{array}$ & No & orie & $(3)$ \\
\hline $3 \mathrm{~B}$ & Horizontal & slot & $\begin{array}{l}\text { Entry mid- } \\
\text { pillar }\end{array}$ & No & orie & (2) \\
\hline $\mathrm{BC}$ & Hor izontal & Drift & $\begin{array}{l}\text { Pillar side- } \\
\text { drift. }\end{array}$ & No & orie & (2) \\
\hline 4 & Horizontal & Norie & $\begin{array}{c}\text { Erit.ry floor } \\
\text { (corner) }\end{array}$ & No & Orie & $(3)$ \\
\hline 5 & Horizontal & None & $\begin{array}{c}\text { Enit.ry floor } \\
\text { (non-parallel) }\end{array}$ & No & orie & $(3)$ \\
\hline$\Leftrightarrow$ & Hor izontal & $\begin{array}{l}\text { Trancti } \\
\text { (center) }\end{array}$ & $\begin{array}{l}\text { Eritry floor } \\
\text { (parallel) }\end{array}$ & No & orie & $(2)$ \\
\hline$\therefore A$ & Horizontal & $\begin{array}{l}\text { Trencti } \\
\text { (ceriter) }\end{array}$ & $\begin{array}{l}\text { Eritry floor } \\
\text { (parallel) }\end{array}$ & No & orie & $(3)$ \\
\hline$\Leftrightarrow B$ & Horizorital & Trencti & $\begin{array}{c}\text { Entry floor } \\
\text { (rion-parallel) }\end{array}$ & No & Orie & $(\overline{5})$ \\
\hline $6 \mathrm{C}$ & Horizontal & $\begin{array}{l}\text { Trench } \\
\text { (corner) }\end{array}$ & $\begin{array}{l}\text { Entry flnor } \\
\text { (parallel) }\end{array}$ & No & orie & $(3)$ \\
\hline 7 & Horizontal & Hole & Pillar & Yes & one & - \\
\hline $7 A$ & Hor izontal & Hole & Pillar & No & one & $-\cdots$ \\
\hline 8 & Hor izontal & Hole & Pillar & Yes & Multi & $t .00 \mathrm{ft}$ \\
\hline$B A$ & Horizontal & Hole & Pillat & No & Mullti & $300 \mathrm{ft}$ \\
\hline
\end{tabular}

NOTES:

(2) Shifelded

(5) Uristicielded 
"SUMMARY OF "MUST" CRITERIA EVALLUATIONS:

All alternative emplacement modes satıfactorily met the MUST coristraints.

SUMMARY OF SCORING AGAINST "WANT" CRITERIA:

The scoring of each alternative agalnit the WANT criteria within each sub-level catexory ate shown in Table 2 on the following page. The sub-level totals are suinmed for each alternative, resulting in a composite total score. The top five (5) scoring alternatives were then scrutinized for potentlal adverse consequences (adverse accidents or events that inght occur should an alternative be implementod) in the riext section. 
Table 2

SUMMARY OF ALTERNATIVE SCORES

(Scoring of Alterratives Agalnst WANT Criterla)

Weighted scores

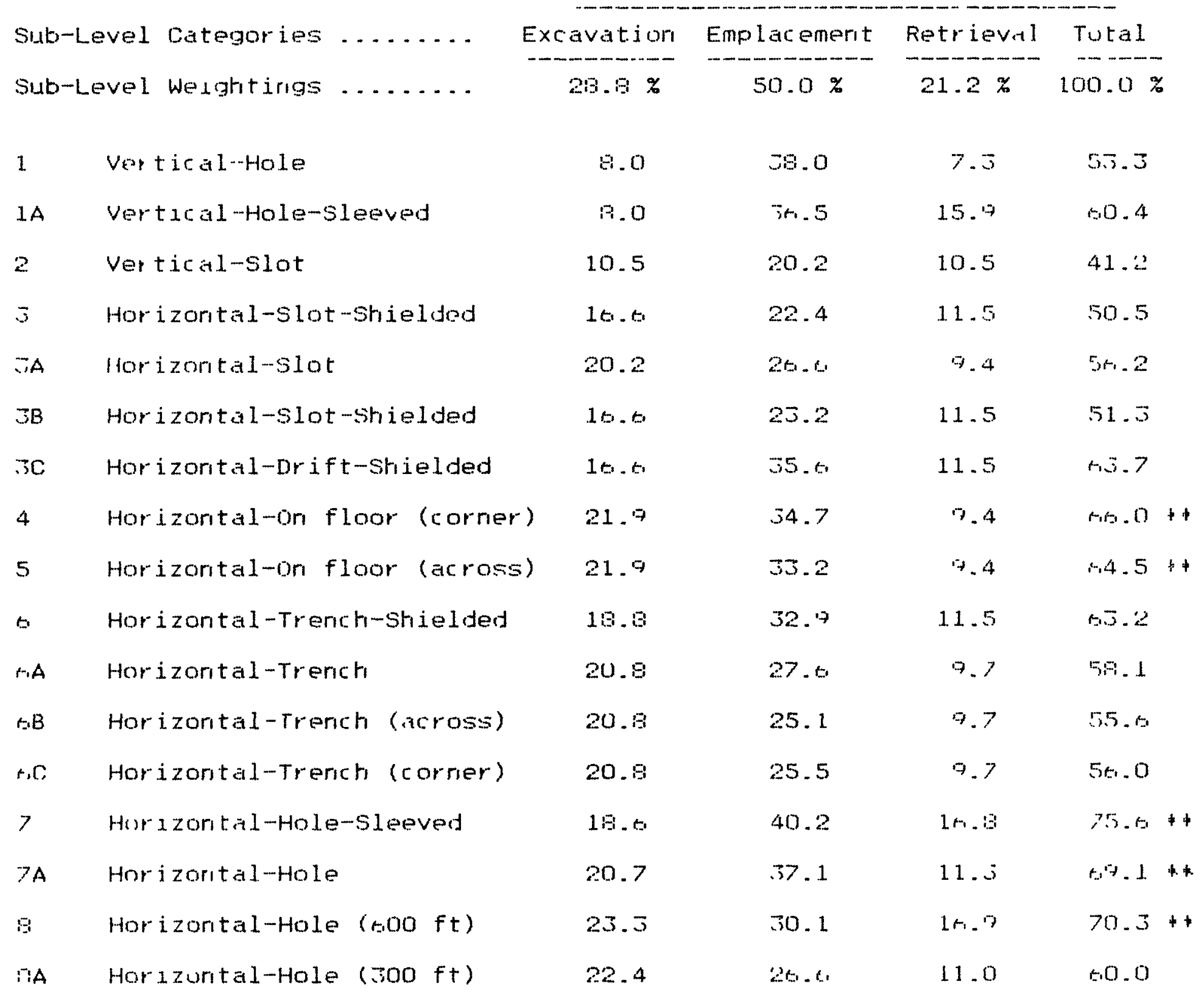

\footnotetext{
+ + Hoghest scoring alternatives
} 
ADVERSE CONSEQUENCES: (Potential adverse everits fhould an alternative be implemented)

Alterrative

Adverse Corisequence

Protiability

Seriousness

\# 4 Horizontal-on flour (correr)

1. If low backfill thermalcoriduct 1 vity pesults in excessive peak salt temperature, then smaller (lower heat output) waste packages will be required. "Smaller packaqes" means more packages would be emplaced for the same amourit of waste.

High Medium

2. Nonuniform forces may $c$ ause the package to fall.

Low High

3. If a great amount of tor 1 ine 15 in the underground, then the package integrity may be affected.

Low Mediun

\# 5 Horizontal-on floor (across)

1. If a great amount of brine is in the uriderground, then the package iritegrity may be affected.

Low Medium

2. Nonuriform forces may cause the parkage to fall.

Low High

\# 7 Horizontal-Hole-sleeved

1. If the sleeve deforms, then retrieval is made difficult.

Low High

\# 7A Horizontal-Hole

1. If insertion step damages the package, then Gidity Assurance requiremerits will rot be met.

High 
\# $\mathrm{Horizontal-Hole} \mathrm{(t.00} \mathrm{ft.} \mathrm{long)}$

1. If the sleeve deforms, then brine may

collect and effect the package

integrity.

Low

Medium

2. If the sleeve deforms, then retrieval

is made difficult.

L.OW

Medium

3 . If the packing material (arourid the sleeve) does rot meet guality Assurarice spec ifications, then the packitge does not ineet performance requlrements for lorig term solation.

Merdium High

\section{BALANCED CHOICE:}

Based on the weighted scores arid conslderation of adverse consequences of the alternatives, the balanced choice of this decision analysis for emplacement mode 15 Alternative 7, horizontal emplacement in the pillar into a sleeved hole.

The analysis showed, based on the alternatives considered and the criteria the group perceived as being most significant, that horizontal emplacement modes are feasible and appear superior to the other modes.

A summary of weighted scores and adverse consequences for the top five ( 5 ) scoring alternatives is shown below:

Alter hative

7 Horizontal-sleeved

9 Horizontal-sleeved-multiple pkg

7A Hor izorital-unsleeved

4 Horizontal-floor correr-operiunstivelded

5 Horizontal-floor nonparallel-operurishielded
Worst *

Woighted

score

Proti- Serious-

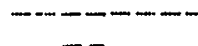

75.

at) $t y$ ness

-.........

Low

70.3

Mers

Hegh

$r \cdot i^{2}+1$

Low

High

$\operatorname{ton} 0$

High

Med

Low

High

0.4 .5

Low

$\mathrm{Hlgh}$

* Worst Adverse Corisequerice(s). The spec ific Adver as Consequences are described or the previous pages. 
INDIVIDUALS IN ATTENDANCE:

\section{Name}

J. Carr

B. Chytrowski

L. Smith

J. Clark

H. Kortnicki

J. Cogan

$R$. Marier

R. Whitori

J. Arbital

M. Gross

R. Tome

R. Nelson

D. Ham 11 tor

J. Hopper (Facilitor)

D. Josselyn

J. Logan (Documentation)

P. Kumar
Organization

Battelle/onwI

Battelle/onWI

Bat tel le/onwt

Fluor Tectinology, Inic.

Fluor Technology, Inic.

Morrisoni-Knudsen

Morr isori-Knudsen

Morrison-Kriudsen

Science Applications Int'l Corp

Science Applications Int'l Corp

Science Applications Int'l Corp Woodward-clyde Consultants

Engineered Systems \& Developmont

Englneered Systems \& Development

Engineered systems \& Development

Engineered Systems \& Development Westorl/Jat obs 


\section{REFERENCES:}

MSHA, 1994; Mirie Safety and Health Admiristration, Code of Federal Regulations, Title 30, Mirieral Resources, Part 57, "Safety and Health Standards - Metal and Non-Metallic Underground Mines", Subpart 57.21 , "Gassy Mines".

RE/SPEC, 19G4; Thermomechanicical Analysis of Conceptual Repository Desıgris for tre Paradox arnd Fermiari Basins, RE/SPEC, RSI - 0204, November, draft.

ONWI, 19g5; Engineered Waste Package Coriceptual Design, Westinghouse Electric Corporation, ONWI-43E, April. 


\section{APPENDIX E}

SUBSURFACE TRANSPORTER MODE SELECTION 


\section{APPENDIX E}

TABLE OF CONTENTS

$\underline{\text { Page }}$

E.1 Subsurface Transporter Mode Selection ............. E-4

ATTACHMENT 1 - Decision Analysis Summary Information 
LIST OF FIGURES

$\underline{\text { Page }}$

E-1 Equipment Specifications $\ldots \ldots \ldots \ldots \ldots \ldots \ldots \ldots \ldots \ldots \ldots \ldots$ E-5

E-2 Equipment Sketch $\ldots \ldots \ldots \ldots \ldots \ldots \ldots \ldots \ldots \ldots \ldots \ldots \ldots \ldots$ E-6 


\section{E.1 APPENDIX}

SUBSURFACE TRANSPORTER MODE SELECTION

As part of this study, the feasibility of transporting the reference waste package was evaluated (Section 3.5 in the main report). In concert with determining this feasibility, it was necessary to establish a concept for transporter mode (1.e., wheeled vehicle, crawler-type vehicle, tracked system, etc.) as a basis to conduct the feasibility assessments. This appendix documents the decision process used in establishing a concept. However, this documentation was included for information on the proposed salt project transporter. It is not meant to be reviewed for SRPO approval of the concept. Other salt conceputal design documentation will be provided for concept approval.

Kepner-Tregoe $(\mathrm{K}-\mathrm{T})$ decision analysis techniques were applied to this decision. The $\mathrm{K}-\mathrm{T}$ methodology is given, for information on its use, in Appendix $\mathrm{H}$.

Following the K-T documentation are the specifications for currently available equipment that could be modified to serve as a subsurface transporter. These specifications are given in Figures E-1 and E-2. 
$\begin{array}{ll}\text { APPENDIX E } & \text { Summarv } \\ 4-17-85\end{array}$

ATTACHMENT 1

DECISIUN ANALYSIS

SUMIMAFY INFOFMATION

\section{DECISION STATEMENT:}

Select mode (crawler, wheel, rail, etc.) to transport disposal package between subsurface loading area and emplacement point.

\section{ASSUMPTIONS and DEFINITIONS:}

1. This analysis includes equipment for transporting waste packages in transfer casks from the shaft to the emplacement room. It does not include actual emplacement machinery.

2. Assume payload includes the disposal package and shielded transfer cask.

3. Assume payload Dimensions: $217^{\prime \prime}$ long $X 48^{\prime \prime}$ diameter (G $50 \mathrm{mrem} / \mathrm{hr}$ dose rate)

4. Assume payload Weight: 42 metric torines

5. Underground Dimensions:

- Drifts (main corridor) - $18 \mathrm{ft}$ wide $x 1.3 .5 \mathrm{ft} \mathrm{high}$. - Drift intersection angle - 90 degrees.

o. Assume worst salt characteristics out of all three (3) sites.

7. Masimum grade (transporter loaded) $3 \%-5 \%$ Maximum grade (transporter empty) $12 \%$

The transporter must be able to negotiate grades as steep as the above.

8. Assume floor heave will cause local road movement causing pot holes, etc.

9. Transporter to be designed to taken down waste shaft in modular form.

10. Eecause of grade requirements, the weight of the payload must be applied to the traction system of the transporter.

11. The integritv of the roof or pillar must not be leopardized, ie damaged during transport operation. 
12. The radiation exposure $11 \mathrm{mit}$ of $750 \mathrm{mrem} / \mathrm{vr}$ is applicable to normal operating conditions. See MUST objective 201.

13. For purposes of this evaluation, assume a disposal pacleage of 12 SFA's, 10 vears out of the reactor, and 3 it MW.

14. This evaluation considers onlv the technical considerations on this matter. Folitical factors are not considered.

DECISION OEJECTIVES:

MUSTS (Constraints)

MUST OEJECTIVES

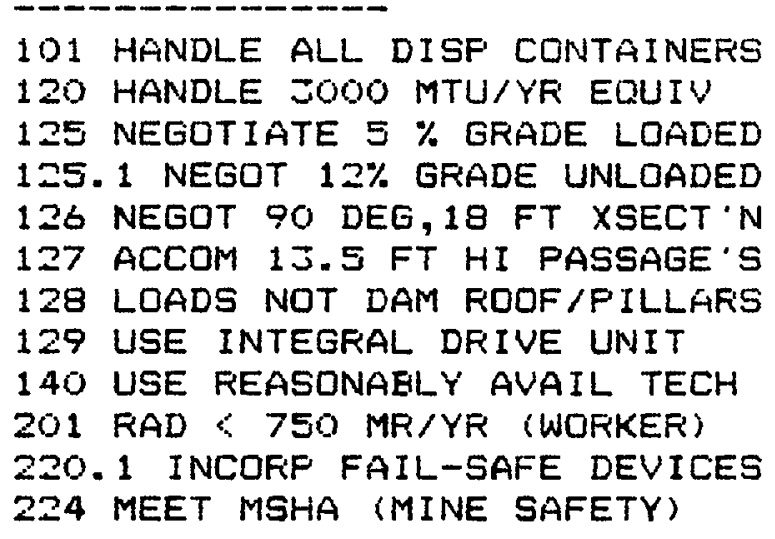

WT. WANT DEJECTIVES

$\begin{array}{rl}10 & 316 \text { MIN MEAN TIME TO REFAIR } \\ 9 & 332 \text { MIN IMFACT-OFENNING MAINT. } \\ 9 & 303 \text { MAX FLEX - TRAVEL ROUTINGS } \\ 8 & 300 \text { MAX FELIAEILITY } \\ 7 & 328 \text { MIN FLOOR/MOVE DEPENDENCY } \\ 6 & 304 \text { MIN OFERATIONAL COMFLEXITY } \\ 6 & 301 \text { MAX MAINTAINAEILITY } \\ 5 & 35 \Xi \text { MIN RISK OF INDUS ACCID'S } \\ 4 & 329.1 \text { MIN DAMAGE TO MAIN LINE } \\ 3 & 329 \text { MIN FLOOF BEAFING FRESSURE } \\ 2 & 315 \text { MIN OFEFATING/MAINT COSTS } \\ 2 & 331 \text { MIN XFORTER STOFFING DIST. } \\ 2 & 314 \text { MIN CAFITAL COSTS } \\ 1 & 330 \text { MIN ACCID DAMAGE-VEH,LOAD }\end{array}$

(See explanations following)

- 101. Must be able to handle all disposal packages required to be emplaced.

- 120. Must handle a minimum of $\$ 000$ MTU/YFi equivalent at 
the repository.

- 125. Transporter must be able to negotiate a $5 \%$ orade when loaded.

- 125.1 Transporter must be able to negotiate a 12 \% grade when empty ieg on separate return path from emplacement point to loading area).

- 126. Transporter must be able to negotiate 90 degree drift intersections which are 19 feet wide.

- 127. Transporter must be able to accomodate $13.5 \mathrm{ft}$ high passageways.

- 128. Suspended loads on the transporter must not damage the integrity of the underground roofs and pillars.

- 129. Transporter payload carrying unit must have an integral drive unit to assure adequate traction under the payload.

- 140. Feasonably available technology regarding payload transporter systems must be available for whichever al ternative is recommended.

- 201. Worker radiation exposure must be 1 imited to 750 mrem/yr including any radiation exposure from the subsurface transporter operation.

-220.1 . Transporter system must incorporate fail-safe devices.

- 224. Must meet MSHA (mine safety regulations).

WANTS (Desired Characteristics)

- 316. To minimize the mean time to repair and restore the waste shaft operation.

- 332. To minimize the impact on maintaining orift opennings in subsurface.

- 303. To maximize the flexibility of travel routings, ie use alternate corridors in event of route blockage from drift maintenance or in-place vehicle maintenance.

- 300. To maximize system reliability of the transporter operation, ie minimize equipment failure that causes operation downtime.

- 328. To minimize the impact on transporter movement from underground floor conditions. A certain amount of floor 
heave (deformation) in the salt is expected; it is desirable for the transporter svstem to be as independent of these conditions as possible.

- J04. To minimize operational comple:ity in order to minimize operator errors and thereby increase average throughput.

- 01 . To mai:imize maintainability of the transporter system, ie have a transporter svstem that 35 as easy to malntain as possible.

- 5s. To minimize the rist: of industrial accidents (phvsical injuries) to repository personnel.

- 329.1. To minimize the roadway wear on the main corridor caused by the transporter. This objective refers to surface damage rather than deep deformities as covered by objective 329 .

- 329. To minimize bearing pressure on the roadway floor caused by the transporter. Heavy bearing pressures would lead to deep cracks and other deformities.

- 315. To minimize operataing and maintenance costs.

- 331. To minimize stopping distance of the transporter.

- 314. To minimize capital costs of the transporter system.

- 30. To minimize damage to the transporter and disposal package, or injury to the operator, due to accidental impacts (collisions) at operating speeds.

NOTE: The WANT objectives were prioritized using FairedComparison Evaluation. This method compares each objective against every other object 3 ve and then summarizes the objectives in relative ranking based on tallies of "better than" evaluations. (See previous pages for criteria welghtings.) 
Subsurface Transporter Mode

$\because$ IL IEFIVATIVES:

ALTEFINATIVE NAME

3. MONOFAIL-OVEFHD-TURINTABLE

4. MONORAIL-FLOOR-TUFNTAELE

7. WHEELED-SKID STEEFING

9. WHEELED-PIVOT POST STEERING

11. CFAWLER-SKIID STEEFINNG

12. CRAWLER-PIVOT STEERING

13. WALKING DEVICE

16. MOND-OVERHD-TURNTABLE-S. FWF:

17. MONO-FLOOR-TUFNTAELE-S. F'WF

18. FAIL-COG DFIVE-TURNTAELE

19. WHEELED-AUTO STEER-TUFNTAEL
MUST OBJECTIVES

TOTAL SCOFE

\section{(See explanations below)}

\#3. Monorail - overhead - turntable.

Use a cable driven (pulled) monorail transporter system which runs on overhead rails. Turning at drift

intersections is accomplished by a turntable. The overhead rails are supported by "sets" (trusses) spaced along the transfer path. These sets are floor supported and attached to orift wall and roof surfaces.

\#4. Monorail - floor - turntable.

Same as \#3 except rails are laid along the floor.

\#7. Wheeled vehicle - skid steering.

Use a rubber tired vehicle system employing stid steering. The drive unit is self-contained.

\#9. Wheeled vehicle - pivot steering.

Same as \#7 except steering is by pivot mechanisin. Fivot steering is accomplished by turning each wheel on an independent basis, thereby allowing more precise turning movements.

\#11. Crawler vehicle - skid steering.

Use a crawler type vehicle system employing skid steering. The drive unit is self-contained. This crawler vehicles use a continuous track for steering and traction. 
\#12. Crawler vehicle - pivot steering.

Same as \#11 except steering is by pivot mechanism. Pivot steering on a crawler vehzcle is accomplished by independent steering contral of shorter length tracks than used on skid steering crawler vehucles.

\#15. Walking device.

Use a device, generally slower travelling than the other alternatives, that moves the payload $1 n$ incremental feet of travel. The payload is supported (carried) on the "beliy" of the device. This beliy support is alternately set down on the drift floor then ralsed and moved foreward a given distance (as designed, perhaps 6 feet). Fontoons, or feet, support the beliy and payload during this foreward motion of the payload. After the load is set back down, the feet then move foreward to the next incremental postion. Turning is accomplished when the feet are down - the load is rotated on a turntable integral to the walking device. This system is not as manueuverable as wheeled or crawler al ternatives.

\#16. Monorail - overhead - turntable - selfpowered

Use a self-powered monorail transporter system which runs on overhead rails. Turning at drift intersections is accomplished by a turntable. The overhead rails are supported by "sets" (trusses) spaced along the transfer path. These sets are floor supported and attached to drift wall and roof surfaces.

\#17. Monorail - floor - turntable - selfpowered

Same as \#16 except rails are laid along the floor.

\#18. Rail - turntable - cog driven

Use a cog-driven transporter that runs on standard type dual rails. The rails are fastened to the drift floor. Turning at drift intersections is accomplished by a turntable.

\#19. Wheeled vehicle - automotive steering - turntable

Use a rubber tired vehicle system employing automotive type steering. The drive unit is self-contained. Turnina at drift intersections is accomplished by a turntable. 


\section{ADVERSE CONSEOUENCES (Fotential rists):}

Two potential adverse consequences lof implementing these alternatives) were recognized for the crawler and wheeled vehicle modes, which were the highest scoring alternatives. The first potential event is a transporter fire (fuel, electical, and for rubber kires). The other adverse consequence recognized 1 s that the vehicle mode will not meet 1 ts performance specifications. Frobability of occuring and serlousness assessments follow:

\begin{tabular}{lllll} 
& \multicolumn{2}{c}{ Fire } & \multicolumn{2}{c}{ Ferformance } \\
Alternative & $\begin{array}{l}\text { Froba } \\
\text { bility }\end{array}$ & Serious & Froba Serious \\
Crawler-skid steer & low & medium & bility \\
Crawler-pivot steer & low & medium & medium (1) low \\
Wheeled-skid steer & low & high i2) & low & low \\
Wheeled-pivat steer & low & high & medium low
\end{tabular}

Note: (1) Fivot steering is more complex than skid steering and therefore has slightly higher probability of not meeting performance specifications under operating environment. (2) Fire danger was considered greater for rubber wheeled vehicles than crawler vehicles due to the $f l$ amability of the rubber and the very large $s i z e$ of the tires.

\section{BALANCED CHOICE:}

The balanced cholce, considering total weighted scores and adverse consequences, is to use a crawler vehicle with skid steering. Three other alternatives scored very $h i g h$ also and appear to be good backup cholces: crawler vehicle with pivot steering, wheeled vehicle with skid steering, and wheeled vehicle with pivat steering.

\section{DISCIFLINES IN ATTENDANCE:} Mechanical Engineering Nuclear Tech Mining Engineering Industrial Engineering Fiernote Engineering Equipment Engineering DNWI 
Cb cateapillaA induetaial paoducto, inc.

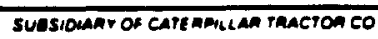

MODEL 235.D7 EXCAVATOR LOWER

\section{SPECIFICATIONS}

Figure E-1. Equipment Specifications

ESTIMATED WEIGHT-BOTH TRACK FRAMES COMPLETE WITH DRIVE MOTORS

CARBODY WEIGHT (OPTIONAL)

- ApPRoximate loAd CAPACITY

Approximate Crane Rating

APPROXIMATE TOTAL

.

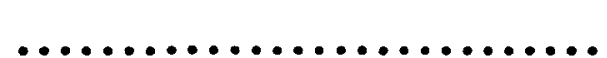

TRACK MOTOR WORKING PRESSURE.

TRACK MOTOR WORKING TOROUE.

MAXIMUM MOTOR SPEED

TRACK MOTOR DISPLACEMENT.

FINAL DRIVE TYPE

FINAL DRIVE GEAR RATIO

RECOIL SPRING PRE.LOAD

IDLER ADJUSTMENT

NUMBER OF TRACK SECTIONS

PITCH OF TRACK SECTION

TAACK SHOE BOLT DIAMETER .

SINGLE GROUSER SHOES

DOUBLE GROUSER SHOES

TRIPLE GROUSER SHOES

FLAT SHOES

NUMBER OF TRACK ROLLERS PER SIDE

- dependent upon travel speed and application

$\cdots 27420 \mathrm{~kg}(60450 \mathrm{lb}$ ) optional

$13608 \mathrm{~kg}$

(30000 16)

$2041 \mathrm{~kg}$

(4500 (b)

$27216 \mathrm{~kg}$

$00000 \mathrm{lb}$

$200,0001 b$.

$42865 \mathrm{~kg}$

(94 $500 \mathrm{lb})$

$27580 \mathrm{kPa}$

(4000 psi)

$1356 \mathrm{~N} \cdot \mathrm{m}$ at $27580 \mathrm{kPa}$ (1 000 lb-ft at 4000 psi)

2000 APM

0.32 litre (19.7 cu in)

Triple Spur

46:1

$22703 \mathrm{~kg}^{\circ}$ ( $50050 \mathrm{lb})$

$114.3 \mathrm{~mm}$

(4.5 in)

49

$215.9 \mathrm{~mm}$

(8.50 in)

$19.1 \mathrm{~mm}$ (.750 in)

$457 \mathrm{~mm}$ (18 in)

$457,610 \mathrm{~mm}$

(18, 24 in)

$762,914 \mathrm{~mm}$ (30, 36 in)

NONE

9 
Figure E-2. Equipment Sketch

All dimenslons shown are in millimeters - inches in parentheses.
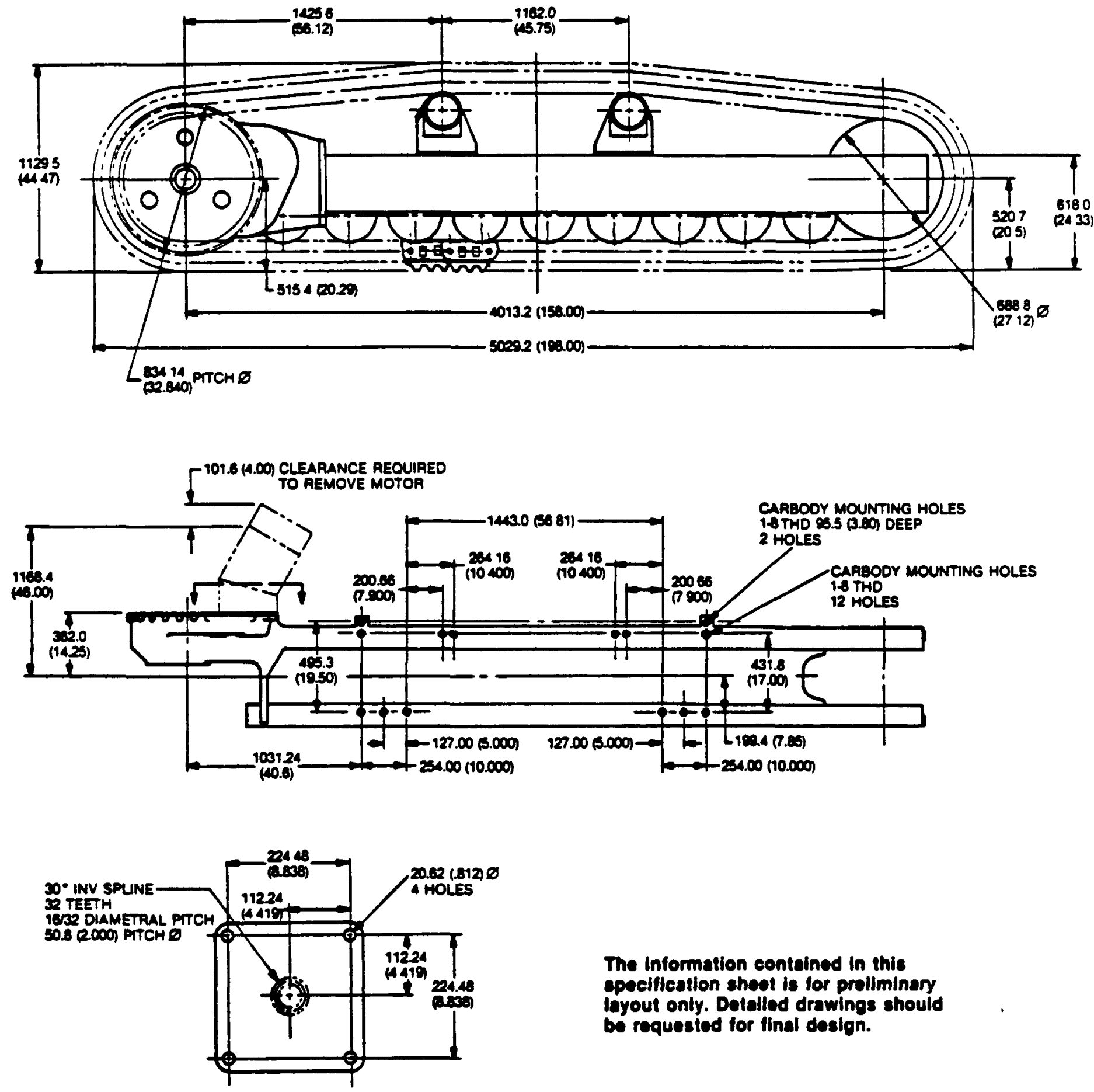

The Information contained in this specifleation sheot is for prollminary layout only. Dotalled drawings should be requestod for final design.

\section{MOTOR MOUNT AND SPLINE VIEW A.A}

eatagullat inguetmial onoduete, me.

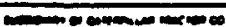

Ceterpititer, Cat and 0 are Trademants of Caterpliter Trector Co.

Matorials and spectifications ere subject to chenge without notice

WEHE1123 (PE2)
CATERPILLAR INDUSTAIAL modUCtS. INC

PEORIA, ILLINOIS U S.A. 61620

Prom: (300) $075-0133$

Tolex No.. 404435

The International Systom of Units (SI) is used in this publication 
APPENDIX F

HOIST SYSTEM DECISIONS AND CALCULATIONS 


\section{APPENDIX F}

TABLE OF CONTENTS

\section{$\underline{\text { Page }}$}

F.1 Decision on Use of Shielding in the Waste Hoist ...... F-4

F.2 Hoist Payload Calculation .................. F-5

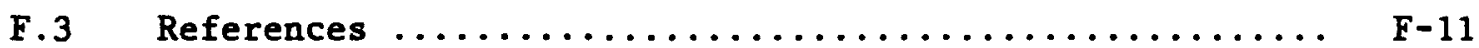

ATTACHMENT 1 - Decision Analysis Summary Information 
APPENDIX F

LIST OF FIGURES

Page

F-1 Hoist System Schematic $\ldots \ldots \ldots \ldots \ldots \ldots \ldots \ldots \ldots \ldots \ldots$ 
F.1 DECISION ON USE OF SHIELDING IN THE WASTE HOIST

An evaluation of the feasibility of hoisting the waste package using currently available hoist systems (in terms of weight capacity) was conducted as discussed in Section 3.6. Prior to that evaluation it was necessary to determine whether shielding should be used in the waste hoist since it would contribute significantly to the total hoist payload weight. A decision analysis was conducted to make this determination. The Kepner-Tregoe (K-T) method for decision analysis was employed. The $K-T$ methodology is given, for information on it's use, in Appendix $H$.

The $K-T$ analysis resulted in the selection of shielded transfer in the shaft. It was also decided that the most reasonable approach would be to use a moveable shield cask that stays with the waste package (also referred to as a "transfer cask"). The following documentation describes this decision analysis and gives rationale for the results. This documentation is submitted for information at this time. It is not meant for SRPO review for approval of the concept. Other salt conceptual design documentation will be provided for approval purposes. 


\author{
APPENDIX $F$ \\ ATTACHMENT 1 \\ DECISION ANALYSIS
}

SUMMARY INFOFIMATION

\title{
DECISION STATEMENT:
}

Determine whether the disposal package snould be transterred upldown the waste shaft shielded or unshielded.

\section{ASSUMFTIONS and DEFINITIONS:}

1. The radiation exposure $13 \mathrm{~m} 1 \mathrm{t}$ of $750 \mathrm{mremiyr}$ is applicable to normal operating condztions. See MUST objective 201.

z. For purposes of this evaluation, assume a disposal package of 12 SFA's, 10 years out of the reactor, and $\because 3 K$ MW.

3. The purpose of shielding 15 for worker protection $1 n$ the shaft near the package during recovery from abnormal operations.

4. Assume the shielding (alone) weight 15 approximately 24 metric tonnes for shielding to the level of $50 \mathrm{mrem} / \mathrm{hr}$ at the package surface. The combined weight of the disposal package and shielding is approximately 42 metric tonnes.

5. Assume the weight of an unshielded disposal package 15 approximately 18 metric tonnes with radiation level of $200,000 \mathrm{mrem} / \mathrm{hr}$.

6. The holst/conveyance system can accomodate both shielded and unshielded packages with weights per 4 \& 5 above.

7. This evaluation considers only the technical considerations on this matter. Folitical factors are not considered.

\section{DECISION OEJECTIVES:}

MUSTS (Constraints)

- 120. Must handie a minimum of 3000 MTU/YFi equivalent at the repository. 
- 124. The shielding al ternative recommended must preverit the SFA rod cladding from exiceeding 375 degrees $C$ and HLW from exceeding 500 degrees $C$.

- 140. Reasonably aval able technology reqaraing hoist/conveyance system must be avallable for whichever al ternative is recommended.

- 141. A technicaliv conservative desian for the shielding and holst convevance options must be used to account for uncertainties in the repository design.

- 200. Radiation released from the repository to the public must be $11 \mathrm{mited}$ to $5 \mathrm{mrem} / \mathrm{yr}$ per person. Repository radiation includes that coming from the waste shaft operation.

- 201. Worber radiation exposure must be $11 \mathrm{mited}$ to 750 mrem/yr including any radiation exposure froin the waste shaft operation.

- 203. The waste shaft transfer approach must prevent criticality from occurring.

- 224. Must meet MSHA (mine safety regulations).

\section{WANTS (Desired Characteristics)}

- 352. To minimize radiation exposure below the $750 \mathrm{mrem} / \mathrm{yr}$ $11 \mathrm{mit}$ ) to repository workers. (ALARA principle).

- 318. To maximzze the ease recovery from a shaft/hoist malfunction.

- 316. To minimize the mean time to repair and restore the waste shaft operation.

- 300. To maximize system reliability of the waste transfar operation, ie minimize equipment fallure that causes operation downtime.

- 304. To minimize operational complexity in order to minimize operator errors and thereby increase average throughput.

- 301. To maximize maintainability of the transfer system.

- 319. To maximaze the use of proven/demonstrated technologv in the waste transfer operation.

- 314. To minimize capital costs of the waste transfer system. 
- E15. To minimize operataing and maintenance costs.

NOTE: The WANT objectives were prioritized using PairedComparison Evaluation. This method compares each oblective against every other objective and then summarlzes the objectives in relative ranking based on tallies of "better than" evaluations. (See previous pages for criteria weightings.)

\section{ALTEFINATIUES:}

1. Shield the disposal pactage during transfer between surface and subsurface levels. The shielding could be done in various ways, which is the subject of another evaluation.

2. Transfer the disposal package between surface and subsurface levels without shielding around the package. Frotection of repository workers would be provided by the salt media and other fixed barriers at the entrarice/exit of the shaft.

\section{ADUEFISE CONSEQUENCES (Fotential risks):}

Shielded Transfer

1. A more complex hoisting and conveyance system may be required than expected due to weight of payload (cable stretch, etc.). Probalility of this occurring was rated "low"; and seriousness, should this event occur, was rated "low" - ie, no significant effect on the repository design, construction, and implementation.

Unshielded Transfer

1. Accidental exposure of personnel by failure of englneered and/or administrative controls. Frobability of this occurring was rated "low"; however, seriousness, should this event occur, was rated "high" - ie, significant effect on health of repository worker (s).

2. Adverse effects on the hoist/conveyance materials (equipment) from radiation. Frobability of this occurring was rated "low"; and seriousness, should this event occur, was rated "low" - ie, no significant effect on hoist operations.

\section{BALANCED CHOICE:}

Considering the weighted scores and the possible adverse consequences of selecting each alternative, the balanced 
choice is to shield the transfer. This alternaitve scored high against the most important "want" criteria: Minimize radiation exposure to repository personnel, Maximize the ease of recovery from an abnormal event in the shaft, and Minimiae the time to repair and restore the hoisticonvevance system. In addition, there were no significant risks of adverse consequences for shielding the transfer.

\author{
DISCIFLINES IN ATTENDANCE: \\ Mechanical Engineering \\ Nuclear Tech \\ Mining Engineering \\ Industrial Engineering \\ Fiemote Engineering \\ Equipment Engineering \\ DNW I
}




\section{F.2 HOIST PAYLOAD CALCULATION}

Problem Statement: Determine the maximum payload weight for a frictiontype hoist using current technology.

\section{Current Technology Restrictions:}

1. Maximum suspended load - 252 tons (ASEA, 1983)

2. Wheel diameter $-5 \mathrm{~m}=196.8$ inch (ASEA, 1983)

3. 8 ropes, maximum (ASEA, 1983)

\section{Assumptions:}

1. Rope length $-3,175$ feet

2. Minimum safety factor $=7-0.0005 \times$ depth

$$
=5.5 \text { (MSHA, 1985) }
$$

3. Cage weight $=0.75 \times$ payload (SME, 1973)

4. $T_{1} / T_{2} \leq 1.5(\mathrm{SME}, 1973 \mathrm{a})$ (see Figure $F-1$ )

5. $D_{\text {wheel }} / D_{\text {rope }} \geq 120$ for locked coil ropes (Tiley, 1957)

6. Maximum tread pressure $=300$ psi (Accepted Industry Standard)

Determine $T_{1}$ Maximum:

$$
\begin{aligned}
\text { Maximum suspended load } & \left.=252 t=\left(T_{1}+T_{2}\right) \max \text { (see Figure } F-1\right) \\
& =252=T_{1}+\frac{T_{1}}{1.5}=1.67 T_{1} \\
T_{1}(\max ) & =151.2 t \text { ( } t=\text { tons) }
\end{aligned}
$$




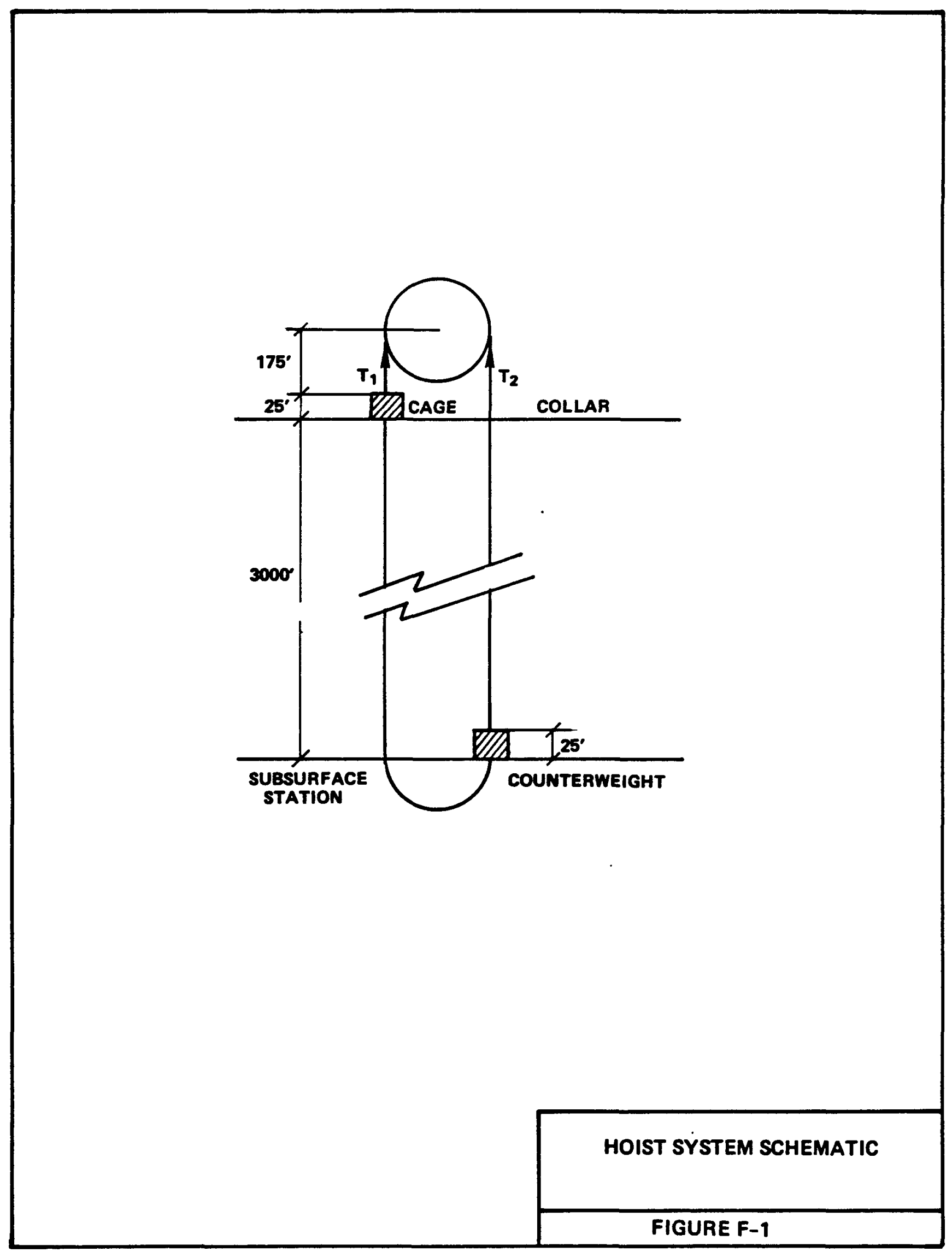

F- 6 
Determine Rope Size -6 ropes:

Safety factor $=\quad 5.5 \leq \frac{\text { Total Rope BS }}{T_{1}(\max )}=\frac{6 \text { (BS/rope })}{151.2 t}$

$$
\begin{aligned}
& \text { where } B S=\text { Breaking Strength } \\
& \text { BS } / \text { rope } \geq 138.6 \mathrm{t}=277,200 \mathrm{lb}
\end{aligned}
$$

From Bridon Rope Table (BAC, 1984)

Use 1.5" diameter rope - full locked - coil hoisting rope

Rope BS total $=138.9(6)=833.4 \mathrm{t}$

Weight of rope $=5.25 \mathrm{lb} / \mathrm{ft}(3,175 \mathrm{ft})=8.33 \mathrm{t}$

Total rope weight $=8.33(6)=50 t$

Determine Maximum Payload:

$$
\begin{aligned}
& T_{1}(\max )=151.2=\text { cage } w t+\text { rope } w t+\text { payload } \\
& 151.2=.75 \text { (payload) }+ \text { rope } w t+\text { payload } \\
& \text { Payload }=\frac{151.2-50}{1.75}
\end{aligned}
$$

$\underline{\text { Payload }=57.8 \mathrm{t}}$

\section{Check Safety Factor:}

$$
\begin{aligned}
\text { Safety factor }= & \frac{\text { Total Rope BS }}{\mathrm{T}_{1}} \\
5.5= & \frac{833.4}{151.2} \\
& 5.5=5.5 \quad \text { (Safety factor checks) }
\end{aligned}
$$


Check Tread Pressure:

$$
\begin{aligned}
\text { Tread pressure }= & \frac{\left(T_{1}+T_{2}\right) \max }{D \times d \times n} \\
\text { where } D & =\text { Wheel diameter, inches } \\
d & =\text { Rope diameter, inches } \\
n & =\text { Number of ropes } \\
\text { Tread pressure }= & \frac{252 \mathrm{t} \times 2000}{196.8 \times 1.5 \times 6} \mathrm{lb} / \mathrm{t} \\
300 \mathrm{psi} & \geq 285 \mathrm{psi} \text { (checks) }
\end{aligned}
$$

Check $\mathrm{T}_{1} / \mathrm{T}_{2}$ :

1. For unloaded cage (switch $T_{1}$ and $T_{2}$ sides on Figure $F-1$ )

$$
\begin{aligned}
\mathrm{T}_{1}{ }^{\prime} & =\left(\mathrm{T}_{1}+\mathrm{T}_{2}\right) \max -\mathrm{T}_{1} \\
\mathrm{~T}_{1}{ }^{\prime} & =252 .-151.2=100.8 \mathrm{t} \\
\mathrm{T}_{2}{ }^{\prime} & =\text { cage wt }+ \text { rope } w \mathrm{t}=.75(57.8)+50 \\
\mathrm{~T}_{2}{ }^{\prime} & =93.35 \\
\mathrm{~T}_{1}^{\prime} / \mathrm{T}_{2}{ }^{\prime} & =100.8 / 93.35=1.1
\end{aligned}
$$

2. For loaded cage (use original $T_{1}$ and $T_{2}$ )

$$
\mathrm{T}_{1} / \mathrm{T}_{2}=151.2 / 100.8=1.5
$$

(Both cases check)

Other cases were investigated to determine maximum payload. 
CASE 1 - 4 Rope System

$$
\begin{aligned}
& \text { Safety factor }=5.5 \leq \frac{\text { Total Rope BS }}{T_{1}}=\frac{4 \text { (BS/rope) }}{151.2} \\
& \text { BS/rope }=207.9 t=415,800 \mathrm{lb} . \\
& \text { From Bridon Rope Table (BAC, 1984) } \\
& \text { Use } 1.88 " \text { diameter rope } \\
& \text { Rope wt }=8.461 \mathrm{~b} / \mathrm{ft}(3,175 \mathrm{ft})=13.43 \mathrm{ft} \\
& \text { Total rope wt }=13.43 \mathrm{t}(4)=53.72 \mathrm{t} \\
& \text { T } 1 \text { (max) }=151.2=\text { cage wt }+ \text { payload }+ \text { rope wt } \\
& 151.2=.75 \text { (payload) }+ \text { payload }+ \text { rope wt } \\
& \text { Payload }=\frac{151.2-53.72}{1.75} \\
& \text { Payload }=55.7 \mathrm{t}
\end{aligned}
$$

\section{CASE 2 - 8 Rope System}

$$
\begin{gathered}
\text { Safety factor }=5.5 \leq \frac{\text { Total Rope BS }}{\mathrm{T}_{1}}=\frac{8 \text { (BS } / \text { rope) }}{151.2} \\
\text { BS } / \text { rope }=103.95 \mathrm{t}
\end{gathered}
$$

From Bridon Rope Tables (BAC, 1984)

Use 1.31 " diameter rope

Rope $w t=4.07 \mathrm{lb} / \mathrm{ft}(3,175 \mathrm{ft})=6.46 \mathrm{t}$

Total rope wt $=8(6.46)=51.69 t$ 


$$
\begin{gathered}
T_{1}(\max )=151.2 \text { = cage } w t+\text { payload }+ \text { rope } w t \\
151.2=1.75 \text { (payload) + rope wt } \\
\text { Payload }=\frac{151.2-51.69}{1.75} \\
\text { Payload }=56.8 \mathrm{t}
\end{gathered}
$$

In conclusion, on the basis of currently available hoist technology and considering 4,6 , and 8 rope systems, the 6 rope system provides the maximum payload of 57.8 tons. 


\section{F.3 REFERENCES}

ASEA, 1983. Mine Hoist Reference List, Pamphlet No. CR07-3001E 1983-05.

BAC, 1984. North American Division of Bridon American Corporation, Publication 911.

MSHA, 1985. Mine Safety and Health Administration, Code of Federal Regulations, Book 30, Part 56, Subpart 56.19, "Man Hoisting."

SME, 1973. SME, Mining Engineering Handbook, Society of Mining Engineers, New York, New York, p. 15-10.

SME, 1973a. SME Mining Engineering Handbook, Society of Mining Engineers, New York, New York, p. 15-7.

Tiley, 1957. Friction Hoist Design Considerations, The Mining Society of Nova Scotia, Transactions Volume LX. 
APPENDIX G

WASTE PACKAGE/REPOSITORY IMPACT STUDY

DETAILED STUDY OUTLINE 
APPENDIX $G$

TABLE OF CONTENTS

Page

ATTACHEMNT 1 - Waste Package/Repository Impact Study

G.1 References .............................

G-17 
G-1 Waste Package/Repository Impact Study Logic Diagram ..... G-15

G-2 Schedule for Waste Package/Repository Impact Study ..... G-16 


\section{ATTACHMENT 1 \\ WASTE PACKAGE/REPOSITORY IMPACT STUDY}

DETAILED STUDY OUTLINE

Title:

Waste Package/Repository Impact Study

Objectives :

- Evaluate alternative repository design concepts against current reference waste package design concepts to determine a recommended envelope for waste package design parameters which best satisfies repository design requirements.

- Develop a subsurface layout which incorporates both waste package and repository considerations.

\begin{tabular}{|c|c|c|c|}
\hline & & Date & Location \\
\hline \multirow[t]{11}{*}{ Schedule: } & Preplanning inftiated & $12 / 3 / 84$ & (Columbus) \\
\hline & Preplanning completed & $1 / 7 / 85$ & (Irvine) \\
\hline & Study Inftiated & $1 / 14 / 85$ & (Irvine) \\
\hline & Revised study outline & $1 / 18 / 85$ & N/A \\
\hline & $\begin{array}{l}\text { Status reports/working groups to } \\
\text { review status - discuss Task } 1 \\
\text { and overall status }\end{array}$ & $2 / 14 / 85$ & (Irvine) \\
\hline & $\begin{array}{l}\text { Status reports/working groups to } \\
\text { review status }\end{array}$ & $3 / 28 / 85$ & (Columbus) \\
\hline & $\begin{array}{l}\text { Status reports/working groups to } \\
\text { review status }\end{array}$ & $5 / 15 / 85$ & (Columbus) \\
\hline & $\begin{array}{l}\text { Annotated outifne complete. Working } \\
\text { group meeting to review outline }\end{array}$ & $6 / 20 / 85$ & (Columbus) \\
\hline & $\begin{array}{l}\text { First draft to report issued to } \\
\text { DOE/ONWI for review }\end{array}$ & $7 / 29 / 85$ & $(\mathrm{~N} / \mathrm{A})$ \\
\hline & $\begin{array}{l}\text { Working group to resolve DOE/ONWI } \\
\text { comments }\end{array}$ & $8 / 30 / 85$ & (TBD) \\
\hline & Study completed - present results & $9 / 13 / 85$ & (Columbus) \\
\hline $044 / 4032.01$ & $G-4$ & & \\
\hline
\end{tabular}


The following design areas will be affected by evaluations involving waste package design parameters (diameter, weight, shape, heat load) and are therefore included in the scope of this study:

- Disposal package characteristics (including all components)

- Radiation Level

- Lifting/Handling appurtenances \& configuration

- Compatibility with decontamination methods

- Waste handling/packaging building

- Disassembly/Consolidation Methodology

- Layout \& Transfer Routes

- Equipment Interfaces (Handling \& Process)

- Impact on HVAC System

- Surge Storage Areas

- Shafts

- Diameter

- Holsting Equipment

- Shielding

- Cooling

- Subsurface

- Layout (Room, Drift, Intersection sizes)

- Development Equipment

- Development Plan

- Emplacement Equipment

- Emplacement Mode

- Backfilling Methodology

- Monitoring Equipment

- Retrieval

- Concepts

- Equipment Methodology 
Requirements to

Begin:

(See description of Task 1, "Establish Basis" under Techn1cal Approach)

Requirements to

Complete:

- Interim basis for design

- Preliminary results of associated design studies from other project disciplines (see Technical approach)

Technical

Approach :

A recommended envelope for the values of design parameters of the waste package will be determined through analysis and iteration within several repository design areas. Potential impacts to the repository by the waste package reference design w111 be identified, and modifications to package design parameters to reduce these Impacts will be evaluated.

An integrated approach to waste package impact evaluations has been developed. This approach relles on ongoing, sow work elements to either supply data to this task or perform specific support analyses upon request. It is expected that support from other sow elements w11l be within the current scope of those elements. In addition, participation in this task will benefit the supporting sow elements by providing a mechanism to resolve design issues caused by the current reference waste package design.

This study has been organized into nine separate tasks, with the final task being integration and preparation of the final report. The tasks are structured and arranged to initially allow the reference waste package design parameters to be evaluated against repository constraints and design impacts and then to indicate waste package alternatives for design 
parameters which best satisfy repository needs. This organization is shown on the block diagram (Figure G-1) and on the schedule (Figure G-2).

Task 8 will be addressed toward the end of the study and w111 qualitatively assess the Impacts of reducing package length on repository layouts and design. This task will identify advantages from a design (both surface and subsurface facilities), economics or schedule viewpoint, which could be realized from reduction in package length.

The following discussion describes the approach to the study tasks. Each discussion will identify specific data needs (posed as questions) which will be supplied by other related sow work elements on the profect. The related sow paragraphs are identified as well as the project disciplines that will be responsible for performing the evaluations.

\section{Task 1: Establish Bas1s}

The basis for this study will be established and then expanded as the needs for data arise. The basis will initially be extracted from the project Interfm Basis for Conceptual Design. The inftial basis will include:

o Specification of assumed site(s) used for evaluation

- Identification of Waste Forms and Characteristics

- Types (Considered for scope of study)

- Dimensions

- Heat Load (kW)

- Waste Receipt Rates

- Posttions on Repository Design Issues

- Emplacement Mode

- Appilcable Gassy Mine Regulations (Impact on Mine Design) 
- Employing Disassembly/Consolidation

- Thermal limits (waste form, very near-field)

- Retrievability (selective, complete)

- Package performance requirements (10CFR60) (NRC, 1984)

- Dose rate limits

- Package Specific Design Requirements (ONWI-423) (ONWI, 1983)

- Baseline Package Design Data [Corrosion Allowance and Structural Strength (ONWI-438)]

- Assumption of a General Cylindrical Shape for Package

o Baseline Package Length (ONWI-438)(ONWI, 1983a)

- NRC Design Criteria (10CFR60.130-135)(NRC, 1984)

- Specific Cost Factors (1.e., $\$ / \mathrm{m}^{3}$ excavated)

SOW/Disciplines Involved - 4.10.1/SAIC, Fluor

Task 2: Evaluate Waste Package Heat Load

This task will define the maximum quantity of waste that can be contained in each waste package before temperature limits imposed by repository design requirements are exceeded. This is determined by calculating the maximum allowable package thermal loading (at which limits are not exceeded) and then directly relating that loading to an MTU of spent fuel (assuming the waste age is specified).

Thermal limits specifled for this task will consider the effects of heat on handling operations, rock mechanics properties, the waste form and package and host rock integrity. 
Specific questions to be considered include:

- Sow 4.10.2.1 - What are the appropriate temperature limits (pre and post emplacement) for the repository system? What are the references for the data? (SAIC, NucTech, $M-R, W C C$ )

- Sow 4.10.2.1 - What is the maximum thermal loading of the waste package before the approprlate temperature limits are met? (SAIC)

- 4.10.1, 4.3.2.11 - How much waste (In terms of intact assemblies or rods) does the maximum package thermal loading represent? (SAIC, NucTech)

Task 3: Determine Waste Package Weight Envelope

Considering the results of Tasks 1 and 2, and also assuming consolidated fuel pin bundles and spent fuel lengths as specified in the current package baseline, a range of overall package cavity dimensions will be determined. Then, allowing for corrosion tolerance, structural strength and handing requirements, the outside dimensions for the waste package (length and diameter) will be determined. This will be accomplished by assuming several alternative package thicknesses and materials from current design bases (ONWI-438). From these data, package weights will be determined. An envelope of unshielded package weights will result.

This task will also develop an envelope of shielded package weights. Transfer cask materials and dimensions will be analyzed from shielding requirements and then the welghts of these shlelded transfer casks will be calculated. Cask wall thicknesses required for shielding will be determined by considering worker exposure. Several cases of surface dose will be analyzed (1.e., $50 \mathrm{mrem} / \mathrm{hr}, 200 \mathrm{mrem} / \mathrm{hr}$ ). It will be necessary to analyze several cases of worker exposure time and location to account for potentially different operations involving a transfer cask. 
Specific questions to be answered include:

- 4.10.1, 4.10.2.2 - Based on current data, what are the overall sizes and materials for the range of package dimensions from Task 3? (SAIC, Mech.)

- 4.3.2.1, 4.3.2.6 - What are the transfer cask shielding requirements for the range of packages determined in Task 3 , and what are the dimensions of the shielded packages? (NucTech)

- 4.10.1 - What are the weights of the waste packages and transfer casks defined in this task? (SAIC)

\section{Task 4: Evaluate and Recomnend Emplacement Mode}

The objective of this task is to evaluate alternative emplacement modes, considering:

- Study basis - vertical emplacement in floor

- Emplacement equipment requirements

- Retrieval must be accomodated

- Preparation of emplacement position (1.e., drill borehole)

- Volume of excavated material required

- Backfill

Waste package dimension envelopes from previous tasks will be considered a variable in this task as emplacement mode optimization is conducted (optimization decisions will be performed using KT methods). The end product will be a recommendation of an emplacement mode that utilizes a waste package within the study envelope.

Specific questions to be answered include:

o 4.5.1.4.1 - What are the most reasonable emplacement mode variations from the baseline assuming subsurface design is to be optimized? (M-K) 
- 4.5.1.4.1 - What are the impacts of increasing the number of packages on the emplacement mode? (M-K)

- 4.5.1.2.1, 4.1.6.6, 4.5.1.4.2, 4.5.2.1.2, 4.6.1.2.3 - What is the practicality of each emplacement mode defined above? (M-K, WCC, SAIC, NucTech)

- 4.5.1.4.3, 4.3.1.1.1 - Is equipment for waste emplacement (and retrleval) and backfill feasible for the emplacement modes defined? (M-K, ESD)

o 4.5.1.4.1 - From this analysis, what is the best emplacement mode? $(\mathrm{M}-\mathrm{K})$

\section{Task 5: Transporter Conceptual Analysis}

The objective of this task is to determine a reasonable clearance envelope for the subsurface transporter from the standpoint of being physically capable of negotiating the subsurface passage-ways. This evaluation will include transporters that can handle the baseline waste package length.

Another aspect of this Task will be to assess the Impact of the weight of the package and transporter, if any, on mine stability.

Specific questions to be answered include:

o 4.3.1.1.1, 4.5.1.4.3 - What is the minimum clearance within which a waste transporter can operate in the mine (for each of the package sizes defined)? Consider straight transport requirements as well as clearances for turns. (ESD, Mech.)

- 4.5.1.6.1, 4.5.2.1.2 - What is the maximum allowable total weight and size of a vehicle that will routinely traverse the mine passage-ways? (M-K, WCC) 
- 4.5.1.4.3 - Given the estimated disposal package weight, can the total weight of the transporter plus package be kept below maximum allowable? (ESD)

o 4.5.1.4.3 - What are the impacts of increasing the number of waste packages on transporter design and/or emplacement duty cycle? (ESD, M-R)

Task 6 - Evaluate Hoist Technologies

This Task will Involve identifying shaft holst technologies capable of handling the package weights (including transfer casks) defined in Task 3 . An evaluation of these hoists will be conducted relative to the state-of-the-art to assess feasibility of each. The weight limits for the most feasible hoists may be a practical limit on package and transfer cask size (and weight) recommendation.

Specific questions to be answered:

- 4.4.2.8 - What hoist technologies are avallable, and what are the1r maximum demonstrated payloads? (M-K)

o 4.4.2.8, 4.4.1.4.5 - Which holst technology is recommended considering status of technology and operational reliability and safety? (M-K)

- 4.4.2.8 - Based on this recommendation, what is the maximum load for waste shaft hoists? (M-K)

- 4.4.2.8, 4.3.2.1, 4.3.2.6 - Can the waste package as specifled be transported down the shaft - unshielded? - shielded? - If not recycle to Task 3 . (M-K, NucTech)

o 4.4.2.8, 4.10.2.1 - What are the effects of package heat load on the hoist system? (M-K, SAIC) 
- 4.4.2.8 - What are the impacts of Increasing the number of waste packages on the hoist design and/or shaft duty cycle? (M-K)

Task 7 - Subsurface Layout Analysis

The objective of Task 7 is to produce a subsurface design and layout which is consistent with both waste package and repository considerations. The final layout produced from this task will include results of Tasks 1 through 6 .

The reference layout used for a starting point of this task will be that included in the ESF Impact Report, updated to consider designs based on more realistic criteria for extraction ratio and thermal loading. Note that the waste package as defined as the reference is the basis for the ESF Impact Report Layouts. The reference layout will be developed in parallel with the early phases of this study and will then be combined with this task to produce the final comprehensive layout.

For this task, subsurface design features that are affected by the package size and assoclated impacts (1.e., transporter dimensions) will be identified. The impacts of the package size on these parameters w111 analyzed. The impacts will then be assessed with respect to the reference subsurface layout through comparative analyses.

Task 7 activities w111 also include an assessment of the impact the waste package and resulting subsurface layout will have on surface facilities and layout. Design requirements on the surface facilities due to the package size will be identified.

Specific questions to be answered include:

- 4.5.1.2.1, 4.5.1.2.3, 4.5.2.1.2 - What are the minimum dimensions of the subsurface facility (corridors and intersections) that can accommodate the transporter defined in previous tasks? (M-K) 
- 4.5.1.2.1, 4.5.1.2.3 - What are the minimum disposal room and plllar dimensions considering package dimensions and emplacement modes? (M-K, WCC)

o 4.5.2.1.2, 4.10.2.1 - What package spacing would be required to achieve the areal thermal loading limits? (SAIC)

- 4.5.2.2, 4.5.1.3.1 - What are the impacts of the various drift dimension options on quantities of excavated material and mine development schedules? (M-K)

- 4.5.1.5 - Can ventilation requirements be met with subsurface dimensions specified in this task? (M-K, HVAC)

- 4.3.1.1.1 - What are the impacts of waste package size on the surface facllities? (Mech. ESD)

\section{Task 8: Waste Package Length Assessment}

This task will explore the Impacts of reducing the waste package length on surface and subsurface design features. Varlations of shorter package lengths will be considered to 1dentify resulting impacts on equipment, facilities and layouts. In addition, the extent of those impacts will be assessed. These data can ultimately be used to determine the benefits of modifying the package length and then if it is cost effective. SOW/Discipline for Task 8 : 4.10.1, 4.3.1.1.1, 4.5.1.2.1. Disciplines involved: SAIC, M-K, ESD, Mech.

\section{Task 9: Integration and Report}

The results of the study tasks will be integrated and an optimum package size will be recommended. Iterations between study tasks will be conducted during the study until values within the suggested waste package design parameter envelope are consistent with repository design requirements. A final report w111 be prepared.

SOW/Disciplines for Task 9: 4.10.1/SAIC, Fluor 


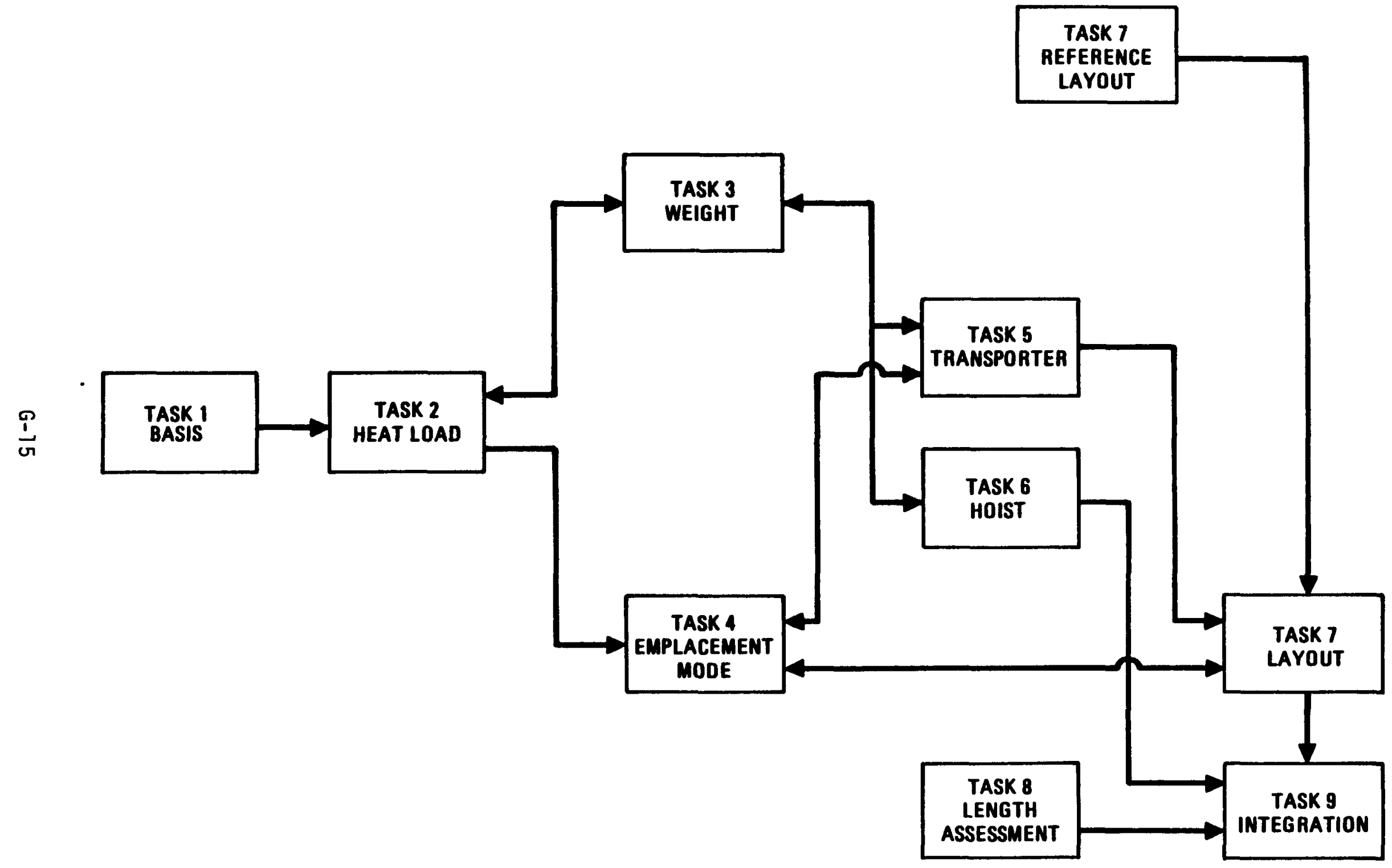

Figure G-1. Waste Package/Repository Impact Study Logic Diagram 


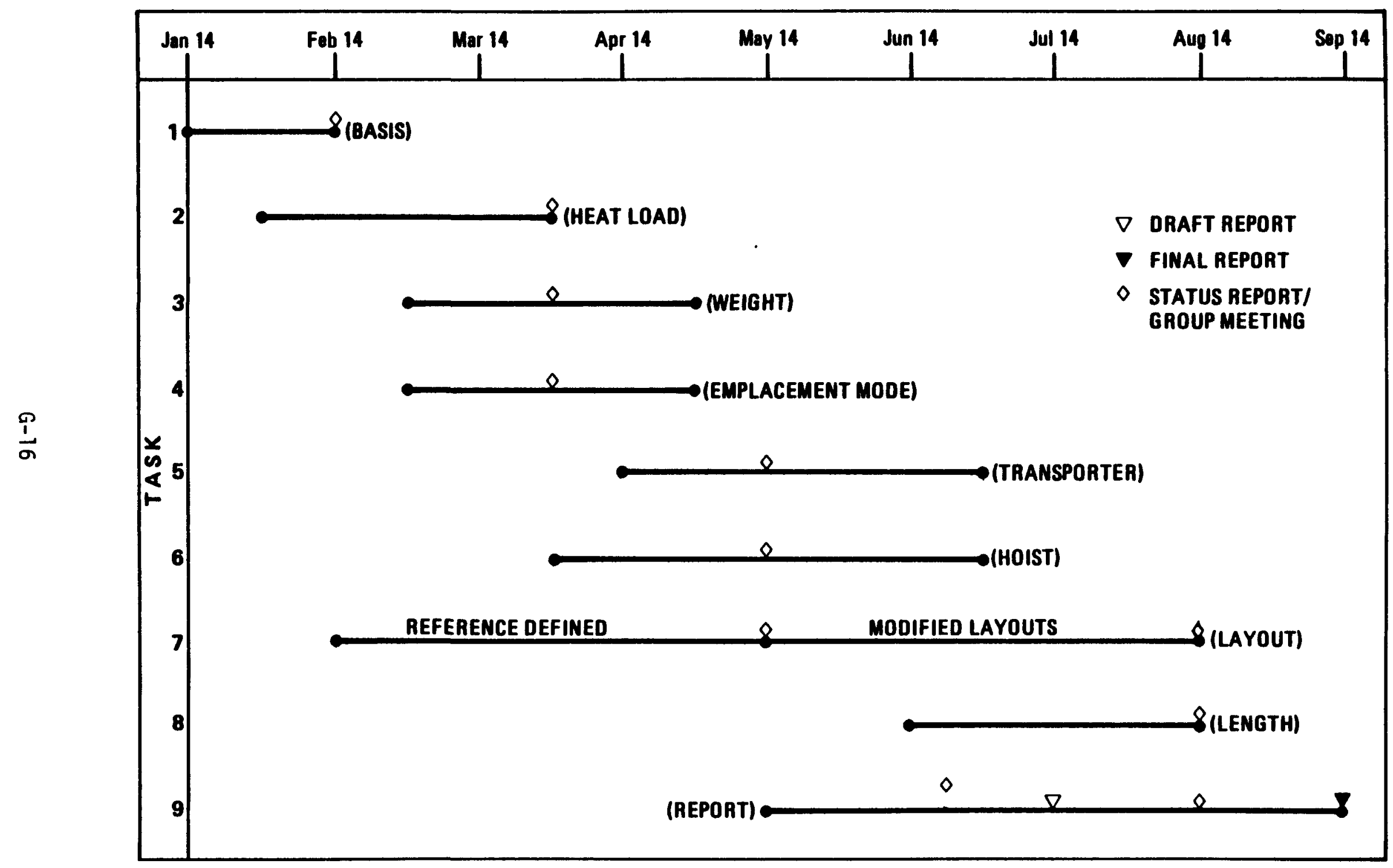

Figure G-2. Schedule for the Waste Package/Repository Impact Study 


\section{G. I REFERENCES}

NRC, See U.S. Nuclear Regulatory Commission.

Office of Nuclear Waste Isolation, 1983. Engineered Waste Package System Design Specifications, Westinghouse Electric Corporation, ONWI-423, May.

Office of Nuclear Waste Isolation, 1983a. Engineered Waste Package Conceptual Design, Westinghouse Electric Corporation, ONWI-438, April.

ONWI, See Office of Nuclear Waste Isolation.

U.S. Nuclear Regulatory Commission, 1984. U.S. Nuclear Regulatory Commission, Code of Federal Regulations, Book 10, Energy, Part 60, "Disposal of High-Level Radioactive Waste in Geologic Repositories: Technical Criteria," 10CFR60, Washington, D.C. 
APPENDIX H

KEPNER TREGOE (K-T) METHODOLOGY 
APPENDIX H

TABLE OF CONTENTS

Page

H.I K-T Decision Analysis Process ................... H-4 
LIST OF FIGURES

Page

H-1 Decision Analysis Process ................... H H 


\section{H.1 K-T DECISION ANALYSIS PROCESS}

Following is a brief description of the decision analysis process used in evaluating and recommending approaches to design issues. In order to provide a well documented trail of the decision making process, a structured decision analysis technique has been adapted for use. The method employs techniques proposed by Kepner-Tregoe, Inc., and makes use of a computer program, DECISION AIDE, also by Repner-Tregoe, for documentation purposes. The make-up of the Fluor Task Force and the general approach to the evaluation of alternatives is outlined in the following paragraphs.

The Fluor $\mathrm{K}-\mathrm{T}$ decision analysis task force is made up of a multi-discipline englneering team, each member of whtch brings to the analysis his individual engineering expertise. This interdisciplinary discussion is important in many of the decisions which are of a multi-objective type since it promotes better understanding and communication between the disciplines. The task force facilitator is a member from ESD. The Individual disciplines involved in the $\mathrm{K}-\mathrm{T}$ task force are:

\begin{tabular}{ll}
\multicolumn{1}{c}{ DISCIPLINE } & ORGANIZATION \\
\cline { 2 - 2 } Mechanical Engineering & Fluor \\
Nuclear Engineering & Fluor \\
Remote Engineering & SAIC \\
Rellability, Avallability & \\
and Maintalnability & Fluor \\
Mining Engineering & M-R \\
Industrial Engineering & ESD \\
Geotechnical Englneering & WCC
\end{tabular}

Note: this Task Force may be expanded to include other disciplines from Fluor and/or outside organizations as the need arises for any specific decision analysis. 
The purpose of the decision making exercise is to select from several alternatives, the most suitable approach to be used for resolution of design issues in the conceptual design. See Figure A, "Decision Analysis Process," for a graphical representation of the process and the steps mentioned below.

The first step is to define the subsystem to be evaluated (step 1). Group consensus is used to define the combination of functions appropriate to a subsystem. Once the subsystem is defined and documented as performing a given set of functions, the problem statement is formulated thus: "Select a man/ machine approach to perform the functions included in subsystem X." (step 2).

The task force then develops a list of objectives to be achieved by the alternatives in accomplishing the subsystem functions (step 3). A listing of basic and frequently used criteria is presented in Section 2. From this 1ist, written on flip charts, the task force determines which objectives truly are constraints of the system; these are designated MUSTS. (Steps 4 and 5.) The balance of the objectives are designated as WANTS representing desired characteristics and then restated in terms of "either minimize or maximize," (step 6). The WANTS are then assigned numerical weights based on their order of importance. Generally, the method of "paired comparison" is used to determine weights in which each WANT is compared against every other WANT in pairs (step 7).

Since the salt profect will be the subject of extensive review, regulatory agency scrutiny, and public examination, it is important that the alternatives list be comprehensive. For this reason, even alternatives which are known not to meet specific constraints (MUSTS) are entered in the interest of completeness (step 8).

Descriptions of the alternatives are next outlines on large flip-chart sheets. The evaluation of each alternatives is usually preceded by some discussion clarifying the details of the alternative or more specifically definIng a MUST or a WANT. This open discussion promotes understanding by the whole group of precisely what is meant by each particular word or phrase. This common understanding is probably one of the major strengths derived from undertaking a group decision making project. 
The facilitator then leads the task force through a consensus evaluation as to which of the potential alternatives satisfies the list of MUSTS. Those alternatives which pass this primary filter could be considered feasible alternatives, i.e., anyone of the alternatives is capable to meeting all of functional requirements of the subsystem and satisfies all of the constraints as stated in the MUSTS (step 9A).

The next step is to score each of the WANTS criterla against each of the alternatives that pass the MUST filters, again using group consensus. The alternative that best satisfies the particular criteria is given a score of "10." The other alternative are calculated (numerical weight value of WANT (step 7) times the individual alternative score value (step 9B). These weighted WANT values are then totaled for each alternative providing a single total point score.

The alternatives that passed the MUST filter and have the highest ranking WANT scores are considered for further evaluation. Here the task force develops a listing of potential adverse consequences. In the evaluation of "potential adverse consequences," events are Identifled (for each alternative) that might occur and negatively impact each alternative's intended purpose. A 3-point scale (high, medium, and low) is used to evaluate the probability of occurrence and the severity of each adverse event. Recording continues on flip chart sheet for group reference while the information is input into the computer for ultimate documentation. The potential adverse consequences that have either a high probability of occurrence and/or a high level of severity are flagged in final decision making (step 11).

Based on the documentation developed to this point, the task force decides which of the alternatives is the "balanced choice" by balancing the adverse consequences against the total weighted scores (step 12).

Not all declstons prove to be clear cut, and some subsystem functions will have multiple alternatives recommended for further consideration when the conceptual design is specifled down to the machine element level. 


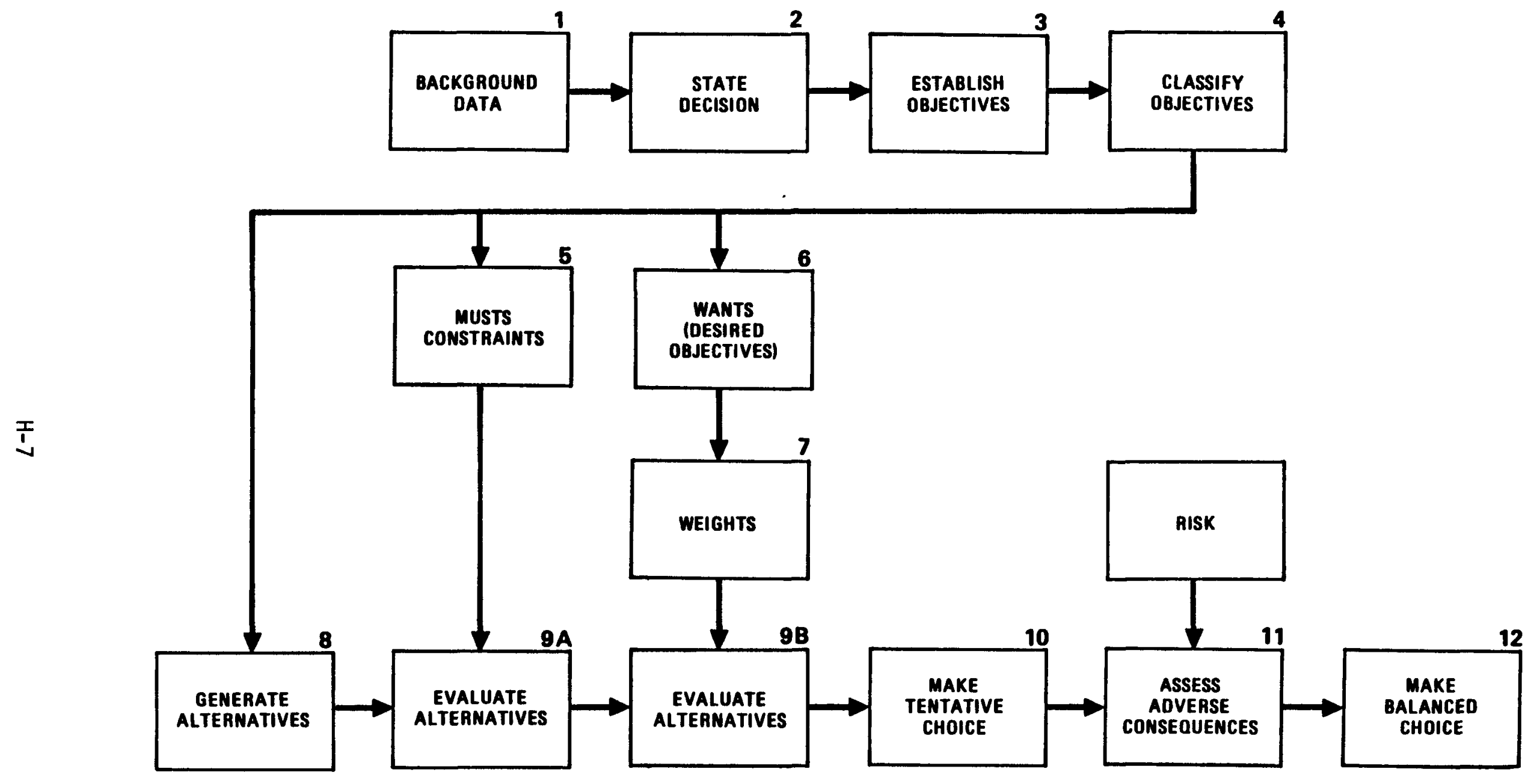

Figure H-1. DECISION ANALYSIS PROCESS 
WORD OR PHRASE

anticline

backfill

backfilling

barrier

baselining

bedded

bedded salt

bedrock

borehole

bounding calculation

buffer

buffer zone

\section{DEFINITION}

A fold in the rocks in which the strata dip outward from the axis of folding. This is the opposite of a syncline.

(As related to a waste package) Barrier material surrounding the containment portions of the waste package that can act as a radionuclide sorptive medium, hydrologic intrusion barrier, heat transfer agent, and plastic stress adjustment medium.

Placement of originally removed or new materials into evacuated areas of a mine, including holes drilled for waste canisters, drifts, access ways, and shafts.

(As related to nuclear waste disposal) Features of a waste disposal system that act to contain or isolate radioactive waste from the accessible environment.

Formally establishing and controlling program documents which contain task and subtask criteria, requirements, objectives, schedule, cost, and definition of deliverables.

Arranged in layers.

Consolidated layered salt separated from other layers by distinguishable planes of separation such as layers of argillaceous sediments. These deposits formed by evaporation of sea water in shallow continental basins.

Solid rock that underlies all soil, sand, clay, gravel, and loose material on the earth's surface.

A hole drilled into the earth, often to a great depth, as a prospective oil well or for exploratory purposes. A borehole is generally of small diameter, such that workers cannot work inside it, and is drilled mostly vertically, or possibly on a slant or horizontally. A borehole could be near the surface, or could penetrate into the repository formation or through it.

Calculation based on an envelope of parametric values to indicate the limits of results that can be obtained.

(As related to a waste package) A possible component of the waste package, located between the canister and overpack, which is tailored to chemically condition (adjust Eh and $\mathrm{pH}$ ) intruding groundwater.

(As related to a repository site) A designed and controlled portion of the site that surrounds the repository facility and is composed of essentially undistrubed geologic and surficial environment. (See also control zone.) 
burnup

canister

caprock

casing

cask

characteristic

characterization

cladding

code

cold

commercial waste

conductivity

conservative

containerized waste
A measure of reactor fuel consumption, normally expressed as the amount of thermal energy produced per unit weight of uranium placed in the reactor.

A container for waste, spent fuel, and high-level waste. The waste will remain in this canister during and after burial in the repository. A canister affords physical containment but not radiation shielding.

A heterogeneous, relatively impervious, rock that imnediately overlies a salt dome, typically anhydrite, limestone, or gypsum, or possibly all three arranged in layers.

(As used in site characterization) 1. Special steel tubing welded or screwed together and lowered into a borehole to prevent entry of loose rock, gas, or liquid into the borehole, or to prevent the loss of circulation liquid into porous, cavernous, or fractured ground. 2. The process of inserting casing into a borehole.

A shielded container used to transport radioactive material.

Any property or attribute of an item, process, or service that is distinct, describable, and measurable.

The collecting of information necessary to evaluate suitability.

(As related to nuclear fuel) A metal or ceramic covering that contains the fuel material.

1. A standard which is recommended or imposed by a jurisdiction or regulatory agency. 2. A series of coupled mathematical expressions or algorithms which provide a method for calculating solutions to problems using computers.

With reference to radioactive waste, no radioactive nuclides are present.

Radioactive wastes generated in private industrial and other nongovernment facilities, principally wastes generated in power reactors and chemical processing plants, but also including research laboratories and medical facilities.

The relative ability of a rock or other material to allow passage of heat, electric current, or fluids.

Providing large margins of safety against undesirable outcomes.

Container and contents including waste form and any liner or stabilizing material. 
WORD OR PHRASE

containment

contamination

criteria, design

criteria, functional

criteria, performance

criterion

criticality

Curie (Ci)

decay (radioactive)

decommissioning

decontamination

defense wastes

\section{DEFINITION}

(As defined in 10 CFR 60 ) The confinement of radioactive waste within a designated boundary.

(General) Undesired radioactive material present on outside surface. This contamination can be either transferable or fixed. Radiation penetrating the walls of a waste package from within is not contamination.

Quantitative limits placed on a design, which assure compliance with functional criteria. (See also design and design criteria.)

Quantitative (and qualitative) limits placed on a design for acceptability within the framework of performance criteria of the waste management system. Originally called acceptance criteria.

Qualitative limits placed on the geologic repository system for acceptability within the framwork of waste managenent criteria (policy).

A standard, rule, or test by which a decision or judgment may be based.

A condition or state in which there occurs a self-sustaining nuclear chain reaction.

A unit of radioactivity equal to $3.7 \times 10^{10}$ disintegrations per second.

The spontaneous transmutation of a radionuclide into another nuclide by the emission of a charged particle or electromagnetic radiation.

Activities associated with removing a repository from service, f.e., backfilling, shaft sealing, and the end of surface-facility use (including demolition, dismantling, etc.).

The selective removal of radioactive material from a surface or from within another material.

(Nuclear) Radioactive wastes generated in activities related to the national defense program, including the manufacture of nuclear weapons, the operation of naval reactors, and research and development at weapons laboratories. (See also commercial waste.) 
WORD OR PHRASE

design bases

design control

design input

design output

design process

design review

disposal package

disposal system

documentation

drift

emplacement

emplacement hole liner

engineered barrier

engineering barrier system

entry
DEFINITION

Information which identifies the specific functions to be performed by a geologic waste repository. Specific values or ranges of values chosen to control reference bounds for design. These values may be: 1 . restraints derived from generally accepted "state-of-the-art" practices; 2. requirements derived from analysis; or 3 . requirements of applicable codes and standards.

The process and procedures invoked to assure that a design meets the design criteria and standards. Quality assurance procedures are one aspect of design control.

Those criteria, paramenters, bases, or other design requirements upon which detailed final design is based.

Documents, such as drawings, specifications, and other documents, defining technical requirements of structures, systems, and components.

Technical and management processes that commence with identification of design input and that lead to and include the issuance of design output documents.

A documented critique of system or subsystem design by specialists in appropriate disciplines who did not participate in the design.

Waste form and overpack ready for emplacement.

(As used by the EPA) Any combination of engineered and natural barriers that contains radioactive wastes after disposal.

Any written or pictorial information describing, defining, specifying, reporting, or certifying activities, requirements, procedures, or results.

Horizontal, or nearly horizontal, mined passageway.

Placing the waste in its location for storage or disposal.

A metallic or ceramic sleeve placed in a vertical or horizontal emplacement hole to prevent sloughed rock from interfacing with waste package emplacement or in retrieval operations.

An addition to the geologic environment which has been designed, fabricated, and emplaced to minimize or preclude radionuclide transport.

The waste package and the underground facility including a portion of the host rock required for structural stability.

Same as drift 
environmental assessment

evaluation

factor

far field

final design

fuel

fuel assembly

fuel cycle

fuel rod

functional CID

geologic isolation

goal
A concise public document, for which a federal agency is responsible, that serves to: 1. Briefly provide sufficient evidence and analysis for determining whether to prepare an environmental impact statement or a finding of no significant impact; 2. Aid an agency's compliance with the NEPA when an environmental impact statement is necessary; 3 . Facilitate preparation of a statement when necessary.

An objective appraisal by qualified personnel to determine whether engineering, manufacturing and construction processes, and quality programs are capable of producing a quality item or service, and generating evidence that supports decisions of acceptability.

A characteristic that is evaluated to determine whether a criterion is fulfilled.

Rock formations outside of the repository, including the surrounding strata.

Approved design output documents and approved changes thereto.

(Nuclear reactor) Fissionable material used as the source of power when placed in a critical arrangement in a nuclear reactor.

A unit of nuclear reactor core composed of fuel rods, ends, spacers, and support structures. The fuel rods contain pellets of urantum oxide and (in the case of spent fuel) fission products and transuranic elements. The rods ends, spacers, and support structures are fabricated from an alloy of zirconium.

The complete series of steps involved in supplying fuel for nuclear reactors. It includes mining, refining, the original fabrication of fuel elements, their use in a reactor, chemical processing to recover the fissionable material remaining in the spent fuel, reenrichment of the fuel material, refabrication into new fuel elements, and management of radioactive waste.

A tube form into which fissionable material is fabricated for use in a reactor.

A functional CID shall describe the functional characteristics at and/or across interfaces which are relevant to design of both hardware and software.

Placement of nuclear waste in a deep stable geologic formation.

A desired end result which usually requires prolonged effort to achieve. Whether a particular goal has been achieved is a matter of judgment. 
gradient

guidel ine

high-level radioactive wastes

interface

isolation

i sotope

item

long-term

mined geologic repository

model

multibarrier system

nuclide

objective
Slope, particularly of a stream and land surface. In mathematical terms, a change in value of one variable with respect to another variable.

A suggested practice that is not mandatory but if followed would comply with a standard.

Wastes characterized by intense, penetrating radiation and by high heat-generation rates. Even in protective canisters, high-level waste must be handled remotely.

The functional or physical boundary between two or more systems, pieces of equipment, facilities, or computer programs, or within a system between two or more design organizations.

Segregating wastes from the biosphere to the extent required to meet applicable radiological performance objectives.

A nuclide having the same atomic number but different mass number.

Any level of unit assembly, including structure, subsystem, subassembly, component, part or material; or documentation such as specifications, drawings, procurement documents, or records.

The period extending from 300 to 30,000 years after closing a repository.

A deep underground repository for nuclear waste that is mined in a geologic formation. This term does not imply a specific mediun, e.g., tuff, salt, shale.

In applied mathematics, the analytical or mathematical representative or quantification of a real system and the ways that phenomena occur within that system. Individual or subsystem models can be combined to five system models. Deterministic and probabilistic models are two types of mathematical models.

Concept of using the waste form, the container (canister), the overpack, the emplacement medium, and surrounding geologic media as multiple barriers to isolate the waste from the biosphere. A multibarrier system is a system of barriers, operating independently or relatively independently, which acts to contain and/or isol ate nuclear waste.

A species of atom characterized by its mass number, atomic number, and nuclear energy state.

An end result of an effort whose attainment can be determined by measurement or fact. 
WORD OR PHRASE

operational period

overpack

package

parameters

radiation dose

radioactive waste

radionuclide

reference repository

repository horizon

requi rement

retrieval

sensitivity analysis

\section{DEFINITION}

The period during which a nuclear installation is being used for its intended purpose until it is hut down and decommissioned.

Any receptacle, wrapper, box, or other structure that becomes an integral part of a waste package and is used to enclose a waste container for purposes of providing additional protection or meeting the requirements of an acceptance or isolation criterion for a specific site.

Container and contents including waste form and overpack; may be used with prefix radioactive waste or waste.

Any of a set of physical properties whose values determine the characteristics or behavior of something.

Amount of radiation received by individuals or a population, expressed in units of rem or mrem (1/1000 of a rem). Background radiation from natural sources is approxiamtely $200 \mathrm{mrem} / \mathrm{yr}$ to an average individual in the U.S.

Any material containing or contaminated with radionuclides at concentrations or activities greater than exempt quantities established by the competent authorities and for which there is no foreseen use.

A nuclide (species of atom distinguished by the constitution of its nucleus) that is unstable and is undergoing the process of spontaneously decaying to another nuclide.

A conceptual repository design developed to reduce to practice the current state of knowledge. It is useful in site selection to identify potential unfavorable site characteristics. The value of design changes can be judged by comparison of the new design to the performance of the reference system.

The specific underground level and elevation in which nuclear waste will be emplaced below the earth's surface.

That which is necessary, generally as a prerequisite, to attainment of an objective.

(As defined in 10 CFR 60) The act of intentionally removing radioactive waste from the underground location at which the waste had previously been emplaced for disposal.

A method of determining the importance of changes in parameters or assumptions relative to a predicted outcome. 
shaft

shielding

short-term

site characterization

specification

spent fuel waste

stabilizer

standard

subsurface facilities

surface facilities

technical conservatism

thermal conductivity

thermal loading

transfer cask
(With regard to a geologic repository) The penetration of the natural isolation barrier to provide access to the subsurface facility; it is usually of limited cross-sectional area compared to its depth.

The material interposed between a source of radiation and personnel for protection against danger of radiation; used shielding materials are concrete, water, and lead.

The 50-year period after closing a repository.

(As defined in 10 CFR 60) The program of exploration and research both in the laboratory and in the field, undertaken to establish the geologic conditions and the ranges of those parameters of a particular site relevant to the procedures under this part.

A concise statement of a set of requirements to be satisfied by a product, o material, or process indicating, whenever appropriate, the procedure or means by which it may be determined whether the requirements given ore satisfied.

The final form of spent fuel as waste which could include the fuel in some mechanically processed or disassembled form.

Material or structure used to provide mechanical integrity and/or chemical stability to the waste or waste package.

An acknowledged measure of comparison for quantitative or qualitative value. Commonly used and accepted as an authority.

Engineered facilities below the earth's surface (including shafts and drifts).

Engineered repository facilities on the earth's surface.

A policy applied throughout the NNWSI to ensure that the final storage system will be sufficiently and conservatively safe.

The quantity of heat that will pass between faces of a unit area of a material of unit thickness in unit time when a unit differential of temperature is established between the faces; watts per meter degree Kelvin.

The quantity of heat-generating materials placed in a given area or volume (e.g., kilowatts per hectare).

A shielded (unlicensed) enclosure for the movement of highly radioactive material within a facility. 
underground facility

waste form

waste package

waste-emplacement borehole

waste, cladding

waste, defense

\section{DEFINITION}

(As defined in 10 CFR 60) The underground structure, including openings and backfill materials, but excluding shafts, horeholes, and their seals.

Radioactive waste, in either treated or untreated condition, including any inerts, binder, or stabilizer. (Waste can be specially formed to serve special purposes, e.g., high-level waste can be fixed in vitrified matrix to inhibit leaching waste.)

The sealed canister and overpack (if present) which includes the waste form as well as the enclosing envelope that separates the waste from the geologic emplacement medium. The enclosing envelope may include the canister, buffer, or shielding, overpack, and discrete backfill in the emplacement hole, hole liner, and any other structures, enclosures, or materials reaching to the surface of the rock (borehole emplacement) or tunnel well for tunnel emplacement.

A large-diameter borehole for the horizontal emplacement of waste containers.

$\mathrm{Cl}$ adding fragments and other structural materials from the spent fuel remaining in the dissolving vessel in chemical reprocessing. A transuranic waste.

Waste generated by the federal government and/or federal programs in nongovernment facilities. 


\section{LIST OF ACRONYMS}

ACRONYM

$A-E ; A / E ; A \& E$

AEC

ALARA

ANS

ANSI

BAT

BPMD

BWR

CDR

CFD

CFR

CHLW

CHTRU

Ci

$D / D ; D \& D$

DB

DHLW

DOE

DOT

EA

EDBH

HLW

$\mathrm{kW}$

\section{DEFINITION}

architect-engineer

U.S. Atomic Energy Commission

as low as reasonably achlevable

American Nuclear Society

American National Standards Institute

best available technology

Battelle Project Management Division (Informal name). Formal name is Project Management Division of Battelle Memorial Institute

bolling water reactor

conceptual design report

Certified for Conceptual Design

Code of Federal Regulations

commerclal high-level waste

contact-handled TRU (waste)

curle

decontamination and decommissioning; development and demonstration

data base

defense high-level waste

U.S. Department of Energy

U.S. Department of Transportation

environmental assessment

Engineering Design Borehole

high-level waste(s)

kilowatt 
LA

LWR

mg

$\mathrm{Mg}$

$\mathrm{MPa}$

mrem

MRS

MSHA

MT

MTHM

MTU

MW

MWD

NA

NBS

NRC

NWTS

ONWI

OSHA

PIC

PWR

QA

R\&D

RAM license application

light water reactor

milligram

megagram ( 1 million grams or equivalent to a metric ton)

megapascals; a unit of applied stress

millirem

monitored retrievable storage [facility]

Mine Safety and Health Administration

metric tonne

metric tons of hèavy metal

metric tons of uranium

megawatt; molecular weight

megawatt day

not applicable

National Bureau of Standards

U.S. Nuclear Regulatory Commission; National Research Council, NAS

National Waste Terminal Storage (program)

Office of Nuclear Waste Isolation (BPMD)

Occupational Safety and Health Administration

Project Information Control-the system used to administer project records on the SALT Project

pressurized water reactor

quality assurance

research and development

Rellability, Availability, and Malntainability (program); responsibility assignment matrix 
rem

SAIC

SCP

SF

sow

SRPO

SST

WBS

WP roentgen equivalent in man

Science Applications International Corporation

site characterization plan

spent fuel

statement of work

Salt Repository Project Office

Stainless Steel

work breakdown structure

waste package 